\title{
Microbial Field Pilot Study
}

Final Report

\author{
By \\ R.M. Knapp \\ M.J. McInerney \\ D.E. Menzie \\ J.D. Coates \\ J.L. Chisholm
}

May 1993

Work Performed Under Contract No. DE-FG22-89BC14246

\author{
Prepared for \\ U.S. Department of Energy \\ Assistant Secretary for Fossil Energy
}
Rhonda P. Lindsey, Project Manager
Bartlesville Project Office
P.O. Box 1398
Bartlesville, OK 74005

\author{
Prepared by \\ University of OkJahoma \\ Norman, OK 73019
}


TABLE OF CONTENTS

Page

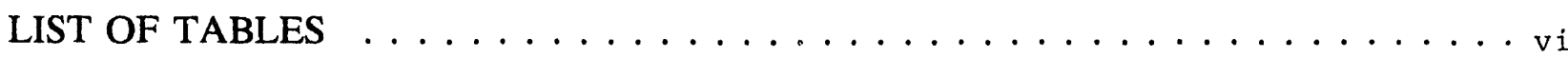

LIST OF ILLUSTRATIONS $\ldots \ldots \ldots \ldots \ldots \ldots \ldots \ldots \ldots \ldots \ldots \ldots$

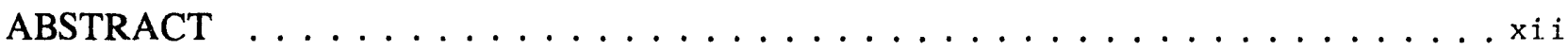

Chapter

1. JNTRODUCTION $\ldots \ldots \ldots \ldots \ldots \ldots \ldots \ldots \ldots \ldots \ldots \ldots \ldots \ldots \ldots \ldots$

2. AN OVERVIEW OF THE MICROBIAL FIELD PILOT STUDY . . . . . . . 7

3. OTHER MEOR WATERFLOODS AND THE SEVVSU FLOOD . . . . . . . 15

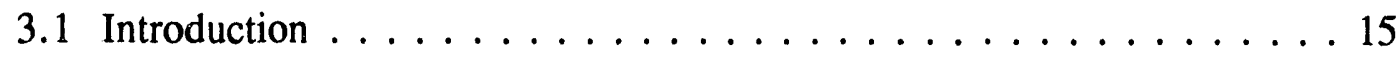

3.2 Nacatoch Formation, Union County, Arkansas $\ldots \ldots \ldots \ldots 15$

3.3 Mink Unit of the Delaware-Childers Field $\ldots \ldots \ldots \ldots \ldots$

3.4 Bondyuzchskoe Oil Field, Tatarian Republic, USSR $\ldots \ldots \ldots \ldots 18$

$3.5 \mathrm{Sa}_{3} \mathrm{Cl}_{1}$ Field, Romania . . . . . . . . . . . . . 19

3.6 Zechstein Formation, German Democratic Republic . . . . . . . 20

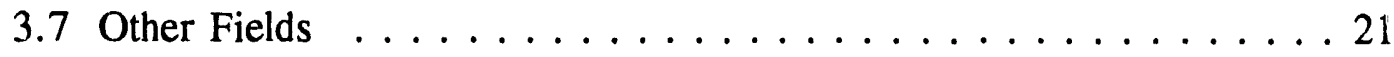

4. THE SOUTHEAST VASSAR VERTZ SAND UNIT $\ldots \ldots \ldots \ldots \ldots$

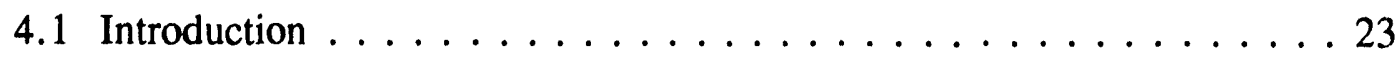

4.2 The Southeast Vassar Vertz Sand Unit $\ldots \ldots \ldots \ldots . \ldots 24$

4.3 Reservoir Simulation $\ldots \ldots \ldots \ldots \ldots \ldots \ldots \ldots \ldots$

5. MICROBIOLOGY AND ECOLOGY OF THE RESERVOIR . . . . . . . 45

5.1 Introduction $\ldots \ldots \ldots \ldots \ldots \ldots \ldots \ldots \ldots \ldots \ldots \ldots \ldots \ldots \ldots$ 
5.2 Materials and Methods $\ldots \ldots \ldots \ldots \ldots \ldots \ldots$

5.3 Results $\ldots \ldots \ldots \ldots \ldots \ldots \ldots \ldots \ldots \ldots \ldots \ldots$

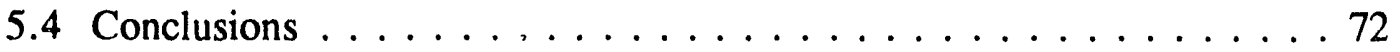

6. CORE FLOOD EXPERIMENTS AND MEOR MECHANISMS $\ldots \ldots \ldots 75$

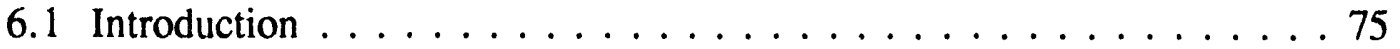

6.2 Experimental Methods $\ldots \ldots \ldots \ldots \ldots \ldots \ldots$

6.3 Microbial Enhanced Oil Recovery Mechanisms . . . . . . . . . . 77

6.4 Experimental Results $\ldots \ldots \ldots \ldots \ldots \ldots$

6.5 Discussion of Results $\ldots \ldots \ldots \ldots \ldots \ldots$

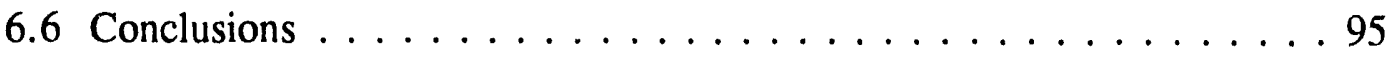

6.7 Nomenclature . . . . . . . . . . . . . . . . . . . 96

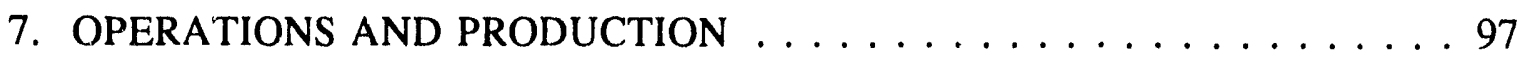

7.1 Surface Facilities . . . . . . . . . . . . . . . . 97

7.2 Field Operations $\ldots \ldots \ldots \ldots \ldots \ldots \ldots \ldots \ldots$

7.3 Production Effects $\ldots \ldots \ldots \ldots \ldots \ldots \ldots \ldots$

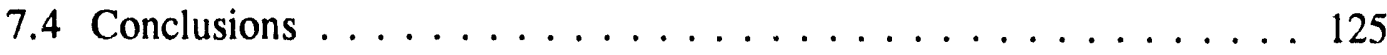

8. PRESSURE TEST ANALYSIS $\ldots \ldots \ldots \ldots \ldots \ldots \ldots \ldots$

8.1 Introduction $\ldots \ldots \ldots \ldots \ldots \ldots \ldots \ldots \ldots \ldots \ldots \ldots$

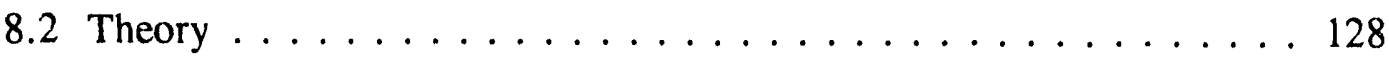

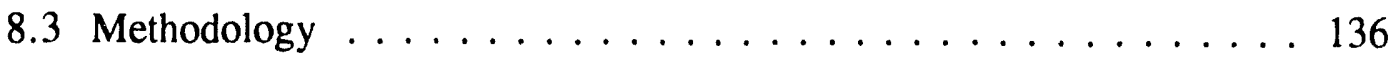

8.4 Results and Discussion . . . . . . . . . . . . . 140

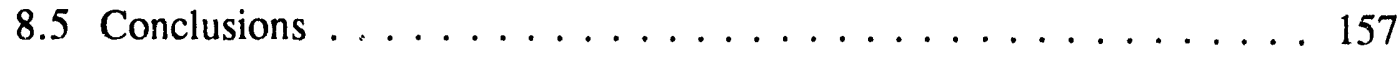


8.6 Nomenclature . . . . . . . . . . . . . . . . . . . 158

9. TRACER STUDIES $\ldots \ldots \ldots \ldots \ldots \ldots \ldots \ldots \ldots \ldots \ldots \ldots \ldots \ldots$

9.1 Introduction $\ldots \ldots \ldots \ldots \ldots \ldots \ldots \ldots \ldots \ldots \ldots \ldots \ldots \ldots$

9.2 Theory $\ldots \ldots \ldots \ldots \ldots \ldots \ldots \ldots \ldots \ldots \ldots \ldots$

9.3 Tracer Selection $\ldots \ldots \ldots \ldots \ldots \ldots \ldots \ldots \ldots \ldots \ldots$

9.4 Tracer Experimental Analysis . . . . . . . . . . 163

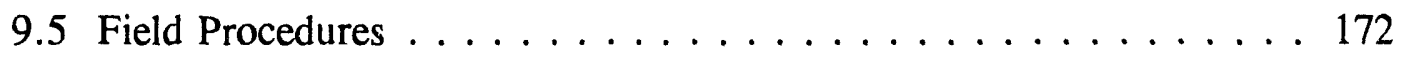

9.6 Results and Changes in Field Operating Policy from Results . . . . 173

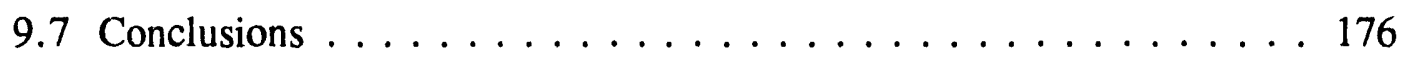

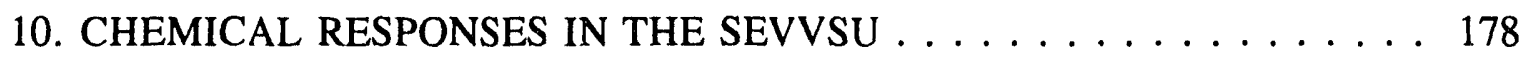

10.1 Introduction $\ldots \ldots \ldots \ldots \ldots \ldots \ldots \ldots \ldots \ldots \ldots \ldots$

10.2 Materials and Methods $\ldots \ldots \ldots \ldots \ldots \ldots \ldots \ldots$

10.3 Results and Discussion . . . . . . . . . . . . . . . 179

10.4 Conclusions $\ldots \ldots \ldots \ldots \ldots \ldots \ldots \ldots \ldots \ldots \ldots$

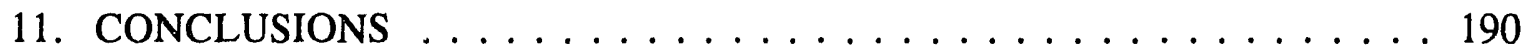

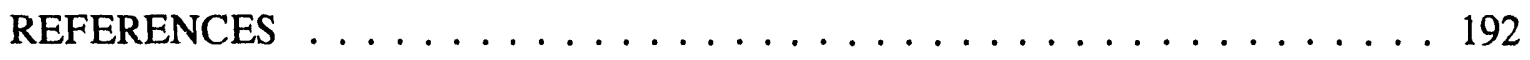




\section{LIST OF 'TABLES}

TABLE

Page

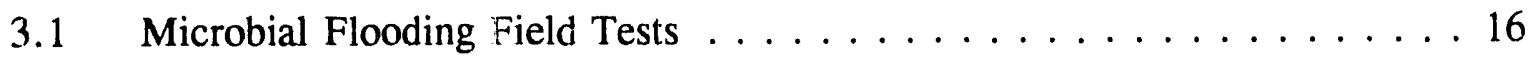

4.1 Southeast Vassar Vertz Sand Unit . . . . . . . . . . . . . . . 30

$4.2 \quad$ Field Pilot Volumetric Data . . . . . . . . . . . . . . . 32

5.1 Chemical Composition of Molasses - Nitrate Medium . . . . . . . . . . 48

5.2 Chemical Composition of Tanner's Mineral Solution . . . . . . . . . . . 48

5.3 Chemical Composition of Tanner's Metal Solution . . . . . . . . . . . . 49

5.4 Chemical Analysis of SEVVSU Brines $\ldots \ldots \ldots \ldots \ldots$

5.5 Chemical Analysis of SEVVSU Brines $\ldots \ldots \ldots \ldots$

5.6 Concentrations of Sulfate and Sulfide in SEVVSU Brines . . . . . . . . 57

5.7 Numbers of Different Groups of Bacteria in SEVVSU Brines . . . . . . 59

5.8 Substrate Utilization by Anaerobic Halophiles Isolated from

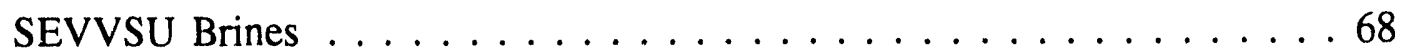

5.9 Glucose Fermentation Products of the Anaerobic Halophiles Isolated from SEVVSU Brines $\ldots \ldots \ldots \ldots \ldots \ldots \ldots$

5.10 Growth in Samples Using Different Nutrient Additions . . . . . . . . 73

$7.1 \quad$ Nutrient Injection History $\ldots \ldots \ldots \ldots 7 \ldots \ldots \ldots$

7.2 Correlation Coefficients Between Total Fluid Production Rate at Well 1A-9 and Injection Rates at the Indicated Wells or Groups of Wells . . 117

8.1 Pressure Fall-off Test Results . . . . . . . . . . . . . . . . 147

8.2 Interference Pressure Test Results $\ldots \ldots \ldots \ldots \ldots$ 
TABLE

9.1 Summary of Experimental Results $\ldots \ldots \ldots \ldots \ldots 6$

9.2 Absorbance and Concentration $\ldots \ldots \ldots \ldots \ldots 6$

10.1 Sulfide Results of Coproduced Brines . . . . . . . . . . . . . 182

10.2 Sulfate Reducing Bacteria Numbers in the Coproduced Brines . . . . . 185

10.3 Molasses-nitrate Utilizing Bacteria in the Coproduced Brines . . . . . . 186 


\section{LIST OF ILLUSTRATIONS}

\section{FIGURE}

Plate I. Plat Map of the Southeast Vassar Vertz Sand Unit . . . . . . . . . . xii

4.1 Oklahoma Geological Regions (After Oklahoma Geological

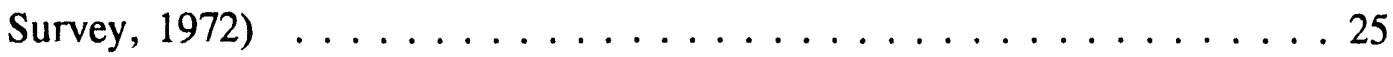

4.2 Plat Map of the Southeast Vassar Vertz Sand Unit . . . . . . . . . 26

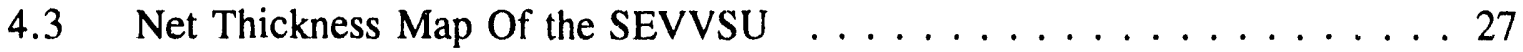

4.4 Simulation Grid with Structure Top Map Of SEVVSU . . . . . . . . . . . 34

4.5 SEVVSU Simulation Thickness Map . . . . . . . . . . . . 35

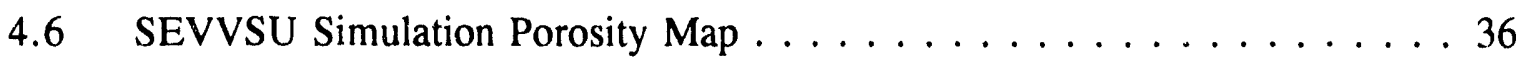

4.7 SEVVSU Simulation X-Direction Permeability Map . . . . . . . . . 37

4.8 SEVVSU Simulation Y-Direction Permeability Map . . . . . . . . . 38

4.9 Observed and Simulated Cumulative Field Water Production . . . . . . . . 39

4.10 Observed and Cumulative Water Production Rates for Well 5-1 . . . . . 41

4.11 Observed and Cumulative Water Production Rates for Well 5-2 . . . . . 42

4.12 Observed and Cumulative Water Production Rates for Well 7-1 . . . . 43

4.13 Observed and Cumulative Water Production Rates for Well 7-2 . . . . . . 44

5.1 Effect of $\mathrm{NaCl}$ Concentration on the Growth of Strain VS-732 . . . . . 62

5.2 Effect of $\mathrm{NaCl}$ Concentration on the Growth of Strain VS-751 . . . . . 63

5.3 Effect of $\mathrm{NaCl}$ Concentration on the Growth of Strain VS-752 . . . . . 64

5.4 Effect of $\mathrm{NaCl}$ Concentration on the Growth of Strain VS-511 . . . . 65

5.5 Effect of $\mathrm{NaCl}$ Concentration on the Growth of Strain TTL-30 . . . . 66 
FIGURE

Page

$6.1 \quad$ Experimental Set-up $\ldots \ldots \ldots \ldots \ldots \ldots$

6.2 Idealized Relative Permeabilities $\ldots \ldots \ldots \ldots$. . . . . . . . 80

6.3 Dependence on Capillary Number (after Stalkup, 1984) . . . . . . . . 83

6.4 Effect of nutrient treatments on PRF, cumulative oil recovery and gas production for Core $\mathrm{C} 06 \ldots \ldots \ldots$. . . . . . . . 87

6.5 Effect of nutrient treatments on PRF, cumulative oil recovery and gas production for Core $\mathrm{CO9} \ldots \ldots \ldots$. . . . . . . . . . . 89

6.6 Effect of nutrient treatments on PRF, cumulative oil recovery and gas production for Core $\mathrm{Cl}$

6.7 Effect of nutrient treatments on PRF, cumulative oil recovery and gas production for Core $\mathrm{Cl}$

7.1 Injection Well Facility $\ldots \ldots \ldots \ldots \ldots$

7.2 SEVVSU Pilot Gathering System . . . . . . . . . . . . . . 101

$7.3 \quad$ Facilities at Tank Battery . . . . . . . . . . . . . . . 102

7.4 Injection Rate at Pilot Injection Well $\ldots \ldots \ldots \ldots$. . . . . . . . 109

7.5 Cumulative Tertiary Oil Production $\ldots \ldots \ldots \ldots \ldots \ldots$

7.6 Total Fluid Production Rate and Oil Production Rate at Well 1A-9 . . . 112

7.7 Fraction of Water in Total Fluid Production at Well 1 A $-9 \ldots \ldots 113$

7.8 Potential Causes of Production Change at Well $1 \mathrm{~A}-9 \ldots \ldots \ldots \ldots \ldots$

7.9 Production from Well 1A-9 Compared to Sum Of Injection into

Wells $3-2,3-3,7-2,7-3,7-5$, and $8-1 \ldots \ldots \ldots 118$ 
7.10 Production from Well 1A-9 Compared to Injection into Well 3-2 . . . 119

7.11 Production from Well 1A-9 Compared to Injection into Well 3-3 . . . . 120

7.12 Production from Well 1A-9 Compared to Injection Well 7-2 . . . . . . 121

7.13 Production from Well 1 A-9 Compared to Injection into Well 7-3 . . . 122

7.14 Production from Well 1A-9 Compared to Injection into Well 7-5 . . . 123

7.15 Production from Well 1A-9 Compared to Injection into Well 8-1 . . . . 124

8.1 Horner Plot of Injection Well Test, February $1991 \ldots \ldots \ldots \ldots$. . . . . 141

8.2 Miller-Dyes-Hutchinson Plot of Injection Well Test, February 1991 _ . 142

8.3 Horner Plot of Injection Well Test. October $1991 \ldots \ldots \ldots \ldots$

8.4 Miller-Dyes-Hutchinson Plot of Injection Well Test, October $1991 \ldots 144$

8.5 Horner Plot Injection Well Test, January $1992 \ldots \ldots \ldots$

8.6 Miller-Dyes-Hutchinson Plot of Injection Well Test, January $1992 \ldots 146$

8.7 Identification of Boundary Effect Points Well 5-1 . . . . . . . . . 150

8.8 Identification of Boundary Effect Points Well $5-2 \ldots \ldots \ldots \ldots \ldots$

8.9 Identification of Boundary Effect Points Well 7-1 . . . . . . . . . 152

8.10 Semi-Log Straight Lines for Well 5-1 Interference Test . . . . . . . . . 153

8.11 Semi-Log Straight Lines for Well 5-2 Interference Test . . . . . . . . 154

8.12 Semi-Log Straight Lines for Well 7-1 Interference Test . . . . . . . . 155

9.1 Diagram of Tracer Experiment Apparatus $\ldots \ldots \ldots \ldots$

9.2 Plot of C/Co versus Injected Pore Volumes (Core \#1, Tracer

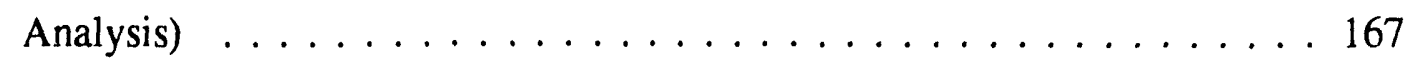


9.3 Pressure Changes During Incubation (Core $\# 2$, Nutrient Injection

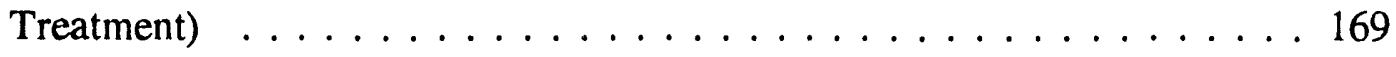

9.4 Tracer Test for Crushed Vassar Rock . . . . . . . . . . . . . . . 170

9.5 Spectrometer Calibration of Fluorescein . . . . . . . . . . 171

10.1 Sulfide Concentration Over the Course of the Field Study in Brines Produced from Wells in the Pilot Area $\ldots \ldots \ldots \ldots \ldots \ldots 1$

10.2 Sulfide Concentration Over the Course of the Field Pilot Study in Brines Produced from Wells in the 1A Tract Pilot Area . . . . . . . 183

10.3 Brine Alkalinities During the Field Pilot Study $\ldots \ldots \ldots \ldots$ 


\begin{abstract}
A multi-well microbially enhanced oil recovery field pilot has been performed in the Southeast Vassar Vertz Sand Unit in Payne County, Oklahoma. The primary emphasis of the experiment was preferential plugging of high permeability zones for the purpose of improving waterflood sweep efficiency.

Studies were performed to determine reservoir chemistry, ecology, and indigenous bacteria populations. Growth experiments were used to select a nutrient system compatible with the reservoir that encouraged growth of a group of indigenous nitrate-using bacteria and inhibit growth of sulfate-reducing bacteria. A specific field pilot area behind an active line drive waterflood was selected. Surface facilities were designed and installed. Injection protocols of bulk nutrient materials were prepared to facilitate uniform distribution of nutrients within the pilot area.

By the end of December, 1991, 82.5 tons (75.0 tonnes) of nutrients had been injected in the field. A tracer test identified significant heterogeneity in the SEVVSU and made it necessary to monitor additional production wells in the field. The tracer tests and changes in production behavior indicate the additional production wells monitored during the field trial were also affected. Eighty two and one half barrels $\left(13.1 \mathrm{~m}^{3}\right)$ of tertiary oil have been recovered. Microbial activity has increased $\mathrm{CO}_{2}$ content as indicated by increased alkalinity. A temporary rise in sulfide concentration was experienced. These indicate an active microbial community was generated in the field by the nutrient injection. Pilot area interwell pressure interference test results showed that significant permeability reduction occurred. The interwell permeabilities in the pilot area between the injector and the three pilot production wells were made more uniform which indicates a successful preferential plugging enhanced oil recovery project.
\end{abstract}




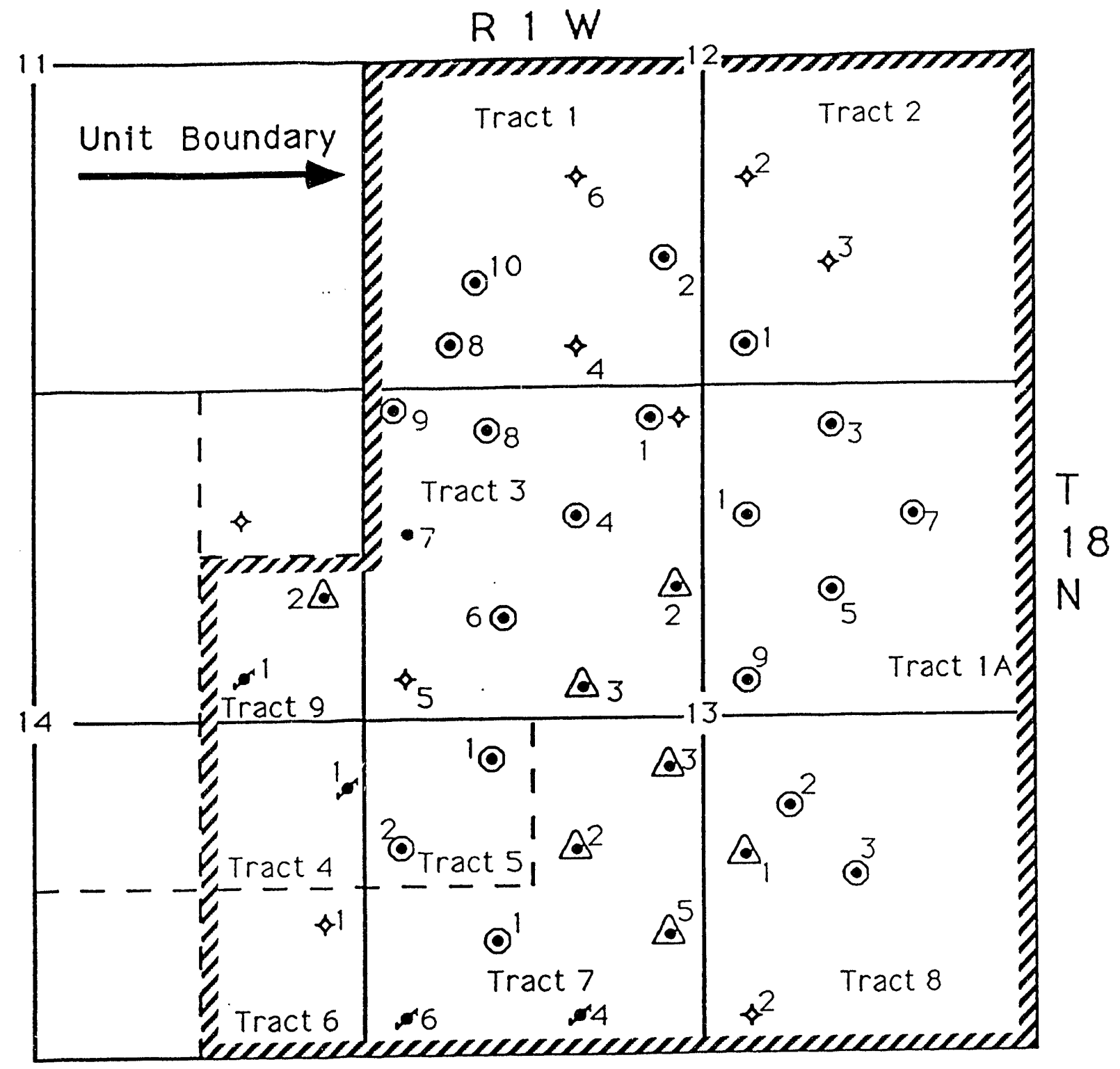

- Active production well

$\triangle$ Active injection well

- Inactive production well

- Inactive Injection well

Southeast Vassar-Vertz

Sand Unit

\& Dry hole

Scale: 1 inch $=1320 \mathrm{ft}$.

(402.6 m)

Plate I. Plat Map of the Southeast Vassar Vertz Sand Unit 


\section{Chapter 1. Introduction}

Of the discovered oil in the United States, more than 350 billion barrels $(5.6 \mathrm{x}$ $10^{10} \mathrm{~m}^{3}$ ) are estimated to remain unrecovered in the reservoir rock. Less than 30 billion barrels $\left(4.8 \times 10^{9} \mathrm{~m}^{3}\right)$ of this are recoverable using present technology. This leaves over 300 billion barrels $\left(4.8 \times 10^{10} \mathrm{~m}^{3}\right)$ of U.S. oil as a target for Enhanced Oil Recovery (EOR). The low oil prices experienced in the late 1980s and early 1990s have limited the economic application of EOR technologies because incremental returns on investment have been too low to justify the financial risk of their application (Hitzman, 1991). The same low oil price has prompted the abandonment of many marginal wells and a general decrease in domestic U.S. oil production capacity. The week of July 20, 1992, $47 \%$ of U.S. oil demand was met with foreign oil (Oil and Gas Journal, 1992). Major oil companies are actively prospecting for large international discoveries, leaving the domestic operations increasingly to the management of independent operators with fewer capital resources than the major oil companies. The need exists for an EOR technology that can be supplied simply and economically in U.S. oil fields.

Microbial Enhanced Oil Recovery (MEOR) has the potential to recover tertiary oil at a low cost per incremental unit. This advantage is to some extent associated with the type of chemicals required for field applications. Traditional enhanced oil recovery methods often require chemicals that are products of hydrocarbons such as some surfactants and polymers, or are associated with expensive delivery and surface facility systems such as steam or $\mathrm{CO}_{2}$ flooding. In the former case, the cost of investment increases with the price of the produced product, and the return on investment remains 
static. In the later case, a large, virtually guaranteed EOR target must exist to warrant the high equipment cost before operations begin. Injected chemicals in an MEOR project are nutrients such as molasses and ammonium nitrate which are readily obtainable in industrial quantities and qualities at reasonable prices. The necessary surface facilities are generally no more complicated than holding tanks, mixing pumps, and an injection pump.

The term Microbial Enhanced Oil Recovery covers any process in which viable microorganisms are used in-situ to recover additional oil. Indigenous or injected microbes are supplied nutrients by injection into the treated wells. The activity of the growing microorganisms provides the changes required to release additional oil. Metabolic products, such as biopolymers or biosurfactants, produced on the surface and injected into wells are normally excluded from MEOR.

Microbial enhancement of oil recovery was first suggested by Beckmann (1927). ZoBell $(1946,1947,1953)$ extended this work and received the first patents for such processes. In the late 1970s, interest was renewed in MEOR as effects of the "energy crisis" prompted the government to increase research in fundamental EOR technologies and the high pice of oil spurred expectation of profitable EOR activities in older oil fields. Much of the work performed in MEOR has been reported in the proceedings of MEOR conferences (Donaldson and Clark, 1983, Zajic and Donaldson, 1985, Burchfield and Bryant, 1988, and Donaldson, 1991). Books specifically on Microbial Enhanced Oil Recovery have been published (Donaldson, et al, 1989, Yen, 1990). Yen (1990) provides a comprehensive bibliography. World wide interest in MEOR is indicated by the diversity of nations contributing to the literature. Investigators from China (Qin and 
Yang, 1991), Australia (Sheehy, 1991), Canada (Jack and Stehmeier, 1988), Eastern Europe (Lazar, 1991), and the United States (Bryant and Burchfield, 1991) have reported MEOR field projects. Lazar (1991) has cataloged the field activity by type worldwide.

The mechanisms of MEOR processes are the same mechanisms addressed by traditional EOR technologies and differ only in that the mechanisms are activated by in situ activity of bacteria. Some bacteria consume paraffin and can be used to clear paraffin from well bore tubing and equipment, and, more significantly, from the formation near the well bore of the treated well. This increases the local permeability and increases oil production. Currently, this technology is commercially available.

Viscosity modification can occur by dissolving metabolically produced gas in the oil phase or by reducing the hydrocarbon chain length of heavy oils by hydrocarbon utilizing bacteria. Microscopic displacement efficiency can be improved by the presence of biosurfactants, solvents, and biopolymers. Acid production can change the character of the rock and improve oil release. Most MEOR field projects have been single well stimulations involving paraffin removal or local reservoir repressurization by metabolically produced gas.

The bacteria occupy the reservoir pore space. In the flowing phase they serve to increase viscosity and can improve mobility ratio. As attached material to pore walls, they selectively plug high permeability paths in the reservoir by reducing permeability in those locations where growth has been abundant. This abundant growth occurs where the nutrients are carried by injection water. Once the high permeability paths are reduced in their capacity to conduct injected fluid, subsequent injected water will sweep areas previously bypassed. The injected water may encounter and sweep additional 
mobile oil.

Multiwell MEOR methods either involve microbially aided waterflooding with enhanced oil recovery by viscosity and interfacial tension effects of bacteria and bioproducts or projects utilizing selective plugging to increase areal and vertical sweep efficiency. Eleven field trials have been reported in the literature (Lazar, 1991). This report details a selestive plugging MEOR project. Recent results from the few other interwell MEOR floods (Lazar, et al., 1991, Wagner, 1991, Bryant and Burchfield, 1991, Ivanov, et al., 1991) reported to date are encouraging.

A multi-well microbially enhanced waterflooding field pilot was conducted in the Southeast Vassar Vertz Sand Unit in Payne County, Oklahoma (SEVVSU). The primary goal of this experiment was to demonstrate preferential plugging of high permeability zones. Preferential plugging should improve waterflood sweep efficiency. The microbial flood was performed in a sandstone reservoir at $1800 \mathrm{ft}(550 \mathrm{~m})$ of depth with wells drilled on a 20 acre $\left(8.1 \times 10^{4} \mathrm{~m}^{2}\right)$ spacing. A single injector was used to drive injected nutrients toward four production wells in a pattern resembling one corner of an inverted nine-spot. This work was performed under US DOE Contract DE-FG22-89BC14246.

The project evolved from a large body of research conducted in MEOR at the University of Oklahoma. Since 1979, 33 papers, seven Master's theses, and three Doctoral dissertations have been produced at the University of Oklahoma. Planning, experimentation, and reservoir characterization in preparation for the project described in this report were performed under a previous contract (Knapp, et al., 1989).

Chapter 2 is an overview of the Microbial Field Pilot Study. The subsequent chapters deal with individual topics and, although complete in themselves, do not 
individually grasp the scope of the project. Chapter 2 attempts to place the various aspects of the field pilot in perspective.

Chapter 3 is a review of the other microbial waterflooding field projects reported to date. Several are compared to characteristics of the SEVVSU. Others with limited information available are summarized.

Chapter 4 introduces the reservoir known as the Southeast Vassar Vertz Sand Unit. The physical and geological characteristics are presented. The results of reservoir simulation studies are also presented.

Chapter 5 revicivs the microbiology and ecology work performed during the pilot. The chemical nature of the brines in the SEVVSU is described. The types of bacteria indigenous to the formation and their growth characteristics are presented. The choice of a nutrient treatment mixture for the field pilot is reported.

Chapter 6 discusses core experiments performed using fluids and bacteria from the SEVVSU. The mechanisms of release of oil from cores is discussed.

Chapter 7 presents the pilot operations and production data. The pilot area is defined and the surface facilities described. Injection procedures and volumes are presented. Changes in production behavior in the reservoir as a consequence of the microbial field pilot are described.

Chapter 8 discusses pressure test analysis conducted at intervals during the pilot test. Single well and multiple well pressure transient tests were performed. Their results and the changes in interwell permeability caused by the field pilot are presented.

Chapter 9 discusses chemical tracer tests performed during the pilot. A fluorescent tracer was used to identify the significant flow paths in the reservoir and 
changes in those flow paths caused by nutrient injection.

Chapter 10 presents the chemical changes of the reservoir brine caused by the microbial flood. The changes in alkalinity and sulphide content of fluids produced during the pilot are presented.

Chapter 11 lists the conclusions from this work.

This project spanned three years and the efforts of many people. Petroleum engineers involved in this project were Dr. Roy M. Knapp and Dr. Donald E. Menzie, coprincipal investigators. Also, John Chisholm, Richard Raiders, Matthew Coughlin, Nixon Silfanus, Sudhendu Kashikar, Dan Garvey, Xu Zhang, Jian Yang, and Thomas Boyce worked on the petroleum engineering aspects of the project.

The microbiology was conducted by Dr. Michael J. McInerney, coprincipal investigator. He was aided by Dr. John D. Coates, Vishvesh Bhupathiraju, Pramad Sharma, Dr. P.J. Reynolds, Woody Jenkins, Tuan-Tuan Liu, Jim Fowler, Frank Caccavo, and Brad Jackson.

The investigators wish to extend thanks to the many individuals and organizations who supported the project. Sullivan and Company of Tulsa, Oklahoma allowed the use of the field for the duration of the pilot. Alan Erwin, Dale Dawson, and William Griffin of Sullivan and Company provided wise counsel and advice regarding field operations. Special thanks are extended to H.E. "Pete" O'Kelly whose assistance in the actual operation of the pilot was crucial. Halliburton Services Research Center donated the use of the injection pump used in the project. Finally, the United States Department of Energy provided financial support for this research. 


\section{Chapter 2. An Overview of the Microbial Field Pilot Study}

The Microbial Field Pilot Study began as a 15 month project to determine whether a microbially enhanced oil recovery process was feasible in the hypersaline oil reservoir, Southeast Vassar Vertz Sand Unit (SEVVSU) (Knapp, et al., 1989). Previous laboratory studies utilized bacteria at $8 \%$ salt content or less. Salinities at the SEVVSU were between $15 \%$ and $19 \%$ salt. This study established that robust growth of indigenous bacteria was possible at reservoir conditions.

This study was one of the first integrated microbiology-engineering studies to determine the feasibility and technical requirements for a microbial waterflooding process. The ecology of the SEVVSU was extensively studied. Several core experiments were performed to show that in situ microbial growth could selectively modify permeability and recover residual oil at the temperature and pressure of the SEVVSU using oil, brine, core material, and bacteria from the SEVVSU. The brines contained diverse populations of anaerobic, facultative, and aerobic halophilic bacteria. Both nitrate-reducing and sulfate-reducing bacteria were isolated.

Bacteria from the SEVVSU were characterized and many unique bacteria isolated. Five anaerobic bacteria were chosen for more extensive analysis. These all proved to be obligate halophiles that stopped metabolic activity at salt concentrations of less than $6 \%$. These bacteria were tested for growth in the presence of different nutrient mixtures. These tests compared the growth of the bacteria with mixtures of pure chemical substrates and mixtures of molasses with other chemicals. The best growth was observed with a mixture of molasses and ammonium nitrate. 
Plate $I$ is a plat map of the Southeast Vassar Vertz Sand Unit. Wells are designated by tract number-well number. The pilot injector was Well 7-2. The pilot production wells were Wells 5-1,5-2, and 7-1. These four wells were inactive injectors prior to the pilot study.

Microbial evaluation of bacteria taken from produced water samples in the Vassar was performed to develop growth parameters. Spacifically, doubling time of Vassar bacteria in the presence of the proposed injected nutrient mixture and the rate of consumption of that mixture we-e evaluated. This information was used to plan inreservoir incubation times during the field pilot.

The simulation of the SEVVSU was updated to include operations through June, 1990 using the Eclipse black oil simulator (Intera-ECL Petroleum Technologies, 1991). This extended the simulation study performed under the previous study (Knapp, et al., 1989). The overall history match was within $5 \%$ of observed data. The four wells to be used in the pilot were prepared for service. The 5-1, 5-2, and 7-1 were converted from injectors to producers. Well 7-2 was returned to active injection in late December 1990. In February 1991, injection into Well 7-2 was stopped for a pressure interference test using Wells 5-1, 5-2, and 7-1.

After completion of the interference test, injection into the 7-2 was resumed and the three pilot production wells were opened to flow. The injection and production rates in the pilot area were balanced in the pilot area. Each production well was allowed to produce approximately $100 \mathrm{bbl}$ per day $\left(16 \mathrm{~m}^{3} / \mathrm{d}\right)$ and the injector was provided water at an injection rate of $300 \mathrm{bbl}$ per day $\left(48 \mathrm{~m}^{3} / \mathrm{d}\right)$.

The first tracer study was initiated April 11, 1991. Sodium fluorescein was 
injected into the 7-2. Samples were collected daily from the 5-1, 5-2, and 7-1. Fourteen days after injection of the tracer, fluorescein was detected at the 1A-9 well. Referring to Plate I, the 1A-9 is $1870 \mathrm{ft}(570 \mathrm{~m})$ northeast of the $7-2$. It is also on the opposite side of the active 7-3 injection well. The true first arrival time of the tracer is not known as 1A-9 was not being sampled. The field pumper discovered the change in produced brine color during other operations. After detection of tracer in the $1 \mathrm{~A}-9$ wells 1A-1 and 1A-5 were sampled and also discovered to have tracer present.

It had been thought that pilot injection water would travel west because of the high pressure ridge established by the line of injectors to the east and the low pressure region established by the production wells to the west. Investigation of activities in the field disclosed that injection volumes had fallen significantly in the 7-3 and 7-5 during the period in which the 7-2 was receiving injection prepatory to the falloff-interference test. Injection pressure at these wells had not changed. Apparently, the increase in subsurface pressure caused by 7-2 injection had reduced the differential injection pressure of the injectors to the east. Well $7-2$ had become a significant injector for the line drive waterflood. It was decided to increase production from the pilot production wells and increase injection into the 7-3 and 7-5. The resulting increase in the pressure gradient from east to west would hopefully direct the brine injected into $7-2$ to the pilot area. Pumping units on the 5-1 and 5-2 were modified to lift $150 \mathrm{bpd}\left(23.8 \mathrm{~m}^{3} / \mathrm{d}\right)$ and $180 \mathrm{bpd}$ $\left(28.6 \mathrm{~m}^{3} / \mathrm{d}\right)$, respectively, and the $7-1$ was adjusted to lift $300 \mathrm{bbl}$ per day $\left(47.7 \mathrm{~m}^{3} / \mathrm{d}\right)$. The injection rate for the $7-2$ remained at $300 \mathrm{bbl}$ per day $\left(47.7 \mathrm{~m}^{3} / \mathrm{d}\right)$. The operator began to stimulate their injectors with a near wellbore cleanout treatment. Wells 3-3, 73 , and 7-5 were all treated and significant rises in injectivity were achieved at all three 
wells.

A second tracer study was performed in early August 1991. With the new injection and production rates in place for 30 days the flow paths in the region were spected to have reached equilibrium. This test produced an 18-day simultaneous arrival of a low tracer concentration at the $1 \mathrm{~A}-9,1 \mathrm{~A}-1$, and $1 \mathrm{~A}-5$ wells. The results suggest the existence of a high transmissivity flow path in the reservoir which flows from the 7-2 to the western part of the 1A tract. The change of operating policy in the field was insufficient to change the direction of flow of the 7-2 injection water to the west. It was decided to proceed with the injection of nutrients into the 7-2 and include the $1 \mathrm{~A}$ wells, specifically the $1 \mathrm{~A}-9$, in all sampling and field monitoring.

The surface facilities for injection of nutrients into the 7-2 well consisted of two oil field "frac" tanks, mixing pumps, an injection pump, a filtering system, and flow meters. One of the tanks served as a storage facility for a mixture of ammonium nitrate and injection water. This mixture was supplied to the second tank as needed. The second tank delivered fluid to the injection pump and contained a mixture of molasses, ammonium nitrate, and brine water. This mixture was filtered and injected into the flow line from the SEVVSU field injection pump at the 7-2 wellhead. The flow streams were combined to produce a $20 \%$ molasses concentration at the sand face of the reservoir. Each injection of nutrient was followed by normal nutrient free injection water to achieve an average volumetric molasses concentration of $2 \%$ in the flooded part of the reservoir.

On August 26, 1991, 41,500 lbs. (18.8 tonnes) of ammonium nitrate were delivered to location and combined with $300 \mathrm{bbl}\left(47.7 \mathrm{~m}^{3}\right)$ of Vassar brine to produce an $18.7 \%$ solution of ammonium nitrate. On August $29,1991,38 \mathrm{bbl}\left(6.0 \mathrm{~m}^{3}\right)$ of this 
mixture were injected into the $7-2$ in an attempt to reduce sulfide concentrations and to stimulate nitrate-using bacteria in the formation. On September 26, 1991, twelve tons (10.9 tonnes) of cattle feed grade molasses were delivered and combined with a portion of the nitrate mixture and additional brine to produce a $46 \%$ molasses $/ 46 \%$ brine $/ 8 \%$ ammonium nitrate mixture. This was injected in three treatments of approximately 37.7 bbl $\left(6.0 \mathrm{~m}^{3}\right)$ each on the September 27 , October 1, and 4, 1991, respectively. On October 7, 1991, injection into the 7-2 well was stopped and the initial incubation period began. This incubation period allowed a large bacterial population to develop in the pilot area. Laboratory growth experiments indicated the nutrients would be effectively consumed in 30 days. On November 7, 1991, 25 tons (22.7 tonnes) of molasses were delivered to location, mixed with ammonium nitrate and brine, and injected in eight treatments between November 9th and November 25th. On December 3, 1991, another 25 tons (22.7 tonnes) of molasses were delivered and mixed in a similar manner. The nutrients were injected in nine treatments between December 4th and 20th.

On February 6, 1992, a second pressure interference test was performed between Well 7-2 and the three pilot injection wells. The pressure interference tests performed before and after nutrient injection revealed a significant reduction in permeability in the pilot area. Interwell permeabilities were reduced to 30 and 40 percent of their pre-test values for the 7-2 to 5-2 and 7-2 to 5-1 doublets, respectively. The 7-2 to 7-1 pair indicated less reduction in permeability with $70 \%$ of pre-test permeability. Average permeabilities in the pilot area became uniform with less than $15 \mathrm{md}$ difference between the three interwell permeabilities. The results indicate that selective plugging of the reservoir occurred during the microbial enhanced oil recovery project. High permeability 
paths from the 7-2 to Tract 5 received the bulk of the nutrients that were retained in the pilot area and consequently received the microbial growth associated with it. This growth reduced the transmissivity of those flow paths.

A final tracer test was performed in the field. On February 18 th, tracer was again injected in Well 7-2. As of July 13, 1992, tracer had not been detected in any field production wells. Lack of arrival of tracer at the 1A-9 indicates this flow path has been significantly reduced in fluid volume transported.

The first tertiary oil was produced the first quarter of 1992. As of May 12, 1992, a cumulative tertiary oil production of 22.5 barrels $\left(3.6 \mathrm{~m}^{3}\right)$ was produced from the pilot wells. Fluid sampling indicates that 5-1 is the most likely source of the oil although the presence of oil was observed in the 7-1. May 12, 1992, production from Well 5-2 was stopped. May 31, 1992, production from Well 7-1 was also stopped. Well 5-1 began to produce $1 \mathrm{bbl}$ per day $\left(0.2 \mathrm{~m}^{3} / \mathrm{d}\right)$ of oil shortly after May 12,1992 . Production from Well 5-1 was stopped July 31, 1992 having produced approximately $60 \mathrm{bbl}\left(9.5 \mathrm{~m}^{3}\right)$ of additional tertiary oil.

The production behavior of the $1 \mathrm{~A}-9$ also indicates an effect of the nutrient treatments. The total fluid production rate of the 1A-9 began to alternate between 100 bbl per day $\left(15.9 \mathrm{~m}^{3} / \mathrm{d}\right)$ to more than $200 \mathrm{bbl}$ per day $\left(31.8 \mathrm{~m}^{3} / \mathrm{d}\right)$. Changes in rate occurred almost daily from January through July of 1992 . There have been no operational changes in the field that explain the production rate changes in the 1A-9. The chronological proximity to the first nutrient injection makes a strong case that the nutrient treatments affected this well; however, the conversion of Well 3-2 to an injector and the increased injection of brine into the 3-3, 7-5, and 7-3 may have contributed to 
the rate levels at the $1 \mathrm{~A}-9$. The daily fluctuations of total fluid production cannot be traced to any changes in the oneration of the field and it is believed the nutrient injections are the cause of the fluctuations. The mechanism causing this behavior is not known.

An alkalinity and sulfide increase in the produced brine showed that metabolic activity occurred in the SEVVSU. The increase in alkalinity was due to the production of $\mathrm{CO}_{2}$ (in solution as $\mathrm{CO}_{3}{ }^{-}$or $\mathrm{HCO}_{3}^{-}$) by microorganisms. A bacterial community may exist in the reservoir that completely mineralized the sugars to carbon dioxide. The length of retention of the nutrients in the formation apparently allowed complete metabolism of the injected substrate, which resulted in a single terminal carbon product, carbon dioxide. Alkalinity levels rose after nutrient injection and returned to pre-test levels 60 days following the last injection of nutrients.

Sulfide levels in the pilot production wells decreased by $50 \%$ after the injection of ammonium nitrate in August 1991. Two increases in sulfide concentration in produced brine from the pilot wells were observed after molasses injection. About 50 days after the first injection of molasses-ammonium nitrate (September 27, 1991) sulfide levels more than doubled at the pilot production wells and the wells in the $1 \mathrm{~A}$ tract. Concentrations fell to near pre-nutrient injection condition in these wells after another 25 days. The second increase in sulfide began around 50 days after the November 7 th injection of molasses. This increase in sulfide lasted approximately eight weeks before sulphide returned to pre-treatment levels.

The lengths of time of the sulfide increases were approximately the same lengths of time as the injections of nutrients that preceded them. The offsets of time between the injection of nutrients and the first indication of sulfide increase were approximately. 
the same for the September injection and the November injection. A clear causal relationship is indicated between nutrient injection and increased sulfide concentrations.

The primary goal of the Microbial Field Pilot Study, to selectively plug high permeability flow paths in the reservoir, was successfully achieved. The change of interwell permeability between the $7-2$ and the three pilot production wells shows that the selective plugging of flow paths occurred. More important is the apparent blockage of the flow path from the 7-2 to the $1 \mathrm{~A}$ region of the field. The change in arrival time of the tracer at the 1A-9 implies that this flow path ceased to function as a major flow channel at least temporarily.

Tertiary oil was recovered. Significant additional oil recovery was not likely because $60 \%$ of the original oil in place had already been recovered in the pilot is ea from primary and secondary recovery.

The injection of ammonium nitrate before molasses injection reduced the sulfide production in the field. Insufficient nitrate was injected to prevent the growth of sulfatereducing bacteria in the reservoir in the presence of large amounts of injected carbohydrate. This resulted in the increases in sulfide content after molasses injection.

Increases in carbon dioxide content, measured as alkalinity, confirm microbial activity in the reservoir. Both alkalinity and sulfide levels returned to pre-test conditions after molasses injection ceased. This indicates that microbial effects in the reservoir are transient. 


\section{Chapter 3. Other MEOR Waterfloods and the SEVVSU Flood}

\subsection{Introduction}

Microbial enhanced waterflooding has been performed in other fields around the world. These floods extend the range of applicable conditions for the use of Microbial Enhanced Oil Recovery (MEOR) in interwell opt ations. This chapter will discuss some of the more publicized microbial floods. Table 3.1 compares information from the microbial waterflooding tests to information from the Southeast Vassar Vertz Sand Unit (SEVVSU) (summarized in Chapter 2).

\subsection{Nacatoch Formation, Union County, Arkansas}

Yarbrough and Coty (1983) presented information on the first U.S. microbial flood. Microbes were used to enhance oil production in the Upper Cretaceous Nacatoch formation in Union County, Arkansas. Clostridium acetobutylicum, a strong gas producer in the presence of $2 \%$ molasses and in salinities up to $3 \%$, was used to stimulate oil production. Four thousand gallons of active bacterial suspensions were injected in 18 batches. Molasses was injected continuously in a $2 \%$ solution for 5.5 months. The distance between injectors and producers was on the order of $800 \mathrm{ft}$. Ninety days after the initial molasses injection, fermentation products and unused molasses were detected in produced brine. One well demonstrated a strong response to the microbial flood. A rise in volatile fatty acids was measured at this well and a very large increase in carbon dioxide was recorded. This well was producing almost $100 \%$ water, oil production from this well increased from $0.6 \mathrm{bpd}$ to $2.1 \mathrm{bpd}$. 


\begin{tabular}{|c|c|c|c|c|c|c|c|c|c|c|c|}
\hline 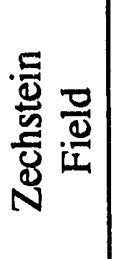 & 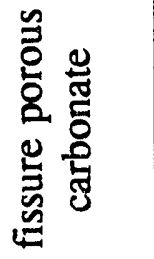 & $\begin{array}{l}\Xi \\
\Xi \\
\beth\end{array}$ & $\begin{array}{l}u \\
0 \\
n \\
n\end{array}$ & $\overleftarrow{z}$ & $\stackrel{\circ}{\sim}$ & $\begin{array}{l}0 \\
\vdots \\
5 \\
0 \\
0 \\
\dot{1} \\
0 \\
0 \\
0\end{array}$ & $\begin{array}{l}\stackrel{\circ}{2} \\
\text { లn } \\
\stackrel{2}{2} \\
0\end{array}$ & $\overleftarrow{z}$ & 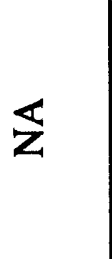 & 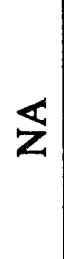 & 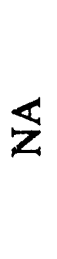 \\
\hline $\overrightarrow{\tilde{U}}$ & 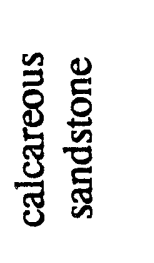 & $\begin{array}{l}E \\
8 \\
8 \\
0 \\
0 \\
\wp\end{array}$ & \begin{tabular}{l}
0 \\
$\circ$ \\
\multirow{\gamma}{*}{}
\end{tabular} & $\begin{array}{l}E \\
\vec{b} \\
\dot{1} \\
\dot{\alpha} \\
\dot{\theta}\end{array}$ & 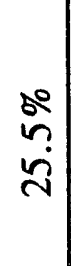 & $\begin{array}{c}\tilde{E} \\
\Sigma \\
\Sigma \\
\vdots \\
\vdots \\
\vdots\end{array}$ & $\begin{array}{l}0 \\
+ \\
0\end{array}$ & 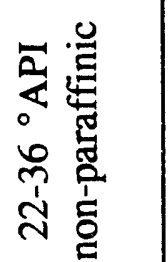 & $\overleftarrow{z}$ & $\stackrel{s}{n}$ & $\begin{array}{l}\infty \\
\stackrel{0}{0} \\
\stackrel{1}{0}\end{array}$ \\
\hline 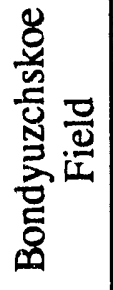 & 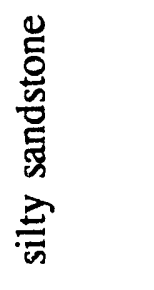 & 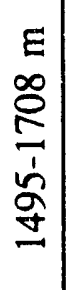 & $\begin{array}{l}u \\
0 \\
n \\
0 \\
j\end{array}$ & 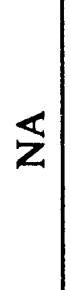 & $\begin{array}{l}\infty \\
\infty \\
\infty \\
\end{array}$ & $\begin{array}{c}\tilde{E} \\
\Sigma \\
\vdots \\
0\end{array}$ & $\frac{50}{5}$ & 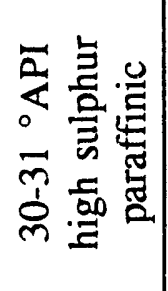 & 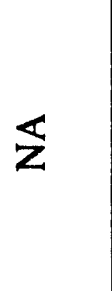 & $\mathbb{z}$ & $\mathbb{z}$ \\
\hline 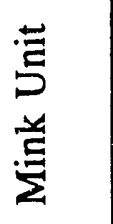 & 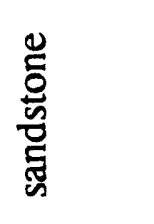 & $\begin{array}{c}E \\
\tilde{\infty} \\
\infty\end{array}$ & $\begin{array}{l}0 \\
\vdots \\
\text { ஸे }\end{array}$ & $\begin{array}{c}E \\
N \\
a\end{array}$ & 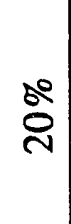 & $\begin{array}{c}\tilde{E} \\
\vdots \\
\delta \\
\delta \\
\vdots\end{array}$ & 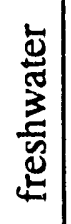 & 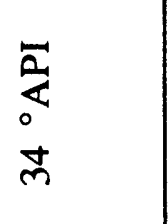 & $\begin{array}{l}3 \\
0 \\
x \\
0\end{array}$ & $\frac{\Delta}{m}$ & $\Sigma$ \\
\hline 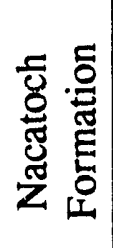 & 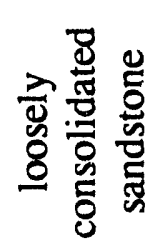 & $\begin{array}{l}E \\
b \\
\dot{n} \\
\infty \\
n\end{array}$ & $\begin{array}{l}u \\
0 \\
i n \\
0 \\
y \\
i \\
\\
m\end{array}$ & $\begin{array}{c}E \\
0 \\
\dot{1} \\
\dot{1} \\
\dot{0}\end{array}$ & 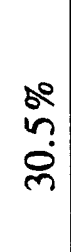 & 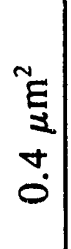 & 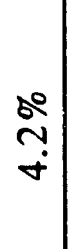 & $\begin{array}{l}Z_{0} \\
0 \\
0\end{array}$ & $\begin{array}{l}\dot{0} \\
\dot{0} \\
\dot{v}\end{array}$ & $\overleftarrow{z}$ & $\overleftarrow{z}$ \\
\hline$\sum_{n}^{2}$ & 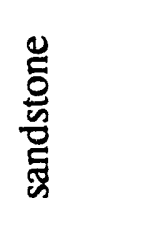 & $\begin{array}{c}E \\
\underset{f}{J}\end{array}$ & $\begin{array}{l}0 \\
0 \\
m \\
m\end{array}$ & $\begin{array}{c}E \\
a \\
\dot{j} \\
\dot{j} \\
\dot{r}\end{array}$ & 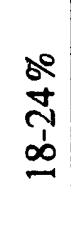 & $\begin{array}{c}\tilde{E} \\
\Xi \\
n \\
0 \\
1 \\
\dot{0}\end{array}$ & $\begin{array}{l}2 \\
a \\
n \\
n\end{array}$ & 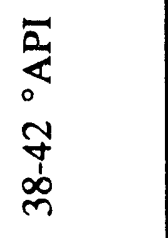 & $\begin{array}{l}\dot{0} \\
x \\
a \\
\dot{n}\end{array}$ & $\begin{array}{l}20 \\
n \\
2\end{array}$ & $r$ \\
\hline$\frac{\overrightarrow{0}}{\overrightarrow{0}}$ & 宽 & $\begin{array}{l}\text { 동 } \\
\text { 号 }\end{array}$ & 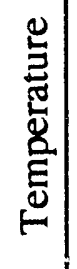 & 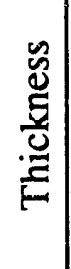 & $\begin{array}{l}\text { 름 } \\
\text { o } \\
0 \\
0\end{array}$ & 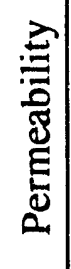 & : & $\begin{array}{l}\stackrel{2}{0} \\
\frac{\pi}{5}\end{array}$ & 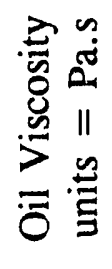 & 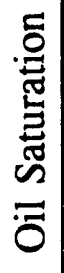 & 窝 \\
\hline
\end{tabular}




\subsection{Mink Unit of the Delaware.Childers Field}

The Mink Unit of the Delaware-Childers Field in Nowata County, Oklahoma was the site of a microbial waterflood conducted by the National Institute for Petroleum and Energy Research (NIPER) in conjunction with Microbial Systems Corp. (MSC) and INJECTECH, Inc. (Bryant and Burchfield, 1991, Bryant, et al., 1991) The field is completed in the Bartlesville sandstone. The area in which the pilot was conducted consisted of four adjacent inverted five-spot injection patterns on five-acre spacing. Generally, injectors and producers were $311 \mathrm{ft}$. from one another. The largest distance between an injector and the nearest neighbor producing well was $696 \mathrm{ft}$. The entire field consisted of 21 injectors and 15 producers. Each injector was receiving 40 bpd at 530 psi injection pressure. The average daily oil production from the 10 production wells monitored by the project was $6.4 \mathrm{bpd}$.

Fluorescein tracer was used to define the flow paths in the Mink field. This was injected into the four injection wells and was detected at all 10 production wells. Total tracer recovery in parts per billion - days was given for each well. First arrival times were not given. Tracer was recovered for a period of two months. Tracer was detected again 1.8 years after tracer injection. It is supposed that this tracer traveled a rock matrix route between injector and producer and the earlier tracer arrivals were associated with high permeability flow paths in the reservoir.

The inoculum chosen for use in the Mink unit was a consortium of bacteria that included a surfactant producer, Bacillus licheniformis ATCC \#39307 (Bryant and Douglas, 1988). ATCC \#39307 is the designation of Bacillus licheniformis strain JF-2 (Javaheri, et al., 1985). Twenty-six gallons of inoculum were injected into each well. 
This was followed by 20 gallons of raw molasses diluted by injection brine to $4 \%$ molasses. After a period of shut-in of 15 days, the injection wells were backflushed and produced foam. The foam was indicative of the presence of surfactant and demonstrated that microbial activity had occurred in situ. From April 3, 1987, through September 21, 1989, each injection well received 2 gallons of molasses per day.

Water-oil ratios at all of the pilot production wells decreased. An estimation of the future performance of the Mink field under continued waterflooding was performed to determine the oil that would have been recovered had the field pilot not been initiated. Total oil production from the Mink unit over the course of the test exceeded the predicted amount by $577 \mathrm{bbl}$. Oil production from the entire Mink unit was apparently commingled and oil production from individual wells is not given. Bryant and Burchfield attribute all of the $577 \mathrm{bbl}$ to the microbial flooding.

The Mink pilot is unique in that only a small amount of injected molasses was used. Only 18.7 tons of molasses were injected over the two year life of the pilot. Assuming that the apparent increase in oil production was due to microbial activity and a cost of molasses of $\$ 100 /$ ton, the cost in molasses per barrel of incremental oil produced was $\$ 3.24$.

\subsection{Bondyuzchskoe Oil Field, Tatarian Republic, USSR}

Ivanov and Belyaev (1991) reported the results of a microbial waterflood in the Soviet Union. This test did not use an inoculum. Bacteria present in the reservoir were stimulated by the injection of fresh water with mineral salts. The bacteria already in the field were methanogens, oil oxidizers, and sulfate reducers. These bacteria were not defined as indigenous, but were suspected to have been introduced to the reservoir over 
the course of the existing waterflood. Near the injection well aerobic methanotrophs were expected to utilize oil as a substrate. Deeper in the field, after the oxygen dissolved in the fresh injection water had been consumed, anaerobic methanogenic bacteria were stimulated as indicated by increased anaerobic methanogenic bacterial counts in produced brine and increased methane production from affected wells.

A single injection well was used in the project. It was surrounded by six production wells. Three wells, all on one side of the injection well, were affected by the microbial stimulating injection indicating that in this trial all of the injected brine went in one direction. The stimulated wells were from 575 to $1280 \mathrm{ft}$. from the injection well. The movement of the injection water was traced by following the decrease in salinity at the producing wells. The predominant flow path in the reservoir connected the injector to a producer located $1280 \mathrm{ft}$. away. Oil production from this well more than doubled after fresh water with mineral salts was injected. With the decrease in salinity associated with the arrival of fresh water, the level of bicarbonate in the produced brine significantly increased and served as an indication of microbial activity in the reservoir. A second production well, which had ceased to produce oil (only water was being produced) began to produce a small amount of oil. A drop in salinity and an increase in bicarbonate were also observed in this well but at much lower levels.

\section{5 $\mathrm{Sa}_{3} \mathrm{Cl}_{1}$ Field, Romania}

The $\mathrm{Sa}_{3} \mathrm{Cl}_{1}$ Field was the site of a successful MEOR project reported by Lazar, et al., 1991a. The reservoir consists of a calcareous sandstone with calcareous marl with microfissures and microcaves. Calcium carbonate content of reservoir rock is $45 \%$. Both microbial waterflooding and single well cyclic microbial processes were used in this 
field. Two injectors surrounded by nine producers are involved in this study.

The inoculum was a mixture of anaerobic bacteria specifically selected for growth under the respective reservoir conditions and tested for metabolic product production under reservoir conditions (Lazar, et al., 1991b). This inoculum was injected with a $2 \%$ molasses nutrient mixture.

Microbial activity in the formation was indicated by increased bacterial counts in produced brines and decreased oil viscosity. The field had been on decline under primary oil production when the original waterflood was begun. The waterflood reduced the rate of decline of oil production, however, total oil production rate was still declining. After the microbial flood was established the oil production rate stabilized and no indication of decline existed at the conclusion of the reported period. Oil rate at the affected wells rose from $0.7-0.8$ metric tons per day to $0.9-1.0$ metric tons per day. The arrest of decline in the field was attributed to an improved fluid flow profile in the reservoir, especially, the modification of permeability in the microfissures and microcaves.

\subsection{Zechstein Formation, German Democratic Republic}

This field test is unique in that the microbial flood was performed in a carbonate with very low porosity. The Zechstein Formation (Wagner, 1991) has $1 \%$ to $2 \%$ porosity in the matrix of the rock. Volume of fissures in the rock contribute $0.1 \%$ to $0.5 \%$ porosity. The project also reports a very large increase in oil production from the field as a result of the injection of nutrients and a consortium of bacteria.

The bacteria inoculum chosen for this project was a consortium that flourished at $10 \%$ salt and produced at least $100 \mathrm{ml}$ of gas per gm of molasses in the nutrients. The 
bacteria were tested using a mixture of molasses, phosphate, ammonium chloride, and calcium carbonate. The mixture was maintained at a $\mathrm{pH}$ of 7.5.

The distance between injector and producers in the field was $1970 \mathrm{ft}$. Each treatment of the formation consisted of 50 metric tons of sugar beet molasses amended with phosphate and soda. Injection from the injection well and production from the production well were stopped, and microbial activity monitored by observing the pressure of the production well. The total number of treatments and the total molasses injected was not reported.

This field was on decline under waterflooding when microbial treatments were started. Before treatment the field was producing 50 metric tons of oil per month. Immediately following treatment production increased to 150 tons per month. About a year after nutrient injection, field production increased to 300 metric tons per month. This increase was associated with a significant decrease in produced water fraction which fell from $90 \%$ to $60 \%$. Over one four month interval during the period one year after nutrient injection, the field was producing nearly 400 metric tons per month and the water cut fell to $30 \%$. The volume of carbon dioxide in produced brine increased from none before the test to $0.2 \%$ at the first encounter of this indicator of metabolism. At the time of reporting, carbon dioxide content as dissolved $\mathrm{CO}_{3}{ }^{-}$and $\mathrm{HCO}_{3}{ }^{-}$in produced brine was at $4 \%$.

\subsection{Other Fields}

Davidson and Russell (1988) report the use of spores of Clostridium in the Royal Loco Unit, Stephens County, Oklahoma. Wells were on a five-acre spacing. Molasses was injected to induce growth of the spores. Metabolic products were encountered in 
wells 300 to $1000 \mathrm{ft}$. from the injector. Oil production increases were attributed to metabolic carbon dioxide and the metabolic solvent, normal butyl alcohol.

Oppenheimer and Hiebert (1988) report the use of a proprietary consortium of bacteria and a propristary metabolic catalyst in two fields in South Texas. These bacteria consume hydrocarbons and enhance oil production by modifying oil to lighter chains and changes caused by the products of metabolism in the form of detergents and carbon dioxide. Oil recovery improved in both fields. The operator of one field also reported a reduction in paraffin problems and increased API gravity.

Lazar (1991) presents in tables information about MEOR field tests conducted in the world since the late 1950s. Several other field tests are listed which were conducted in eastern block nations and are not well documented in the west. One such test from the early 1960s indicates microbial growth at a well over $1600 \mathrm{ft}$ from the injection well. Three others report significant increase in oil production for periods of four months, eight months, and two to eight years, respectively. 


\section{Chapter 4. The Southeast Vassar Vertz Sand Unit}

\subsection{Introduction}

In most experiments, the choice of reaction vessel is not important for it makes no difference whether a chemical reaction is carried out in a test tube, flask, or beaker. Often the specific vessel is named for the purpose of completeness and ensuring that experiments are reproducible. In such cases, the use of terms such as serum bottle, Hungate tube, or Schott bottle clearly defines the reaction vessel used. Artificial porous media can be equally weil defined by terms like filter, bead pack, or sand pack when the identifying parameters are given. Also, and most important, is that any two of the same vessels are identical.

Natural porous media are not so. No two cores are the same. Even if cut side by side from the same stone the specific properties such as porosity and permeability will not be equal. However, these properties can be measured for each core and experiments can be conducted on similar cores with a reasonable knowledge of their properties.

In the Microbial Field Pilot Study, the reaction vessel is the oil bearing sandstone formation known as the Southeast Vassar Vertz Sand Unit (SEVVSU). It is many times larger than a common laboratory core with a wide variability of rock properties from location to location. Reservoir properties are measured on samples from a few discrete locations and values of these properties at other locations are inferred by interpolation or extrapolation. Thickness, porosity, and permeability all vary spatially and permeability varies directionally. Further, properties such as fluid saturation depend on the history of the field as well. Last, the experiment will change these properties over 
its duration. In the case of the Microbial Field Pilot Study, this last point is also the goal.

In a field pilot, the best possible description of the reservoir is important to the interpretation of the field pilot results. The two best tools for this purpose are first, information from direct measurement from cores and logs along with the geological interpretation of the depositional history of the rock and its subsequent diagenesis, and second, reservoir simulation of the operational history of the reservoir. Used together these can yield a conceptual picture of the test vessel, which is required for a successful interpretation of the field pilot results.

\subsection{The Southeast Vassar Vertz Sand Unit}

The pilot was performed in the Southeast Vassar Vertz Sand Unit. Figure 4.1 is a map of the geological regions of the State of Oklahoma (Oklahoma Geological Survey, 1972). As shown on the figure, the Southeast Vassar field is located on the northern shelf area of the Anadarko Basin, about 50 miles $(80 \mathrm{~km})$ north northeast of Oklahoma City, Oklahoma.

Figure 4.2 is a plat map of the Southeast Vassar Vertz Sand Unit. The well configuration is as of June, 1992. The SEVVSU encompasses all of Section 13 and parts of Sections 12 and 14 of Range 1 West, Township 18 North in Payne County, Oklahoma. Wells are designated by tract number-well number. The pilot injection well was the 7-2. The pilot production wells were the 5-1, 5-2, and 7-1. These four wells were inactive injectors prior to the pilot study. The field is physically divided by a permeability barrier. The barrier (shown in the net isopach map, Figure 4.3) passes

through the dry hole, Well 3-5, and curves northward with the 3-6, 3-4, and 3-1 to the 


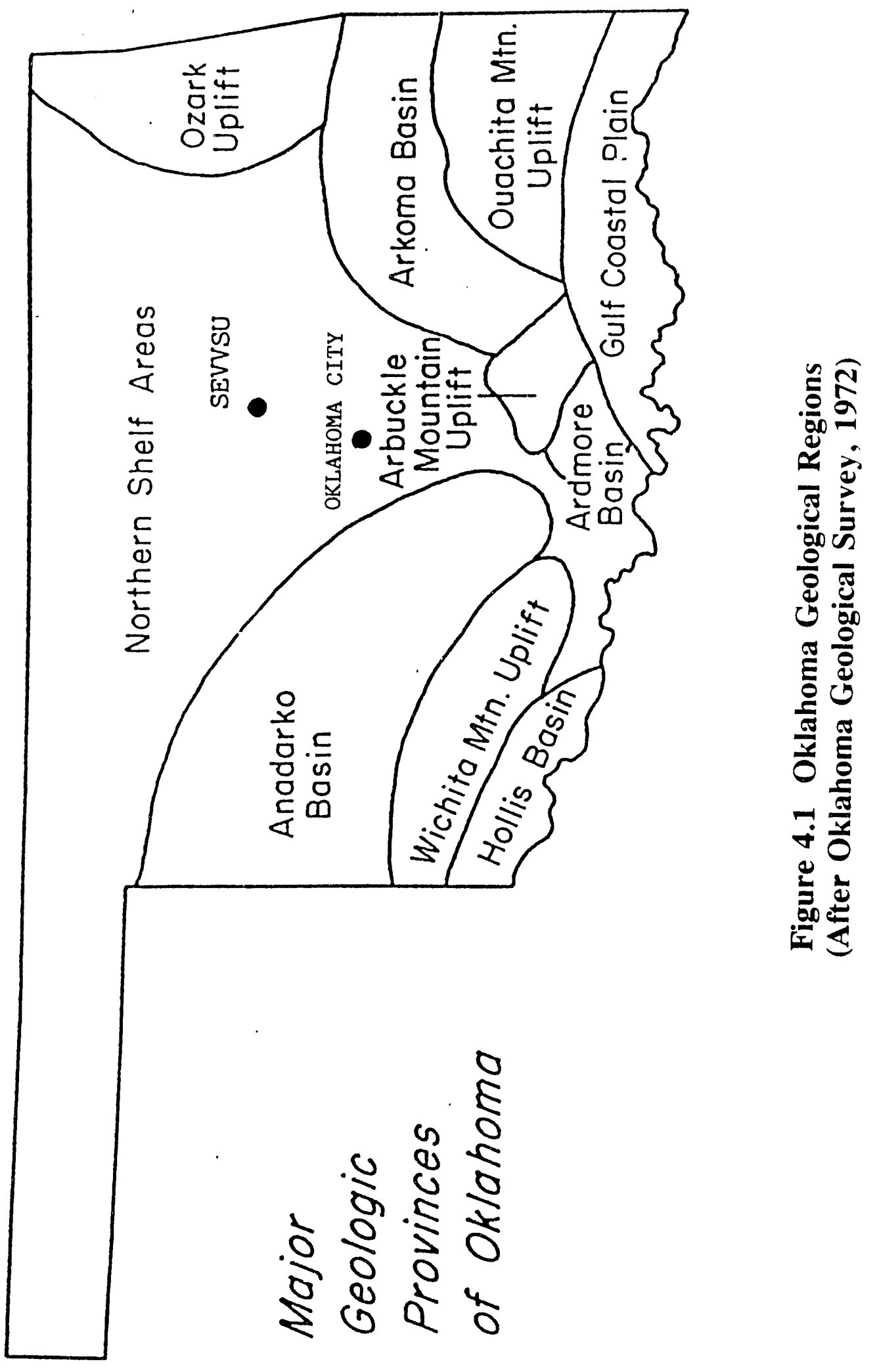




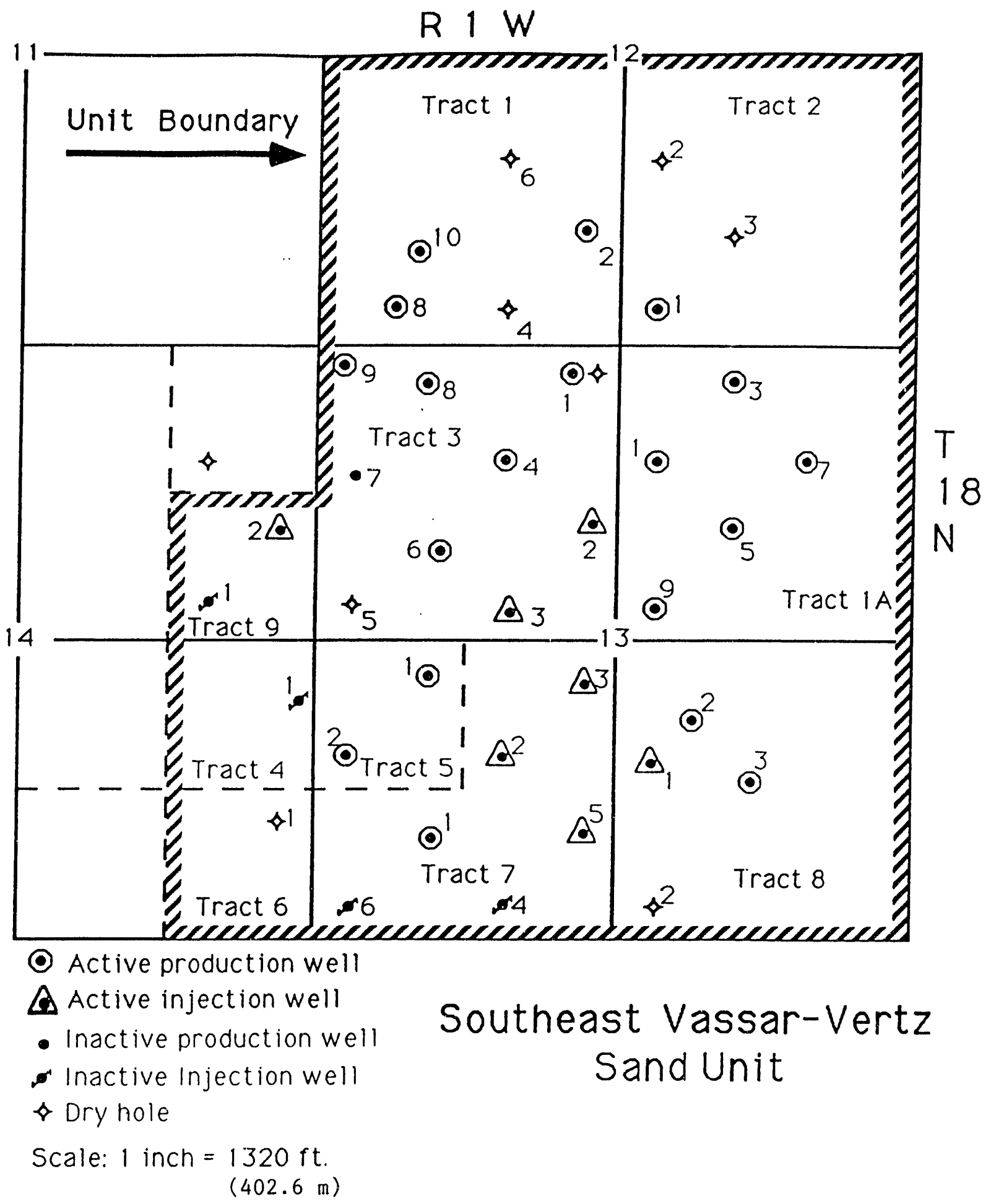

Figure 4.2 Plat Map of the Southeast Vassar Vertz Sand Unit 


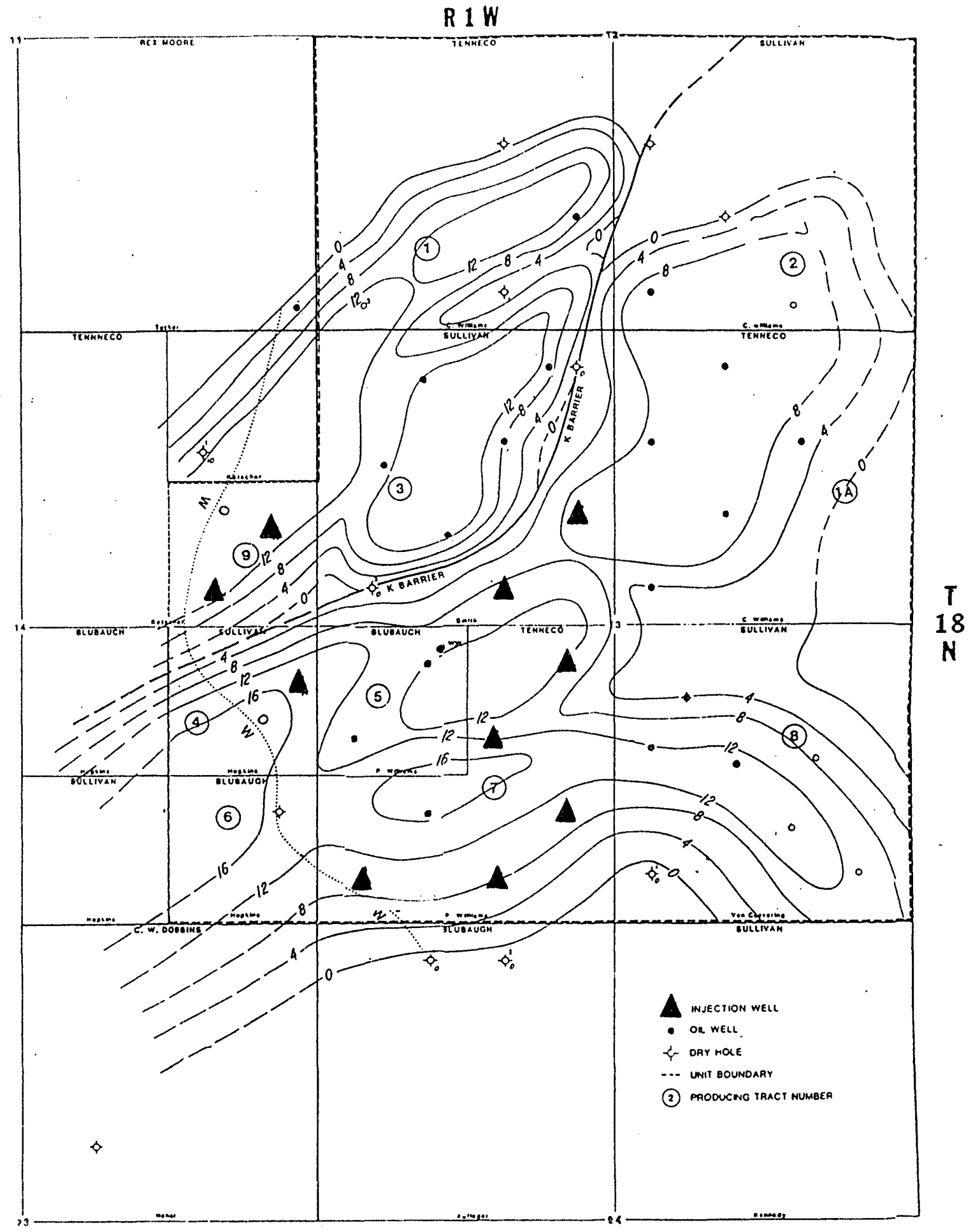

Figure 4.3 Net Thickness Map of the SEVVSU $(1 \mathrm{ft}=0.3048 \mathrm{~m})$ 
north and west of the barrier and the 3-2 and 3-3 to the south and east. The barrier location was identified by the dry hole and the lack of flood water communication across the barrier. The active line of injectors for the field waterflood at the time of the field pilot study were the $3-2,3-3,7-3$, and $7-5$. The $8-1$ was an inactive production well during most of the field pilot operations. The 8-1 was converted to an injector in April 1992, three months after the last nutrient injection occurred. Well 3-2 was converted from an active producer to injector March 1991, one month after the first tracer study. Wells 3-9, 1-8, and 1-10 were drilled over the course of the pilot; however, being north of the permeability barrier, they did not impact the field pilot.

The Vertz sandstone belongs to the Wabaunsee Group of Pennsylvanian age. The field was discovered in 1966. It was unitized in 1974 and a line drive waterflood was initiated soon thereafter. The general flood direction has been from southwest toward the northeast. As each production well exceeded a 10 to 1 water-oil ratio, it was converted to an injection well. The injection wells behind the active injectors were used to maintain pressure to ensure that injected water continued to drive to the northeast. These pressure maintenance wells were receiving little or no water prior to the field pilot.

The Vertz sandstone was probably formed by a braided stream depositional system. Willhite (1986) describes such environments. The Vertz is a uniform well-ordered sandstone which gradually fines upward and has a basal lag of pebble size clasts. The sandstone has little permeability variation in the vertical direction and the preferential horizontal permeability probably lies in the direction of the stream current of the original depositional environment. In a meandering stream system, a channel may 
become cut off forming an oxbow lake. If the abandoned channel is not subsequently reworked prior to system burial, it will fill with silt and form a clay plug. This will create a permeability barrier in the sandstone reservoir (Scarbrough, et al., 1987).

By the end of August, 1991, the start of nutrient injection, the cumulative oil production from the Southeast Vassar was 2.56 million stock tank barrels (STB) $(4.1 \mathrm{x}$ $10^{5}$ standard $\mathrm{m}^{3}$ ). Twenty-four wells were operating as injectors or producers. The formation is at a vertical depth of around $1800 \mathrm{ft}(550 \mathrm{~m})$. The original reservoir pressure was 870 psia $\left(6 \times 10^{6} \mathrm{~Pa}\right.$ absolute) at $92^{\circ} \mathrm{F}(306 \mathrm{~K})$. Oil gravities from hydrometer readings range from 38 to 42 degrees API. Gas gravities ranging from 0.70 to 1.18 (air $=1.0$ ) have been measured using a gas chromatograph. An oil gravity of 40 degrees API and a gas gravity of 0.85 were used to estimate fluid properties from the correlations by Vasquez and Beggs (1980). The oil and water viscosities are $2.9 \mathrm{cp}(2.9$ x $\left.10^{-3} \mathrm{pa} . \mathrm{s}\right)$ and $1.1 \mathrm{cp}\left(1.1 \times 10^{-3} \mathrm{~Pa} . \mathrm{s}\right)$ at standard temperature and pressure, respectively, and were determined ısing Canon-Fenske viscometers (ASTM, 1987).

The Dykstra-Parsons permeability variation factor (Dykstra and Parsons, 1950), was 0.35 from core permeabilities indicating little vertical variability in permeability. The high recovery obtained by the waterflood is consistent with this value. In the region of the reservoir behind the flood front, it is estimated that primary and secondary recovery have produced almost $60 \%$ of the original oil in place. The mobile oil phase in the region of the pilot study may have been as low as $5 \%$ of the original oil in place.

The characteristics of the SEVVSU are summarized in Table 4.1. Jenneman (1989) lists criteria for MEOR target reservoirs. Comparing the SEVVSU to these criteria, the Vassar's temperature, $33^{\circ} \mathrm{C}$, is less than $75^{\circ} \mathrm{C}$. The porosity, $18-24 \%$, 
Table 4.1 Southeast Vassar Vertz Sand Unit

\begin{tabular}{|c|c|}
\hline Formation & Vertz Sandstone \\
\hline Geologic Age & Pennsylvanian, Wabaunsee Group \\
\hline Depositional System & Braided Stream \\
\hline Location & $\begin{array}{l}\text { Payne County, Oklahoma } \\
\text { T } 18 \mathrm{~N}, \mathrm{R} 1 \mathrm{~W}, \text { Sec. } 12,13,14\end{array}$ \\
\hline True Vertical Depth & $1800 \mathrm{ft} .(550 \mathrm{~m})$ \\
\hline Formation Temperature & $92^{\circ} \mathrm{F} \quad\left(33^{\circ} \mathrm{C}\right)$ \\
\hline Pilot Area Formation Thickness & $12-16 \mathrm{ft}(3.7-4.9 \mathrm{~m})$ \\
\hline Porosity & $18-24 \%$ \\
\hline Permeability (from cores) & $100-500 \mathrm{md}\left(0.1-0.5 \mu \mathrm{m}^{2}\right)$ \\
\hline Brine Salinity & $15-19 \% \mathrm{NaCl}$ equivalent \\
\hline $\mathrm{pH}$ & $\approx 7$ \\
\hline Original Oil In Place & 7.13 MMSTB $\left(1.13 \times 10^{6} \mathrm{SCM}\right)$ \\
\hline Recovery as of 8-31-91 & $36 \%$ \\
\hline Recovery Factor Behind Floodfront & $50-60 \%$ (estimate) \\
\hline Oil Saturation in Pilot Area & $25 \%$ (estimate) \\
\hline Oil Gravity & $40(38-42){ }^{\circ} \mathrm{API}$ \\
\hline Gas Gravity & $0.85(0.75-1.18)($ air $=1)$ \\
\hline Dead Oil Viscosity (STP) & $2.9 \mathrm{cp}$ at $92^{\circ} \mathrm{F}\left(2.9 \times 10^{-3} \mathrm{~Pa} . \mathrm{s} @ 33^{\circ} \mathrm{C}\right)$ \\
\hline Water Viscosity (STP) & $1.1 \mathrm{cp}$ at $92^{\circ} \mathrm{F}\left(1.1 \times 10^{-3} \mathrm{~Pa} . \mathrm{s} @ 33^{\circ} \mathrm{C}\right)$ \\
\hline Solution Gas & Near dead $(\approx 0 \mathrm{scf} / \mathrm{stb})$ \\
\hline $\begin{array}{l}\text { Formation Pressures } \\
\text { Average Reservoir Pressure } \\
\text { Producing Well Bottomhole } \\
\text { Pressure } \\
\text { Injection Well Bottomhole } \\
\text { Pressure } \\
\text { Initial Reservoir Pressure }\end{array}$ & $\begin{array}{l}1100 \text { psia (estimate) }\left(7.6 \times 10^{6} \mathrm{~Pa} \text { absolute) }\right. \\
100 \text { psia (estimate) }\left(6.9 \times 10^{5} \mathrm{~Pa} \text { absolute) }\right. \\
1700 \text { psia }\left(1.2 \times 10^{7} \mathrm{~Pa} \text { absolute }\right) \\
870 \text { psia (hydrostatic) }\left(6.0 \times 10^{6} \mathrm{~Pa}\right. \\
\quad \text { absolute) }\end{array}$ \\
\hline
\end{tabular}


suggests an average pore size distribution of 7 to $15 \mu \mathrm{m}$ indicating effective transportability of microbes through the porous media. Core permeabilities range from 100 to $500 \mathrm{md}\left(0.10\right.$ to $\left.0.50 \mu \mathrm{m}^{2}\right)$, well above the limiting permeability of $75 \mathrm{md}(0.0$ ? $\left.\mu \mathrm{m}^{2}\right)$. The $40^{\circ} \mathrm{API}$ Vassar oil gravity is well above $18^{\circ} \mathrm{API}$. The pressure range is not extreme and bacterial activity flourishes over the entire range. The $\mathrm{pH}$ of the Vassar brine is 7.0. Acidity values between 4 and 9 are suggested for MEOR activity. Some basic volumetric data regarding the SEVVSU pilot unit are given in Table 4.2.

\subsection{Reservoir Simulation}

Reservoir simulation is accomplished by dividing the reservoir into discrete "blocks" and assigning values for the reservoir properties to each block. These apparent average values for each block control the behavior of the block in relation to an external source or sink such as a well and to the surrounding blocks. The blocks and sources and sinks are related by the fundamental equations governing fluid flow in porous media.

The first task of a reservoir simulation is a history match. A history match is achieved when the mathematical simulation of the reservoir performance is similar to the observed behavior of the oil field. A history match is accomplished by defining at least two time series of information observed from the field, i.e., oil production and water production. The simulator is forced to produce one of these, say, oil production. Values of the other variable, in this case, water production calculated with the simulator are compared to the observed values from the field. If they do not match, fluid properties, general rock properties, or reservoir property values assigned to individual blocks are changed and another simulation is run. This process is performed iteratively until the match parameter, water production, is similar to the observed values from the field. A 
Table 4.2 Field Pilot Volumetric Data

\begin{tabular}{||l|l||}
\hline \hline Area Bounded by Field Pilot Wells & 20 acres $(8.1$ hectare $)$ \\
\hline Average Thickness in Pilot Area & 14 feet $(7.3 \mathrm{~m})$ \\
\hline $\begin{array}{l}\text { Oil Production in Pilot Area } \\
\text { (Primary and Secondary) }\end{array}$ & $\begin{array}{l}592 \mathrm{bbl} / \mathrm{acre}-\mathrm{ft} \\
(762 \mathrm{~m} / \mathrm{hectare} . \mathrm{m})\end{array}$ \\
\hline Original Oil in Place in Pilot Area & $\begin{array}{l}1034 \mathrm{bbl} / \mathrm{acre}-\mathrm{ft} \\
(1332 \mathrm{~m} / 3 / \mathrm{hectare} . \mathrm{m})\end{array}$ \\
\hline EOR Target (Mobile Oil in Pilot Area) & $\begin{array}{l}52 \mathrm{bbl} / \mathrm{acre}-\mathrm{ft} \\
(67 \mathrm{~m} / \mathrm{hectare} . \mathrm{m})\end{array}$ \\
\hline Total Reservoir Pore Volume in Pilot Area & $\begin{array}{l}434,500 \mathrm{bbl} \\
\left(6.9 \times 10^{4} \mathrm{~m}^{3}\right)\end{array}$ \\
\hline Aqueous Pore Volume in Pilot Area & $325,800 \mathrm{bbl}$ \\
& $\left(5.2 \times 10^{4} \mathrm{~m}^{3}\right)$ \\
\hline
\end{tabular}


history match should converge in a statistically significant representation of observed data. The term similar implies a judgement on the part of the individual performing the simulation that the two series of data are similar and that the conditions as described by the parameters in the simulator are of the same nature as those that exist in the reservoir. A simulation study ends when the individual conducting the study concludes that the effort expended to improve the history match does not increase the knowledge or understanding of the reservoir environment. At this point, the parameter values used to define the field is referred to as the history match.

The Eclipse 100 black oil simulator (Intera-ECL Petroleum Technologies, 1991) was used to simulate the Southeast Vassar Vertz Sand Unit (SEVVSU). Oil production and water injection were used as the driving parameters. Water production and arrival time of first water production at the field wells were used as match variables. A history match was achieved using ihe 29 by 21 areal grid superimposed on the structural map shown in Figure 4.4. The $x$ direction (running from left to right on Figure 4.4) is along a southwest to northeast line. This is believed to be the direction of the current during the formation deposition and is the direction of preferential permeability. Distances are in feet from the origin at the top left hand corner of the figure. The area of the finest grid [2500 to $3500 \mathrm{ft}$. (762 to $1067 \mathrm{~m}$ ) in the $\mathrm{x}$ direction, 3500 to $4500 \mathrm{ft}$. (1067 to 1372 $\mathrm{m}$ ) in the $y$ direction] bounds the pilot wells. Looking at the figure, Wells 5-2 and 5-1 are at the top of the fine gridded area reading left to right and Wells 7-1 and 7-2 are at the bottom. The contour maps of thickness, porosity, and permeabilities in the $\mathrm{x}$ and $\mathrm{y}$ directions are shown in Figures 4.5, 4.6, 4.7, and 4.8, respectively. 


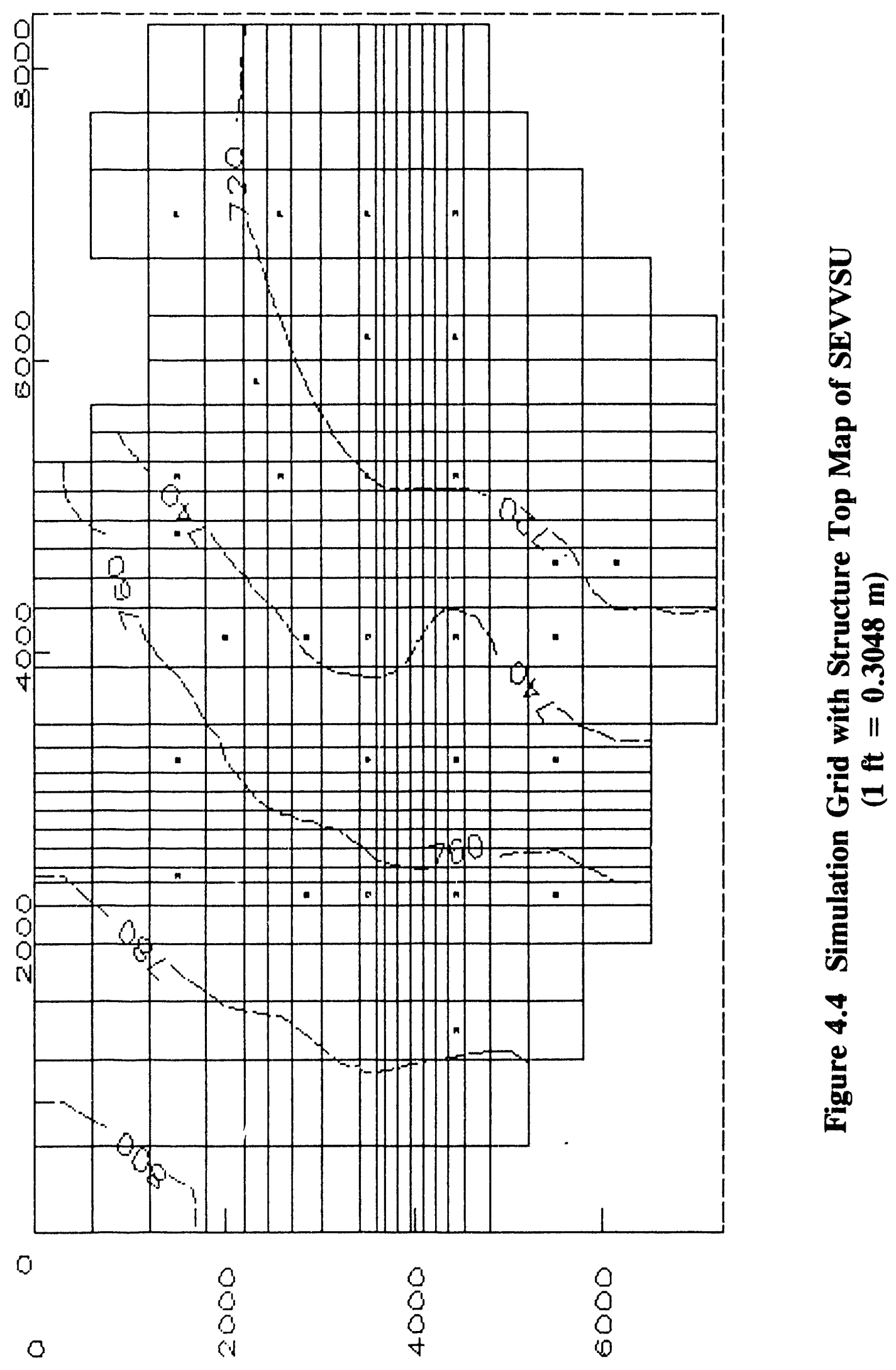




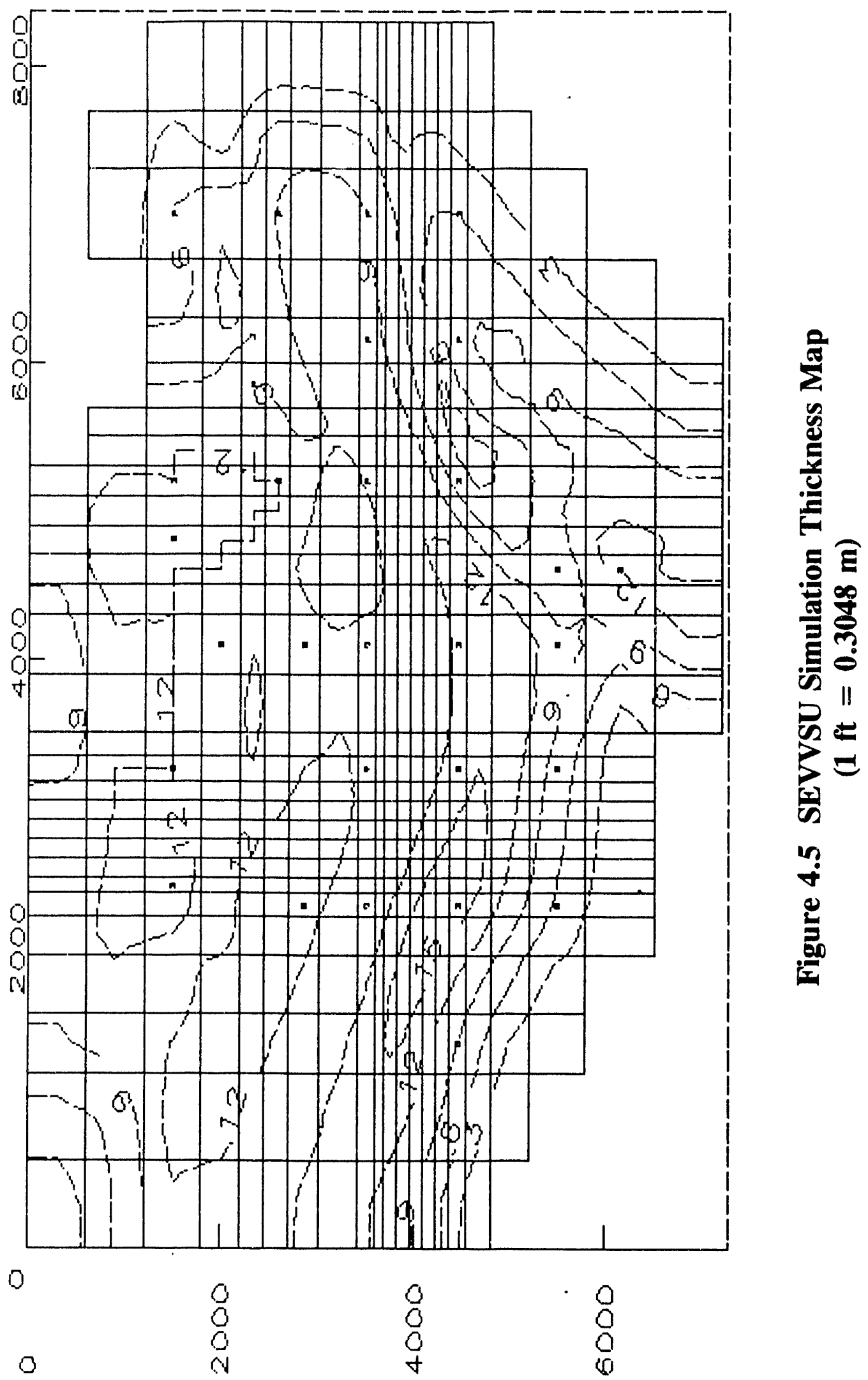




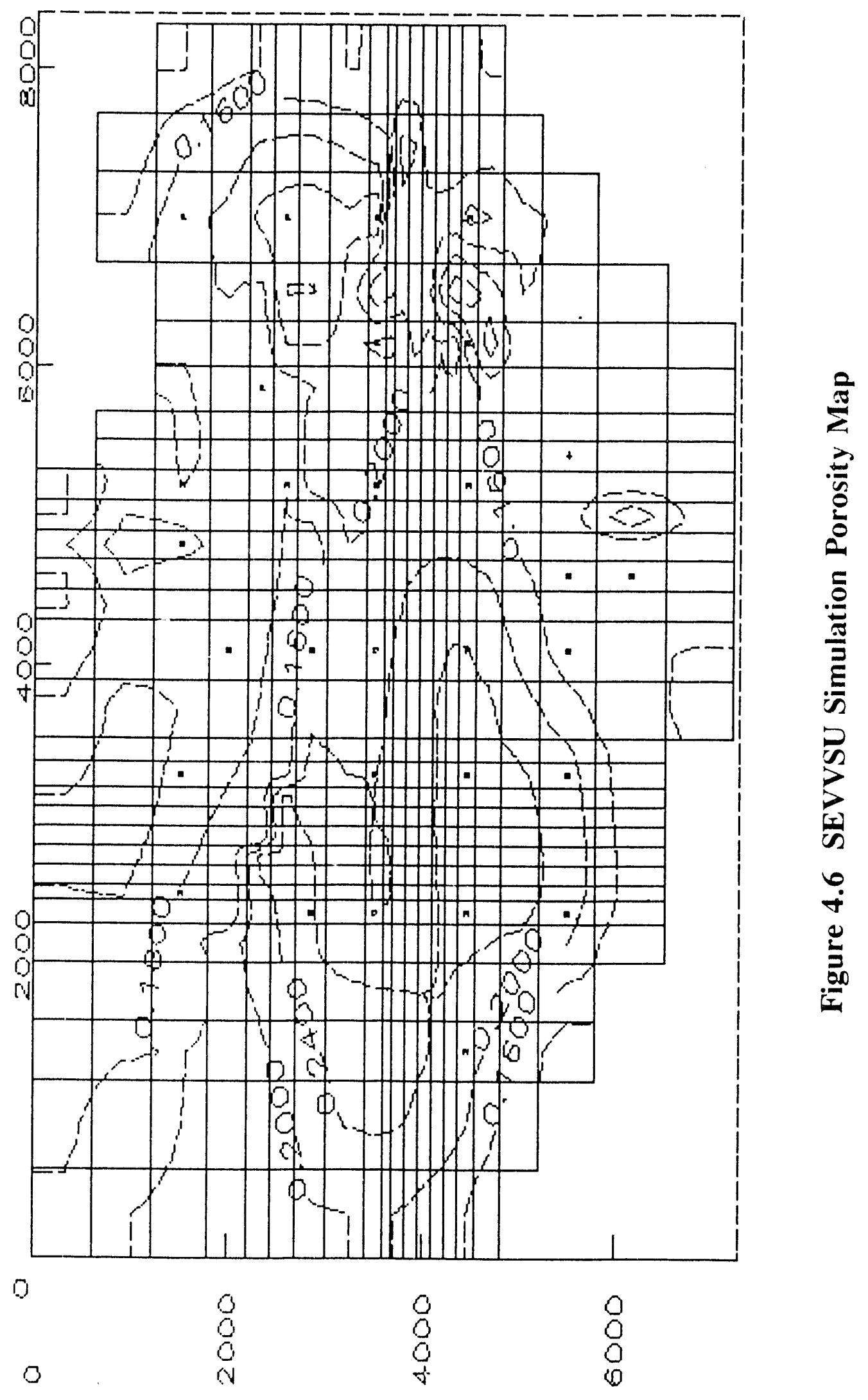




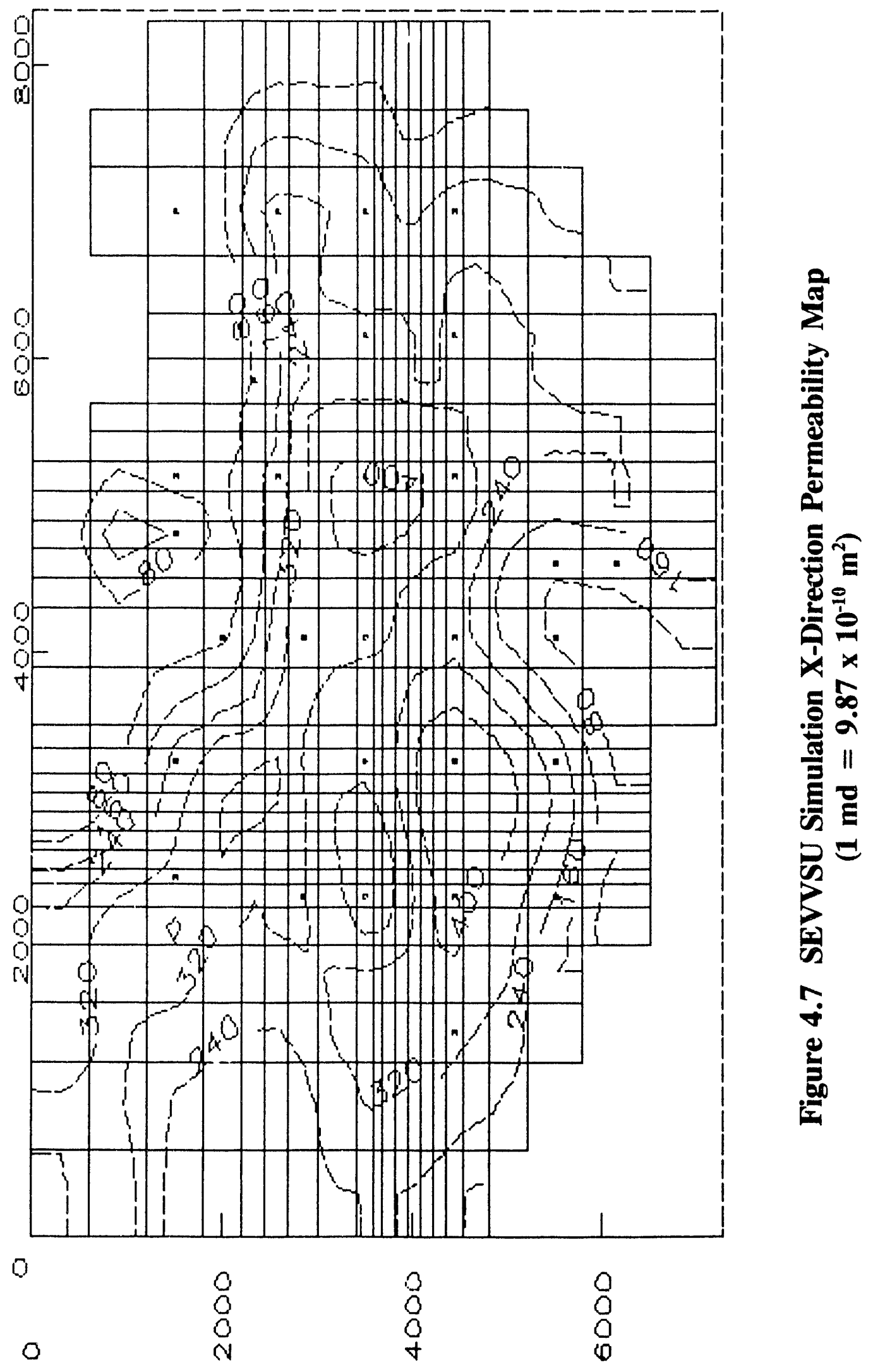




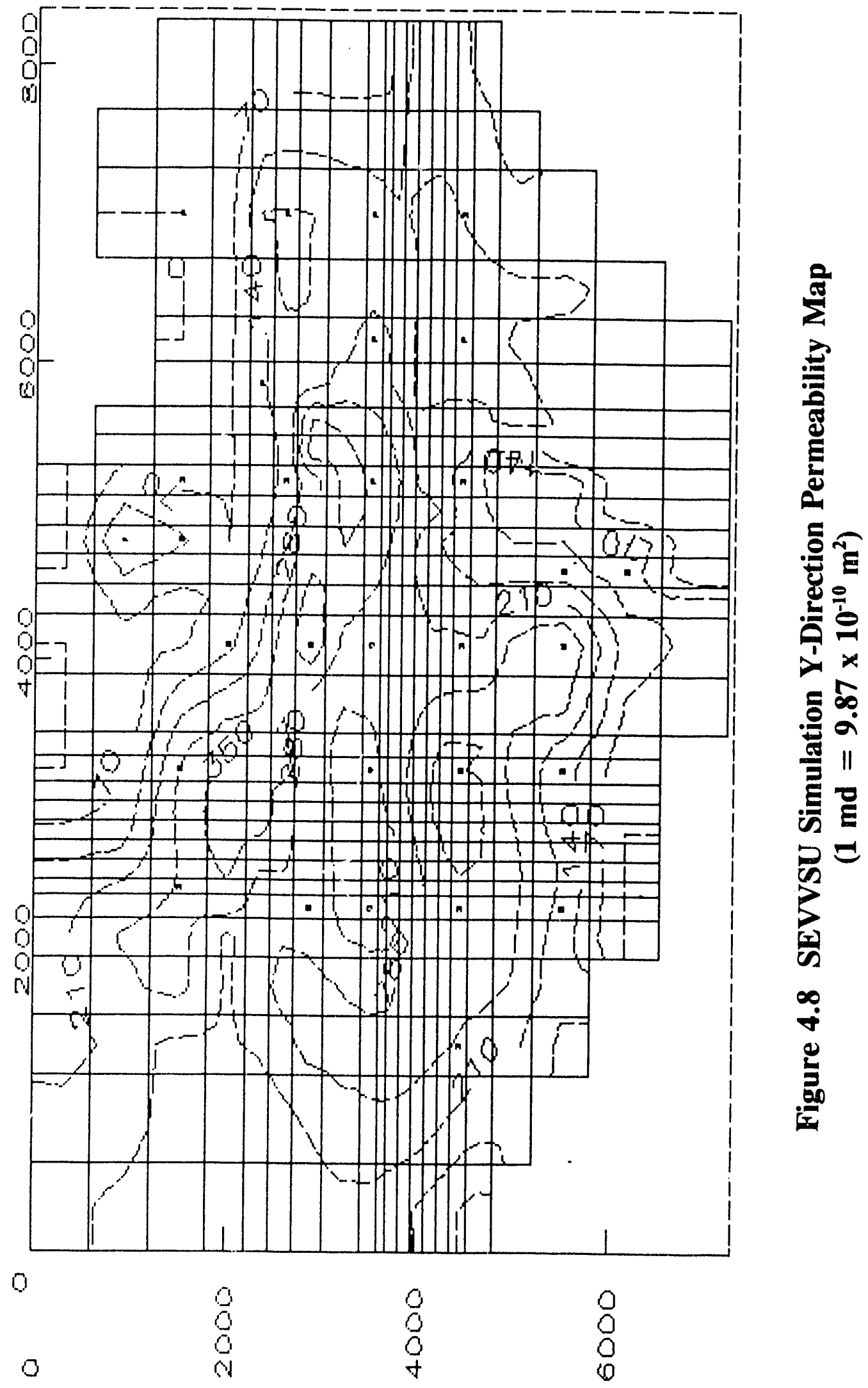




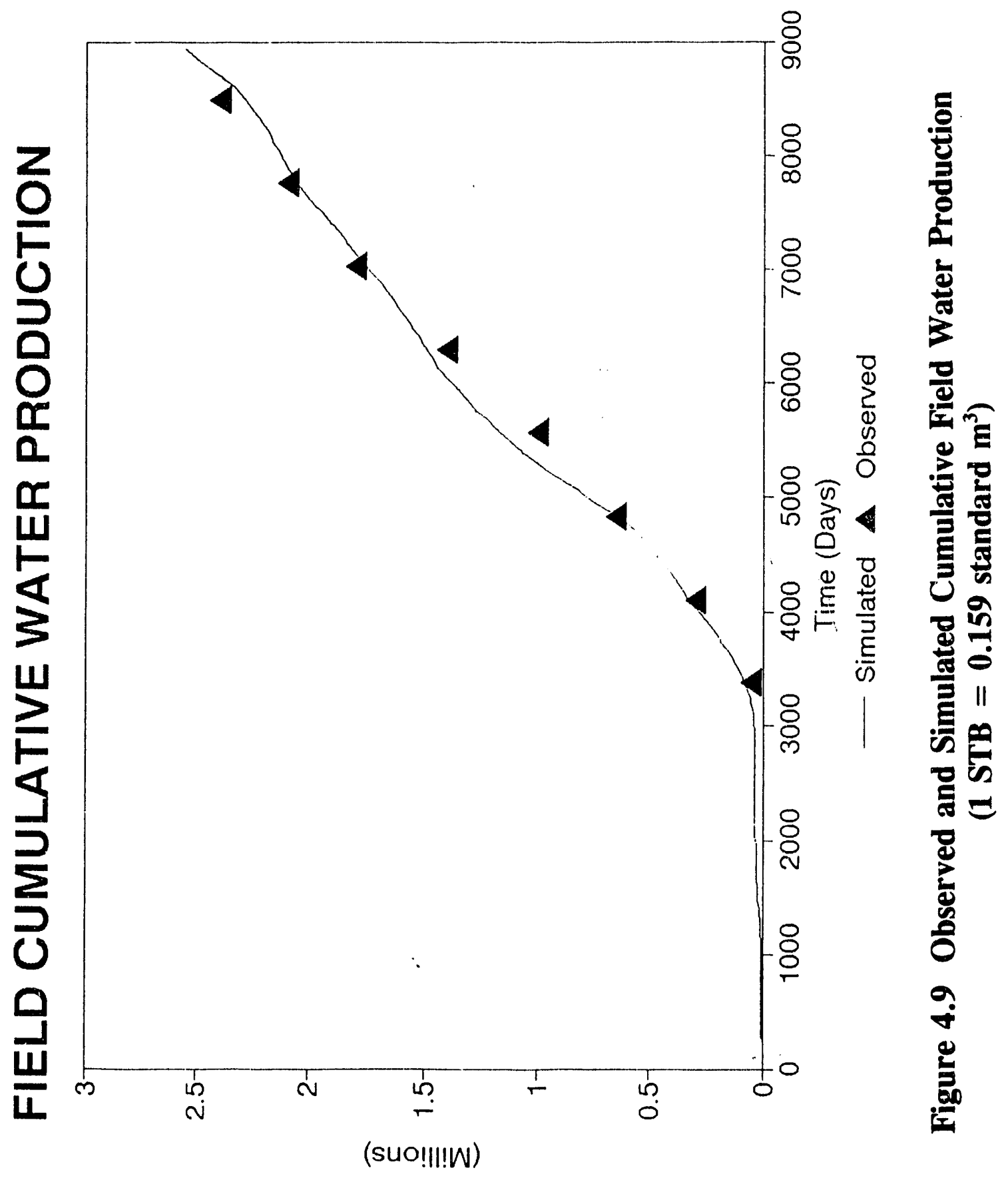

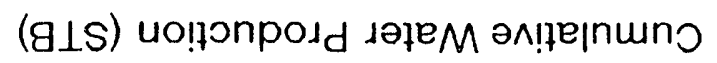


A plot of observed and simulated cumulative total field water production is presented in Figure 4.9. The match is within $5 \%$ of observed values at the conclusion of the simulation. Individual matches were performed on each well also. Although not all wells were matched to within $5 \%$, the overall history match was good. The primary emphasis of the simulation study was a good match in the pilot area. The history matches for Wells 5-1, 5-2, 7-1, and 7-2 are provided as examples in Figures 4.10, 4.11, 4.12 , and 4.13 , respectively. Wells $5-1$ and $7-2$ are very good matches. Only oil production records were maintained on Well 5-2 before it was converted into an injector. Therefore, the accuracy of the simulated water production from this well can not be judged. The simulation of Well 7-1 has water production indicated prior to any observed water production. This is also during the period when water production records on individual wells were not being accurately kept. Well 7-1 displays an excellent simulation of waterflood floodfront arrival time. 


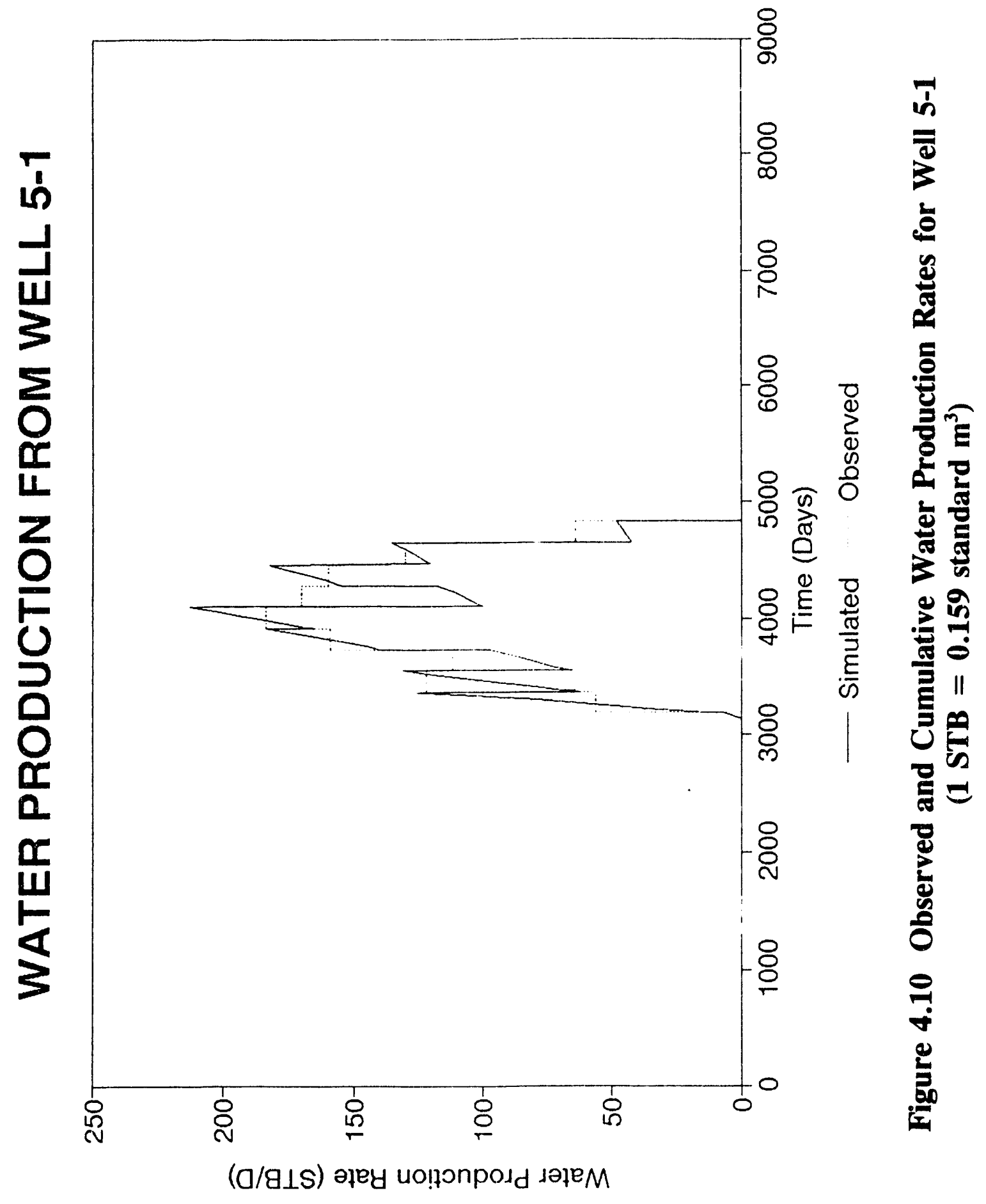




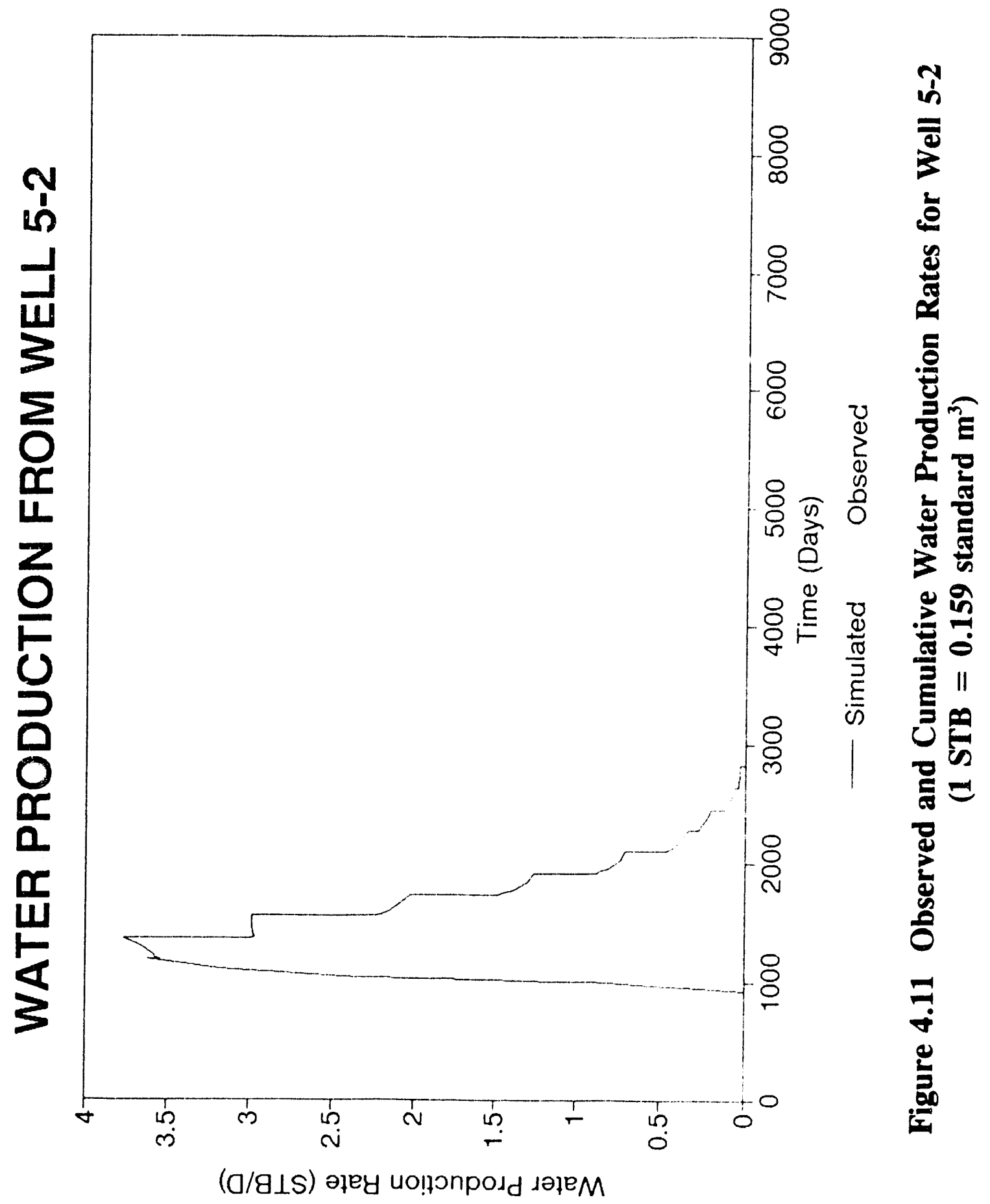




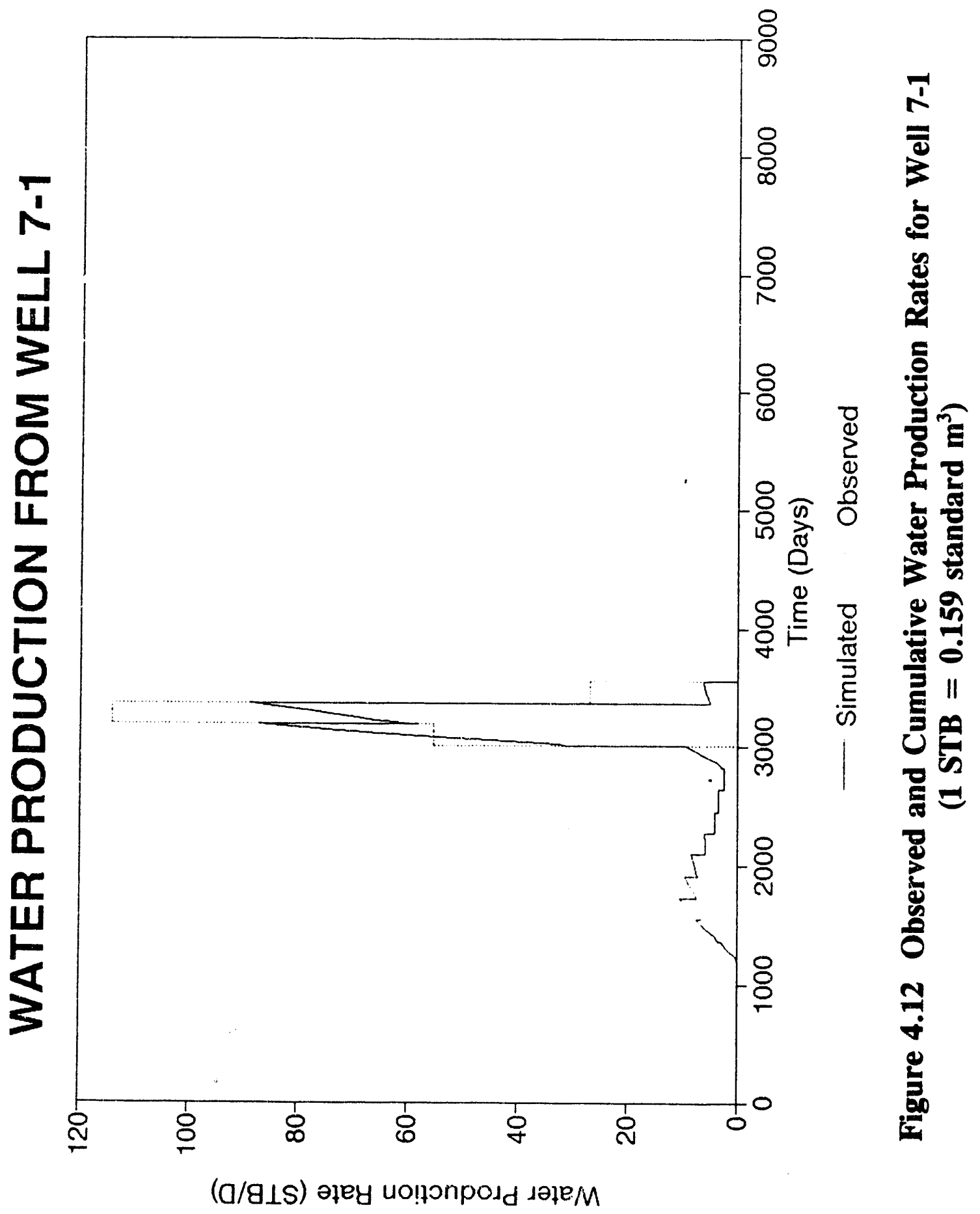




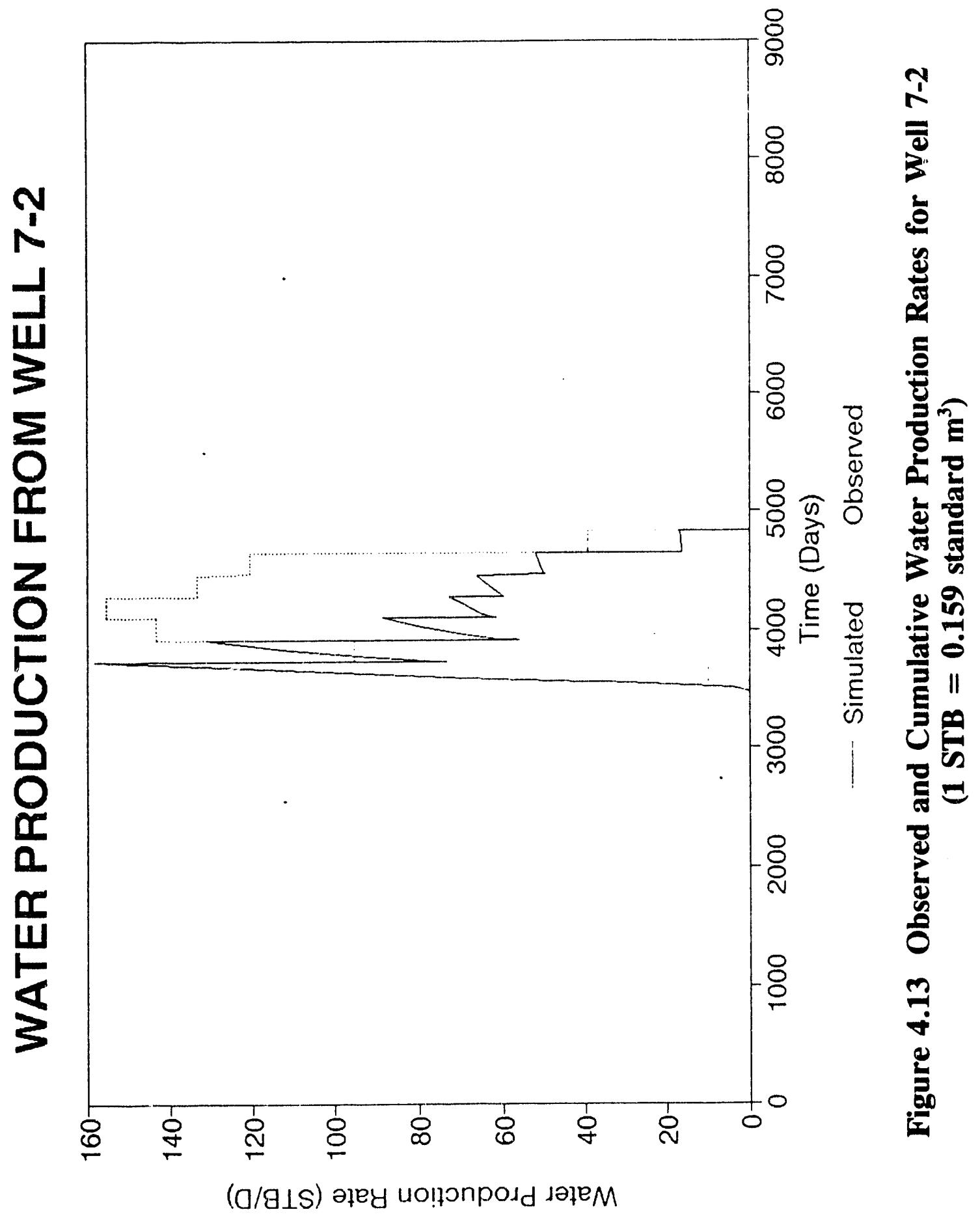




\section{Chapter 5. Microbiology and Ecology of the Reservoir}

\subsection{Introduction}

Microbially enhanced oil recovery (MEOR) processes require that microorganisms, either indigenous or injected, anaerobically metabolize added nutrients and produce useful products such as gases, biosurfactants, polymers, etc., under the environmental conditions that exist in the reservoir (Clark, et al., 1981, McInerney and Westlake, 1990). Therefore, it is necessary that the chemical composition of the brines be determined, and the ecological and physiological factors governing the microbial ecology of the reservoir be evaluated before any MEOR process is initiated. It is also necessary to determine the nutrient source that will best stimulate the desired microbial growth and to examine which type of microbial activity would achieve the maximum effect in enhanced recovery of oil. In addition, a thorough understanding of the physiology and metabolism of the microorganisms native to the oil reservoir is essential for predicting and interpreting the success of an MEOR project.

Research at the University of Oklahoma over the past several years has focused on the use of indigenous microorganisms and their metabolic products to improve volumetric sweep efficiency. The procedure involves the addition of a nutrient mixture to stimulate the growth of microorganisms in highly permeable regions saturated with water. The growth of microorganisms in these regions blocks the pores to immobilize the channelling water, improve the volumetric sweep efficiency, and recover additional oil.

An MEOR field pilot study was conducted in the Southeast Vassar Vertz Sand Unit (SEVVSJ) in Payne County, Oklahoma (see Chapter 4). Prior to the initiation of 
nutrient injection physiologically important groups of bacteria in the brines were enumerated and five strictly anaerobic and obligately halophilic bacteria isolated from the brines in the pilot area were characterized. A nutrient treatment mixture was defined by adding various nutrient combinations to produced water samples from the SEVVSU and measuring parameters indicative of growth. Prior to and during the field pilot, chemical analyses of the brines were performed on a routine basis to establish baseline conditions and monitor changes induced by nutrient injection and metabolic activity stimulated by the nutrient injections.

\subsection{Materials and Methods}

\section{The Southeast Vassar Vertz Sand Unit}

The Southeast Vassar Vertz Sand Unit is described in Chapter 4 and a plat map of the well locations is presented in Plate I.

\section{Sampling Procedure}

Before the initiation of the field pilot, brine samples were collected periodically from several locations in the SEVVSU reservoir. The sampling sites included the waterflood brine source well, the injection pump manifold, the pilot wells 7-2 and 5-1, wells 1A-1, 1A-3, 1A-7, 1A-9, 8-2, and 8-3. Samples from the pump manifold and injection wells 5-1 and 7-2 represent the brine used in the waterfiood which is a composite of the brine from the source well and coproduced brine from the Vassar reservoir. Samples from wells 1A-1, 1A-3, 1A-9, 8-2, and 8-3 are coproduced brines from wells influenced by the waterflood. Initial samples of water produced from well 1A-7 are believed to be native reservoir brine. Fluids were allowed to flow for several minutes before sampling. During this time $\mathrm{pH}$, temperature, and the $\mathrm{H}_{2} \mathrm{~S}$ concentration 
of the brine were measured. Samples were collected in sterile two-liter Schott (Bellco Glass, Inc., Vineland, N.J.) bottles. In most cases, each bottle was allowed to overflow for 20-30 seconds to avoid the introduction of oxygen into the samples. Bottles were stoppered, taken back to the laboratory, flushed with oxygen-free nitrogen and analyzed within four hours for bacterial numbers. The samples were stored at $4^{\circ} \mathrm{C}$ until all the analyses were completed.

\section{Chemical Analyses}

Specific gravity, total dry residues and suspended solids were determined using standard procedures (American Public Health Association, 16th eds., 1985). Hydrogen sulfide was determined colorimetrically (Tanner, 1989). Known amounts of $\mathrm{NaCl}$, sulfate and sulfide were added to brine samples to test the accuracy and reliability of the salinity, sulfate and sulfide analyses, respectively.

\section{Bacteriological Analyses}

All microbial enumeration studies were done by the most probable number (MPN) technique (Cochran, 1950). The MPN numbers were estimated using three tubes per dilution (Banwart, 1981). All media used in the enumeration studies contained $15 \% \mathrm{w} / \mathrm{v}$ $\mathrm{NaCl}$. Aerobic and anaerobic heterotrophic bacteria were enumerated using medium containing plate count broth (Knapp, et al., 1989). Anaerobic molasses/nitrate-using bacteria were enumerated using molasses-ammonium nitrate medium described in Tables 5.1, 5.2, and 5.3 (Knapp, et al., 1989). Sulfate-reducing bacteria were enumerated using API-RST medium (Tanner, et al., 1985). Methanogenic bacteria were enumerated using mineral salts medium containing $10 \mathrm{mM}$ each, of, acetate, methanol, and formate and with a $\mathrm{H}_{2}: \mathrm{CO}_{2}(80: 20)$ gas phase at $20 \mathrm{psi}\left(1.38 \times 10^{5} \mathrm{~Pa}\right)$. Methods for preparation and 

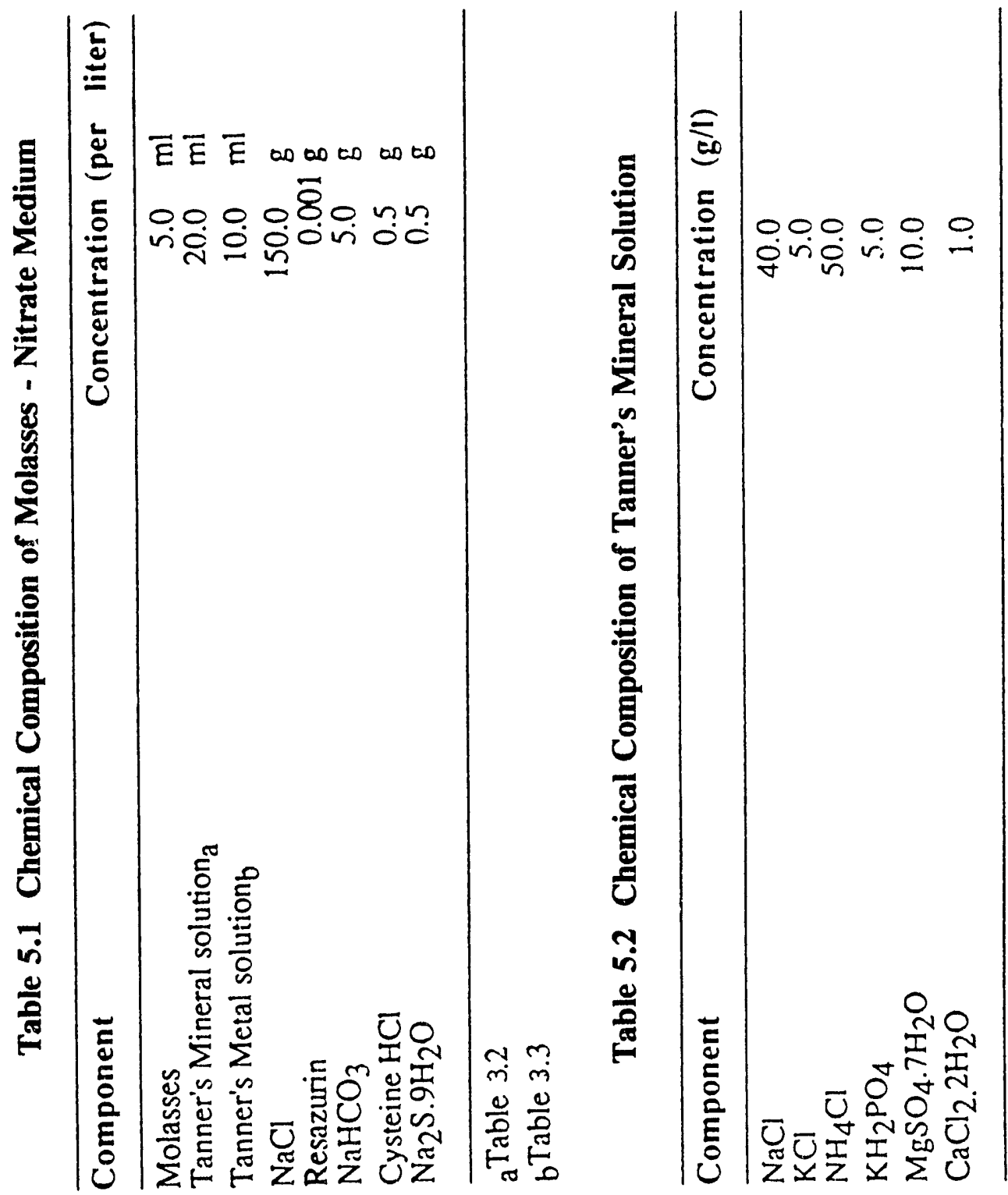


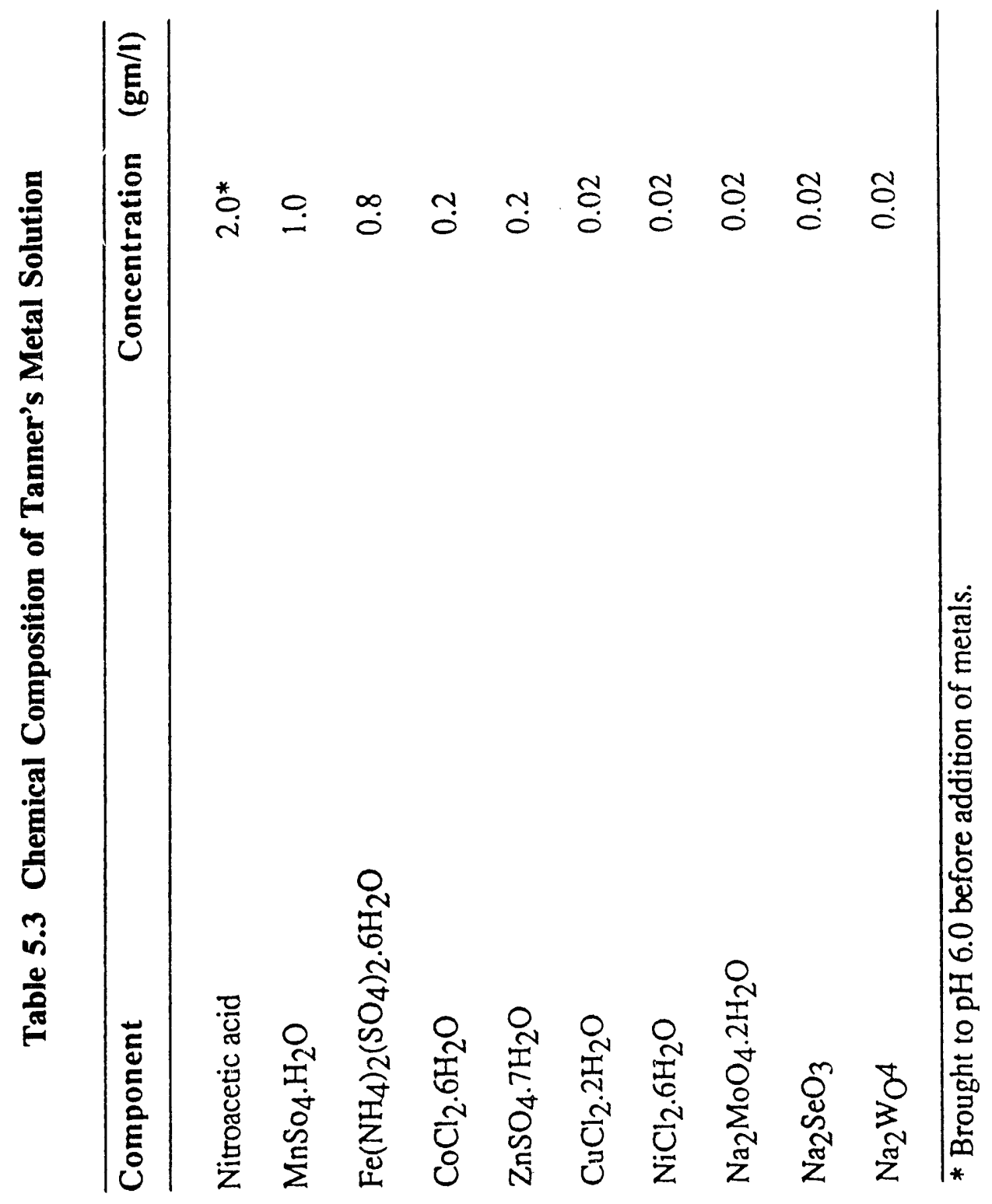


use of anaerobic media were those of Bryant (1972) as modified by Balch and Wolfe (1976). All tubes were incubated at $35^{\circ} \mathrm{C}$ for 45 days or until no more growth was observed. Growth of aerobic heterotrophs, anaerobic heterotrophs and molasses-nitrate users was indicated by turbidity. Growth of sulfate reducers was indicated by turbidity and the formation of a black FeS precipitate. Growth of methanogens was indicated by turbidity and production of methane: All tubes showing growth were examined by phase contrast microscopy.

\section{Isolation and Culture Methods}

Several anaerobic halophilic bacteria were isolated from the brines. Anaerobic heterotrophic halophiles were isolated by serially diluting brine samples in $15 \%$ saline solution and plating them on plate count agar with $15 \% \mathrm{NaCl}$. Plates were incubated anaerobically at room temperature. Isolated colonies were restreaked several times to obtain pure cultures. Anaerobic nitrate-using halophiles were enriched in molasses nitrate medium with $15 \% \mathrm{NaCl}$. These enrichments were serially diluted and agar roll tubes containing molasses nitrate medium with $15 \% \mathrm{NaCl}$ were inoculated. Several isolated colonies were selected and transferred to similar medium. Seven anaerobic heterotrophic halophiles and thirty anaerobic nitrate-using halophiles were isolated. Of these, four anaerobic heterotrophic halophilic strains designated VS-732, VS-751, VS-752, VS-511, and one molasses-using halophilic strain designated TTL-30 were selected for further studies. Molasses nitrate medium with $15 \% \mathrm{NaCl}$ was modified by reducing the $\mathrm{NaCl}$ concentration to $12 \%$, deleting molasses, including glucose $(5 \%, \mathrm{w} / \mathrm{v})$, casamino acids $(1 \%, \mathrm{w} / \mathrm{v})$ and yeast extract $(1 \%, \mathrm{w} / \mathrm{v})$, and a gas phase of $80 \% \mathrm{~N}_{2}: 20 \%$ $\mathrm{CO}_{2}$ to grow and maintain all the isolates. For experiments requiring a medium prepared 
without $\mathrm{CO}_{2}$, bicarbonate was replaced with PIPES (piperazine-N,N'-bis[2-ethanesulfonic acid]) dipotassium salt $(1.5 \mathrm{~g} / \mathrm{l})$. Vitamins (Balch and Wolfe, 1976) were added to culture medium whenever complex medium was not used. Cultures were routinely checked under the phase contrast microscope to ensure purity.

\section{Growth and Metabolic Characteristics}

All experiments were done in duplicate and the results represent mean values. The ability of the isolated strains to utilize different substrates were tested by replacing yeast extract, casamino acids, and glucose with the test compound, at $10 \mathrm{mM}$ (unless otherwise indicated) and comparing the growth $\left(\mathrm{A}_{660} \mathrm{~nm}\right)$ and the amount of acetate produced, with that obtained in uninoculated control tubes with each substrate. The ability of the isolates to utilize amino acid mixtures was also tested. The amino acid combinations tested included the following: alanine-glycine, leucine-proline, isoleucine-tryotophan, valine-ornithine, phenyl alanine-leucine and histidine-sarcosine. The effect of the gas phase on the growth of the isolates was tested by changing the gas phase from $80 \% \mathrm{~N}_{2}: 20 \% \mathrm{CO} 2$ to $80 \% \mathrm{H}_{2}: 20 \% \mathrm{CO}_{2}$. The ability to use carbon monoxide was determined using different gas phase concentrations $\left(100 \% \mathrm{CO}, 75 \% \mathrm{CO}: 25 \% \mathrm{~N}_{2}\right.$, $50 \% \operatorname{CO}: 50 \% \mathrm{~N}_{2}, 25 \% \mathrm{CO}: 75 \% \mathrm{~N}_{2}$ ). The effect of external electron acceptors on the growth of the isolates was tested in medium with glucose as an electron donor. Compounds tested as electron acceptors included elemental sulfur, sodium sulfate; sodium thiosulfate, sodium sulfite, sodium nitrate, and sodium nitrite at a concentration of $0.3 \%(w / v)$.

To determine the best nutrient source for the stimulation of indigenous microorganisms, brine samples were amended with various nutrient mixtures. Brine 
samples were dispensed into serum tubes which were closed with rubber bungs and crimp sealed. Where indicated, molasses, sucrose, glucose, and fructose were added to give a final concentration of $0.2 \%$ (wt/volume except for molasses which was added on a vol/vol basis). Ammonium nitrate and sodium sulphate were added to give a final concentration of $0.3 \%(\mathrm{wt} / \mathrm{vol})$. Sodium lactate and sodium thiosulphate were added to give a final concentration of $0.1 \%(\mathrm{vol} / \mathrm{vol})$ and $0.2 \%(\mathrm{wt} / \mathrm{vol})$, respectively. Unamended brine samples served as controls. Tubes were incubated at $35^{\circ} \mathrm{C}$, reservoir temperature, and routinely checked microscopically and turbidimetrically for growth.

\section{Miscellaneous Tests}

Gram staining was performed using both heat-fixed smears and smears fixed with acetic acid (Dussault, 1955). Antibiotic susceptibility tests were performed by adding various filter-sterilized antibiotics to the growth medium. Antibiotics tested included chloramphenicol, tetracycline, penicillin, cyclohexamide, each at $10 \mu \mathrm{g} / \mathrm{ml}$. The effect of sodium azide on growth, at $50 \mu \mathrm{g} / \mathrm{ml}$ was also tested. Susceptibility to the above inhibitors was determined by comparison of growth at $A_{600}$ in medium containing the inhibitor, to controls that lacked it.

\section{Analytical Techniques}

Growth was followed by measuring the increase in absorbance at $660 \mathrm{~nm}$ using a Bausch and Lomb Spectronic 21 spectrophotometer. Microscopic examinations were performed using an Olympus Photomicrographic System Model DM-10AD phase contrast microscope. Glucose was measured colorimetrically by the glucose oxidase method (Sigma Chemical Co., St Louis, MO.) using a Beckman DU 64 Spectrophotometer. Volatile fatty acids and alcohols were analyzed with a Varian Model 3400 series Gas 
Chromatograph using a Carbopack c/o 3\% Carbowax $20 \mathrm{~m} / 0.1 \% \mathrm{H}_{3} \mathrm{PO}_{4}, 30 " x 1 / 4 "$ $(760 \mathrm{~cm} \times 6.35 \mathrm{~mm}) \mathrm{OD} \times 4 \mathrm{~mm}$ ID glass column operating at a temperature of $130^{\circ} \mathrm{C}$ and $60^{\circ} \mathrm{C}$ respectively. The operating temperatures for injector, and detector were $170^{\circ} \mathrm{C}$, $175^{\circ} \mathrm{C}$ respectively. Nitrogen was used as the carrier gas at $55 \mathrm{ml} / \mathrm{min}$. Samples for volatile fatty acids were acidified by adding $0.2 \mathrm{ml}$ of $25 \% \mathrm{H}_{3} \mathrm{PO}_{4}$ to $0.8 \mathrm{ml}$ of sample. A $1 \mu 1$ injection volume was used for the analysis of fatty acids and alcohols. Fatty acid analyses were also performed using a high-pressure liquid chromatograph, equipped with a Bio-Rad, 300x7.8mm Aminex HPX-87H column and an isocratic mobile phase of $0.016 \mathrm{~N} \mathrm{H}_{2} \mathrm{SO}_{4}$ at a flow rate of $0.9 \mathrm{ml} / \mathrm{min}$. Hydrogen was analyzed using a RGA 3 Reduction Gas Analyzer fitted with a 3'x1/8" column packed with $60 / 80$ mesh spherocarb, operating at temperature of $90^{\circ} \mathrm{C}$. The detector temperature was set at $264^{\circ} \mathrm{C}$. Nitrogen was used as the carrier gas at $20 \mathrm{ml} / \mathrm{min} . \mathrm{CO}_{2}$ and $\mathrm{CH}_{4}$ were measured with a gas chromatograph equipped with a thermal conductivity detector and a Poropack Q column (Supelco, Inc.) (Jenneman, et al., 1986). All gas analyses were performed using gas tight syringes. Calibration curves for gases were prepared by adding high purity gases with a gas tight syringe to $160 \mathrm{ml}$ serum bottles flushed with oxygen free nitrogen and sealed with a black rubber stopper. All products were identified and quantified by comparison of retention times and peak areas with those of known standards. Identification of fatty acids and alcohols was also confirmed by the addition of internal standards.

\subsection{Results}

\section{Chemical Analyses of the Brines}

Chemical analyses were performed on a routine basis, to provide a description of 


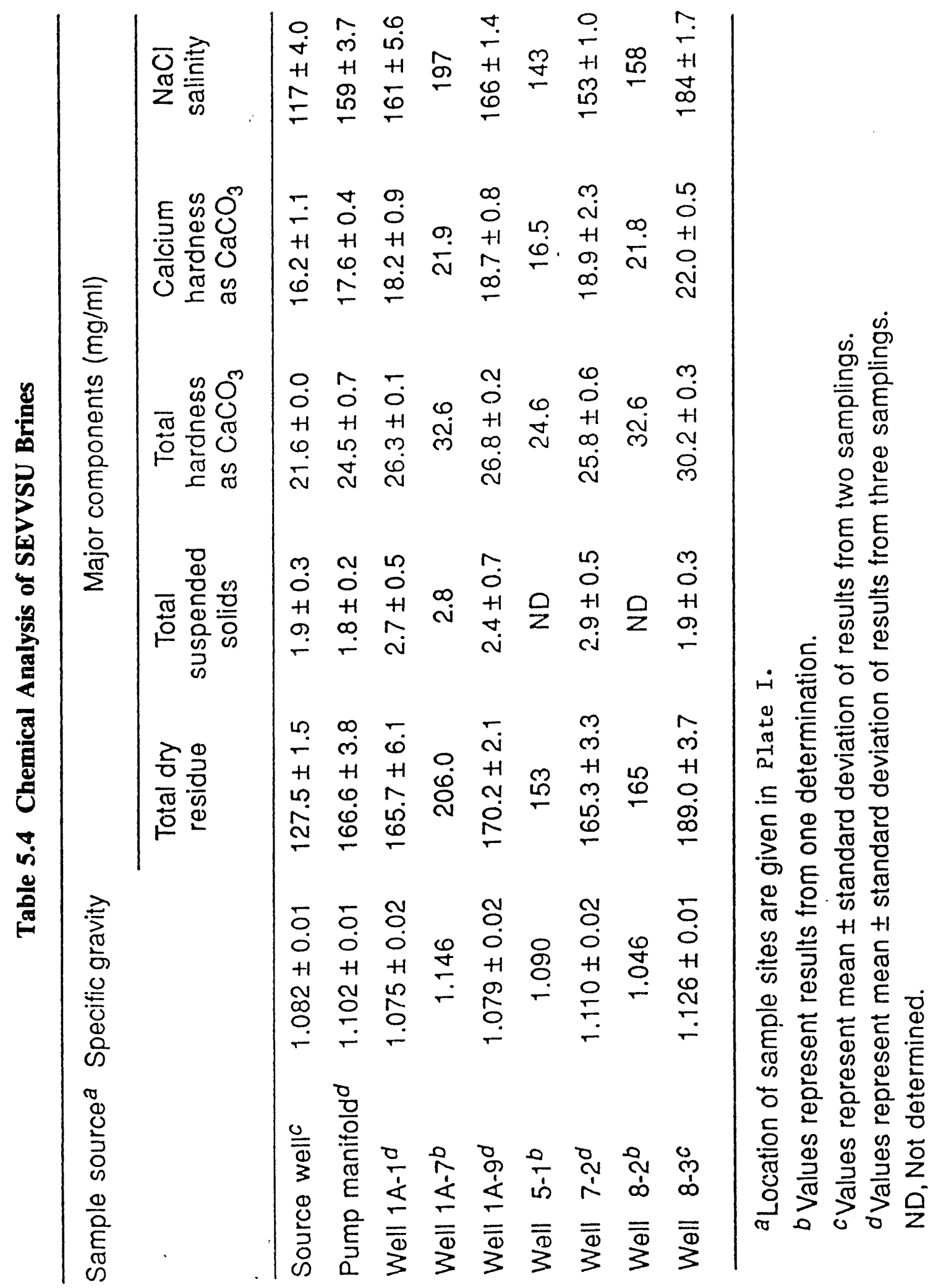




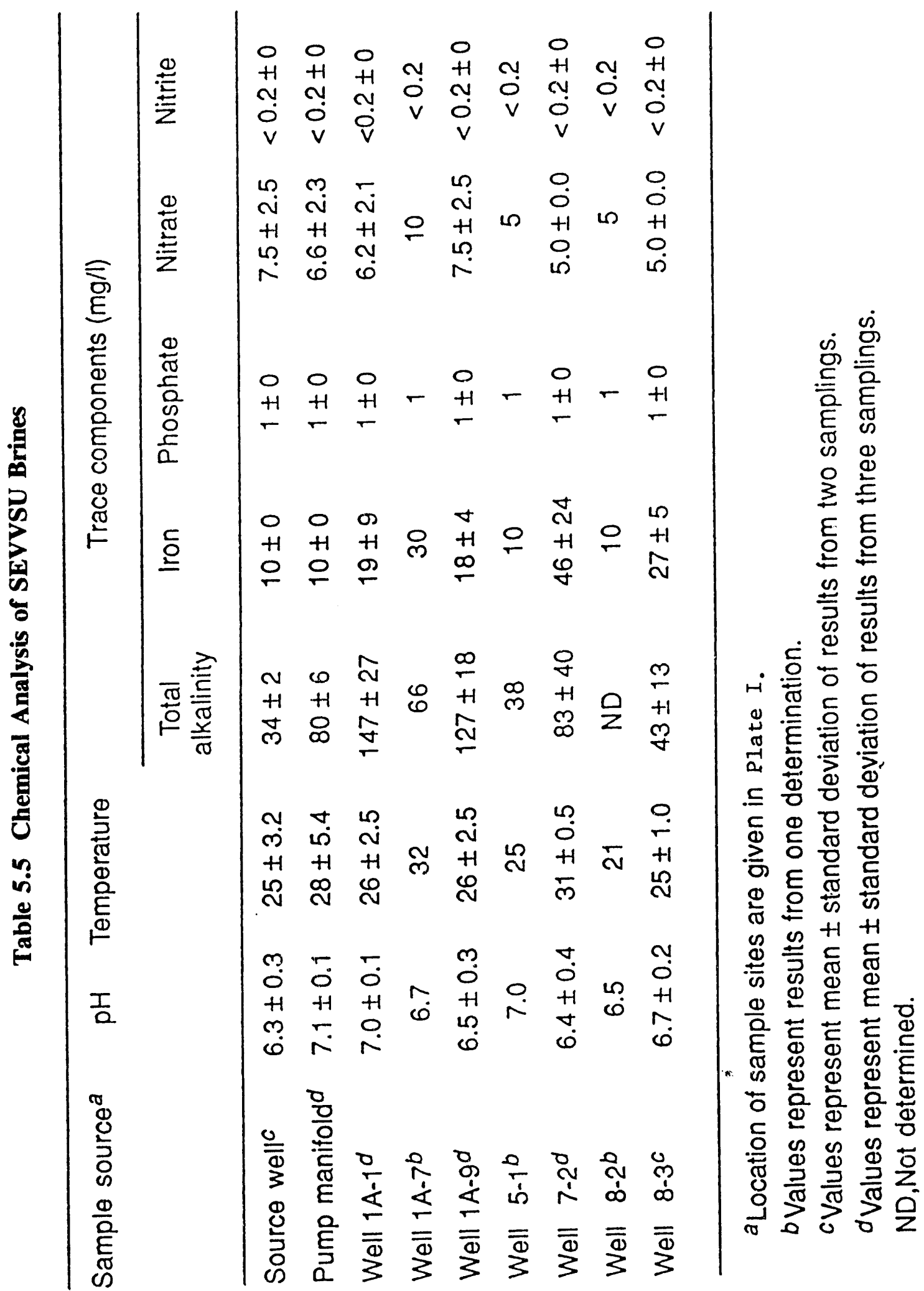


the dominant chemical species in the brines. The chemical compositions of the brines from SEVVSU reservoir are shown in Tables 5.4 and 5.5. All brines were highly saline with total dry residue ranging from about $13 \%(w / v)$ for the source well, 15 to $19 \%$ for the water flooded portion of the reservoir (wells $1 \mathrm{~A}-1,1 \mathrm{~A}-9,8-2$, and $8-3$ ), to over $20 \%$ for well 1A-7. Salinity as sodium chloride ranged from $11 \%$ for the source well to over $19 \%$ for well $1 \mathrm{~A}-7$. The brines from the injection manifold, the injection wells $7-2$ and $5-1$, and the water flooded portion of the reservoir had intermediate salinities ranging from 14 to $16 \%$, except for well $8-3$ which was around $18 \%$. The brines contained high levels of divalent cations, particularly calcium, as indicated by the hardness data, ranging from 1 to $3 \%$. The brines also contained low levels of suspended solids $(0.2$ to $0.3 \%)$. Moderate levels of alkalinity were detected in most of the brines, indicating the presence of carbonates. Detectable levels of iron and nitrate were present in all brines; however, little or no nitrite or phosphate were detected. The temperature of the brines ranged between $20^{\circ}$ and $30^{\circ} \mathrm{C}$, and the $\mathrm{pH}$ was close to neutrality.

The sulfate and sulfide content of the brines were monitored to assess the potential for anaerobic corrosion problems in the reservoir. Pre-nutrient injection sulfate and sulfide concentrations are presented chronologically in Table 5.6 with sulfate concentrations from April of 1989 (sulfides were not measured). Consistent with the previous history of the reservoir, high levels of sulfate were detected in the source well. The brines from the injection manifold, which were an aggregate of the water from the source well and water reused in the water flooding process, generally contained higher levels of sulfate when compared to the brine from the water flooded portion of the reservoir. The brines from the injection well $7-2$ had high levels of sulfate during the 


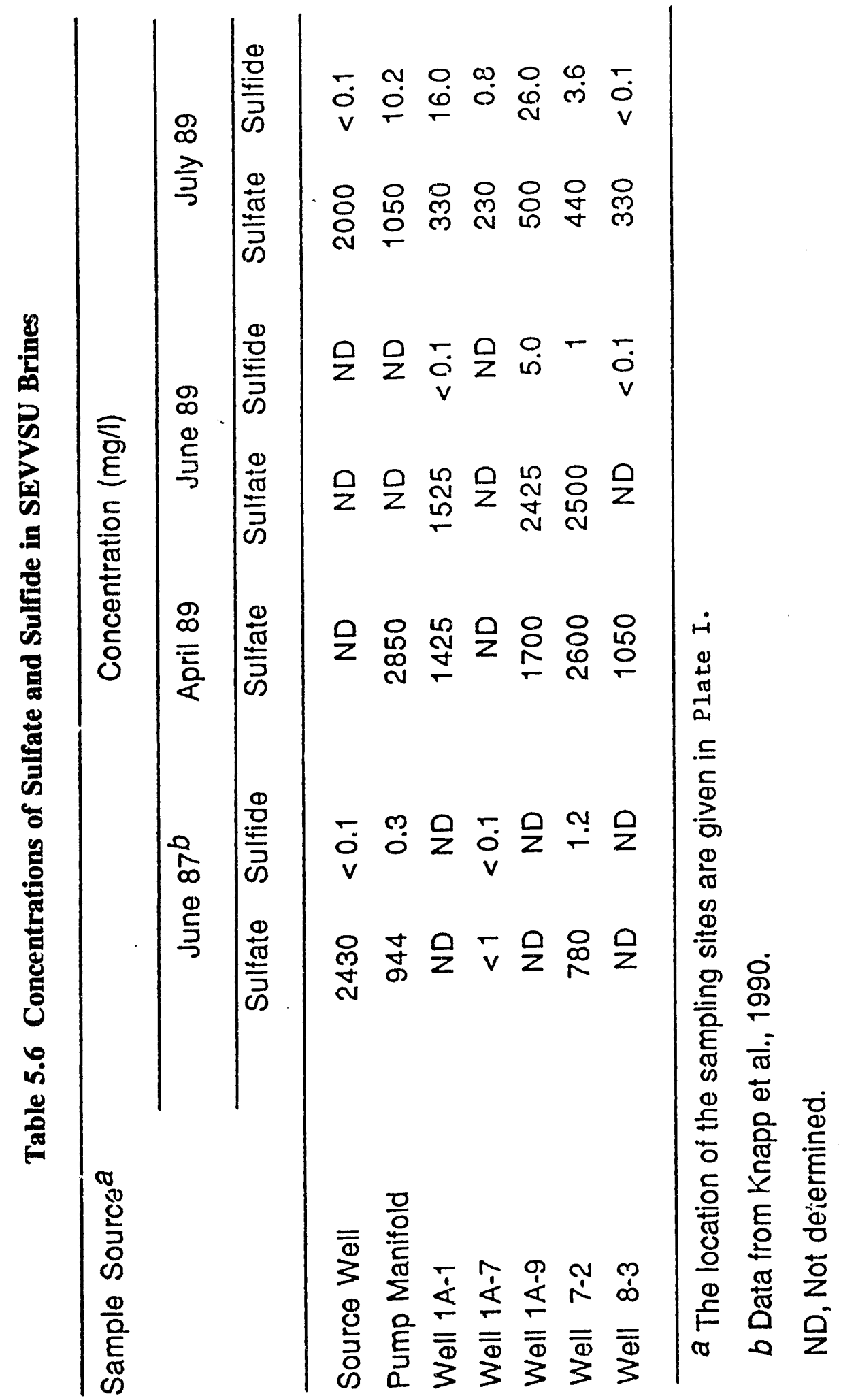


first two samplings in 1989 which were probably due to operational activities in the field rather than microbiological changes. Brines from well $1 \mathrm{~A}-9$ had rather high levels of sulfate and sulfide when compared to brines from other portions of the reservoir which had been water flooded. Samples from well 1A-7 which were previously (1987) devoid of both sulfate and sulfide recorded substantial increase in the levels of sulfate (from $<1$ to $230 \mathrm{mg} / \mathrm{ml}$ ) and sulfide (from $<0.1$ to $0.8 \mathrm{mg} / \mathrm{ml}$ ).

The source of sulfate in the waterflooded area of the field is believed to be the brine from the source well. As the concentration of the source well brine increased the sulfate concentration also increased. The increases of sulfate and sulfide in the 1A-7 produced water indicated arrival of the floodfront at this location. The decrease in sulfate coupled with the increase in sulfide at the 7-2 indicated metabolic activity by sulfate reducing bacteria in the injection tubing.

\section{Bacteriological Analyses}

Because of the high salinities of the brines, it was important to determine whether the brines contained indigenous microbial populations which could be useful in enhanced oil recovery. Physiologically important groups of bacteria were routinely enumerated using a three tube most probable number method (Table 5.7). Aerobic heterotrophic bacteria, anaerobic heterotrophic bacteria, anaerobic moiasses nitrate-using bacteria, and sulfate-reducing bacteria were enumerated on three separate occasions prior to nutrient injection. Methanogenic bacteria were enumerated on two separate occasions.

Anaerobic heterotrophic bacteria $\left(<1\right.$ to $\left.4.6 \times 10^{3}\right)$ were generally more numerous than aerobic heterotrophic bacteria $\left(<1\right.$ to $\left.7.5 \times 10^{2}\right)$. Bacteria that grew in molasses nitrate meriium were consistently found in all brines, and in higher 


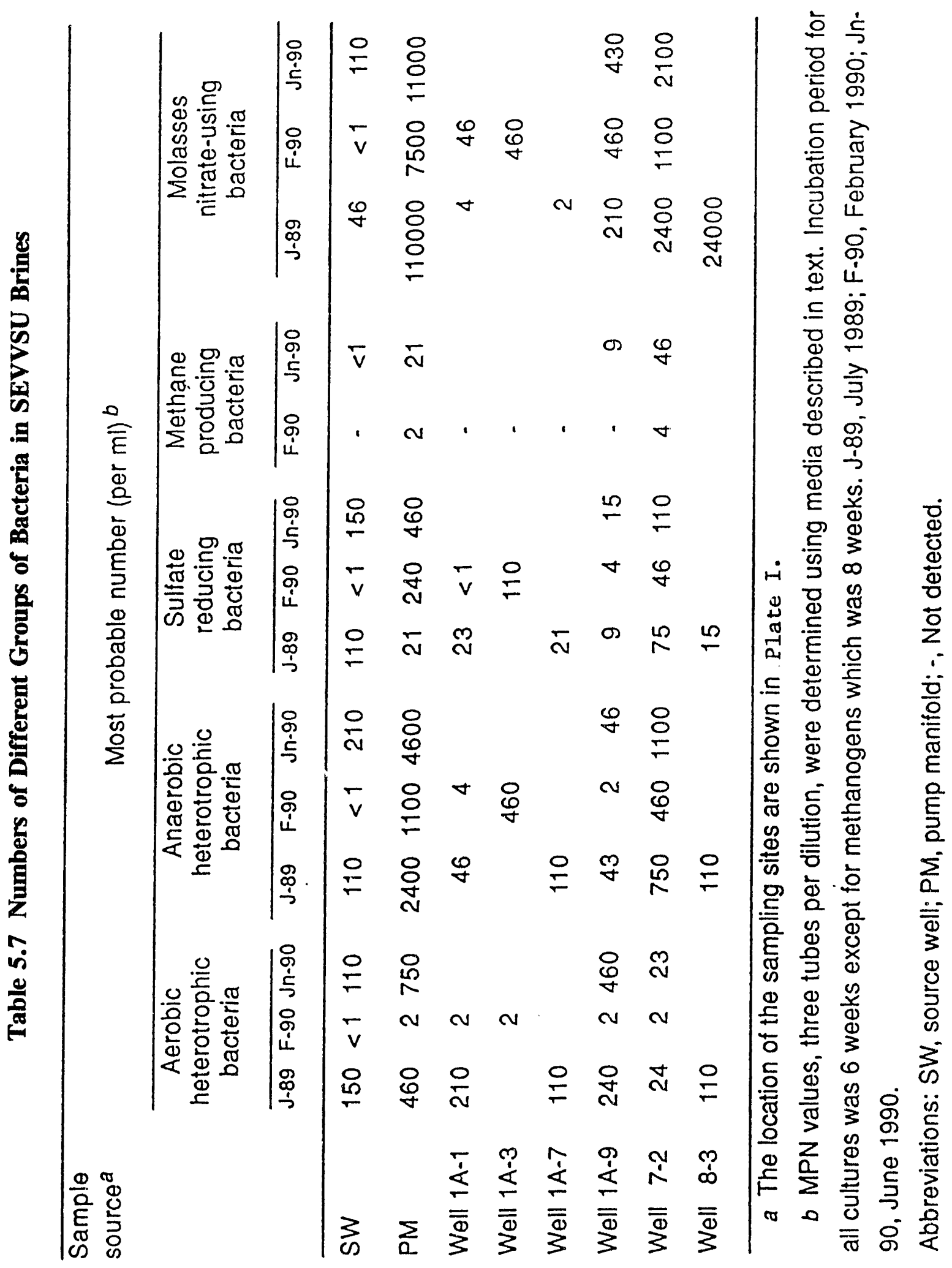


concentrations $\left(<1\right.$ to $\left.1.1 \times 10^{5}\right)$ than the other tested groups of bacteria. Sulfatereducing bacteria were present in all the brine, however, in lower numbers ( $<1$ to $\left.4.6 \times 10^{2}\right)$ than the other groups of bacteria. Relatively high numbers of sulfatereducing bacteria were present in the brines from the source well and the injection manifold, which is consistent with the amount of sulfate and sulfide detected in these brines. Brines from well 1A-7 which did not previously have any sulfate-reducing bacteria or sulphide (Knapp, et al., 1989), had a substantial increase in sulfate-reducing bacteria. Methanogenic bacteria ranging from 2 to $46 / \mathrm{ml}$ were detected in only two of the tested brines, namely the brines from the injection manifold and well 7-2. Methanogens were not detected in brines from the source well and the coproduced brines from water flooded portions of the reservoir.

In an attempt to enrich for halophilic methanogens, culture media showing turbidity and methane production were transferred into fresh methanogenic medium containing either $\mathrm{H}_{2} / \mathrm{CO}_{2}$, formate or acetate as the substrate. Tubes incubated at $35^{\circ} \mathrm{C}$ for 4 weeks were routinely monitored for growth and methane production. Although methane production was observed in all the tubes, visible growth was observed only in tubes containing acetate as the substrate. Tubes containing $\mathrm{H}_{2} / \mathrm{CO}_{2}$ as the substrate, had substantial methane production and pressure decreases (under vacuum in some cases), indicating the utilization of $\mathrm{H}_{2} / \mathrm{CO}_{2}$. After repeated refeeding of $\mathrm{H}_{2} / \mathrm{CO}_{2}$ to these enrichments, substantial methane production was again observed (data not shown); however, absorbance increase was low $(<0.15$ at $660 \mathrm{~nm})$. The same was the case for tubes containing formate as the substrate. 


\section{Cellular Growth and Metabolic Characteristics of the Halophilic}

\section{Bacteria Isolated from the Brines}

Four anaerobic heterotrophic halophiles designated as VS-732, VS-751, VS-752, VS-511, and one isolated from molasses nitrate medium designated TTL-30 were characterized. Strains VS-732, VS-751 and VS-752, and VS-511 were isolated from wells 7-3, 7-5, and 5-1 respectively. All five were Gram-negative, non-spore-forming rod shaped bacteria. Cells of strains VS-751 and VS-752 were straight rods, appearing singly, in pairs, occasionally as long chains, and measuring $0.7-0.8 \times 2-3.3 \mu \mathrm{m}$, and 0.3-0.4 x 2.6-4 $\mu \mathrm{m}$, respectively. Cells of strains VS-732 and VS-511 were relatively smaller, occurring either singly or in pairs, with dimensions of $0.5-0.8 \times 0.7-1.9 \mu \mathrm{m}$ and 0.5-0.7 x 1.3-2.6 $\mu \mathrm{m}$, respectively. Cells of strains VS-732, VS-751, and VS-752 were motile, while that of strains VS-511 and TTL-30 were non-motile.

All five strains were unable to grow in an aerobic medium and required high concentrations of $\mathrm{NaCl}$ for growth. At least $6 \% \mathrm{NaCl}(w / v)$ was required for the growth of all the strains. At $\mathrm{NaCl}$ concentrations less than $6 \%$ the cells lysed. Strains VS-732 and VS-752 grew at $\mathrm{NaCl}$ concentrations ranging between 6 and $25 \%$, with optimum growth occurring at 9 to $12 \%$ and 6\%, respectively (Figure 5.1 and Figure 5.3). The range of $\mathrm{NaCl}$ concentrations for the growth of strains VS-751 and VS-511 was between 9 and $18 \%$, with optimun growth occurring at $12 \%$ (Figure 5.2 and Figure 5.4). The optimal $\mathrm{NaCl}$ requirement for strain TTL-30 was $15 \%$, with growth occurring between 6 and 22\% (Figure 5.5). None of the strains grew at $\mathrm{NaCl}$ concentrations greater than $25 \%$. The optimum temperature for growth of strains VS-751, VS-752, and TTL-30 was between 23 and $45^{\circ} \mathrm{C}$, and for strains VS-732, and VS-511 was between 23 and $37^{\circ} \mathrm{C}$. 


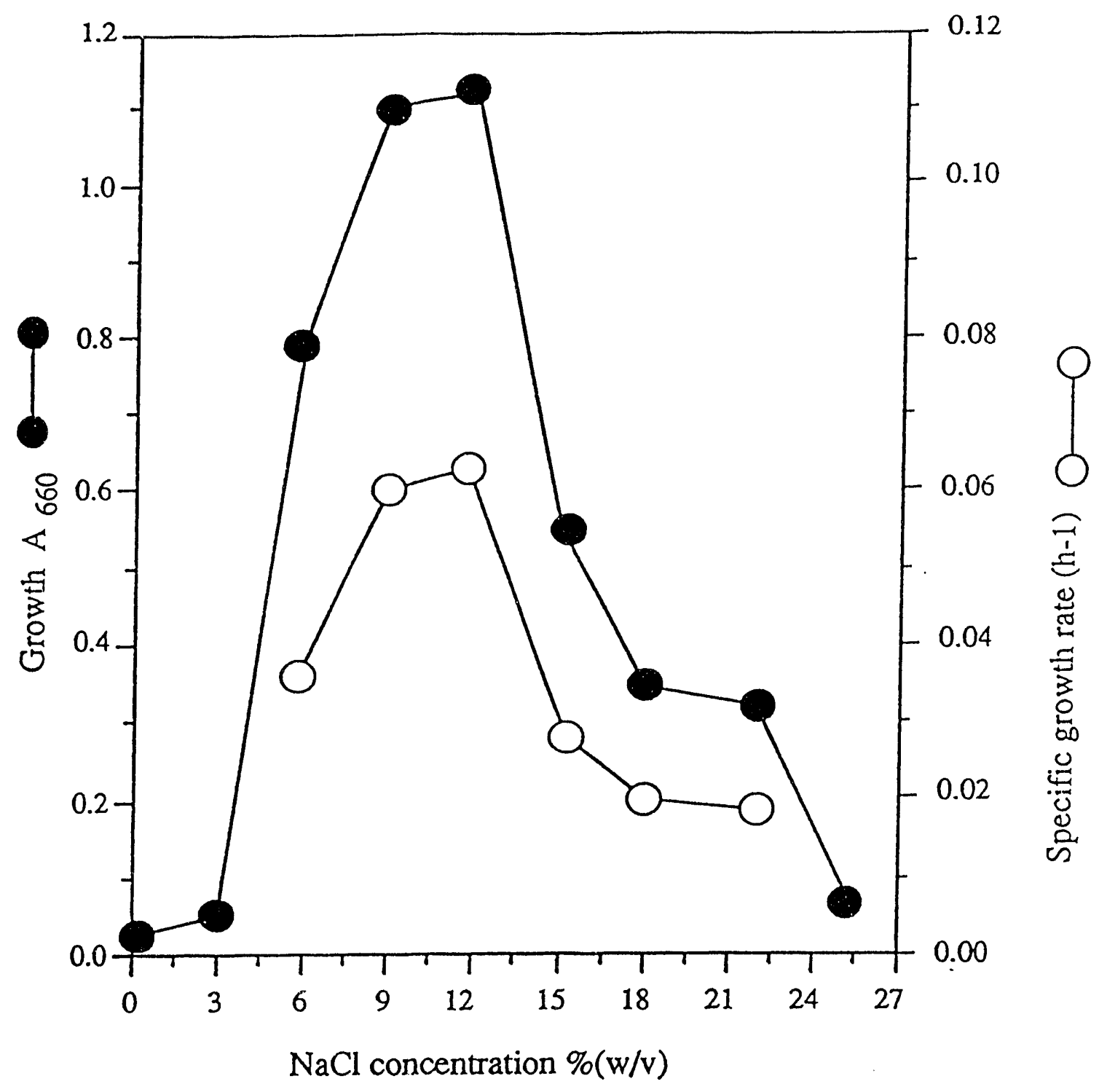

Figure 5.1 Effect of $\mathrm{NaCl}$ Concentration on the Growth of Strain VS-732. Cells were grown at $35^{\circ} \mathrm{C}$ in mineral salts medium containing yeast extract, casamino acids, glucose, and the $\mathrm{NaCl}$ concentration indicated. After different incubation periods at $35^{\circ} \mathrm{C}$ the absorbance of the cultures was measured and the growth rates were calculated from the exponential part of the growth curves. 


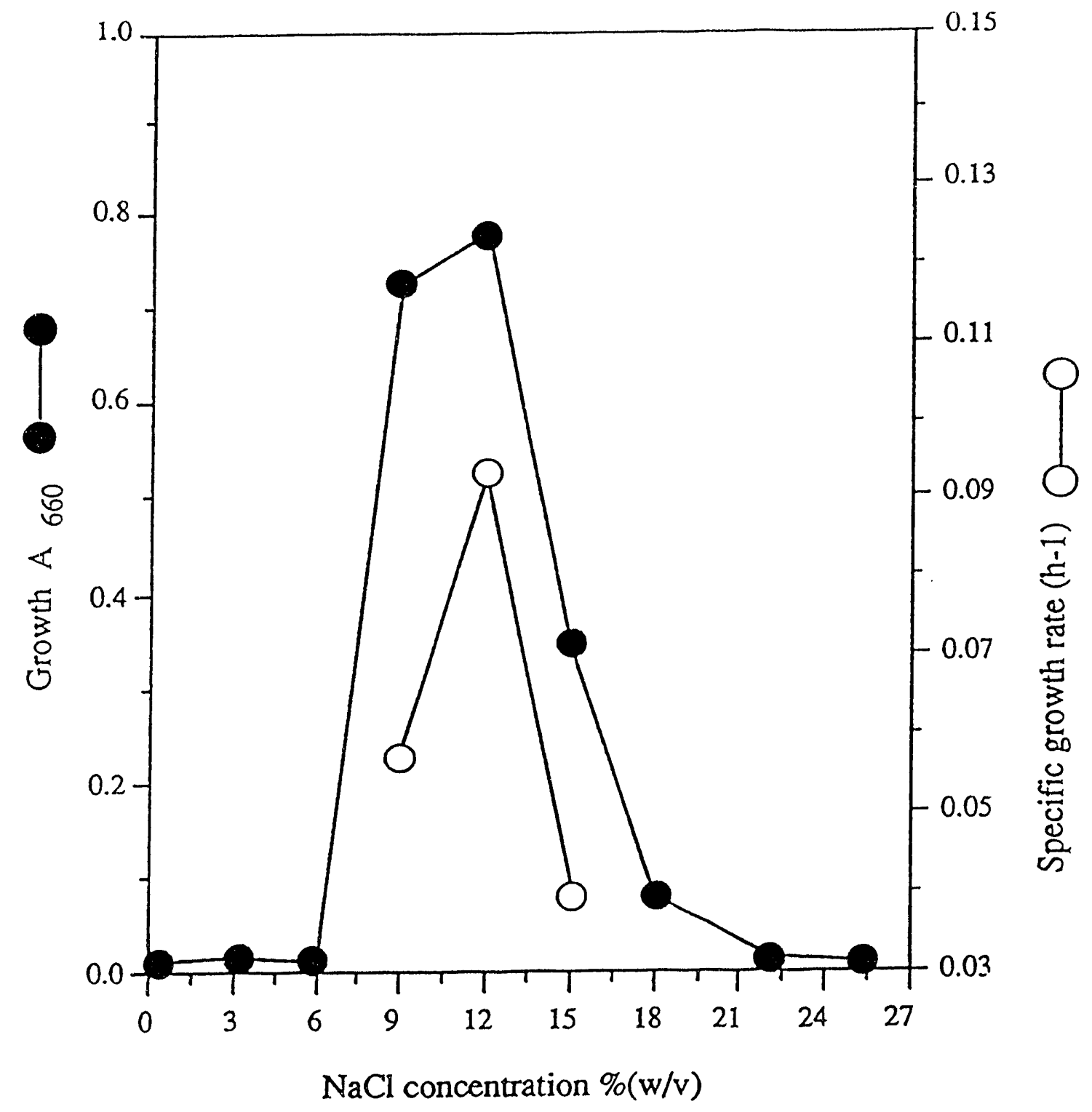

Figure 5.2 Effect of NaCl Concentration on the Growth of Strain VS-751. Cells were grown at $35^{\circ} \mathrm{C}$ in mineral salts medium containing yeast extract, casamino acids, glucose, and the $\mathrm{NaCl}$ concentration indicated. After different incubation periods at $35^{\circ} \mathrm{C}$ the absorbance of the cultures was measured and the growth rates were calculated from the exponential part of the growth curves. 


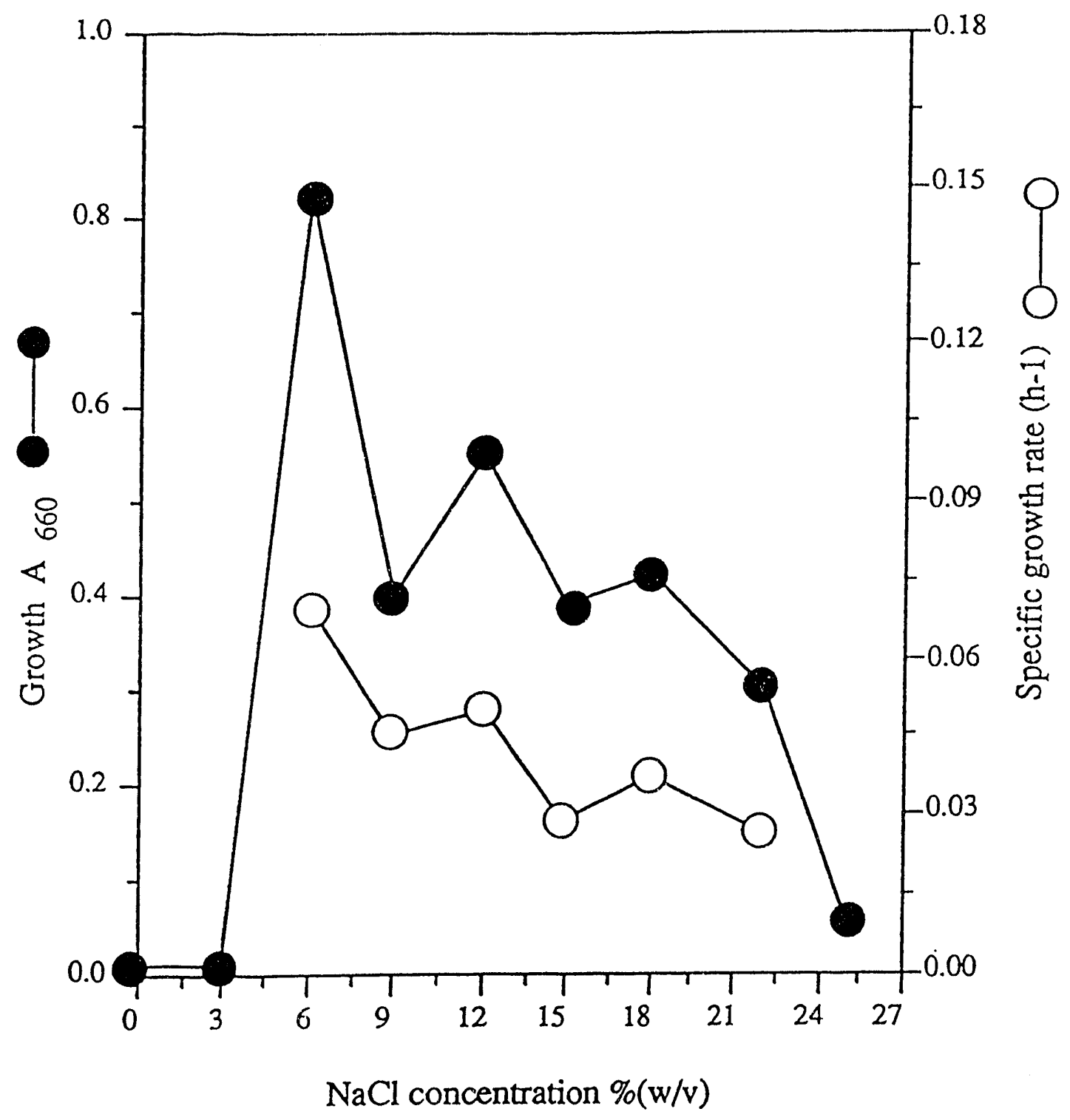

Figure 5.3 Effect of $\mathrm{NaCl}$ Concentration on the Growth of Strain VS-752. Cells were grown at $35^{\circ} \mathrm{C}$ in mineral salts medium containing yeast extract, casamino acids, glucose, and the $\mathrm{NaCl}$ concentrate indicated. After different incubation periods at $35^{\circ} \mathrm{C}$ the absorbance of the cultures was measured and the growth rates were calculated from the exponential part of the growth curves. 


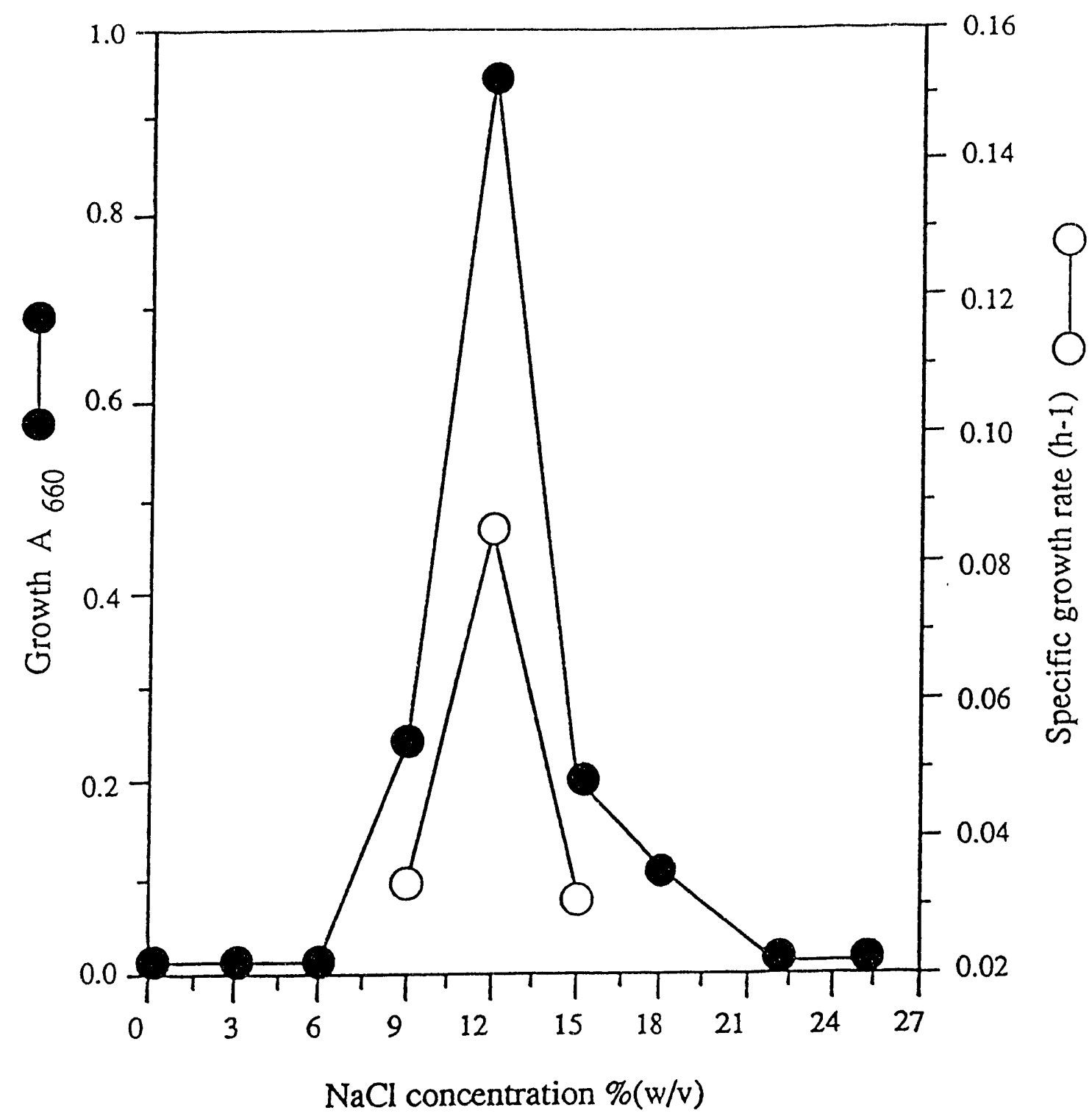

Figure 5.4 Effect of $\mathrm{NaCl}$ Concentration on the Growth of Strain VS-511. Cells were grown at $35^{\circ} \mathrm{C}$ in mineral salts medium containing yeast extract, casamino acids, glucose, and the $\mathrm{NaCl}$ concentration indicated. After different incubation periods at $35^{\circ} \mathrm{C}$ the absorbance of the cultures was measured and the growth rates were calculated from the exponential part of the growth curves. 


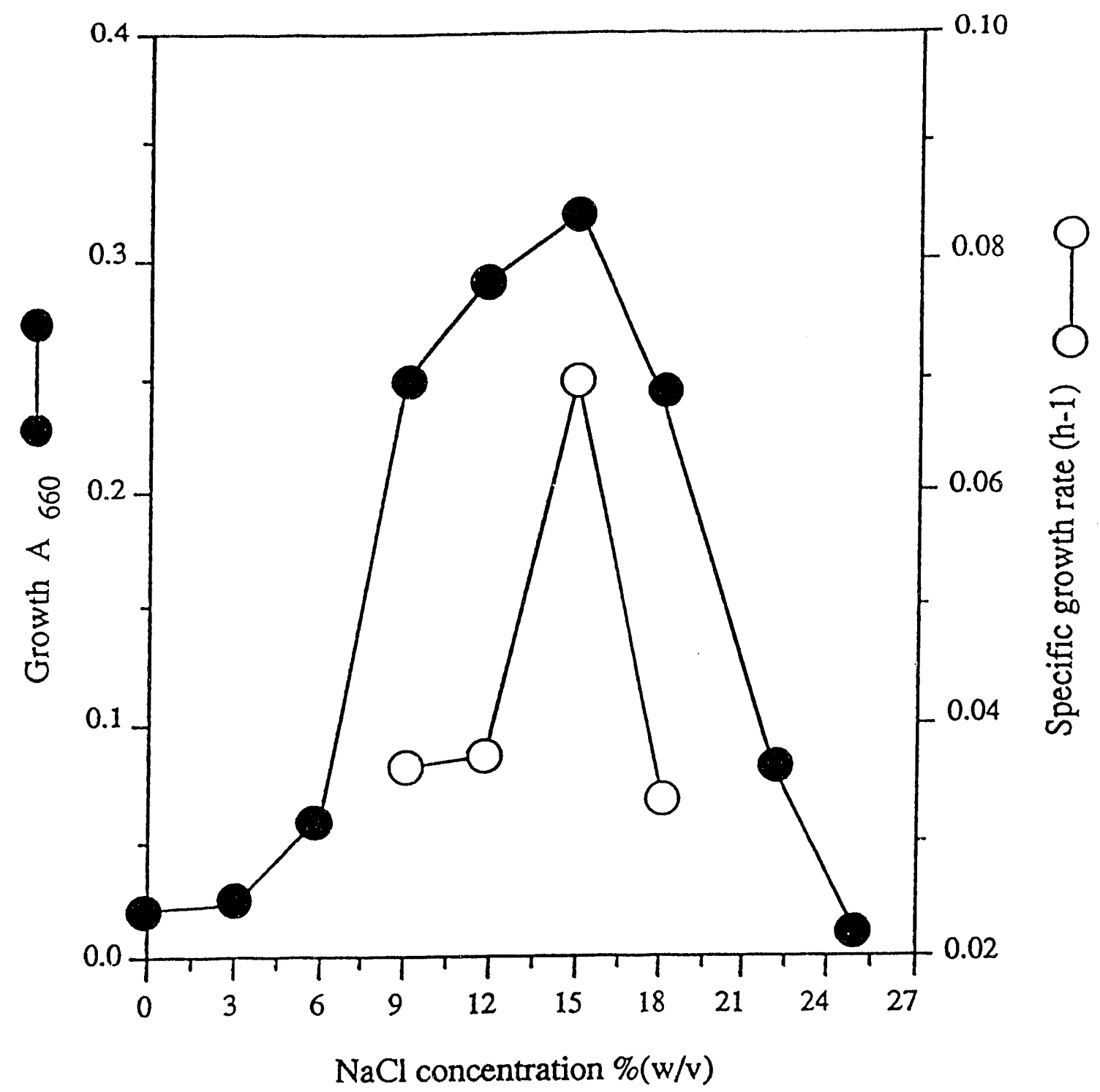

Figure 5.5 Effect of NaCl Concentration on the Growth of Strain TTL-30. Cells were grown at $35^{\circ} \mathrm{C}$ in mineral salts medium containing yeast extract, casamino acids, glucose, and the $\mathrm{NaCl}$ concentration indicated. After different incubation periods at $35^{\circ} \mathrm{C}$ the absorbance of the cultures was measured and the growth rates were calculated from the exponential part of the growth curves. 
The doubling time for strains VS-751, VS-511, and VS-732 was 7.2, 8, and 11 hours, respectively, and that for strains VS-752 and TTL-30 was around 10 hours. All strains were catalase and oxidase negative and inhibited by chloramphenicol, tetracycline, and penicillin, but not cyclohexamide or azide.

The effect of added electron acceptors on the growth of the strains was tested in medium containing glucose as the carbon source. None of the tested electron acceptors appeared to stimulate the growth of the strains, except for sulfite which stimulated the growth of strain TTL-30. Nitrate neither stimulated nor inhibited the growth of the strains. Elemental sulfur, sulfate, thiosulfate, and nitrite inhibited the growth of all the strains. The change of gas phase from $\mathrm{N}_{2} / \mathrm{CO}_{2}$ to $\mathrm{H}_{2} / \mathrm{CO}_{2}$ in tubes containing glucose as the carbon source and no added electron acceptors, stimulated the growth of strains VS-511 and VS-732, but completely inhibited the growth of strain TTL-30. The presence of a carbon monoxide gas phase at any of the tested concentrations in medium with and without glucose, completely inhibited growth of all the strains.

Energy sources for the strains were tested by adding an individual carbon source at $10 \mathrm{mM}$ (unless otherwise indicated) to the mineral salts medium containing $12 \% \mathrm{NaCl}$, and $0.025 \%$ yeast extract. A variety of compounds were able to serve as energy sources (Table 5.8). Substrate utilization was indicated by both growth (A660) and product (acetate) formation. Substrates utilized by all the strains included arabinose, fructose, galactose, glucose, inulin, mannose, sucrose, and trypticase. Substrates not utilized by any of the strains included the following: ascorbate, crotonate, dihydroxybenzoate, gallic acid, methanol, propionate, phenoxyacetate, and resorcinol. The ability of the strains to utilize amino acid mixtures was also tested. Amino acid mixtures such as 


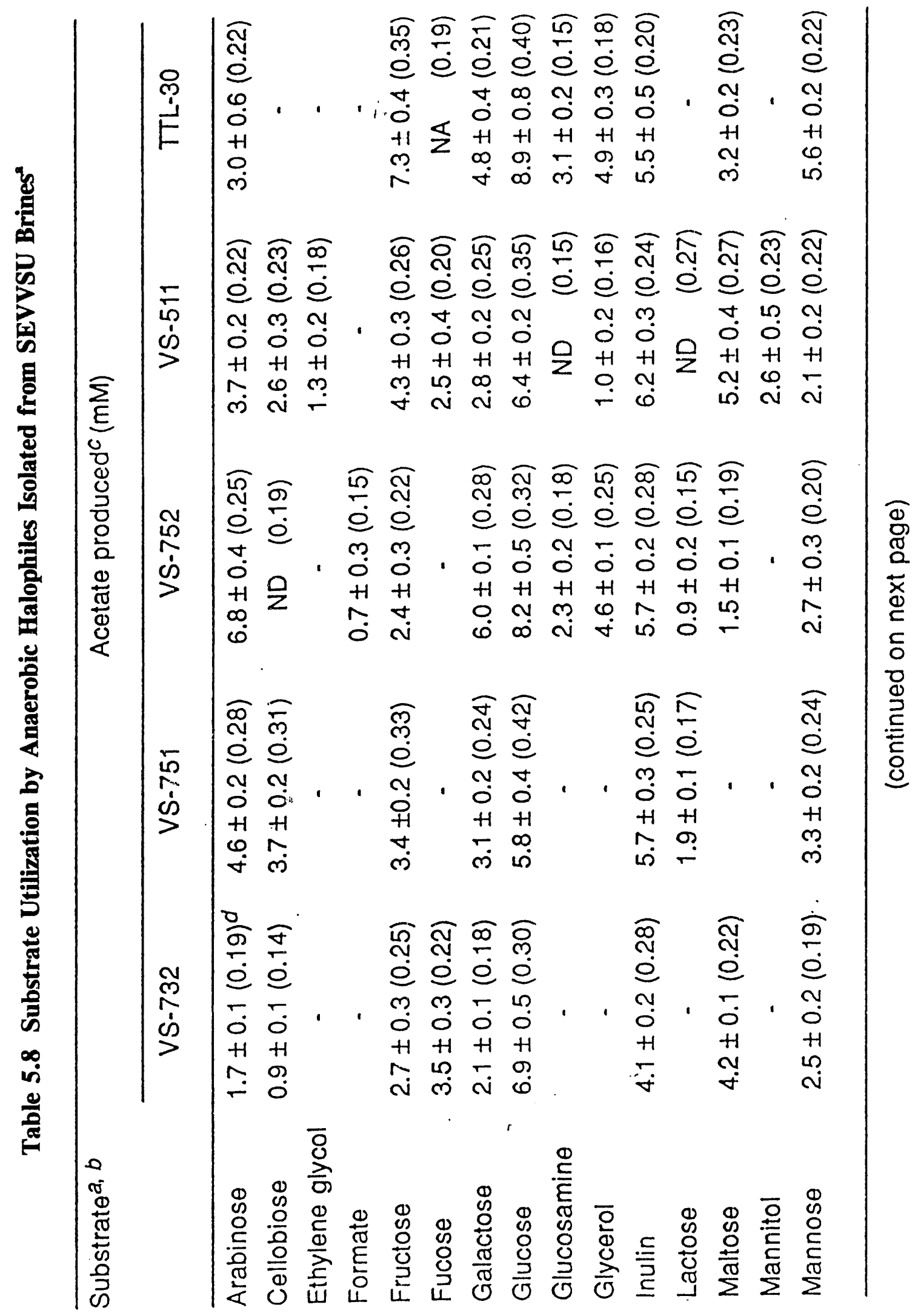




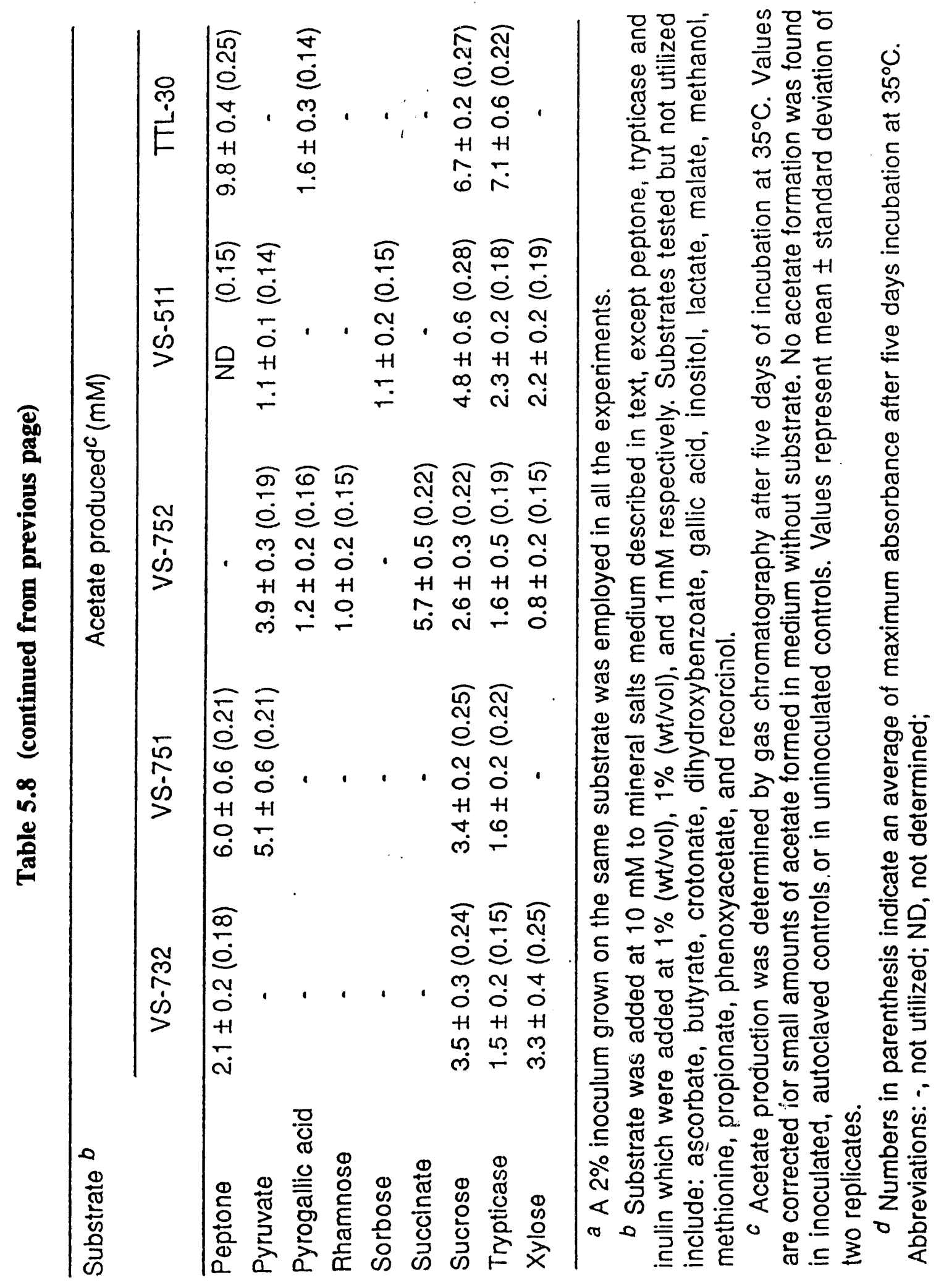


alanine-glycine, leucine-proline, isoleucine-tryptophan, valine-ornithine, phenylalanine-leucine, and histidine-sarcosine also were not utilized by any of the strains.

The glucose fermentation products of the strains were determined in $160 \mathrm{ml}$ serum bottles containing a mineral salts medium with $1 \%(\mathrm{w} / \mathrm{v})$ glucose, $0.025 \%$ yeast extract and a gas phase of nitrogen (Table 5.9). Analysis of culture fluids after 96 hours of incubation at $35^{\circ} \mathrm{C}$, by gas and liquid chromatography indicated the following products: ethanol, acetate, formate, and $\mathrm{CO}_{2} / \mathrm{H}_{2}$ in the case of strains VS-732, and VS-751; acetate, ethanol, and $\mathrm{CO}_{2} / \mathrm{H}_{2}$ in the case of strains VS-752 and TTL-30; and ethanol, acetate, and $\mathrm{CO}_{2} / \mathrm{H}_{2}$ in the case of strain VS-511. For strain VS-732 an unidentified peak was detected in HPLC chromatograms, as a product of glucose metabolism. Lactate, malate, succinate, butyrate, propionate, valerate, isovalarate, and caproate were not detected in any of the culture fluids. Based on the amounts of substrate used and the products formed, the following fermentation balances were derived:

Strain VS-732:

1.0 Glucose $-->>1.0$ Ethanol +0.7 Acetate +0.3 Formate $+1.7 \mathrm{CO}_{2}+0.5 \mathrm{H}_{2}$ Strain VS-751:

1.0 Glucose --- > 1.4 Ethanol +0.6 Acetate +0.3 Formate $+1.9 \mathrm{CO}_{2}+0.5 \mathrm{H}_{2}$ Strain VS-752:

1.0 Glucose --- > 1.1 Ethanol +1.5 Acetate $+1.7 \mathrm{CO}_{2}+0.4 \mathrm{H}_{2}$

Strain VS-511:

1.0 Glucose ---> 1.4 Ethanol +0.7 Acetate $+1.8 \mathrm{CO}_{2}+0.5 \mathrm{H}_{2}$

Strain TTL-30:

1.0 Glucose --->0.4 Ethanol +1.6 Acetate $+2.7 \mathrm{CO}_{2}+0.3 \mathrm{H}_{2}$ 


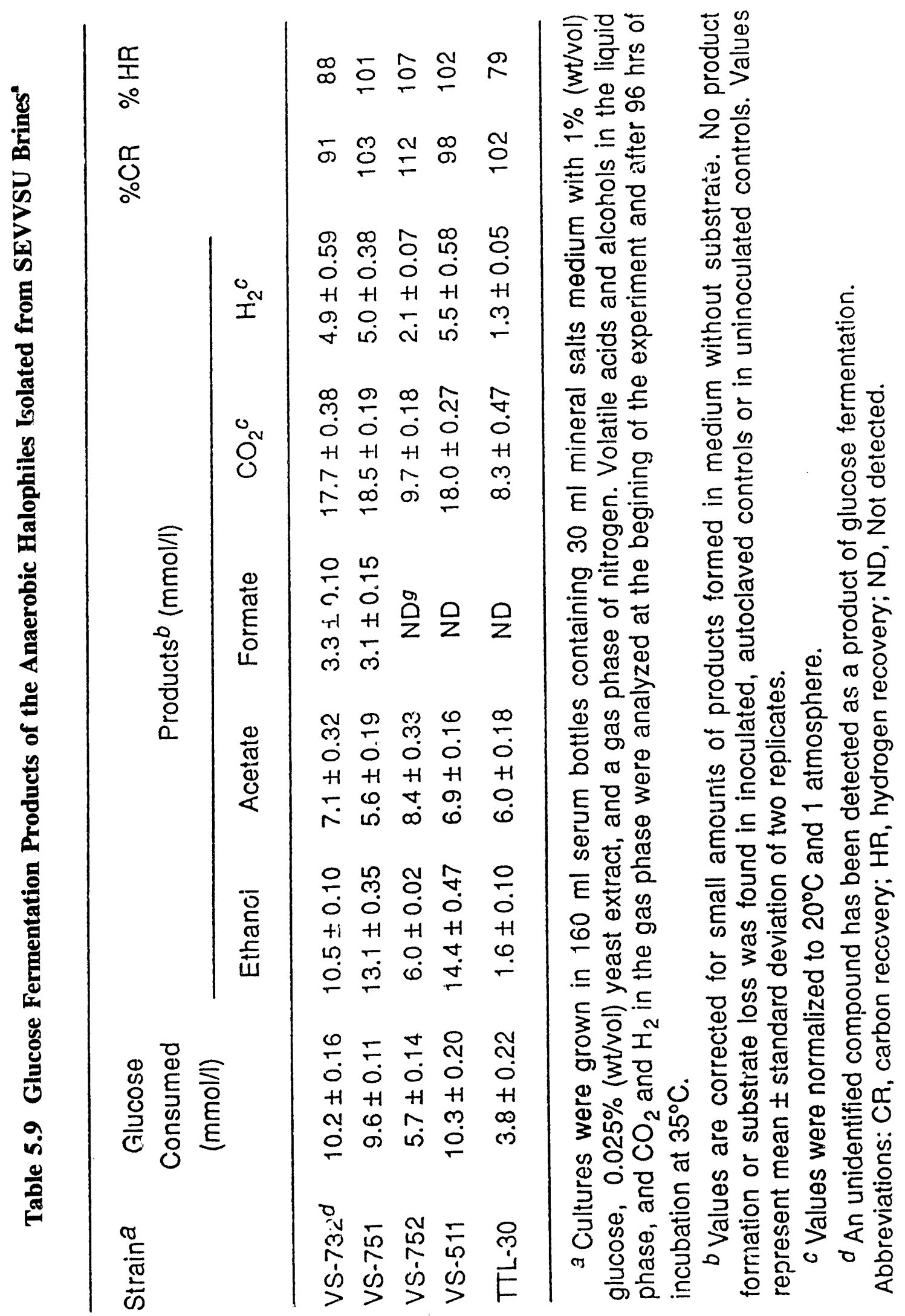




\section{Nutrient Selection}

Since previous studies showed the presence of indigenous microbial populations that were able to grow readily with simple nutrient additions (Knapp, et al, 1989), it was important to determine which nutrient source would best stimulate microbial growth. Brines from several wells were amended with different nutrient mixtures (Table 5.10). Results from these experiments show that molasses alone supported good growth of indigenous populations. However, the addition of molasses together with ammonium nitrate resulted in the largest increases in the growth of the indigenous microbial populations. In some brines, the addition of either glucose or sucrose with or without ammonium nitrate stimulated growth. The addition of a phosphate source and an additional nitrogen source to brines amended with individual sugars did not stimulate micrcbial growth. Based on these results, molasses and ammonium nitrate were chosen for the field injection.

\subsection{Conclusions}

The ecology of the Southeast Vassar Vertz Sand Unit was extensively investigated prior to initiation of the field pilot. This allowed evaluation of changes in the produced fluid chemistry that were indicative of the effect of the microbial treatment in the reservoir. It also allowed potential problems involved in the field pilot, specifically, sulpiiide production, to be addressed in the choice of nutrient treatment performed.

Extensive microbiological investigation into indigenous bacteria from the SEVVSU were performed. Aerobic and anaerobic halophilic bacteria, methanogens, and sulphate-reducing bacteria were presunt in produced brines from the field. Five anaerobic heterotrophs were closely examined and ranges were established for growth 


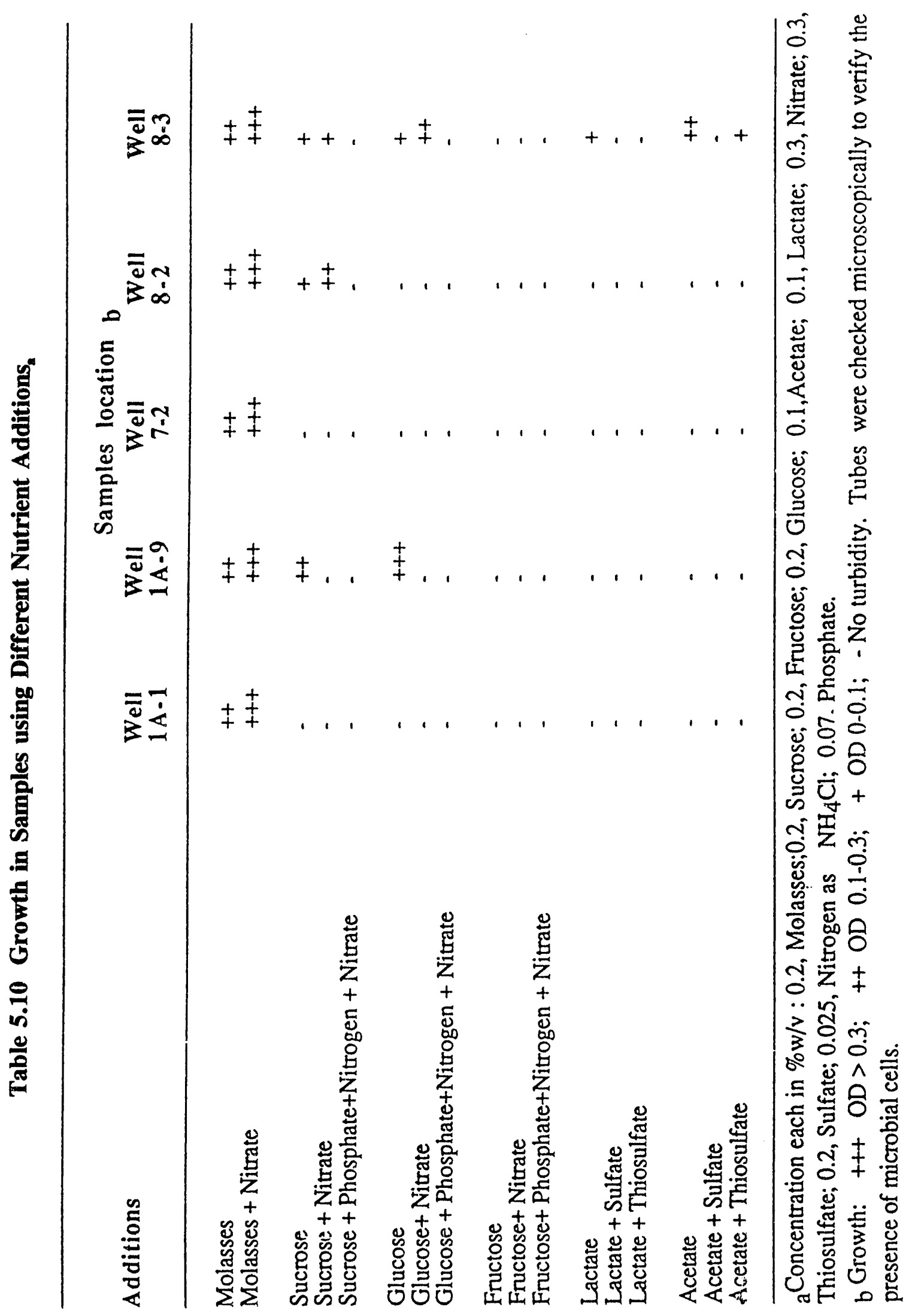


of these bacteria. These bacteria were also used to determine substrate utilization and product formation.

A nutrient treatment mixture was defined for the field pilot study. Many combinations of substrate were added to unamended brine samples and the degree of growth observed. Molasses and ammonium nitrate proved to provide the most robust growth in all cases and was chosen for use in the field pilot study. 


\section{Chapter 6. Core Flood Experiments and MEOR Mechanisms}

\subsection{Introduction}

For the development of microbially enhanced oil recovery (MEOR) as a viable technology in the petroleum industry, it is important that the mechanisms involved in this process be understood. MEOR has the potential to recover a portion of the residual oil remaining after waterflooding through changes brought about by metabolic activity. The changes include selective plugging of the reservoir and modification of the reservoir fluids and their saturations. The latter two of these will be discussed in the following sections.

\subsection{Experimental Methods}

The experiments reported were conducted to provide information about the mechanisms of oil recovery caused by microbial activity within a core. Specifically, samples of microorganisms from well 1A-9 in the Southeast Vassar Vertz Sand Unit (SEVVSU), Fayne County, Oklahoma were investigated for their potential in microbial enhancement of oil recovery. All experiments were performed using oil and brine taken from the SEVVSU. The $\mathrm{NaCl}$ salinity of the brine was $15 \%$. The experiments were performed at reservoir temperature using the apparatus in Figure 6.1. The cores were prepared and experiments conducted using the techniques of Silfanus (1990) and Knapp, et al. (1990). The experiments were performed using the three step treatments described below.

Four MEOR core floods were performed with apparatus arranged as shown in Figure 6.1. For each experiment a core was cleaned, dried, and flushed with brine, oil, 


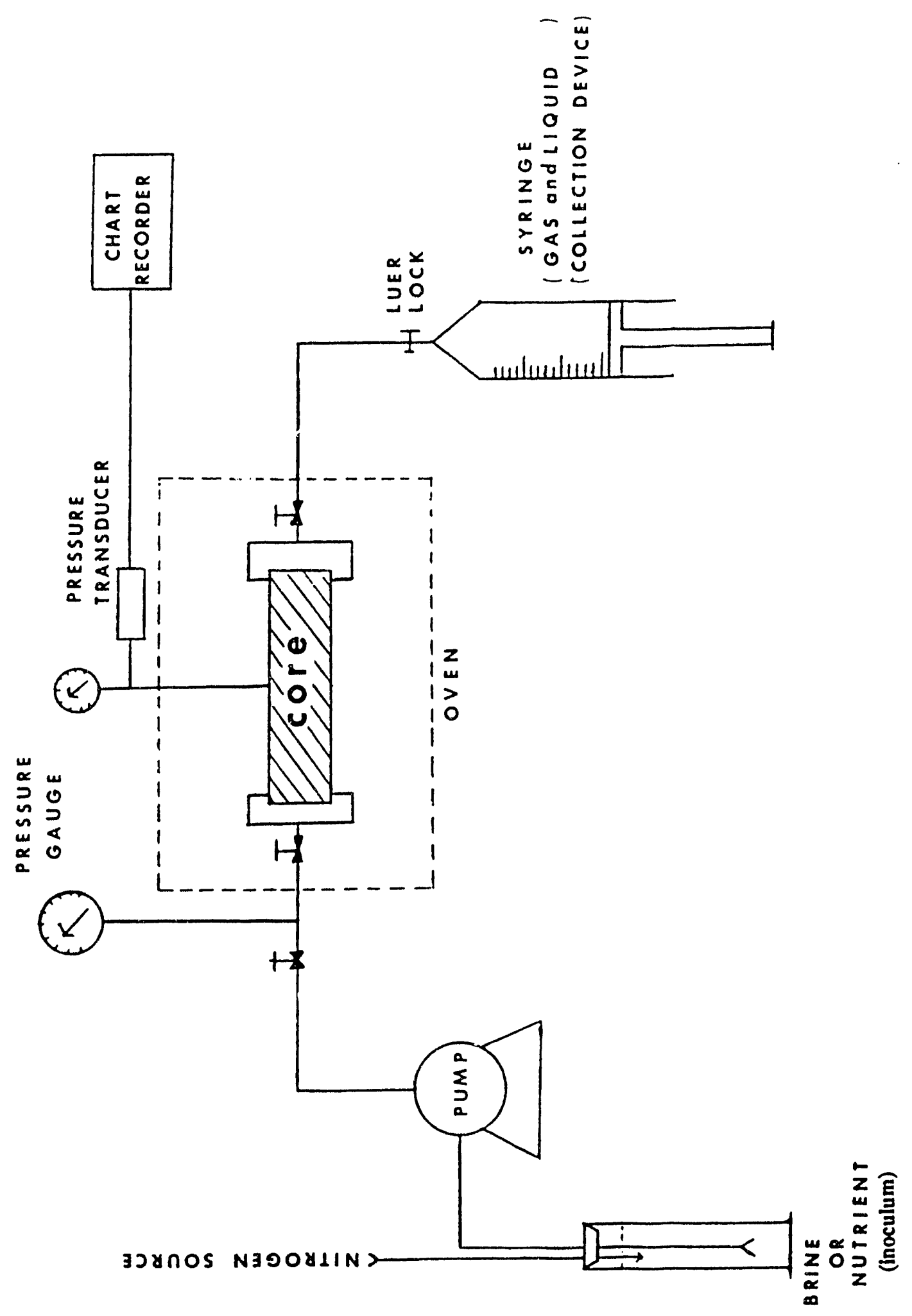


and brine again, such that the core's final condition was water wet at residual oil saturation. The MEOR treatments were begun by an injection of nutrient rich brine containing bacteria. The experiment proceeded with three steps per treatment. First, the core was isolated by closing valves at both ends and allowed to incubate. Second, the effluent end of the core was opened and fluids were produced under the influence of any internal driving force. Third, the core was flooded and fluids were produced under the influence of the flood. The displacing liquid was a nutrient rich brine which represented the carbon source for the next incubation. These three steps were repeated for each treatment.

The effective permeability reduction factor (PRF) is defined as:

$$
P R F=\frac{k_{w i}}{k_{\text {wsor }}} 100, \%
$$

In the MEOR processes, a series of nutrient treatments were used to improve oil recovery. The incremental oil recovery associated with each nutrient treatment is the oil produced by the release of pressure caused by the in situ gas produced during incubation of the core with nutrients plus the oil that is produced by the injection of the subsequent treatment. The recovery factor $(\mathrm{RF})$ is defined as:

$$
R F=\frac{N_{p}}{O I P W} 100, \%
$$

\subsection{Microbial Enhanced Oil Recovery Mechanisms}

Metabolism within the reservoir changes the chemical nature of the formation fluids. Bacteria often produce products such as surfactants, polymers, and co-surfactants (alcohols) which change the properties of the water phase and the interaction between the fluid phases and the fluids and the matrix. In particular, changes in the interfacial 
tension can be related to microscopic sweep efficiency. The production of gases is associated with almost all biogenetic activity. This gas can either dissolve in the pore fluids or exist as a free gas phase within the porous medium. In the latter case, the relative permeabilities in the medium will be changed and the presence of a free gas phase can affect the residual oil saturation.

The presence of cell bodies in the porous media also causes changes in the reservoir characteristics. Bacteria can exist both in the flowing water phase and as sessile (attached) bacteria along pore walls. The sessile bacteria occupy space within the pores. Often they have polymeric films or coatings. This reduces the volume available for flowing fluids and reduces both effective porosity and permeability. In cases where the nutrient source for the bacteria is provided by the injected brine, growth is concentrated in preferential flow paths for the water phase. When these flow paths are effectively blocked by cell bodies, subsequent injections of brine will be forced to follow other flow paths. They will then encounter and displace oil that may have been bypassed by the original waterflood.

\section{Biogenic Gas Effects}

Several chemical changes occur as a result of the MEOR processes which affect the fluids in the reservoir. Microbial processes result in a change in the relative permeability relationship by the presence of biogenetic gas. The metabolism of many microorganisms results in the production of carbon dioxide, hydrogen, nitrogen, or possibly methane, which can create a free gas phase at low pressures in the reservoir.

A free gas phase has been found to decrease residual oil saturation. Holmgren and Morse (1951) and Kyte et al. (1956) studied waterflood recoveries with varying 
initial gas and oil saturations. They observed that increasing the initial free gas saturation caused the residual oil saturation to decrease. The presence of the gas phase caused a decrease in residual oil saturation of six to ten percent of pore volume. Lower residual oil saturations were obtained at successive flooding stages when gas was present compared to those floods performed in the absence of gas.

An idealized set of relative permeability curves for wetting and non-wetting phases is presented in Figure 6.2. At the conclusion of a waterflood in a core the saturation of the wetting phase, $S_{w}$, will be at a maximium. In the case of Figure 6.2 , the maximum $S_{w}$ is 0.9 . At this point the relative permeability of the non-wetting phase is zero. Assume the non-wetting phase initially is residual oil. If the core is flooded with nutrient rich brine inoculated with a viable bacteria and allowed to incubate, biogenetic gas will be produced by bacterial metabolism. The result of this metabo':c gas is an increase in pore pressure in the core.

If the core is allowed to produce fluids under the influence of its internal pore pressure, the first fluid produced will be water. However, as the water is produced and pore pressure drops, gas will come out of solution and volumetrically replace the produced water. Referring again to Figure 6.2 , the wetting phase saturation has, by production, been reduced to some value less than 0.9 . Now, the relative permeability of the non-wetting phase; oil plus gas, has a small value. Further production by reduction of pore pressure will consist of brine and a small quantity of oil with some entrained gas.

When the core is flooded with nutrient rich brine, the core will be swept with a Buckley-Leverett (1942) piston-like front of the new fluid. Behind this floodfront the 


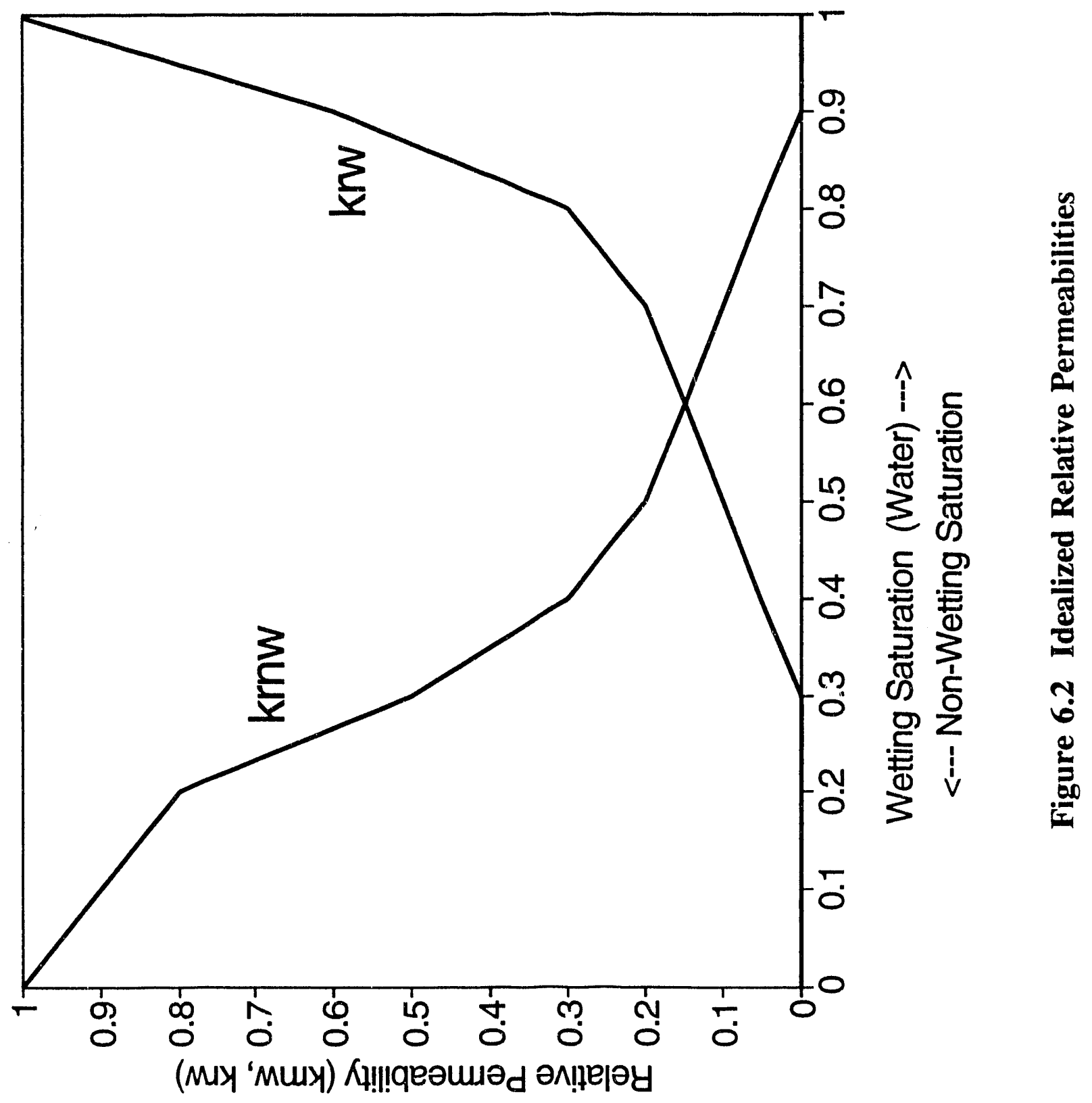


saturation of the wetting phase will be near 0.9 and the relative permeability of the non-wetting phase almost zero. However, the saturations downstream of the piston-like front are still at the values they were at the end of the production by internal pressure step. For example, $S_{w}$ might equal 0.85 and the non-wetting phase is still mobile. As these fluids are pushed by the floodfront some additional oil and gas will be produced from the core.

This process of oscillating the fluid saturations about the residual oil saturation condition provides a mechanism for enhanced oil recovery. As previously stated, the presence of a free gas phase can reduce residual oil saturation. Based on Holmgren and Morse's (1951) 6 to 10 percent of total pore volume decrease in residual oil saturation, this can represent from a fifth to a third of the residual oil in place after waterflooding which might be recovered through this mechanism.

\section{Interfacial Tension}

Biosurfactants and cosurfactants (alcohols) are produced as a byproduct of metabolism (Javaheri, et al, 1985). These chemicals lower the interfacial tension at the oil-water interface and displace oil that cannot be displaced by water alone. Capillary forces that trap residual oil in porous media are reduced by lowering interfacial tension. One of the problems of surfactant flooding is the adsorption of surfactant on the surface in the reservoir rock. This decreases the concentration of the surfactant below that required to perform the task. This problem maybe less likely to occur if the surfactant is produced in situ (Hitzman, 1991).

Melrose and Bradner (1974) defined the capillary number $\left(\mathrm{N}_{\mathrm{ca}}\right)$ to relate the magnitude of viscous forces to the magnitude of the capillary forces as: 


$$
N_{c a}=\frac{V \mu_{w}}{\sigma_{o w}}
$$

The reduction in interfacial tension caused by in situ surfactant and alcohol generation increases microscopic displacement efficency in the porous medium and reduces the residual oil saturation (Moore and Slobod, 1956). This is illustrated in Figure 6.3 (Stalkup (1984)) where the residual non-wetting phase (oil) saturation is plotted as a function of dimensionless capillary number. This result is also indicated by Stegemeier (1977).

A relationship between the capillary number after $\mathrm{i}$ treatments, $\mathrm{N}_{\mathrm{ca}}^{\mathrm{i}}$, and the capillary number before treatment, $\mathbf{N}_{\mathrm{ca}}^{\mathrm{c}}$, can be developed. This relationship is based on the definition of capillary number and permeability reduction factor (PRF). Substituting $\mu / \phi$ for $\mathrm{V}$ and comparing capillary number after the ith treatment, $\mathrm{N}_{\mathrm{ca}}^{\mathrm{i}}$ and the original capillary number before treatments, $\mathbf{N}_{\text {ca }}^{\circ}$ yields:

$$
\begin{gathered}
N_{c a}^{i}=\frac{V_{i} \mu_{w}}{\sigma_{o w}}=\frac{\frac{u_{i}}{\phi_{i}} \mu_{w}}{\sigma_{o w}^{i}} \\
N_{c a}^{o}=\frac{V_{o} \mu_{w}}{\sigma_{o w}}=\frac{\frac{u_{o}}{\phi_{o}} \mu_{w}}{\sigma_{o w}^{o}}
\end{gathered}
$$

$$
\frac{N_{c a}^{i}}{N_{c a}^{0}}=\frac{\frac{\frac{u_{i}}{\phi_{i}} \mu_{w}}{\sigma_{o w}^{i}}}{\frac{u_{o}}{\phi_{o}} \mu_{w}} \frac{\sigma_{o w}^{o}}{\sigma_{w}}
$$




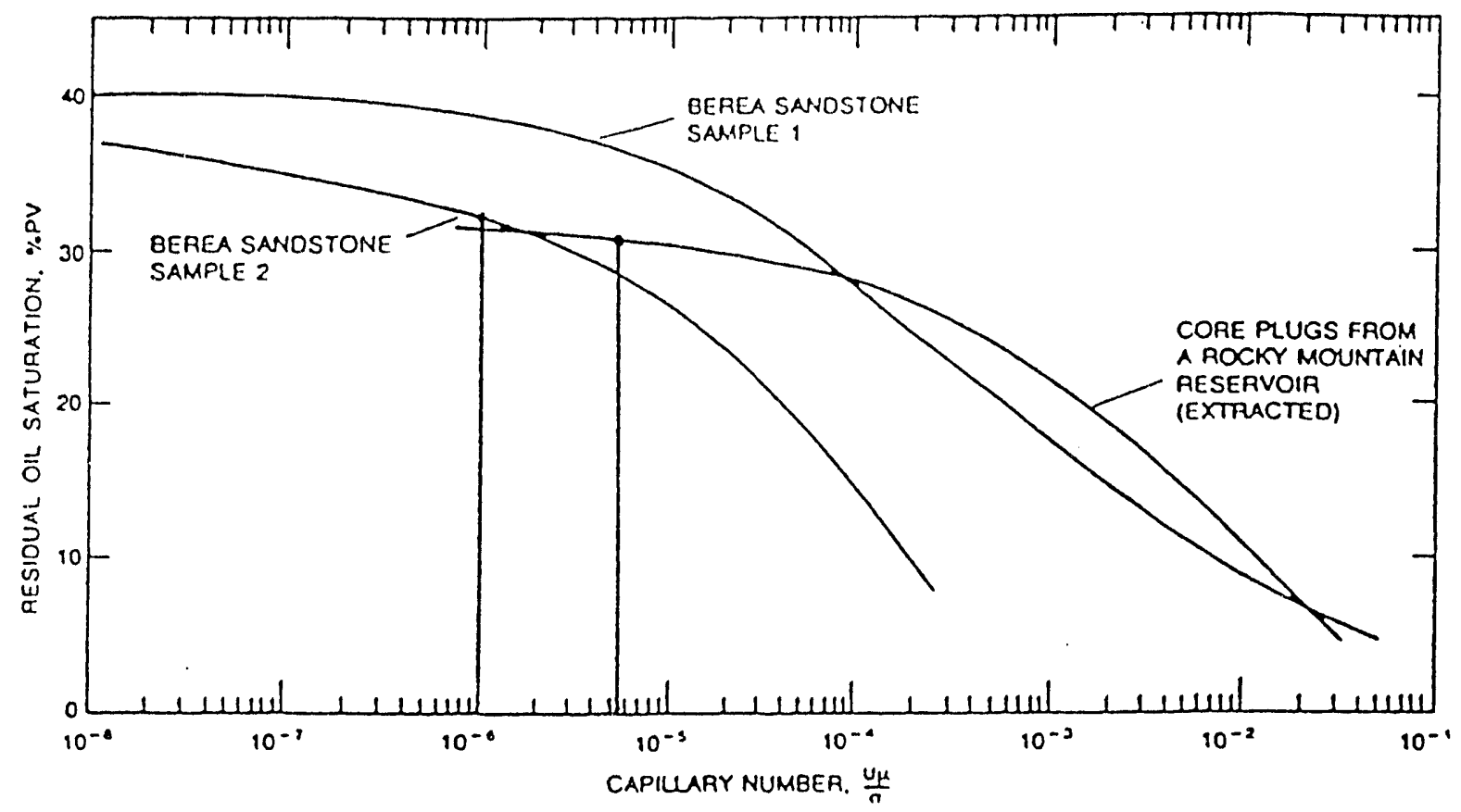

Figure 6.3 Dependence on Capillary Number (after Stalkup, 1984) 
If the viscosity of water is the same before and after the treatment (as was the case in the experiments discussed later) and the Darcy velocity, $u$, is kept constant for each treatment, the ratio of capillary numbers becomes:

$$
\left[\frac{N_{c a}^{i}}{N_{c a}^{o}}\right]=\left[\frac{\Phi_{o}}{\phi_{i}}\right]\left[\frac{\sigma_{o w}^{o}}{\sigma_{o w}^{l}}\right]
$$

A correlation of the rate of change in porosity versus the rate of change in permeability due to selective plugging by microorganisms was introduced by Civan et al. (1988) from fines migration theory:

$$
P R F=\frac{k_{i}}{k_{o}}=\left[\frac{\phi_{i}}{\phi_{o}}\right]^{3} \text {. }
$$

Substituting this expression into the capillary number ratio results in:

$$
\left[\frac{N_{c a}^{i}}{N_{c a}^{o}}\right]=\left[\frac{1}{P R F}\right]^{1 / 3}\left[\frac{\sigma_{o w}^{o}}{\sigma_{o w}^{i}}\right]
$$

Physically, two aspects of microbial activity combine to affect the value of the capillary number and the oil recovery associated with its change. First, the chemicals produced by metabolism reduce interfacial tension. This reduces the pressure drop across a phase boundary and enhances the microscopic sweep efficiency. Second, as the major pores become plugged (decrease in PRF), if the Darcy velocity, $u$, remains constant, the interstitial velocity, $\mathrm{V}$, increases in the smaller pores. These pores which were not previously flooded are then swept by this water. Some bypassed oil is produced by this process. These processes operate at the microscopic level in the core.

\section{Selective Plugging}

Almost all producing zones have variable permeability due to stratification, 
depositional environment, or diagenesis. This phenomena creates preferential flow paths for the displacing fluid (water). The invading fluid moves rapidly through the more permeable zones and more slowly in the less permeable zones. Once a continuous flow path has been established between the injection well and the production well, an increasing portion of injection water flows along this path. Thus, more oil is swept from the higher permeability zones, and less from the lower permeable portions. This reservoir heterogeneity greatly affects the recovery efficiency of the fluid displacement process. Selective plugging of these high permeability zones by microorganisms can improve sweep efficiency. Two types of microbial plugging have been identified: plugging by non-viable cells and plugging by viable microorganisms.

Merkt (1943) reported the use of non-viable microorganisms in changing the permeability. Since dead cells do not produce slime, precipitates, etc, non-viable cells can only act as particulate agents. Kalish, et al. (1964) found that viable bacteria had a greater effect on permeability reduction per bacterium injected than did non-slime-forming or non-viable bacteria. Viable microorganisms have the ability to adhere to the rock and produce an extracellular polysaccharide which covers the cells and the rock surface forming a polymer film. These actions result in more effective plugging than particulate plugging by dead cells. As the bacteria flourish and reproduce these activities exponentially increase. Thus, the cells become an effective plugging agent. Sessile bacteria occupy pore space. This effectively reduces the apparent porosity available to flowing fluids. Further, the pore surface characteristics are changed by the presence of sessile bacteria. Selective plugging represents a macroscopic change in the reservoir. 
Crawford $(1961,1962)$ was one of the first investigators to suggest the in situ growth of bacteria could rectify permeability stratification. Other investigators have concluded that viable microorganisms can penetrate porous media, reduce permeability by as much as $90 \%$, preferentially plug higher permeability zones and larger pores, and produce chemicals and gases which improve recovery. Updegraff (1983), Myers and Samiroden (1967), Jenneman, et al. (1983, 1984, 1985), Torbati, et al. (1986), Raiders et al. (1985, 1986a, 1986b), Jack et al. (1982), and Bryant and Douglas (1987) have all investigated the effects of viable microorganisms in porous media.

\subsection{Experimental Results}

Four Berea sandstone cores were used in these experiments. The cores were six inches $(15 \mathrm{~cm})$ in length and two inches $(5.1 \mathrm{~cm})$ in diameter. The oil, brine, and bacteria were all taken from the SEVVSU.

Figure 6.4 shows permeability reduction factor (PRF), cumulative incremental oil recovery factor, and gas production for core C06. C06 had an absolute permeability of $724 \mathrm{md}$ and a brine permeability after waterflood of $55 \mathrm{md}$. The porosity was $22 \%$ and the oil saturation following waterflooding, $S_{o r}$, was $29.6 \%$. At the end of the treatments, approximately $10 \mathrm{PV}$ of nutrient mixture had been injected and $84.2 \%$ of the oil in place after waterflooding had been recovered. The total gas produced was $217.6 \mathrm{ml}$ measured at ambient laboratory conditions with an average concentration of $70.2 \%$ of $\mathrm{N}_{2}$ and $25.1 \% \mathrm{CO}_{2}$. At the end of the nutrient treatments, 2.6 PV of Vassar brine were injected through the core, and the PRF value stabilized at $4.9 \%$.

In core $\mathrm{C} 06$, no significant oil and gas were recovered during the first three treatments. However, the permeability reduction factor decreased during this period. 


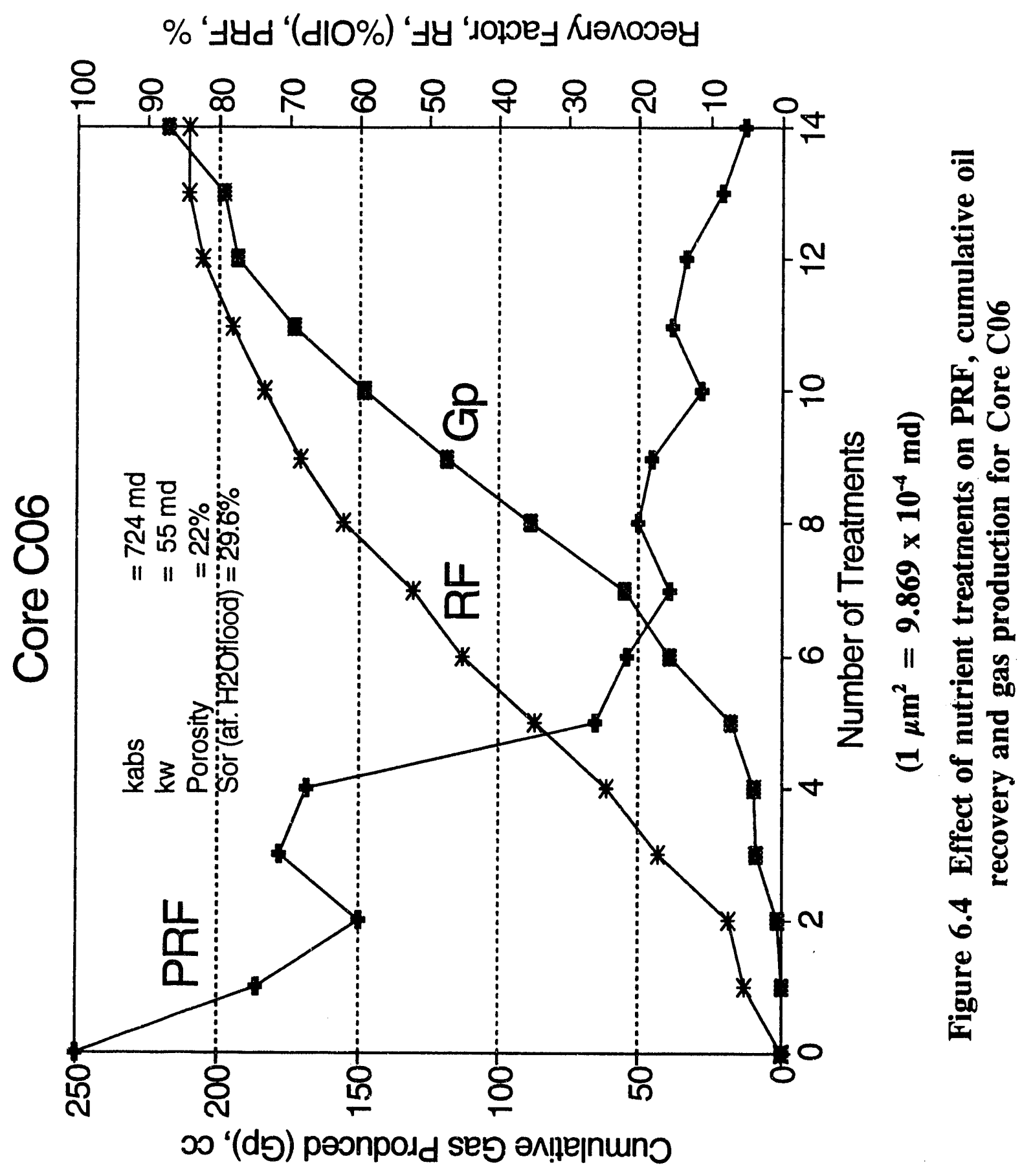


Curiously, during the period of first significant gas production (treatments 4 and 5) PRF rose briefly. After three treatments, the microorganisms had acclimated to the core environment and began to utilize the carbon sources, resulting in the production of biogenic gas and other microbial products. The surface tension of the effluent samples was found to be $52 \%$ of the injected nutrient mixture. The viscosity of the effluent was the same as the injected nutrient mixture.

Figure 6.5 shows PRF, cumulative incremental oil recovery and gas production for core C09. The absolute permeability was $219 \mathrm{md}\left(0.22 \mu \mathrm{m}^{2}\right)$ and the brine permeability after waterflood was $53 \mathrm{md}\left(0.05 \mu \mathrm{m}^{2}\right)$. The porosity was $19.2 \%$ and the $\mathrm{S}_{\mathrm{or}}$ was $30.4 \%$. At the end of eight treatments, after approximately $6 \mathrm{PV}$ of nutrient mixture had been injected, $53.9 \%$ of the oil in place after waterflooding was recovered. The cumulative gas production was $135 \mathrm{ml}$. After the final nutrient treatments, $2.2 \mathrm{PV}$ of Vassar brine were injected through this core and the PRF stabilized at $15.5 \%$. In this core, significant gas production began with the second treatment. PRF rose with this initial gas and then fell quickly with treatment 3 .

Cores $\mathrm{C} 10$ and $\mathrm{C} 11$ were initially considered marginal successes. At the conclusion of 6 and 8 treatments these cores had produced $0.0 \%$ and $8.7 \%$ of the oil remaining after waterflooding respectively. These cores had lower absolute permeablilities than cores C06 and C09. Jenneman et al. (1985) has indicated' that permeabilities less than $100 \mathrm{md}\left(0.1 \mu \mathrm{m}^{2}\right)$ appear to limit the ability of microbes to penetrate the media, proliferate, and produce byproducts. When treatments were stopped, $\mathrm{C} 10$ and $\mathrm{C} 11$ were left in an incubator. After 103 days incubation, core $\mathrm{C} 11$ had 13 psig ( $8.9 \times 10^{4} \mathrm{~Pa}$ gauge) of internal pore pressure. Treatments were resumed 


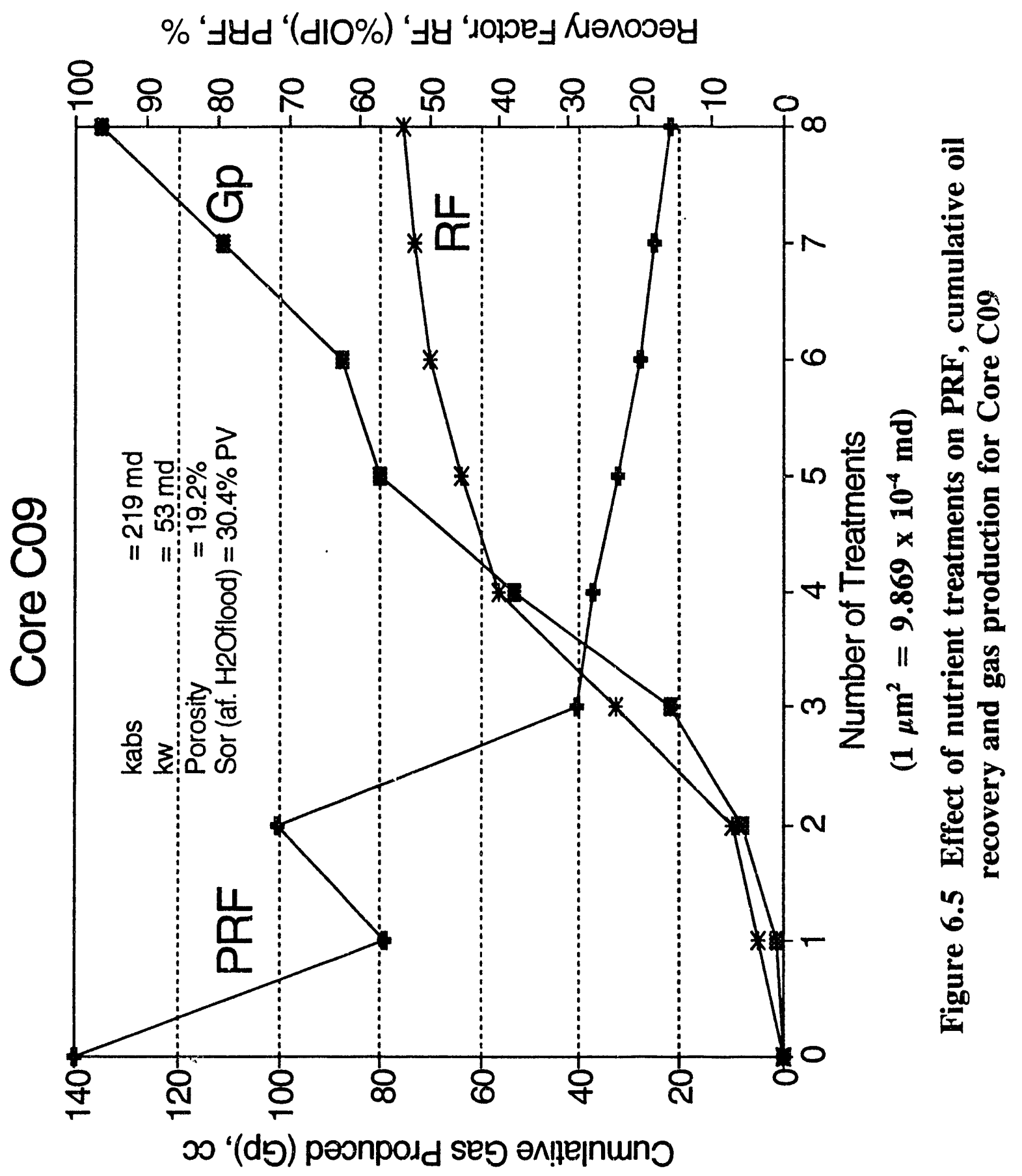


on C11 with significant profuction of gas and oil. Soon thereafter, treatments on core C10 were resumed and C10 produced significant oil and gas as well.

Core 10 had an absolute permeability of $152 \mathrm{md}\left(0.15 \mu \mathrm{m}^{2}\right)$ and a brine parmeablility after waterflood of $9.4 \mathrm{md}\left(0.01 \mu \mathrm{m}^{2}\right)$. The porosity of C10 was $19 \%$ and the $S_{o r}$ was $36.8 \%$. Because of the high pressure drop across the front half of the core prior to the long incubation, $\mathrm{ClO}$ was thought to have had facial plugging on the inlet sand face. After treatments were resumed significant oil and gas recovery were observed. After four additional treatments, bringing the total number of treatments to $10, \mathrm{C} 10$ had a recovery factor of $30.4 \%$ of oil in place after waterflooding. Gas production was $64.3 \mathrm{ml}$ and finally the PRF was $3.6 \%$. C10 had a very slight rise in PRF associated with first gas production. Results for C10 are given in Figure 6.6.

Core $\mathrm{C} 11$ had an absolute permeability of $76 \mathrm{md}\left(0.08 \mu \mathrm{m}^{2}\right)$ and a brine permeablility after waterflood of only $7 \mathrm{md}\left(0.01 \mu \mathrm{m}^{2}\right)$. The porosity of C11 was $17.2 \%$ and the $S_{\text {or }}$ was $41.3 \%$. After eight treatments, the recovery factor was $8.7 \%$. Based on the conclusions of Jenneman et al. (1985) mentioned above, low recovery of oil was expected given the low initial permeability. After the long incubation, core C11 was treated six additional times, bringing the total number of treatments to 14 , and eventually recovered $45.7 \%$ of the oil remaining after waterflooding. The final PRF was $5.7 \%$. Once again, PRF rose with the first two treatments in which significant gas was produced, C11 results are presented in Figure 6.7 .

\subsection{Discussion of Results}

For Cores C06 and C09, as the permeability reduction factor started to decrease below $25 \%$, oil recovery increased substantially. This suggests that microorganisms had 


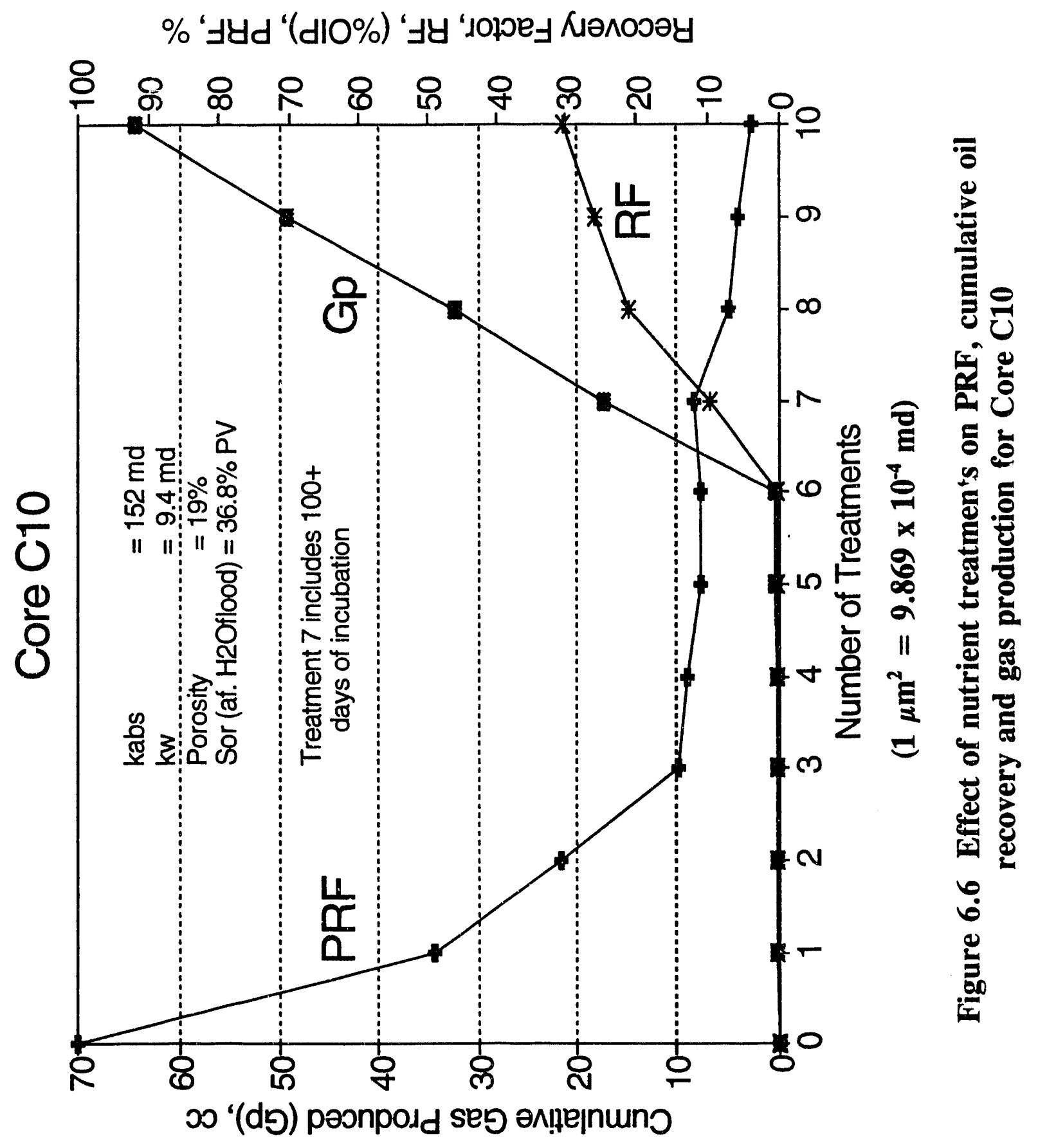




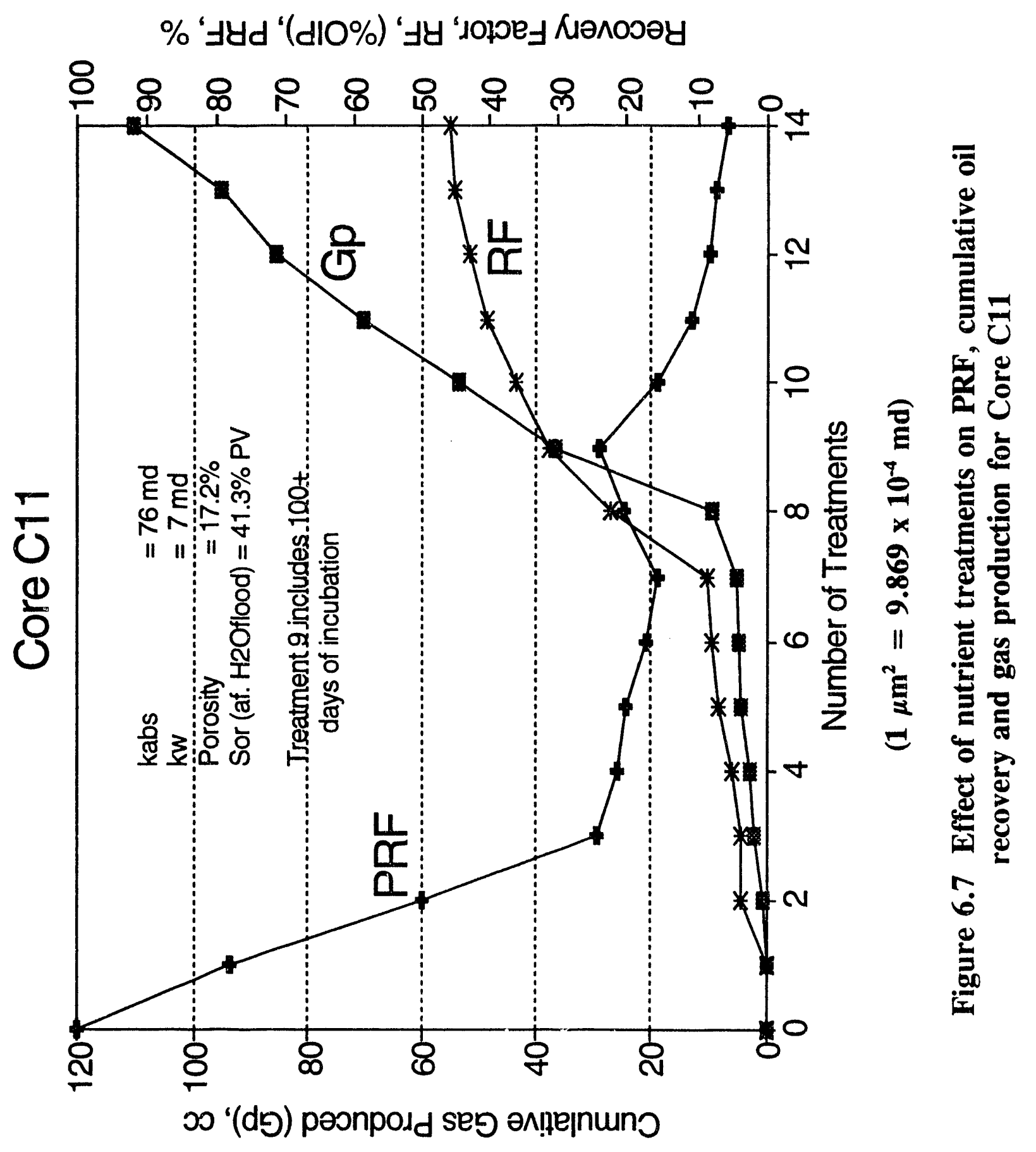


preferentially plugged the larger pores within the core and diverted the flow of the brine to the smaller pores (unswept regions) where more oil was trapped, apparently increasing the displacement efficiency of the flood. In C06, carbon and nitrogen analyses were also performed. $\mathrm{CO}_{2}, \mathrm{~N}_{2}$, acetate, butyrate and ethanol were detected in the effluent samples. The results show that microorganisms proliferated and produced metabolic products that helped recover more oil.

Microscopic displacement efficiency also increased by changes in the chemical composition of the fluid. One of the products, ethanol, is soluble in the oil. Ethanol production can increase microscopic displacement efficiency by decreasing the viscosity of oil and reducing interfacial tension. The surface tensions of the effluent urine samples were lower than the initial nutrient samples. This suggests that biosurfactant was also produced. Thus, microbial processes led to reductions of the oil viscosity and surface tension which increased oil mobility and capillary number.

For core C06, using a stabilized PRF of $5 \%$ and a surface tension $52 \%$ of original value (results following 14 treatments) and assuming that the reduction in the interfacial tension between oil and water was the same as the reduction in surface tension, the change in the capillary number ratio for core $\mathrm{C} 06$ is

$$
\left[\frac{N_{c a}^{i}}{N_{c a}^{o}}\right]=\left[\frac{1}{0.05}\right]^{1 / 3}\left[\frac{1}{0.52}\right]=5.2
$$

The capillary number after treatment 14 was 5.2 times the initial capillary number. From Figure 6.3, assuming $\mathrm{N}_{\mathrm{ca}}^{\circ}=10^{-6}$, the increase of 5.2 in capillary number could have caused a decrease in residual oil saturation of as much as $4 \%$ and the increase in capillary number could explain recovery of $6 \%$ to $13 \%$ of the oil left after waterflooding. 
A time lag appears to exist with respect to microbial activity. This may be roughly correlated to absolute permeability. Initial microbial activity is low because of the low initial cell population. Once cell populations increase, significant microbial activity occurs. In lower permeability cores, the time required for the induced bacteria to permeate the core and establish a significant population increases. Cores $\mathrm{C} 06$ and C09, with higher absolute permeability, began to produce gas and oil within three treatments of experiment initiation. Hindsight indicates that treatments of $\mathrm{C} 11$ never should have been stopped. The necessary seed population appears to have developed after seven treatments. Core $\mathrm{C} 10$ appears to have needed some part of the $100+$ days of incubation to achieve this necessary seed population. Jenneman and Clarke (1992) suggest that the existence of a gas headspace can promote bacterial growth. Carbon dioxide in solution increases acidity and inhibits metabolism. If this $\mathrm{CO}_{2}$ is able to enter the gas phase, the acidity of the aqueous phase decreases and promotes growth. Significant metabolic activity was not observed until after the first gas production and probable existence of a gas saturation in the cores.

Significant microbial activity was associated first with increases in pore pressure and then with significant gas production. It should be noted that PRF dropped with the first treatment in all cases and preceded the advent of either much pressure increase or gas production. Whether this is the result of particulate piugging by the cells or some metabolic activity within the core that has no external manifestation is not known.

In addition, currently no predictable explanation exists for the brief increase in brine permeablility associated with the first significant gas production. This period lasts only one or two treatments and the magnitude of the permeability recovery is not 
strongly arsociated with any core characteristic. After the first few treatments with significant gas production the PRF again begins to decrease. The phenomena appears similar to "bridge-breaking" in particulate plugged porous media.

\subsection{Conclusions}

Increases in oil recovery from Berea sandstone cores were accompanied by production of biogenic gas, acids, ethanol, and biomass of bacteria collected from well 1A-9 of SEVVSU. The production of biogenic gas decreased the residual oil saturation due to relative permeability changes associated with the creation of a free gas phase in the cores. This can explain the recovery of up to a third of the oil left after waterflooding. The increase in capillary number can explain up to $13 \%$ of additional oil recovery from core $\mathrm{C} 06$. The above mechanisms were active in the core experiments but do not fully explain the the additional oil production observed from the cores. The contributions to recovery of other mechanisms, such as selective pore plugging, have not yet been quantified. There may be other active mechanisms that have not yet been identified.

A successful MEOR core flood has been performed in a core with $76 \mathrm{md}(0.08$ $\left.\mu \mathrm{m}^{2}\right)$ absolute permeability. Previous studies indicated $100 \mathrm{md}\left(0.1 \mu \mathrm{m}^{2}\right)$ as the lower limit on microbial core flooding.

A time lag exists before significant gas and oil production. Longer lag times are associated with the target cores low absolute permeability. The time lag may be associated with a period of acclimatization of the bacteria to the core environment. Significant growth was observed to follow first gas production. The existence of a headspace may affect the time lag also. 


\subsection{Nomenclature}

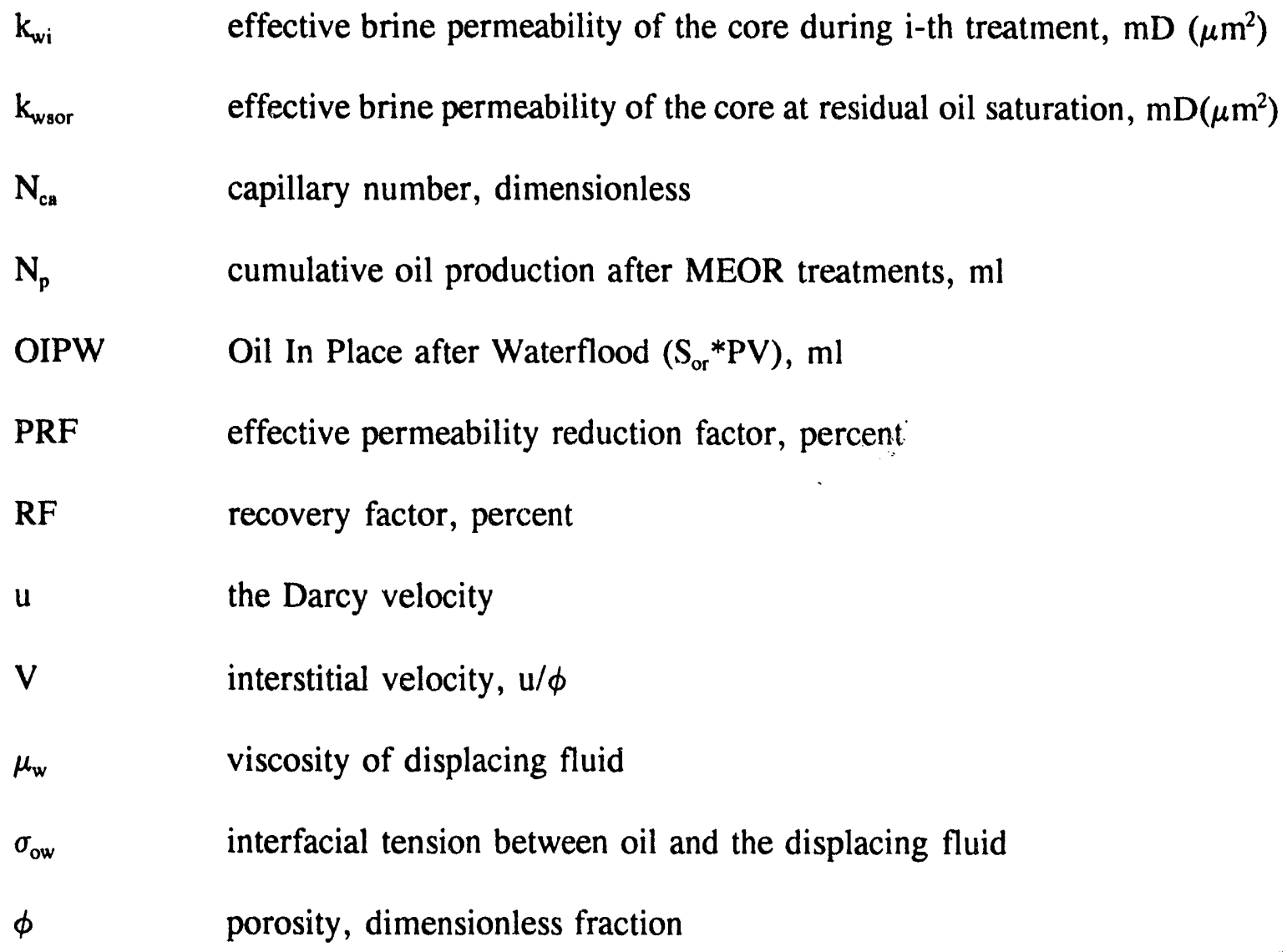




\section{Chapter 7. Operations and Production}

\subsection{Surface Facilities}

The injection well, 7-2, was recompleted with a packer run on a 2.5 inch $(6.35$ $\mathrm{cm}$ ) tubing string set immediately above the perforations in the Vertz sandstone. The well was cleaned and acidized to restore injectivity. The well was returned to injection December 13, 1990, with an injection pressure of $653 \mathrm{psig}\left(4.4 \times 10^{6} \mathrm{~Pa}\right.$ gauge $)$ at the surface. A 30 inch $(76 \mathrm{~cm}), 125$ micron Nowata filter was installed on the injection well to remove iron sulfide particulate matter from the injected brine. Initial injection rate was around $170 \mathrm{bbl}$ per day $\left(27 \mathrm{~m}^{3} / \mathrm{d}\right)$. At the injection rate of about $300 \mathrm{bpd}(47.7$ $\left.\mathrm{m}^{3} / \mathrm{d}\right), 750 \mathrm{psig}\left(5.2 \times 10^{6} \mathrm{~Pa}\right.$ gauge) surface pressure was expected.

Halliburton Services Research Center loaned the project a refurbished Polyflood injection pump unit for the field pilot study. The unit was a self contained, skid mounted, 440 volt three-phase motor with variable eddy current drive connected to a triplex pump. The pump was able to pump up to 6 gallons/minute $(231 / \mathrm{min})$ of the nutrient mixture into the flowline. The expected maximum injection pressure of $800 \mathrm{psi}$ $\left(5.5 \times 10^{6} \mathrm{~Pa}\right)$ and mixture viscosity of $20 \mathrm{cp}(0.02 \mathrm{~Pa} . \mathrm{s})$ were well within the pump's capacity. The skid was equipped with two 30 inch $(76 \mathrm{~cm})$ filtration units downstream of the triplex pump. During the study 125 micron filters were used. The filters were connected in parallel so that they could be used individually. This allowed a filter element to be changed without interrupting injection. A 50 psi $\left(3.4 \times 10^{5} \mathrm{~Pa}\right)$ pressure drop across the filters indicated the need to change the filter element. During the injection, the filter elements were changed as needed. This proved to be a rarity. Only 
five filters were changed in the course of the pilot injection. These changes were often a matter of maintenance rather than necessity.

An overall plan of the injection well facility is shown in Figure 7.1. The Southeast Vassar Vertz Sand Unit triplex pump is the existing injection pump for the field. This pump provided brine which was combined with the nutrient mixture during treatment injection and injected the brine spacers between treatments of the nutrient mixture. Two $500 \mathrm{bbl}\left(79.5 \mathrm{~m}^{3}\right)$ "frac" tanks were used to mix the brine water, molasses, and ammonium nitrate and store the nutrient mixture during injection. One of the tanks served as a storage facility for a mixture of ammonium nitrate and brine water. This mixture was supplied to the second tank as needed. The second tank provided the molasses-rich nutrient mixture to the Halliburton pump and contained a mixture of molasses, the ammonium nitrate-brine mixture, and additional brine to approximately produce a $46 \%$ molasses, $46 \%$ brine water, $8 \%$ ammonium nitrate mixture. A small pump constantly circulated the molasses-rich mixture during nutrient injection to maintain uniform consistency. A "Y-trap" strainer was used to remove large particulate matter from the mixture. The Halliburton Polyflood pump was used to inject the fluid into the injection well flow line. As shown on the figure, flow from the Halliburton pump and the SEVVSU triplex pump combined in the flow line. The total fluid volume injected was metered at the well head. The nutrient-rich fluid injection was metered immediately before the injection point. The surface injection pressure was also monitored. Prior to injection, the nutrient-rich fluid was pumped through two 30 inch (76 cm) 125 micron filters. After mixing with injected brine from the SEVVSU pump in the Well 7-2 tubing, the nutrient concentration was about $20 \%$ molasses $/ 3.5 \%$ 


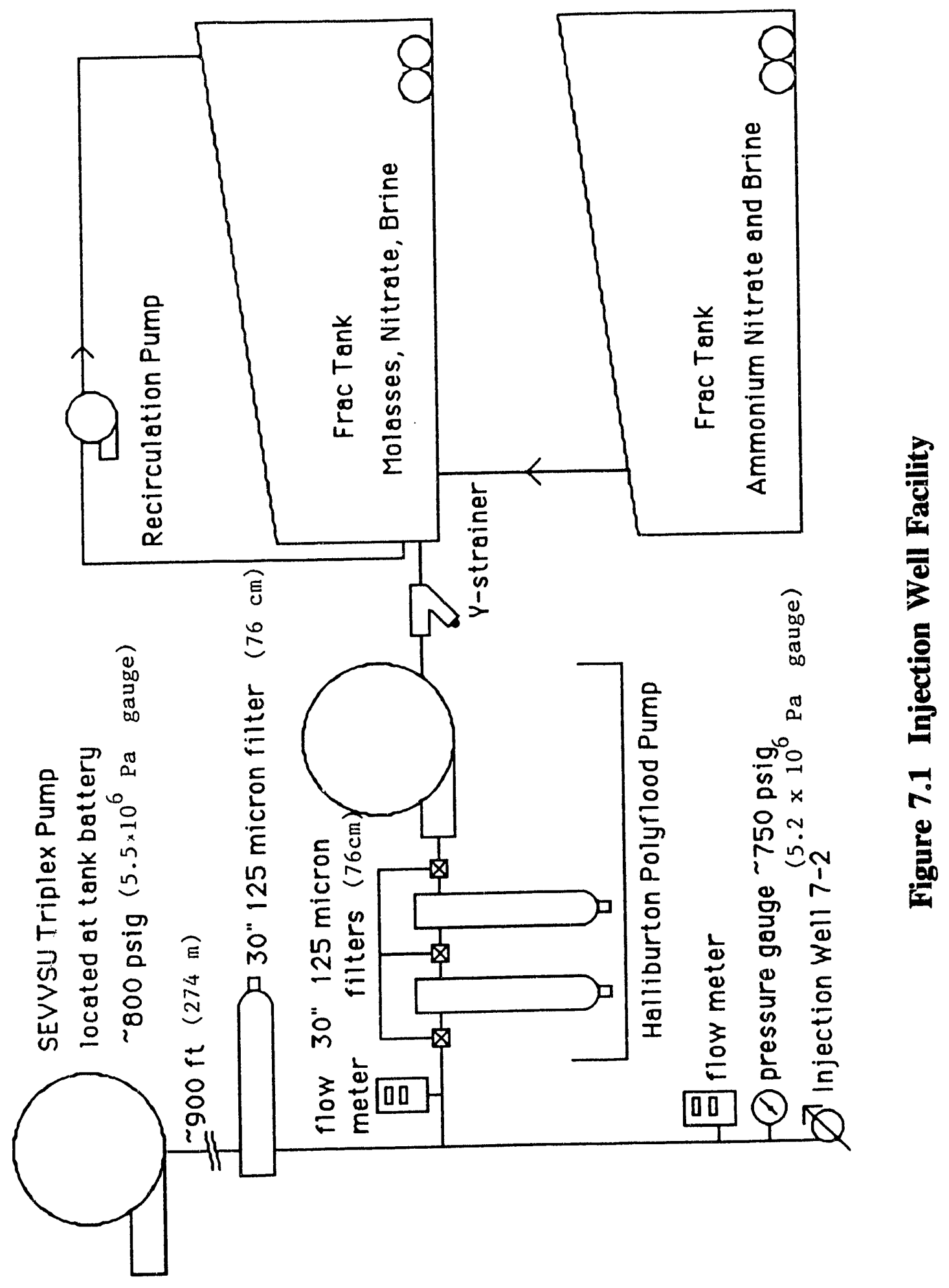


ammonium nitrate at the perforations.

Ammonium nitrate was delivered as dry "prills" to location by bulk ti uck. The prills were blown into the first "frac" tank and dissolved in $300 \mathrm{bbl}\left(47.7 \mathrm{~m}^{3}\right)$ of Vassar brine. This solution was supplied to the second "frac" tank as needed. Molasses was delivered to location by insulated tank truck. The molasses truck's unloading pumps were able to completely unload the truck and avoided the need to heat the molasses or add viscosity reducers to it. The mixtures were circulated during delivery until the combined fluids were of uniform consistency.

Figure 7.2 is a schematic of the field pilot gathering system. Wells 5-1, 5-2, and 7-1 are the producing wells. These wells were cleaned and sucker rod pumps and pumping units installed. Produced fluids were returned to the tank battery through the flowlines that served these wells when they were injectors. Fluids were combined at the manifold. Gauges to measure surface tubing pressure along with meters to record total fluid volume were installed on wells 5-1 and 7-1. Well 5-2, located in the middle of a wheat field and with some accessibility problems, had its meter and gauge located at the manifold. After the last of the nutrients were injected, meters on the 5-1 and 7-1 were also moved to the manifold for monitoring convenience. The SEVVSU triplex pump, injection line to the 7-2, and the nutrient treatment surface facilities are also shown on Figure 7.2.

Figure 7.3 shows the tank battery facilities. The three producing wells' flowlines were connected to a manifold at the tank battery. At the manifold, each well's flow could be isolated so that a portable sampling separator could determine individual well water/oil ratios. Produced fluids from the pilot wells were commingled and separated 


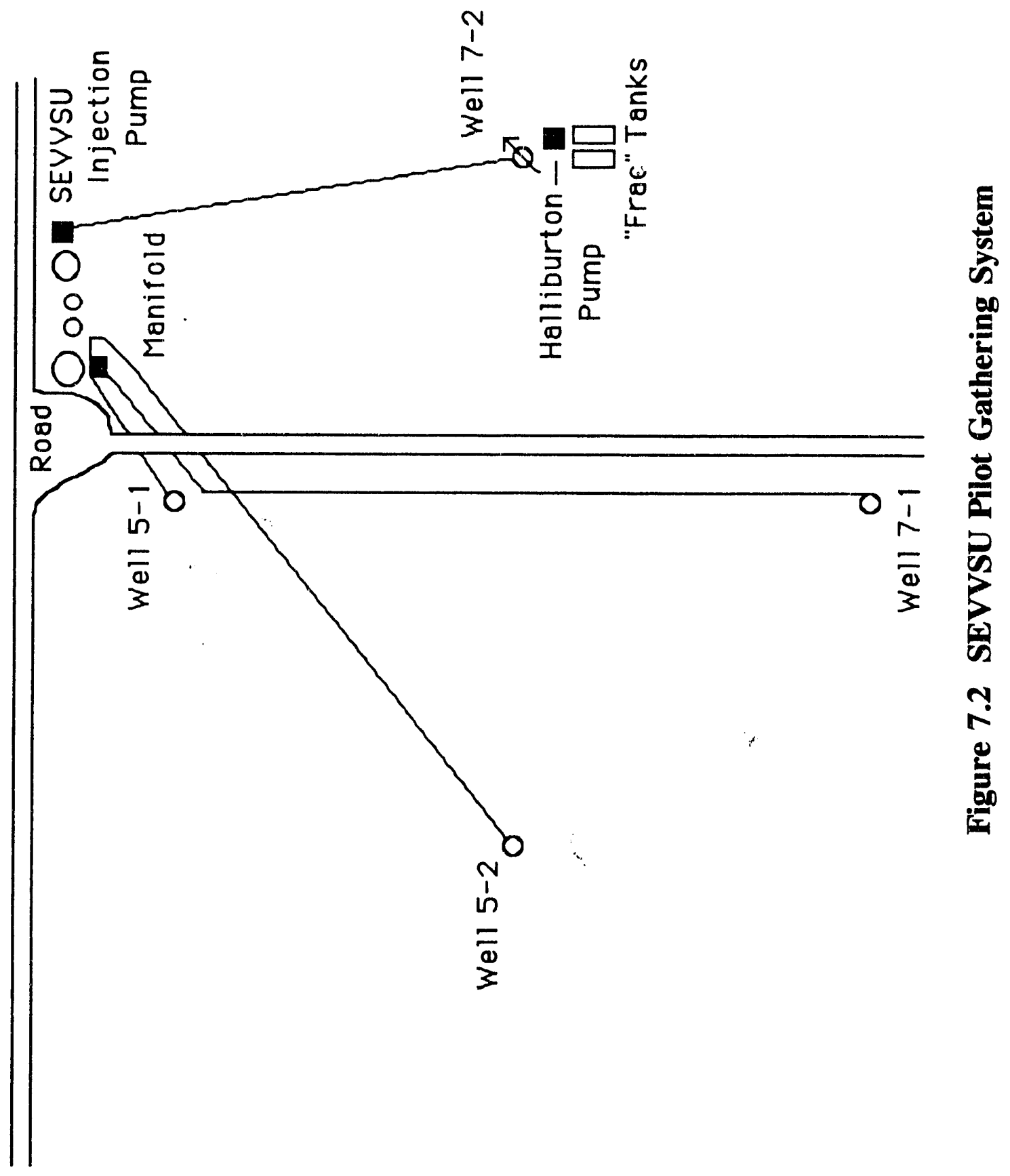




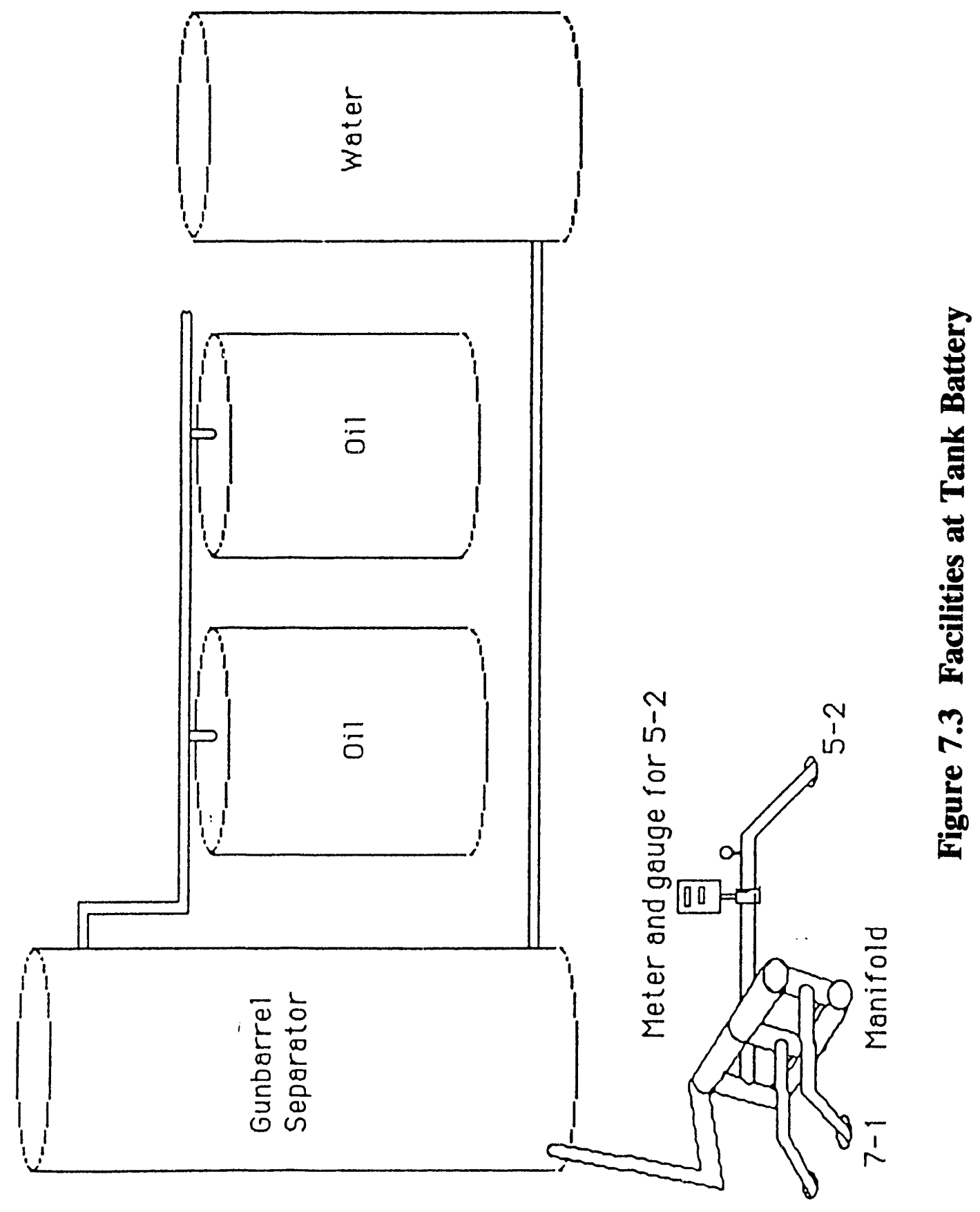


in a gunbarrel separator dedicated to the pilot wells. Oil produced from the pilot wells was stored in two oil tanks separate from the field production to measure the tertiary oil produced. Produced water was returned to the main water storage tanks for reuse in the SEVVSU water flood.

\subsection{Field Operations}

Field activities associated with the Microbial Field Pilot Study are presented as a general chronology. Complete discussion of the various tests performed in the field are given in appropriate sections of this report. Each event and its results, if they affected later operations in the field, are presented.

In November and December, 1990, the four pilot wells were converted from inactive injectors to either active producers for the 5-1, 5-2, and 7-1 or an active injector in the case of the 7-2. In late December, Well 7-2 began to receive injection water. The production wells were not produced at this time in preparation for a pressure interference test between the 7-2 and the three production wells.

In late February, 1991, a pressure falloff test was performed on Well 7-2. Simultaneously, the pressure transients at Wells 5-1, 5-2, and 7-1 were monitored and evaluated as a pressure interference test. At the completion of the test, Well 7-2 was returned to active injection and flow was initiated from the three production wells.

Production was volumetrically balanced in the pilot area. Injection into Well 7-2 was restricted to $300 \mathrm{bpd}\left(47.7 \mathrm{~m}^{3} / \mathrm{d}\right)$ injection, and the three production wells were allowed to flow at 100 bpd $\left(15.9 \mathrm{~m}^{3} / \mathrm{d}\right)$. Sufficient pressure was available to produce this amount from each well without engaging the pumping units.

On April 11, 1991, sodium fluorescein tracer was injected into Well 7-2. The 
tracer was detected fourteen days after injection at Well 1A-9. The increase in subsurface pressure caused by the injection of water into Well 7-2 had affected the injection at Wells 7-3 and 7-5. Both wells were receiving much less water than before injection began in the 7-2. Well 7-2 had become the principle injector in this area of the field for the line drive waterflood. Thus, tracer was carried by the injection brine to the northeast.

In June, 1991, changes were made in the field operations to redirect the flow of water injected into Well 7-2 toward the west. Injection rates for the 7-3 and 7-5 were increased after each well received a near well bore clean-out treatment. Production in the three pilot production wells, Wells 5-1, 5-2, and 7-1, was increased to 150 bpd (23.8 $\left.\mathrm{m}^{3} / \mathrm{d}\right), 180 \mathrm{bpd}\left(28.6 \mathrm{~m}^{3} / \mathrm{d}\right)$, and $300 \mathrm{bpd}\left(47.7 \mathrm{~m}^{3} / \mathrm{d}\right)$, respectively. The rates were chosen based on an assumed preferential flow path from the 7-2 to the 7-1 and within the limits of the adjustable settings available on the various pumping units installed on the wells.

On August 5, 1991, sodium fluorescein tracer was again injected into Well 7-2, and was detected at Well 1A-9 eighteen days after injection. The change in injection and production rates were not sufficient to change the direction of flow in the field. this showed that a high transmissivity flow channel existed between the region of the 7-2 and the southwest part of the $1 \mathrm{~A}$ tract. The $1 \mathrm{~A}-1,1 \mathrm{~A}-5$, and $1 \mathrm{~A}-9$ were included in weekly sampling during the remainder of the field pilot test. Well 1A-7, which produces only a trace of water, was available for sampling only when the portable separator was connected. Only one to three samples per month were available for the 1A-7. Plugging of the 7-2 to 1A-9 channel was adopted as an additional Microbial Field Pilot Study goal. 
On August 26, 1991, 41,500 lbs. (18.8 tonnes) of ammonium nitrate were delivered to location and combined with $300 \mathrm{bbl}\left(47.7 \mathrm{~m}^{3}\right)$ of Vassar brine to produce an $18.7 \%$ solution of ammonium nitrate. On August $29,38 \mathrm{bbl}\left(6.0 \mathrm{~m}^{3}\right)$ of this mixture was injected into the 7-2 to reduce sulfide concentrations (Jenneman, et al, 1986) and to stimulate nitrate-using bacteria in the formation. On September 26, 1991, twelve tons (11 tonnes) of cattle feed grade molasses were delivered and combined with a portion of the nitrate mixture and additional brine to produce $113 \mathrm{bbl}\left(18.0 \mathrm{~m}^{3}\right)$ of the nutrient mixture. This was injected in three treatments of approximately $37.7 \mathrm{bbl}\left(6.0 \mathrm{~m}^{3}\right)$ each on the September 29, October 1, and 4, respectively. On October 7, 1991, injection into the 7-2 well was stopped and the initial incubation period began to allow a large bacterial population to develop in the pilot area. Production from the three pilot production wells continued to maintain a low pressure region to the west. Laboratory growth experiments had indicated the nutrients would be consumed in 30 days.

Original injection plans were made in expectation of low injection rates because of increased viscosity of the injected fluids. Mixtures of molasses and water indicated a viscosity of $20 \%$ molasses to be around $4 \mathrm{cp}(0.004 \mathrm{~Pa} . \mathrm{s})$. However, the ammonium nitrate and high salt content brine caused a reduction in viscosity of the injected mixture to values near those of the SEVVSU injection brine. The higher density of the nutrient rich injection stream increased the hydrostatic gradient in the well bore. Instead of an expected decrease in injection rate, an increase in rate was observed. Later treatments were adjusted to maintain a $300 \mathrm{bpd}\left(47.7 \mathrm{~m}^{3} / \mathrm{d}\right)$ injection rate.

On November 7th, 1991, twenty-five tons (22.7 tonnes) of molasses were delivered to location and Well 7-2 was returned to active injection. Following the 
previous protocol, the molasses was combined with ammonium nitrate and brine water and injected in 8 treatments between November 9th and November 25. On December 3 , another 25 tons (22.7 tonnes) of molasses were delivered and nutrients were injected in 9 treatments between December 4 and 20. A list of injections and amounts of molasses and ammonium nitrate injected is given in Table 7.1.

With a large bacterial population presumably in place in the areas flooded by injected nutrients, nutrient consumption was considered to be high enough that a second incubation period was not necessary. In mid-January carbohydrates in a concentration of $100 \mathrm{mg} / \mathrm{l}$ were discovered in the effluent brine of $1 \mathrm{~A}-9$. To limit production of nutrients into the water storage tanks, injection was stopped at Well 7-2. This short incubation period served as an opportunity to prepare for a second interwell pressure interference test. All four pilot wells were shut-in. A pressure falloff test was performed on the 7-2 when injection was stopped. Wells 5-1, 5-2, and 7-1 were shut-in individually with sonic fluid level surveys performed to provide a pressure build-up test on each well. By February 6th, pressures in the pilot area had stabilized with fluid to the surface of the three production wells. To initiate the interference test, fluid was injected into the $7-2$ at the constant rate of $100 \mathrm{bbl}$ per day $\left(15.9 \mathrm{~m}^{3} / \mathrm{d}\right)$. The surface pressures were monitored on all of the pilot production wells. The decrease in produced water in the field by the shut-in of the pilot production wells had also resulted in the shut-in of the 7-5 well. This allowed a pressure interference test of the 7-5 with respect to the pressure pulse at the 7-2 to be performed. The production wells were returned to service February 10, 1992, and a final tracer test initiated on February 18th.

Rates were increased on the pilot production wells in mid-April, 1992. This was 
Table 7.1 Nutrient Injection History

\begin{tabular}{||c|c|c|c|c|c||}
\hline Date & $\begin{array}{c}\text { Injection } \\
\text { Rate } \\
\text { (bpd) }\end{array}$ & $\begin{array}{c}\text { Surface } \\
\text { Injection } \\
\text { Pressure } \\
\text { (psig) }\end{array}$ & $\begin{array}{c}\text { Volume } \\
\text { Injected } \\
\text { (bbl) }\end{array}$ & $\begin{array}{c}\text { Molasses } \\
\text { Injected } \\
\text { (tons) }\end{array}$ & $\begin{array}{c}\text { Ammonium } \\
\text { Nitrate } \\
\text { Injected } \\
\text { (tons) }\end{array}$ \\
\hline \hline $8 / 29 / 91$ & 400 & 800 & 38 & - & 2.7 \\
\hline $09 / 27 / 91$ & 502 & 800 & 38 & 4.0 & 1.2 \\
\hline $10 / 01 / 91$ & 502 & 790 & 35 & 3.7 & 1.1 \\
\hline $10 / 04 / 91$ & 544 & 800 & 40 & 4.2 & 1.2 \\
\hline $11 / 09 / 91$ & 292 & 670 & 29 & 3.1 & 0.9 \\
\hline $11 / 11 / 91$ & 287 & 684 & 28 & 3.0 & 0.8 \\
\hline $11 / 13 / 91$ & 278 & 697 & 30 & 3.2 & 0.9 \\
\hline $11 / 15 / 91$ & 303 & 694 & 23 & 2.4 & 0.7 \\
\hline $11 / 17 / 91$ & 292 & 714 & 30 & 3.2 & 0.9 \\
\hline $11 / 20 / 91$ & 285 & 687 & 28 & 3.0 & 0.8 \\
\hline $11 / 22 / 91$ & 317 & 711 & 25 & 2.7 & 0.8 \\
\hline $11 / 24 / 91$ & 312 & 687 & 42 & 4.5 & 1.3 \\
\hline $12 / 04 / 91$ & 252 & 713 & 30 & 3.0 & 0.9 \\
\hline $12 / 06 / 91$ & 252 & 711 & 30 & 3.0 & 0.9 \\
\hline $12 / 08 / 91$ & 249 & 681 & 30 & 3.0 & 0.9 \\
\hline $12 / 10 / 91$ & 252 & 672 & 30 & 3.0 & 0.9 \\
\hline $12 / 12 / 91$ & 257 & 662 & 30 & 3.0 & 0.9 \\
\hline $12 / 14 / 91$ & 255 & 672 & 29 & 2.9 & 0.9 \\
\hline $12 / 16 / 91$ & 296 & 668 & 29 & 2.9 & 0.9 \\
\hline $12 / 18 / 91$ & 266 & 660 & 29 & 2.9 & 0.9 \\
\hline $12 / 20 / 91$ & 284 & 735 & 10 & 1.0 & 0.3 \\
\hline
\end{tabular}

$$
\begin{array}{ll}
\left(\mathrm{m}^{3} / \mathrm{d}=\mathrm{bpd} * 0.1590\right) & (\mathrm{Pa} \text { guage }=\mathrm{psig} * 0.6895) \\
\left(\mathrm{m}^{3}=\mathrm{bbl} * 0.1590\right) & \text { (tonnes }=\text { tons } * 0.9072)
\end{array}
$$


in expectation of increased oil production because of increased pressure differential across the pilot area. Fluid production increased to 190, 290, and 380 bpd (30.2, 46.1 and $60.4 \mathrm{~m}^{3} / \mathrm{d}$ ) from Wells $5-1,5-2$, and 7-1, respectively. Production was stopped at Well 5-2 on May 14, 1992. Production from Well 7-1 was stopped on June 1, 1992. Production from Well 5-1 was stopped on July 31, 1992.

Figure 7.4 is a plot of daily injection rate into Well 7-2 from July, 1991 through June, 1992. The values plotted prior to July, 1991, are individual values from monthly reports. Injection at Well $7-2$ was generally maintained at $300 \mathrm{bpd}\left(47.7 \mathrm{~m}^{3} / \mathrm{d}\right)$. The high injection rates associated with the first nutrient injections represent the peaks which immediately precede the shut-in period of incubation. The shut-in period after the detection of carbohydrates at Well 1A-9 is also clearly shown. The brief period of injection at 100 bpd $\left(15.9 \mathrm{~m}^{3} / \mathrm{d}\right)$ which follows the carbohydrate directed shut-in is the time of the final pressure interference test. At the end of April, 1992, the field was returned to operation at the discretion of the operator. Injection into Well 7-2 was slowly reduced thereafter.

\subsection{Production Effects}

The first tertiary oil from the pilot area was produced in February, 1992. By May 12,1992, 22.5 barrels $\left(3.6 \mathrm{~m}^{3}\right)$ of tertiary oil had been produced from the pilot wells. Fluid sampling indicates that Well 5-1 is the most likely source of the oil although the presence of oil was observed in the 7-1. When Well 5-1 was first produced in April, 1991 , it produced $2 \mathrm{bpd}\left(0.3 \mathrm{~m}^{3} / \mathrm{d}\right)$ of oil. In June, 1991, this fell to $1 \mathrm{bpd}\left(0.2 \mathrm{~m}^{3} \mathrm{~d}\right)$ of oil. By August, 1991, oil production from Well 5-1 had ceased. From August, 1991, through April, 1992, oil production from the pilot wells was collected in a separate oil 


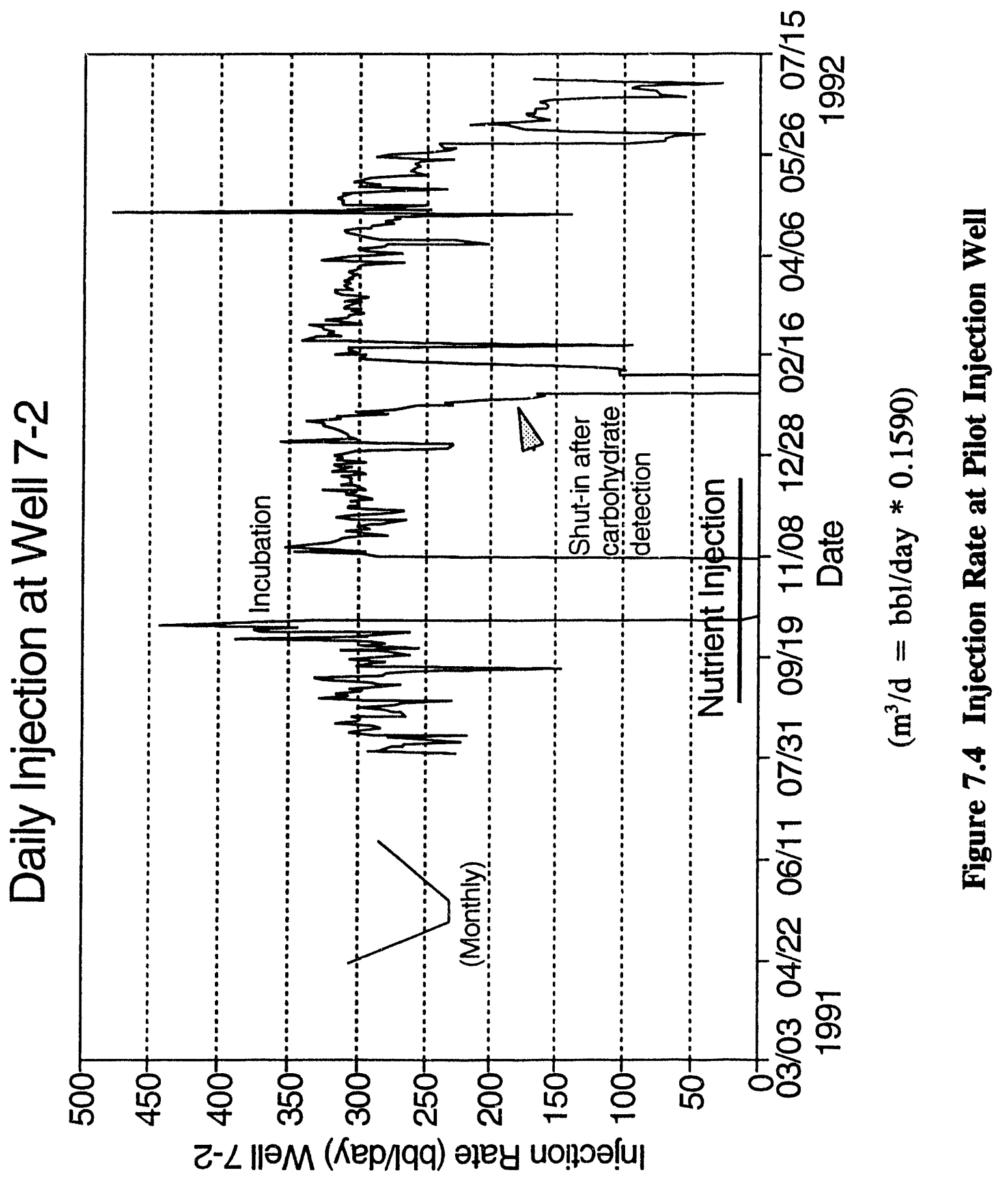


tank from the production in the rest of the field. A cumulative tertiary oil production of 22.5 barrels $\left(3.6 \mathrm{~m}^{3}\right)$ was recovered during this period. Oil was accumulating in the annulus of the wells and was produced whenever well maintenance operations caused the annulus fluids to be exchanged. This accounts for the stepwise nature of this oil production in Figure 7.5. After April, 1992, pilot oil production was commingled with SEVVSU field production and the pilot well fluid production rates increased. Fluid production from Wells 5-2 and 7-1 was stopped May, 12, 1992, and June 1, 1992, respectively. A June production test of Well $5-1$ indicated $1 \mathrm{bpd}\left(0.2 \mathrm{~m}^{3} / \mathrm{d}\right)$ of oil production. It is estimated that 60 barrels $\left(9.5 \mathrm{~m}^{3}\right)$ of additional oil was produced from Well 5-1 between June 1 and July 31, 1992. This additional oil is depicted in Figure 7.5 .

The production behavior of the $1 \mathrm{~A}-9$ also indicated an effect of the nutrient treatments. Figure 7.6 is a plot of production rate (bbl/day) vs. time for the $1 \mathrm{~A}-9$. The solid line indicates the nutrient injection period. All nutrients were injected by December 20, 1991. Two aspects of Well 1A-9's production behavior changed after nutrient injection. First, the average total fluid production rate rose approximately 80 bpd (12.7 $\mathrm{m}^{3} / \mathrm{d}$ ) after nutrient injection. Second, the total fluid production rate of the $1 \mathrm{~A}-9$ began to fluctuate between 100 to $250 \mathrm{bbl}$ per day $(15.9$ to $39.7 \mathrm{~m} / \mathrm{d})$ in early November, 1991. The initial rise in production rate was also associated with a decrease in oil production rate. As the total fluid rate from Well 1A-9 continued to fluctuate, the average oil production rate returned to the level observed before this behavior change. Figure 7.7 is a plot of water fraction of produced fluids from Well 1A-9. The erratic lature of 1A-9's production is also indicated in this figure. Generally, when total fluid 


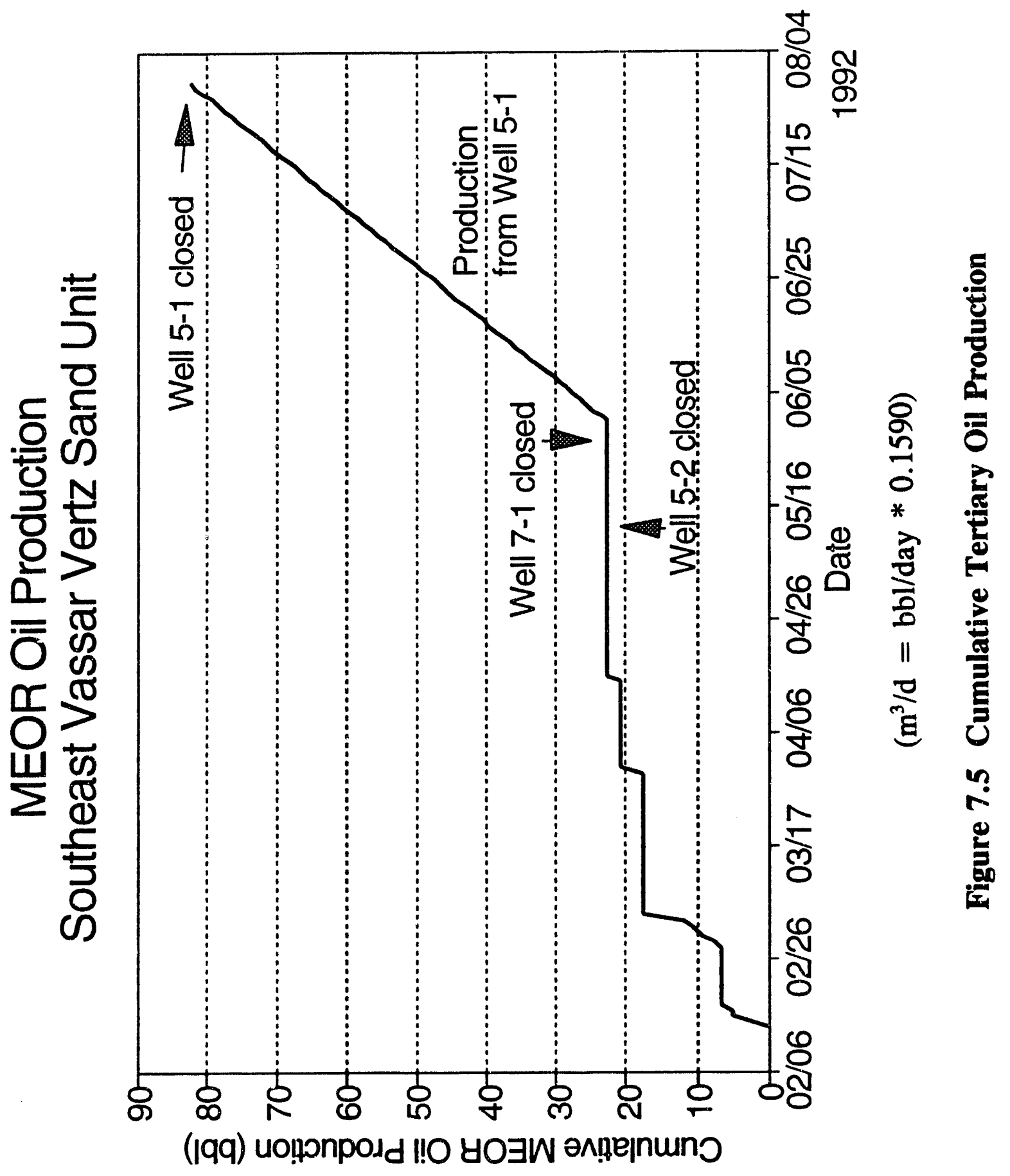




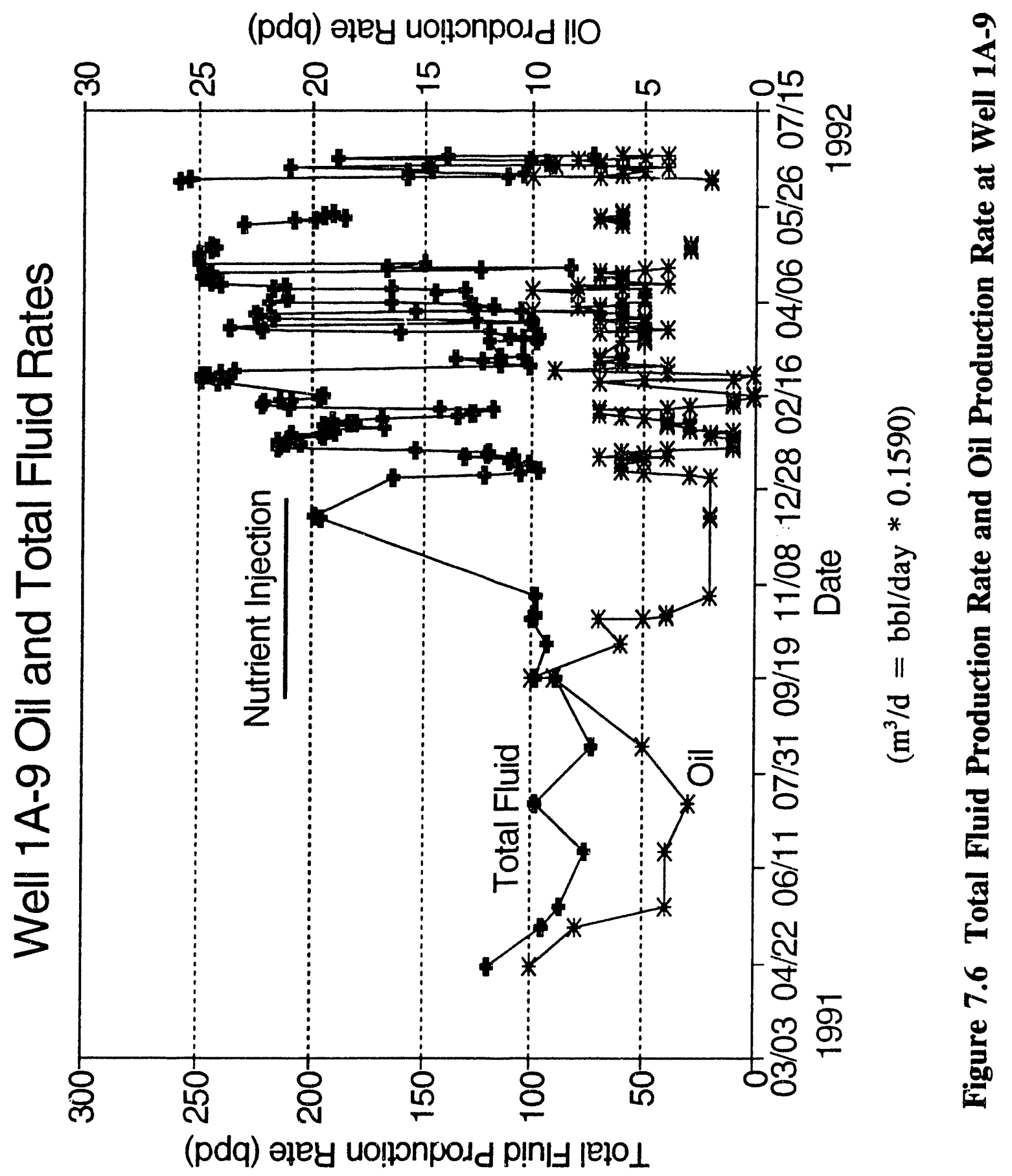




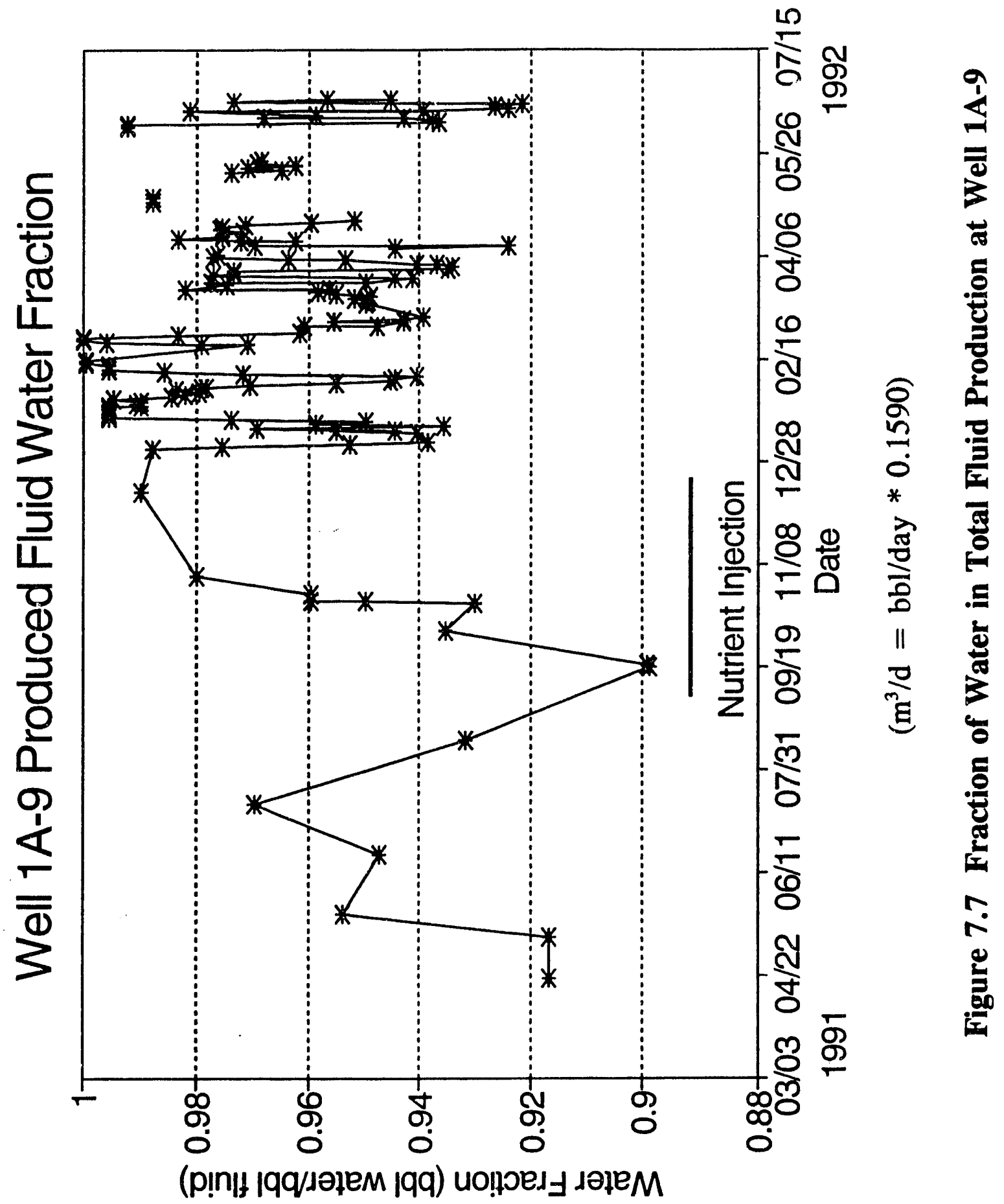


rate was low, the water fraction was near the water fraction values before the change. Whenever the total fluid level was high, the water fraction was also high.

There are two potential causes for the change in total fluid production in 1A-9. Either nutrient injection or water injection operations in this part of the field has affected this well. In Figure 7.8, the average total fluid production from $1 \mathrm{~A}-9$ is presented as two straight lines. Before the change in 1A-9's behavior, average fluid production was around 95 bpd $\left(15.1 \mathrm{~m}^{3} / \mathrm{d}\right)$. After the change, the average production rate was around $175 \mathrm{bpd}\left(27.8 \mathrm{~m}^{3} / \mathrm{d}\right)$. This change occurred within 60 days of the first molasses injection. The proximity of the change in Well 1A-9's average total fluid production rate to the first nutrient injection indicates that nutrient injection may have caused the increase in average total fluid production rate at Well $1 \mathrm{~A}-9$.

To aid in analysis of water injection operations in this part of the field, injection rates have been averaged. The value plotted for each day is the average of the values for the 10 days prior to and including that date. This is a filtering process which removes random variations and is referred to as a "moving average" (Chatfield, 1984, pg. 17). Two sets of moving averages are plotted on Figure 7.8. The 10-day moving average of injection at Well 7-2, the pilot injector, is plotted and, with the exception of periods of no injection, is consistently around $300 \mathrm{bpd}\left(47.7 \mathrm{~m}^{3} / \mathrm{d}\right)$. The sum of the injection at Wells $3-2,3-3$, and $7-3$ is also presented as a moving average and has values between 600 and 1400 bpd $\left(95.4\right.$ and $\left.222.6 \mathrm{~m}^{3} / \mathrm{d}\right)$.

The conversion of Well 3-2 to an injector and the increased injection of brine into the 3-3 and 7-3 after they were treated with the near well bore cleaning treatment in June of 1991 may have contributed to the average total fluid production rate changes at the 


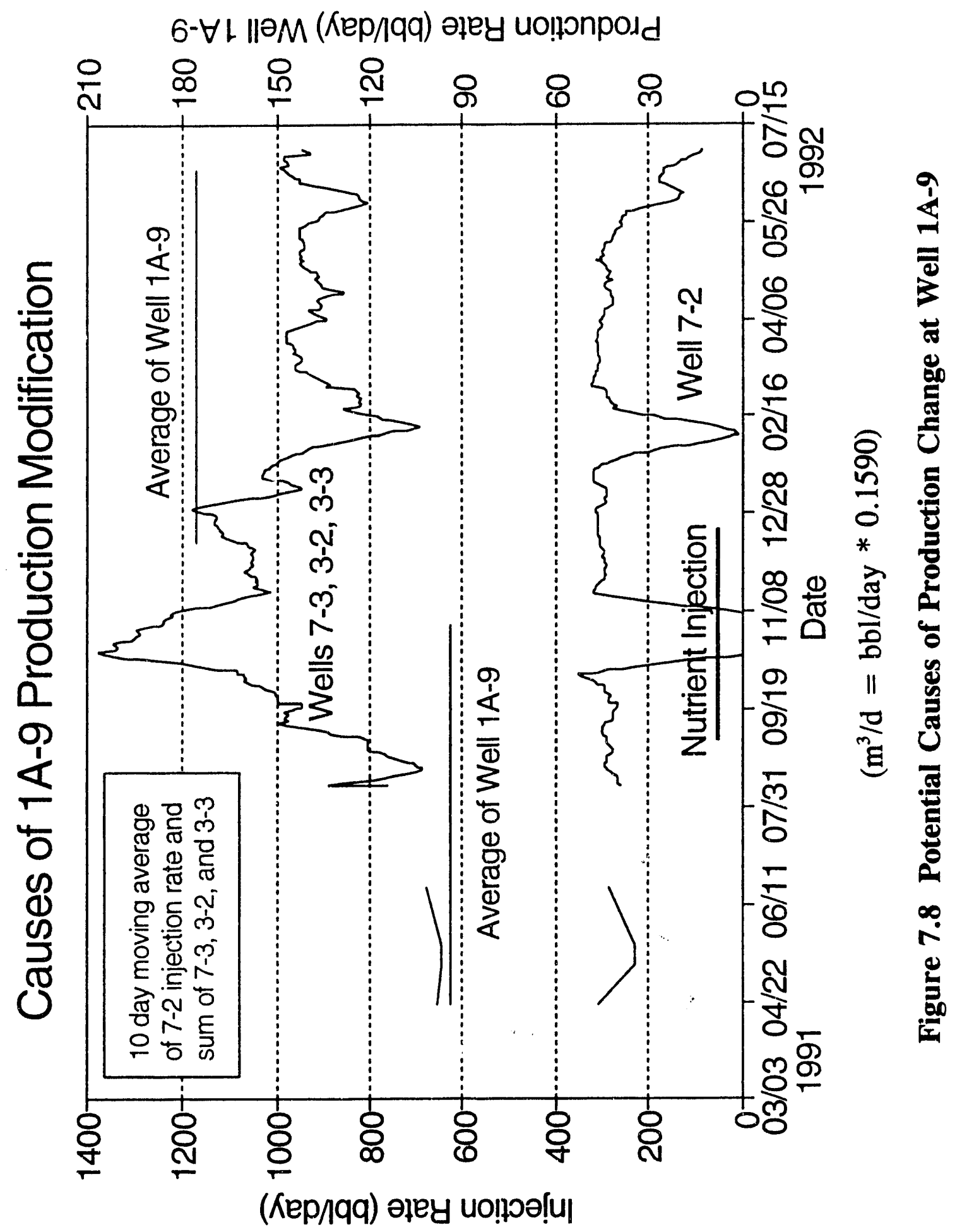


1A-9. These three wells are all closer to Well 1A-9 (Plate I.) than Well 7-2. Increased injection into these wells began in August of 1991. When Well 7-2 was shut-in for the field pilot incubation period, it was necessary to inject the water which would have normally been injected into the 7-2 into other wells. As is clearly shown on the figure, Wells 7-3, 3-2, and 3-3 received the bulk of this excess water. So, 100 days prior to the change in behavior of Well $1 \mathrm{~A}-9$ the three nearest injection wells had increases in injection rate, and 60 days prior to the change in behavior these same wells received a temporary $300 \mathrm{bpd}\left(47.7 \mathrm{~m}^{3} / \mathrm{d}\right)$ increase in injection rate. This increased injection is also a likely cause for the increased average total fluid production rate at Well 1A-9.

The second change in the behavior of Well $1 \mathrm{~A}-9$, the erratic nature of production from the 1A-9, cannot be explained by fluid injection rate changes. Hogg and Craig (1970) define the correlation coefficient as

$$
\rho=\frac{\sum\left(x_{i}-\bar{x}\right)\left(y_{i}-\bar{y}\right)}{\sqrt{\Sigma\left(x_{i}-\bar{x}\right)^{2} \Sigma\left(y_{i}-\bar{y}\right)^{2}}} .
$$

The value of $\rho$ can vary between -1 and 1. A perfect direct correlation between $\mathrm{x}$ and $y$ is indicated by $\rho$ equal 1. A perfect inverse correlation is indicated by $\rho$ equal -1 . If the absolute value of $\rho$ is small, no correlation exists between $\mathrm{x}$ and $\mathrm{y}$. The values of $\mathrm{x}$ and $\mathrm{y}$ must be ordered pairs. Beginning in December, 1991, values of 1A-9 total fluid production rate, $\mathbf{x}$, and injection rate at individual injections wells or groups of injection wells, y, were correlated. The correlation coefficients for Well 1A-9 and the indicated wells or groups of wells is given in Table 7.2. The largest absolute value of $\rho$ is 0.14 . No correlation exists between injection rate and 1A-9 total fluid production. 
Table 7.2 Correlation Coefficients Between Total Fluid Production Rate at Well 1A-9 and Injection Rates at the Indicated Wells or Groups of Wells

\begin{tabular}{|c|c|}
\hline Injector(s) & $\rho$ \\
\hline $3-2$ & -0.14 \\
\hline $3-3$ & 0.03 \\
\hline $7-2$ & 0.02 \\
\hline $7-3$ & -0.03 \\
\hline $7-5$ & 0.02 \\
\hline $3-2,3-3,7-2,7-3,7-5,8-1$ & 0.02 \\
\hline $3-2,3-3,7-3$ & -0.08 \\
\hline
\end{tabular}

Examinations of the individual well injection histories also fail to provide explanations for the variable nature of Well 1A-9's total production rate. Figure 7.9 is a plot of total fluid injection in all the near injectors and includes injection into Wells 7-5 and 8-1. Total fluid production rate from $1 \mathrm{~A}-9$ is also presented. Figure 7.10 compares the injection rate of Well 3-2 to 1A-9's production rate. Wells 3-3, 7-2, and 7-3 injection rates are similarly plotted in Figures 7.11, 7.12, and 7.13.

Well 7-5 is presented in Figure 7.14. The plot starts in June, 1991, because 7-5 was inactive from February through July of that year. Well 7-5 received water on an irregular basis. Most of the sharp downward spikes on the figure are actually periods of no injection masked by the 10-day moving average. Well 8-1 only served as an active injector from April through June of 1992 . Figure 7.15 presents the daily injection into Well 8-1 and is presented for the sake of completeness.

As no correlation exists between injection rate and 1A-9 production rate, the 


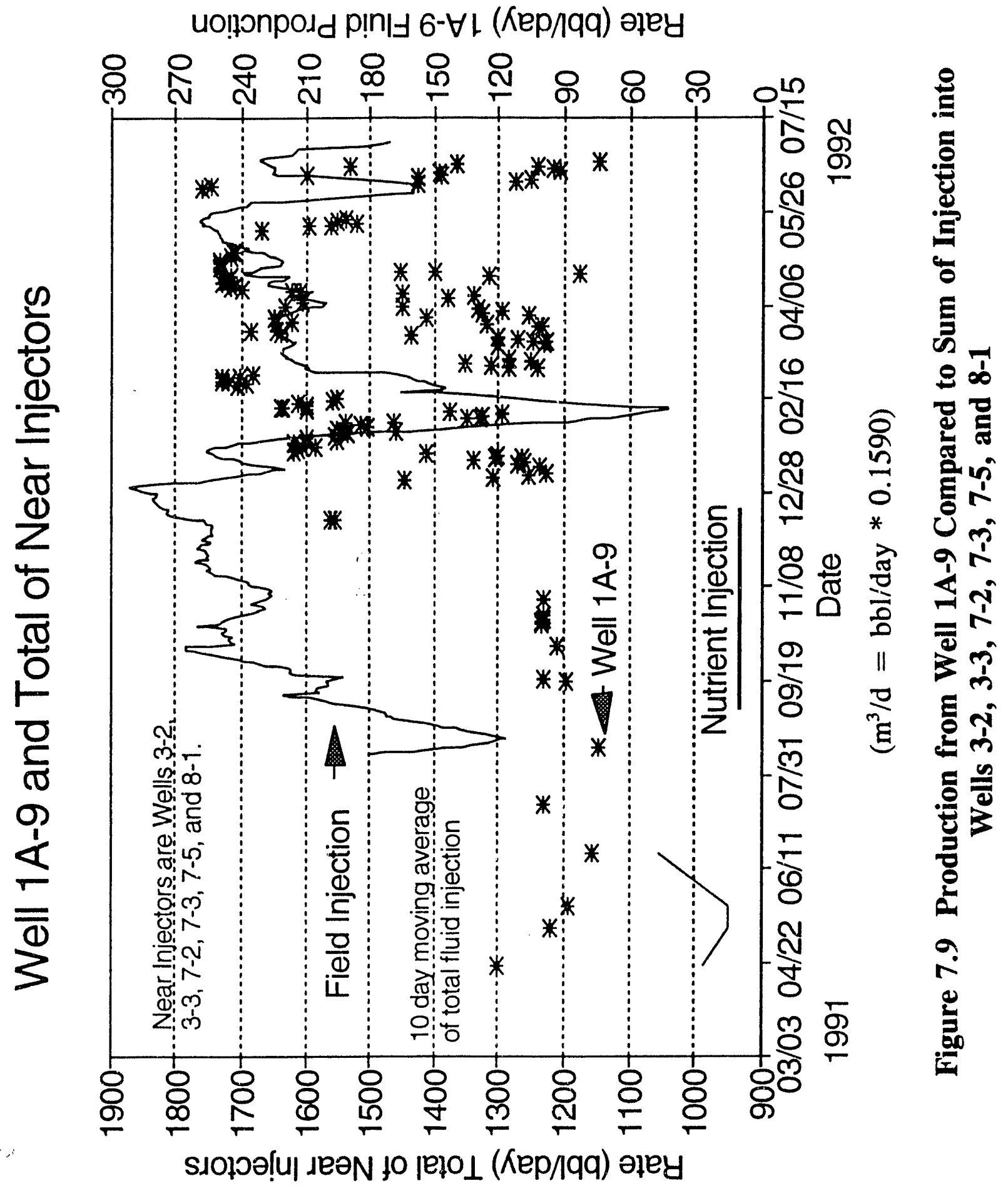




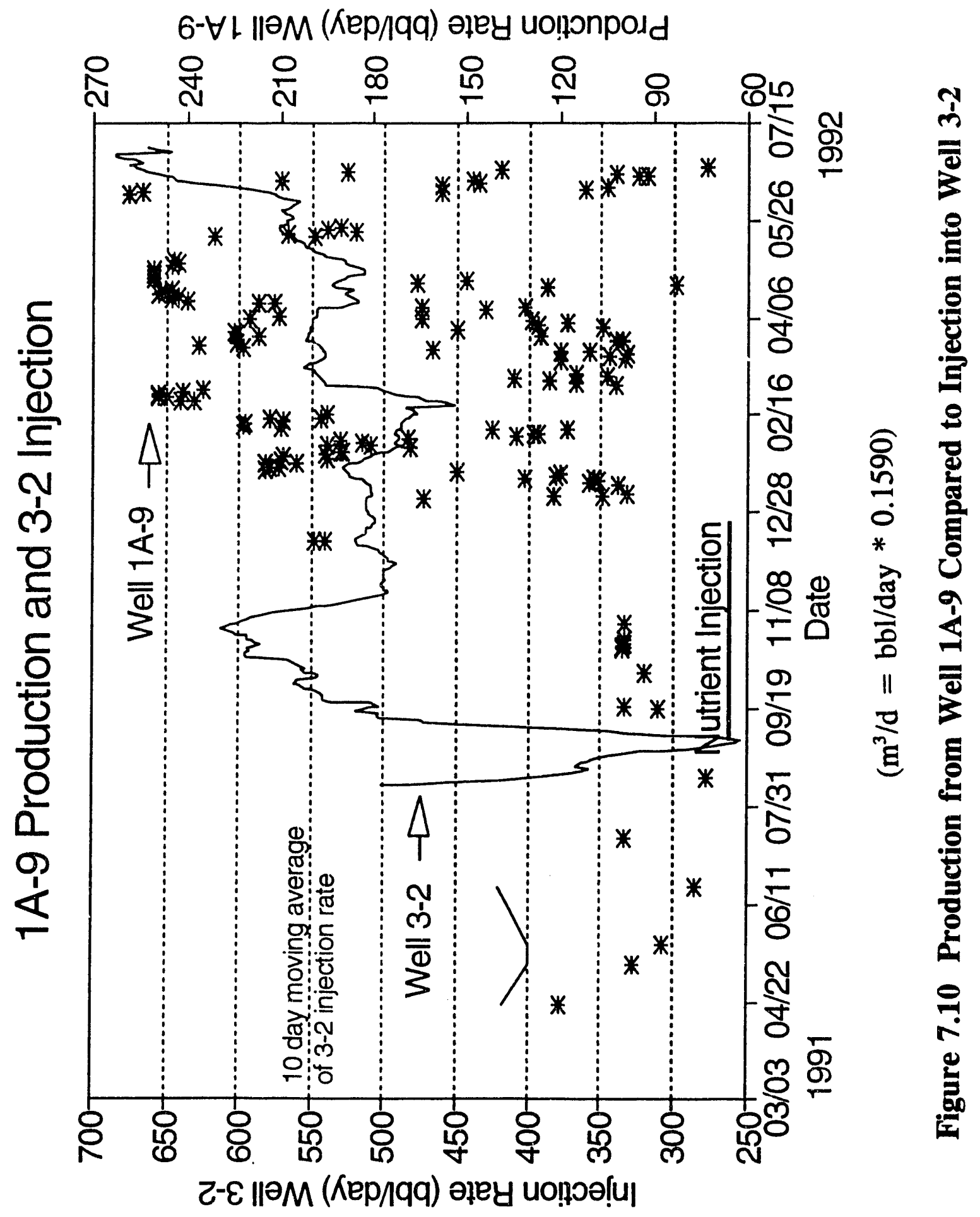




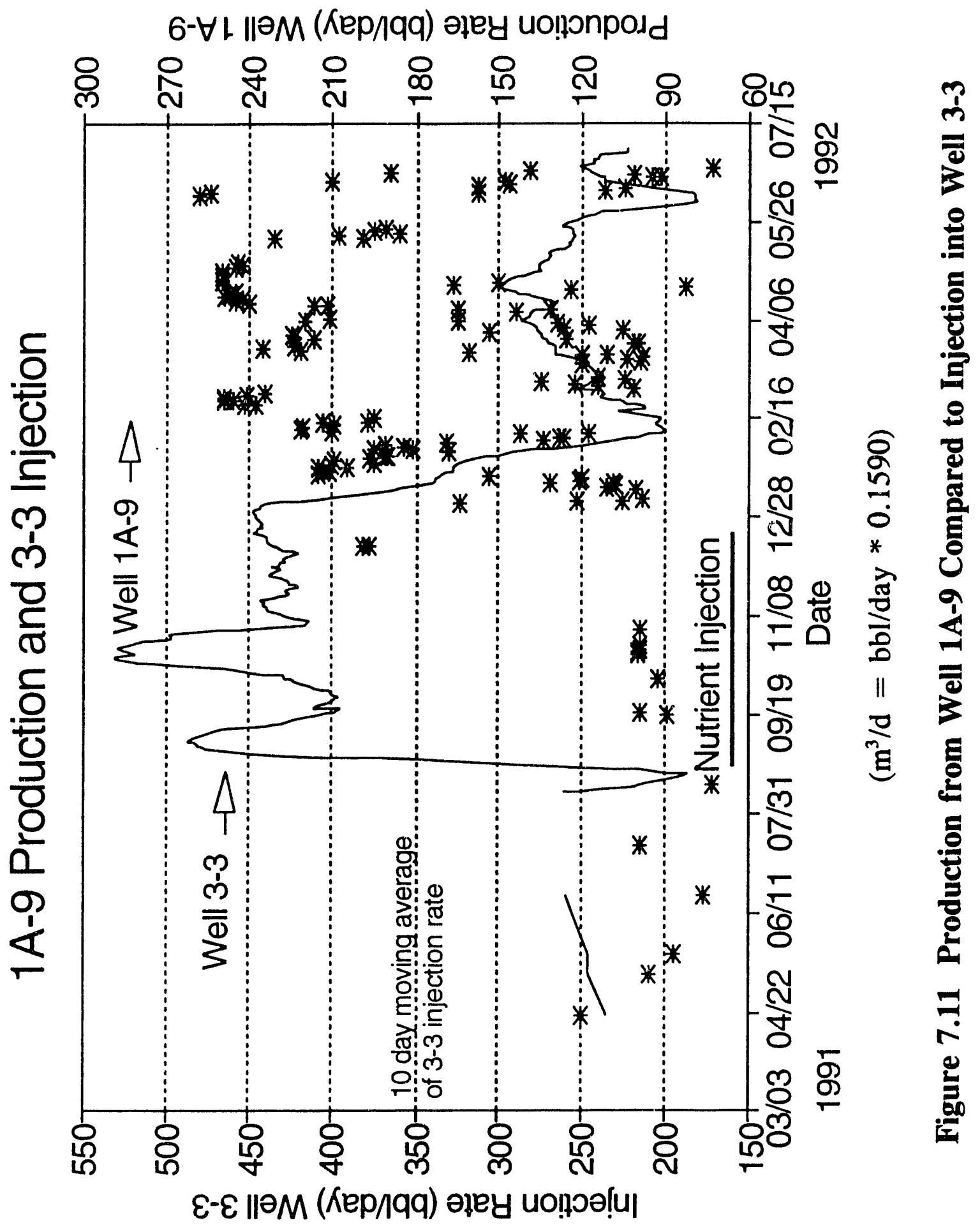




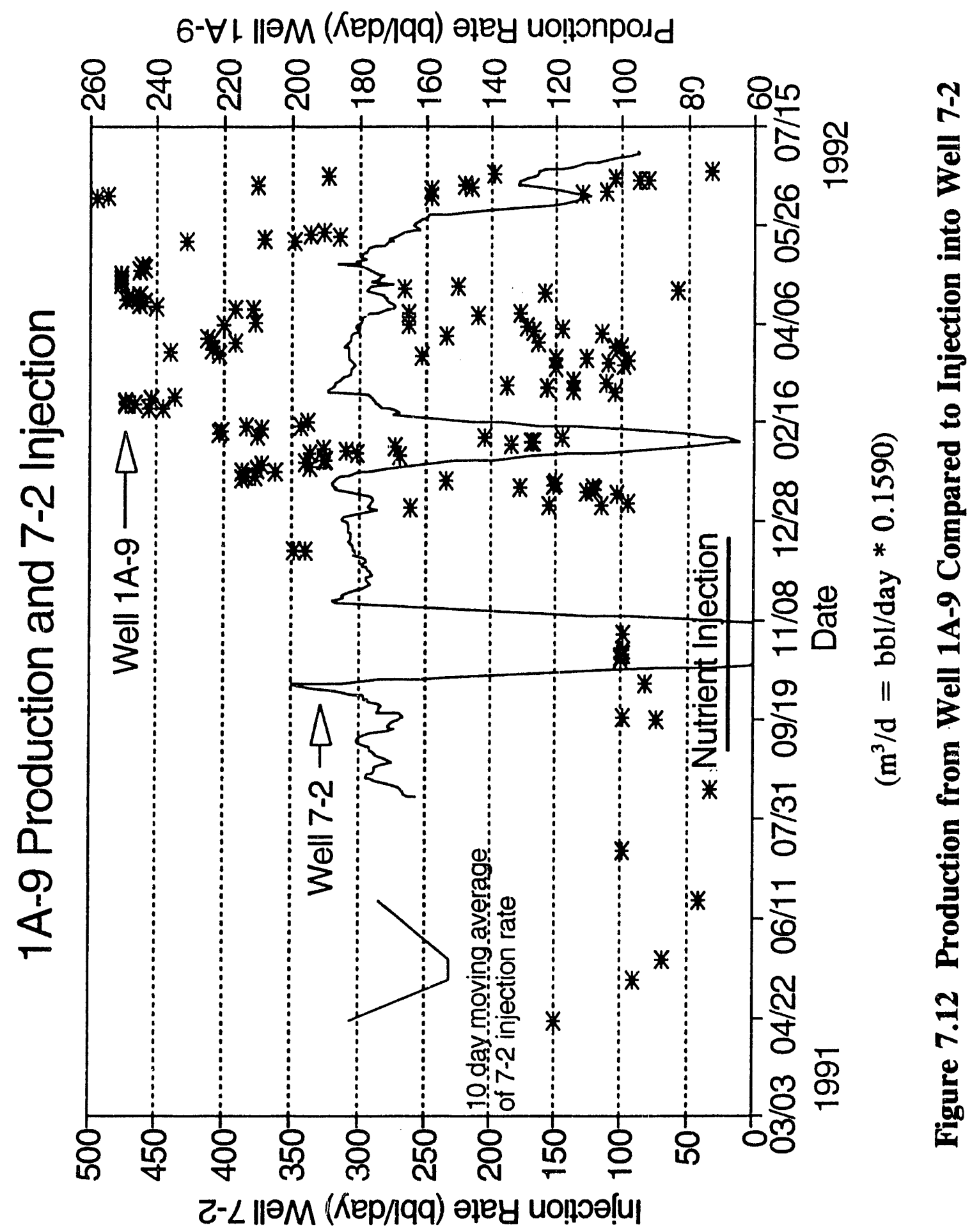




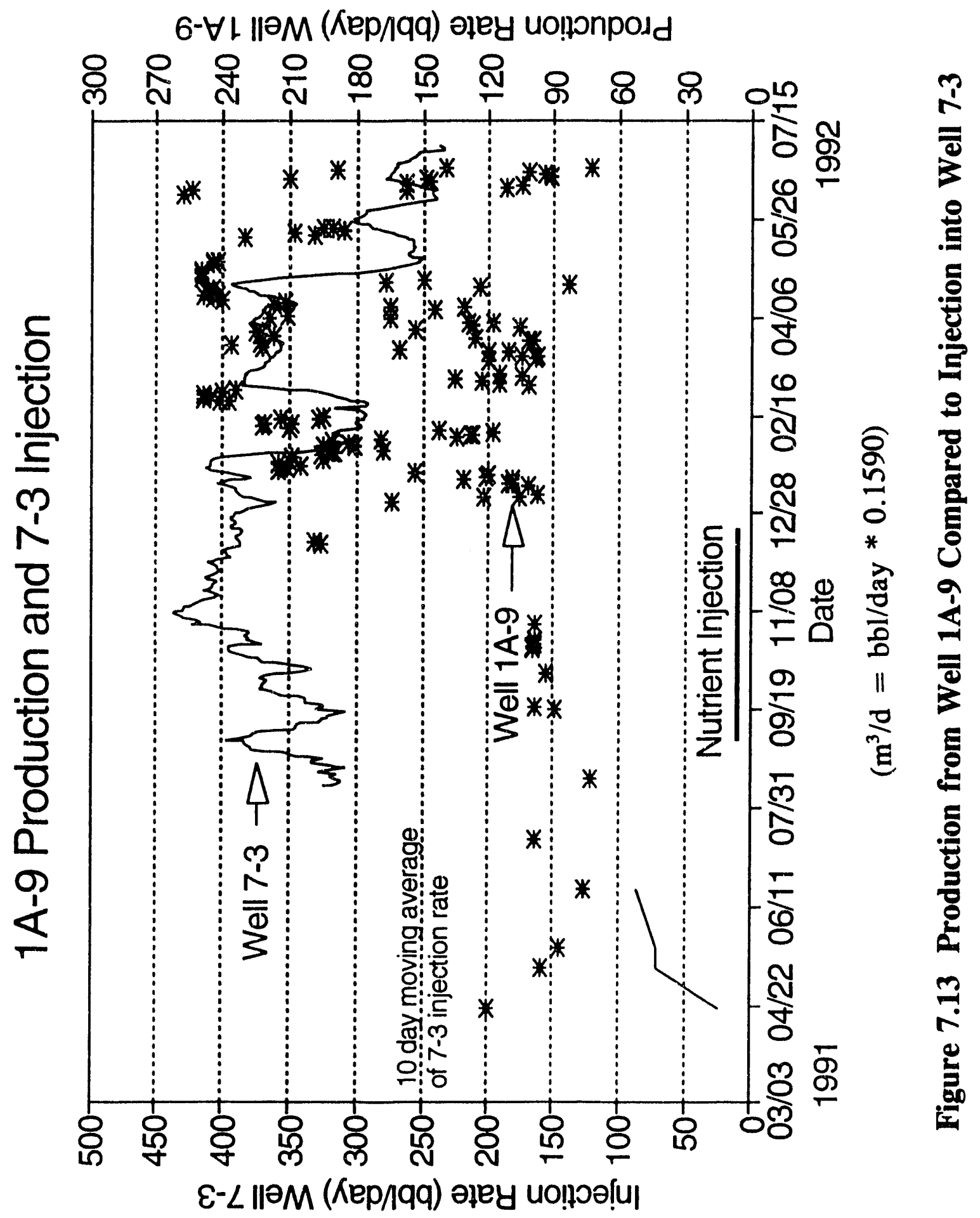




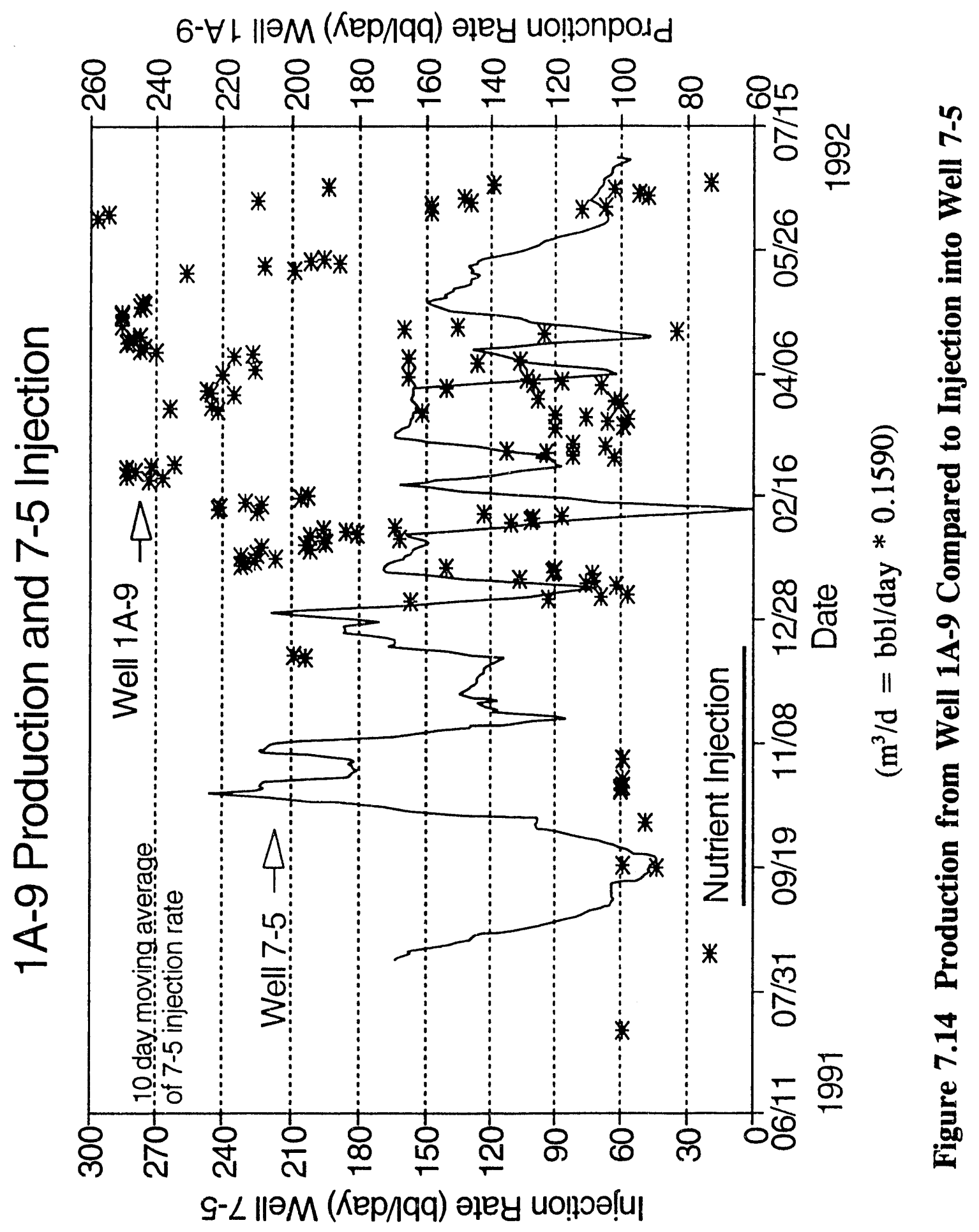




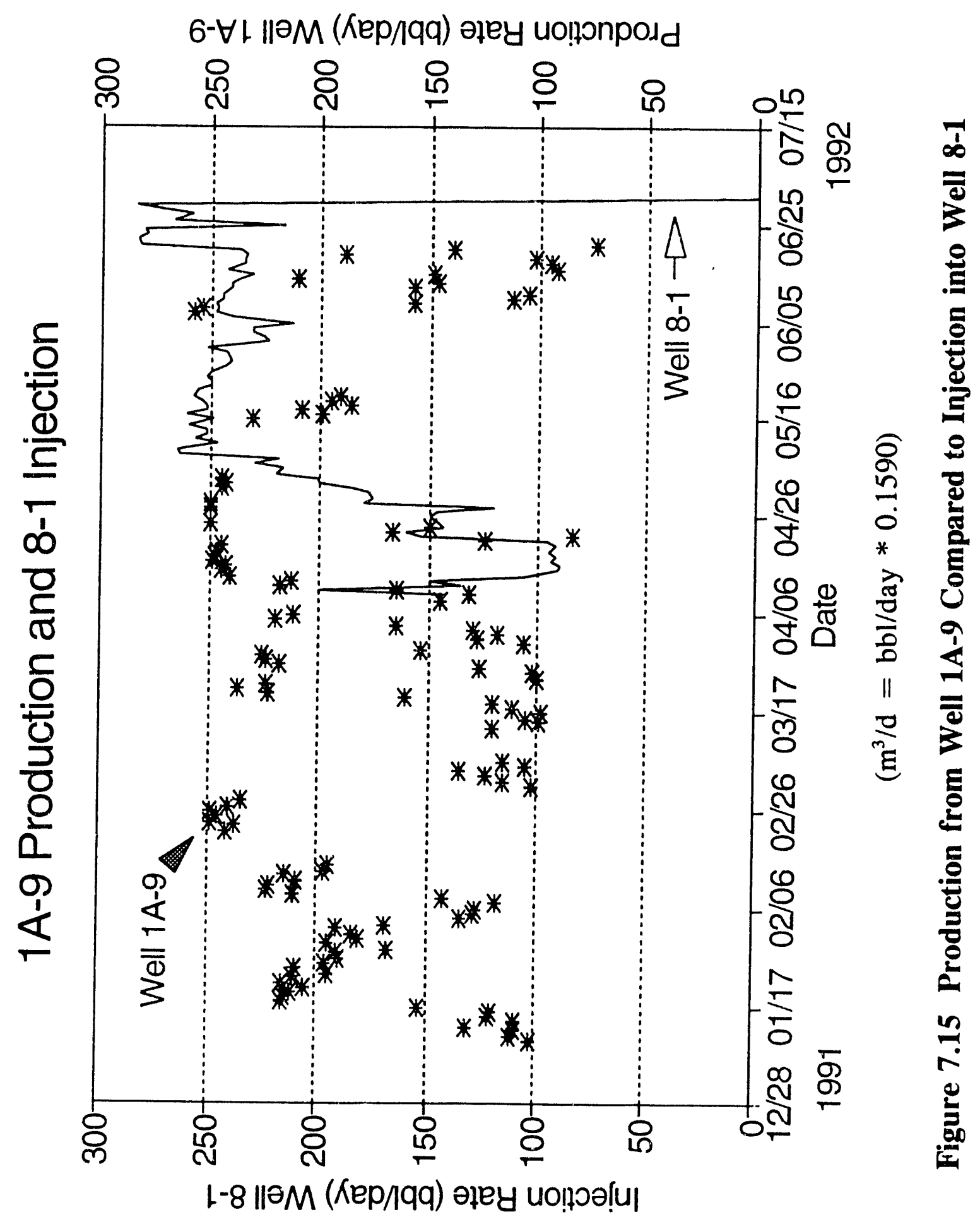


erratic nature of production from Well $1 \mathrm{~A}-9$ can probably be attributed to the nutrient injection into Well 7-2 and microbiological activity induced by that injection. The mechanism causing the behavior at $1 \mathrm{~A}-9$ is not intuitively obvious. The erratic production behavior was not evidenced in core experiments of MEOR processes or field activities of any other permeability modifying EOR process.

\subsection{Conclusions}

Significant additional oil recovery was not likely based on the very high recovery in the pilot area from primary and secondary recovery, $60 \%$ of the original oil in place. This is near the theoretical maximum recovery from the swept portion of the field based on fractional fluid flow (Buckley and Leverett, 1942). Selective plugging of high permeability zones was not expected to increase microscopic displacement efficiency, but rather vertical and area sweep efficiency. Results from the few other interwell MEOR floods (Lazar, et al., 1991, Wagner, 1991, Bryant, et al., 1991, Ivanov and Belyaev, 1991) were encouraging. During the Mic obial Field Pilot Study operations 82.5 bbl (13 $\mathrm{m}^{3} / \mathrm{d}$ ) of additional oil was recovered from the pilot area.

Well 1A-9 experienced an increase in average total fluid production shortly after nutrient injection began. The nutrient injection may have caused this change. However, total fluid injection in the three injection wells nearest Well $1 \mathrm{~A}-9$ increased one month prior to the first nutrient injection and temporarily rose an :dditional $300 \mathrm{bpd}(47.7 \mathrm{~m} / \mathrm{d})$ 15 days after the first molasses injection. The injection in these three wells is also a likely cause of the increase in average total fluid production from Well 1A-9.

The erratic total fluid production levels experienced at Well 1A-9 cannot be explained by changes in injection rates at the injection wells in the vicinity. After the 
injection of nutrients and the incubation period, Well $1 \mathrm{~A}-9$ was observed to produce anywhere from less than $100 \mathrm{bpd}$ to $250 \mathrm{bpd}$ (15.9 to $39.7 \mathrm{~m}^{3} / \mathrm{d}$ ), on any given day. Although some pattern can be observed for brief periods, production was unpredictable. No explanation is offered as to the mechanism involved in this behavior. Because other events in the field are not available to produce this behavior, it is concluded that the nutrient treatments and any microbiological activity stimulated by them is causal in this case. The microbial field pilot significantly changed the behavior of the reservoir, specifically of the flow path from the region of Well 7-2 to the southwest corner of the 1A tract. 


\section{Chapter 8. Pressure Test Analyses}

\subsection{Introduction}

Any time a change in the rate of injection or production from a well in a fluid filled porous media occurs, the overall pressure distribution in the reservoir changes. Immediately after the change in flow rate, the pressure regime in the reservoir is in transition. By monitoring and analyzing pressures of wells before and after a change in rate, an analysis of the transient behavior can be made. This analysis will reveal average permeability near the tested well. By observing the pressure changes at wells surrounding the well experiencing the rate change, estimates of interwell permeability can be made by analyzing this interference. Also, qualitative information on well connectivity can be implied. Over the course of the Microbial Field Pilot Study, several pressure transient studies were conducted to enhance the reservoir characterization and to test for changes in the reservoir due to microbial activity.

Three pressure transient tests were performed on Well 7-2, the pilot injection well. These tests served to determine the effects of nutrient injection and metabolism on the injection well. One test was conducted prior to nutrient injection to establish the pretest permeability in the vicinity of the pilot injection well. A second test was performed after the first 12 tons (10.9 tonnes) of molasses were injected and before a 30 day incubation period. The final pressure test was performed one month after the last nutrient injection.

Two interference tests were performed. These provided information on the changes of interwell permeabilities in the pilot area caused by the microbial project. In 
both cases a change of rate at Well 7-2 was used to induce pressure changes that were monitored at the 5-1, 5-2, and 7-1 (see Plate I.). The tests were conducted in February 1991 before nutrient injection and in February 1992 after the completion of nutrient treatments.

\subsection{Theory}

The basic principles of pressure transient behavior in reservoirs have been presented by Muskat (1937) and Collins (1961). The theory and practice of well pressure testing have been described by Matthews and Russell (1967) and Earlougher (1977).

Pressure transient behavior can be described mathematically for radial flow of a slightly compressible fluid in a semi-infinite, homogeneous, isotropic, horizontal reservoir of uniform thickness. If the well bore radius is sufficiently small with respect to the radius of the reservoir it may be treated as a line source. The equation describing the pressure behavior is given by:

$$
p(r, t)=p_{i}-\frac{q \mu}{2 \pi k h}\left[-\frac{1}{2} E i\left(-\frac{\phi \mu c_{r} r^{2}}{4 k t}\right)\right]
$$

where $\mathrm{Ei}$ is the exponential integral function. The exponential integral function is a standard mathematical function defined as

$$
-E i(-x)=\int_{x}^{\infty} \frac{e^{-s}}{s} d s .
$$

Tables of values for this function exist. If $\mathrm{x}<0.01$ a natural logarithmic approximation of the exponential integral is valid, $-\operatorname{Ei}(-x)=-\ln (\gamma x)$ where $\gamma$ is Euler's constant, 1.781. At the well bore, values of $\phi \mu \mathrm{cr}^{2} / 4 \mathrm{kt}$ are less than 0.01 except for very small values of t. Applying the natural logarithmic approximation of the exponential integral function 
yields:

$$
p(r, t)=p_{i}-\frac{q \mu}{4 \pi k h} \ln \left(\frac{\gamma \phi \mu c_{r} r^{2}}{4 k t}\right)
$$

These equations are in Darcy units. Pressure, $p$, is in atmospheres, total compressibility, $\mathrm{c}_{\mathrm{t}}$, in $\mathrm{atm}^{-1}$, radius, $\mathrm{r}$, and thickness, $\mathrm{h}$, in $\mathrm{cm}$., permeability, $\mathrm{k}$, in darcies, viscosity, $\mu$, in centipoise, flow rate, $\mathrm{q}$, in $\mathrm{cc} / \mathrm{sec}$, and time, $\mathrm{t}$, in seconds. The pressure, $\mathrm{p}_{\mathrm{i}}$, is the initial pressure of the reservoir.

The permeability of the reservoir immediately around the wellbore may differ significantly from the rest of the formation. Damage from drilling fluids, swelling of clays, mud cake or cement, partial penetration, and other causes can induce an additional pressure drop proportional to the rate of production q. This zone of reduced permeability is called a "skin". Skin, s, is a positive dimensionless value for well damage. Stimulated wells may have a negative value for skin due to acidizing or fracturing. This additional pressure drcp is defined as

$$
\Delta P_{s k i n}=s\left(\frac{q \mu}{2 \pi k h}\right) \text {. }
$$

This skin effect is only applicable when the radius being evaluated is the well bore radius, $r=r_{w}$.

Pressure at the well bore of a flowing well is referred to as well bore flowing pressure, $\mathrm{p}_{\mathrm{wf}}$, and is given by

$$
p_{w f}=p_{i}-\frac{q \mu}{4 \pi k h}\left\lfloor\ln \left(\frac{\gamma \phi \mu c r_{w}^{2}}{4 k t}\right)+2 s\right\rfloor \text {. }
$$

A reservoir is not infinite and the boundaries of the reservoir affect the pressure at the flowing well after the pressure pulse produced by the flowing of the well 
encounters the boundary. The flow condition after this time is called "semi-steady state" and the well bore flowing pressure is given by:

$$
p_{w f}=p_{i}-\frac{q \mu}{2 \pi k h}\left[\frac{1}{2} \ln \frac{4 A}{\gamma C_{A} r_{w}^{2}}+2 \pi \frac{k t}{\phi \mu c A}+s\right]
$$

(Dake, 1978) in which $A$ is the area of the bounded reservoir in $\mathrm{cm}^{2}, \mathrm{C}_{\mathrm{A}}$ is the Dietz shape factor (Dietz, 1965) which is a dimensionless positive value which varies according to the shape of the reservoir and the location of the well within the reservoir, and $\gamma$ is Euler's constant, 1.781 .

Well pressure tests are performed by stopping production or injection at a flowing well. The principle of superposition allows the pressure response of the sudden change of rate to be added to the pressure response of the previous flow period. If the well was flowing for a time $\mathrm{T}$ before closure and the time $\Delta \mathrm{t}$ after closure is monitored for pressure, called shut-in well bore pressure, $\mathrm{p}_{\mathrm{ws}}$, then the change in pressure

$$
p_{w s}=p_{i}+\text { pressure change caused by rate } q \text { for time } T+\Delta t+\text { pressure change }
$$
caused by rate $-\mathrm{q}$ (the change of rate at the moment of closure) for time $\Delta t$, or

$$
p_{w s}=p_{i}-\frac{q \mu}{4 \pi k h}\left[\ln \left(\frac{\gamma \phi \mu c_{r}^{2} r_{w}^{2}}{4 k(T+\Delta t)}\right)+2 s\right]-\frac{(-q) \mu}{4 \pi k h}\left[\ln \left(\frac{\gamma \phi \mu c_{r} r_{w}^{2}}{4 k \Delta t}\right)+2 s\right] \text {. }
$$

The skin cancels and the equation simplifies to

$$
p_{w s}=p_{i}-\frac{q \mu}{4 \pi k h} \ln \left(\frac{T+\Delta t}{\Delta t}\right) \text {. }
$$

A plot of $p_{w s}$ versus $\ln ((T+\Delta t) / \Delta t)$ should yield a straight line of slope $-q \mu / 4 \pi k h$ from which permeability may be estimated.

If $\Delta t$ is very small compared to $T$, then $T+\Delta t \cong T$ and $\ln ((T+\Delta t) / \Delta t) \cong \ln T$ - 
$\ln \Delta t$ and Equation $8-8$ becomes

$$
p_{w s}=p_{i}+\frac{q \mu}{4 \pi k h} \ln \Delta t-\frac{q \mu}{4 \pi k h} \ln T
$$

As $T$ is a constant, a plot of $p_{w s}$ versus $\ln \Delta t$ will yield a straight line with slope $\mathrm{q} \mu / 4 \pi \mathrm{kh}$ and again $\mathrm{k}$ can be estimated.

After the conversions are made to standard petroleum industry field units and the natural logarithm is replaced with logarithm base ten, Equation 8-3 becomes

$$
p(r, t)=p_{i}-\frac{162.6 q \mu B}{k h}\left[\log \frac{k t}{\phi \mu c_{r} r^{2}}-3.2275\right]
$$

in which $\mathrm{p}$ is in psi, $\mathrm{c}$ in $\mathrm{psi}^{-1}, \mathrm{r}$ and $\mathrm{h}$ in $\mathrm{ft} ., \mathrm{k}$ in $\mathrm{md} ., \mu$ in $\mathrm{cp}, \mathrm{q}$ in bbl/day, and $\mathrm{t}$ in hours. The formation volume factor, B, is in reservoir barrels per stock tank barrel.

Two general well test evaluation procedures are available. The most common is the Horner plot (Horner, 1951) and it makes use of Equation 8-8. The Horner plot requires a pre-test flow period at a constant rate. The equation for analysis of a Horner plot in practical oil field units is given by

$$
p_{w s}(t)=p_{i}-162.6 \frac{q \mu B}{k h} \log \left(\frac{T+\Delta t}{\Delta t}\right)
$$

where $p_{w s}$ is the pressure after closure of the well being tested and $\Delta t$ is the time since closure. $T$ is the flow time at constant rate prior to closure. The flow rate, $\mathrm{q}$, is the pre-closure constant flow rate. By plotting pressure after closure versus the $\log$ of $(T+\Delta t) / \Delta t$ using semi-log paper a straight line should develop during transient flow. The slope of this line, $\mathrm{m}$, in psi/log $\mathrm{hr}$ (often referred to as psi/cycle) can be used to calculate the apparent permeability of the reservoir in the region influenced by the rate change before any reservoir boundaries are encountered, 


$$
k=\frac{162.6 q \mu B}{m h}
$$

In practical oil field units, skin may be calculated using

$$
s=1.151\left[\frac{p_{1 h r}-p_{w f}}{m}-\log \left(\frac{k}{\phi \mu c_{r}{ }_{w}^{2}}\right)+3.2275\right]
$$

where $p_{w f}$ is the bottom hole flowing pressure of the flowing well prior to closure and $\mathrm{p}_{\mathrm{lhr}}$ is the pressure indicated by the extrapolated straight line portion of the Horner plot at one hour after closure.

The Miller-Dyes-Hutchinson (MDH) plot (Miller, et al, 1950) results directly from Equation 8-9. By plotting pressure versus the common log of closure time a straight line portion should develop with slope m. Again converting to practical oil field units and using the common logarithm base ten yields

$$
p_{w s}=p_{i}-\frac{162.6 q \mu B}{k h} \log \Delta t+\text { constant }
$$

Once the slope and $P_{1 h r}$ have been established from the plot of $\mathrm{p}_{\mathrm{ws}}$ versus $\log \Delta t$, permeability and skin factor can be calculated from Equations 8-12 and 8-13.

Both Horner and MDH analysis can be performed on pressure fall-off tests. Values of flow rate, viscosity, porosity, compressibility, well bore radius, and thickness can be measured or approximated from other information on the well and formation. These techniques can be used to estimate apparent permeability to the flowing fluid phase in the reservoir.

In an actual well test three distinct periods of pressure data are likely to be observed. First, a period controlled by skin and fluid adjustments in the well bore 
immediately after closure is observed. The latter is often referred to as well bore storage or after production. Although theoretically, skin effect should be instantaneous, some amount of time is consumed as the skin effect is made manifest in the pressure data. Also, fluid in the well bore does not immediately stop moving upon closure and some fluid continues to be exchanged between the well bore and the formation. This is also observed in the pressure data.

The second period of pressure information is described by Equations 8-8 or 8-9 and represents the Iransient pressure period used to estimate permeability and skin from Horner and $\mathrm{MDH}$ plots.

The third period is associated with the boundary effects in the reservoir. A boundary can consist of a physical barrier at the edge of the drainage area of the reservoir. Pressure disturbances caused by other sources than the well being tested also serve as barriers. These can be production or injection at nearby wells in the field or an active natural pressure maintenance process such as an active aquifer. This period is governed by Equation 8-6 and will represent a deflection from the straight line of the transient period. If the barriers are very close to the well being tested the transient period may be obscured by the boundary effects.

Data plotted from an actual well test may have several sections that form a straight line on a semi-logarithmic plot. At times a straight line segment (or several straight line segments) may exist during the well bore storage period. When the transient period is fully established the straight line of slope $\mathrm{m}$ will be present. In semi-steady state a plot of pressure versus time since closure will form a straight line and portions of the semi-logarithmic plot of this data may resemble a straight line. 
The choice of the correct straight line is made based on two criteria. First, the three pressure periods will appear in order. Very early and very late straight line segments are generally poor selections. Analytical techniques ure also available to aid in identifying the skin and afterflow dominated period and the semi-steady state period.

The second criteria is that the magnitude of calculated values must agree with general knowledge of the reservoir. For example, using Horner plot analysis both permeability and an estimate of average reservoir pressure can be obtained. (The reservoir pressure is estimated by extrapolating the transient straight line to infinite time at $((\mathrm{T}+\Delta \mathrm{t}) / \Delta \mathrm{t})=1.0$.) In one pressure test performed in this report, a permeability of $40 \mathrm{md}\left(0.04 \mu \mathrm{m}^{2}\right)$ and an average reservoir pressure of $900 \mathrm{psia}\left(6.2 \times 10^{6} \mathrm{~Pa}\right.$ absolute $)$ were obtained. A steeper slope which was determined to be in the well bore storage dominated period would have given values of $12 \mathrm{md}\left(0.01 \mu \mathrm{m}^{2}\right)$ and $200 \mathrm{psia}\left(1.4 \times 10^{6}\right.$ $\mathrm{Pa}$ absolute). The $12 \mathrm{md}\left(0.01 \mu \mathrm{m}^{2}\right)$ value was considered somewhat low and the 200 psia $\left(1.4 \times 10^{6} \mathrm{~Pa}\right.$ absolute) value of average reservoir pressure was unrealistic.

Interference tests between wells can be evaluated using Equation 8-10. The value of $r$ is the distance between the pulsed well and the observation well. Commonly, a type curve matching technique (Earlougher, 1977) can be employed to compare the interference test results to an ideal exponential integral solution (Equation 8-1). This analysis is applicable urtil the time the effects of reservoir boundaries are experienced at the observation well. When boundaries exist in the field causing the solution to differ from the ideal isotropic, homogeneous, infinite horizontal reservoir, the data will diverge from the exponential integral solution. Earlougher (1977, p. 108) shows that this diversion from ideal occurs early in the test history. In some cases the classic 
exponential integral solution is never followed by the pressure data.

In an interference test three unique time periods may be present. An early time exists in which the pressure pulse has not yet reached the observation well. Ideally the pressure at the observation well is constant during this period. This is followed by a period of transient pressure behavior which can be used for interference test analysis. Finally, in late time, a semi-steady state period exists (Matthews and Russell, 1967, Earlougher, 1977) in which a plot of pressure versus time will yield a straight line in a similar manner as Equation 8-6 for a flowing well test. Occasionally the middle period is completely obscured by these boundary effects. By plotting pressure versus time and identifying the early straight line portion (pre-pulse arrival) and the late straight line portion (semi-steady state) those data points between these two portions that will lend themselves to transient analysis can be identified.

Divide both sides of Equation 8-10 by $q$ and expand the logarithm to get

$$
\frac{p_{i}-p(r, t)}{q}=\frac{162.6 \mu B}{k h}\left[\log t+\log \left(\frac{k}{\phi \mu c r^{2}}\right)-3.2275\right] \text {. }
$$

The slope of the normalized transient pressure pulse can be used to determine permeability.

$$
k=\frac{162.6 \mu}{m h} \underline{B} .
$$

The permeability reduction factor, PRF, is the ratio of the permeability after a microbial process (or any other permeability modifying process), $k_{2}$, to the initial permeability, $k_{1}$. If the permeability values are defined using Equation 8-16 and $\mathrm{B}, \mu$, and $\mathrm{h}$ are not altered by the process, i.e., constant, then 


$$
P R F=\frac{k_{2}}{k_{1}}=\frac{m_{1}}{m_{2}} .
$$

A change in permeability will cause a change in the value of the second log term in Equation 8-16. This will cause a shift of the line but will not affect the slope.

Another estimate of permeability reduction factor can be derived from the arrival time of the pressure pulse in a well test. The radius of influence of a pressure transient interference test is approximately

$$
r_{i n t}=0.029 \sqrt{\frac{k t}{\phi \mu c_{t}}}
$$

(Vela and McKinley, 1970). Assuming $\mathrm{r}_{\mathrm{inh}}$ and $\phi \mu \mathrm{c}$ are unchanged by a permeability modifying process, this can be rewritten as

$$
k=\left(\frac{r_{i m l}}{0.029}\right)^{2} \frac{\phi \mu c_{t}}{t} .
$$

Taking the ratio of $\mathrm{k}$ after a permeability modifying process to the value of $\mathrm{k}$ before the process yields
$P R F=\frac{k_{2}}{k_{1}}=\frac{t_{1}}{t_{2}}$.

In this analysis, the times of first arrival of the transient pressure pulse at the observation well before and after the permeability modifying process are also used to estimate PRF.

\subsection{Methodology}

\section{Injection Well Tests}

To examine the effects of nutrient injection on the pilot injection well, three pressure fall-off tests were performed on Well 7-2. The first was prior to nutrient injection $(2 / 22 / 91)$. The second was after the injection of the first 12.5 tons $(11.3$ 
tonnes) of molasses (10/7/91). And, the final test was 39 days after the last injection of nutrients $(1 / 28 / 92)$. For each test, injection into the well was stopped and surface pressures monitored with respect to time for up to four days. Frequency of readings ranged from less than a minute at initial closure to daily near the end of the test. Bottom hole pressures were determined by adding the surface pressure to the pressure caused by the weight of the static column of fluid in the well bore from the surface to the well perforations. These were converted to absolute pressures. The apparent pre-test flow period was determined by dividing the flow rate during the $24 \mathrm{hrs}$ prior to the test into the total volume injected since the last pressure equalization at the location of the well. A net pay thickness of $13 \mathrm{ft}(40 \mathrm{~m})$ was used in the calculations. Both Horner and Miller-Dyes-Hutchinson plots were evaluated. Transient flow regime straight lines were chosen according the criteria discussed above.

Some basic properties of the reservoir and its fluids were assumed to be unchanged by nutrient injection. An average porosity of 0.22 was used from core analysis. Based on the results of the reservoir simulation (Chapter 4), an oil saturation of 0.3 , water saturation of 0.7 , and a gas saturation of 0.0 were assumed. The specific gravities of the reservoir fluids were used to estimate compressibilities. The compressibilities of oil and water are $12.2 \times 10^{-6}$ and $3.1 \times 10^{-6} \mathrm{psi}^{-1}\left(1.77 \times 10^{-9}\right.$ and $0.45 \times 10^{-9} \mathrm{~Pa}^{-1}$ ), respectively, based on empirical correlations (Matthews and Russell, 1967). Rock compressibility of a $22 \%$ porosity sandstone is $3.6 \times 10^{-6} \mathrm{psi}^{-1}\left(0.52 \times 10^{-9}\right.$ $\mathrm{Pa}^{-1}$ ) from an empirical correlation (Matthews and Russell, 1967). This yields a total compressibility, $\mathrm{c}_{\mathrm{l}}$, of $4.9 \times 10^{-6} \mathrm{ps}^{-1}\left(0.71 \times 10^{-9} \mathrm{~Pa}^{-1}\right)$. The viscosity of the flowing phase, brine water, was measured at $1.1 \mathrm{cp}(0.0001 \mathrm{~Pa} . \mathrm{s})$ (see Chapter 4$)$. The 
formation volume factor, $\mathrm{B}$, of the flowing phase, water, is 1.0 reservoir barrels per stock tank barrel $\left(1.0 \mathrm{~m}^{3} / \mathrm{SCM}\right)$ based on empirical correlation (Matthews and Russell, 1967). A well bore radius of $0.33 \mathrm{ft}(10 \mathrm{~cm})$ was used in the calculations from well log records.

\section{Interwell Pressure Interference Tests}

The goal of the Microbial Field Pilot Study was to modify the flow pattern in the pilot area by selectively plugging high transmissivity flow paths in the reservoir. Interwell permeabilities can be measured using interference pressure testing procedures. Modification of permeability in the pilot area caused by nutrient injection and subsequent microbial activity were used to measure the degree of selective plugging achieved by the pilot process. Two sets of interference tests were performed in the pilot area of the SEVVSU. By conducting a test prior to and after the nutrient treatments, the ratios of the results indicate the magnitude of the change in reservoir permeability. In this study, the permeability reduction factor (PRF) was determined from interference tests for Wells $5-1,5-2$, and $7-1$.

The first test was run in conjunction with an injection "fall-off" test. On February 22, 1991, injection into Well 7-2 was stopped. Immediately before closure, the injection rate at Well $7-2$ was 144 bpd $\left(22.9 \mathrm{~m}^{3} / \mathrm{d}\right)$. Well $7-2$ had been receiving injection water at $300 \mathrm{bbl}$ per day $\left(47.7 \mathrm{~m}^{3} / \mathrm{d}\right)$, but clogging of the water filter at the wellhead reduced the rate to $144 \mathrm{bbl}$ per day $\left(22.9 \mathrm{~m}^{3} / \mathrm{d}\right)$ within the 24 hours prior to the test. Wells 5-1, 5-2, and 7-1 had been converted to production wells, but production had not yet been initiated. Prior to the test, these wells were full of fluid and no fluctuations were observed in the pressures measured at the surface for these wells. Pressures of 
these three wells versus time were recorded every few hours for two days and daily for an additional 3 days. The pressure pulse monitored was in response to a decrease in the rate $144 \mathrm{bpd}\left(22.9 \mathrm{~m}^{3} / \mathrm{d}\right)$. This test was conducted six months prior to the injection of the first nutrients associated with the field pilot study.

The second test was in response to resuming injection at Well 7-2. On February 6, 1992 injection was initiated into Well $7-2$ at a rate of $100 \mathrm{bbl}$ per day $\left(15.9 \mathrm{~m}^{3} / \mathrm{d}\right)$. There was no injection into the $7-2$ for nine days prior to the test. Production from Wells 5-1, 5-2, and 7-1 had been stopped January 17, 1992. Liquid levels for these welis were at the surface. Small pressure fluctuations were observed at the surface of the production wells prior to the beginning of the test. The reservoir in the vicinity of the production wells was not fully stable due to other injection wells in the field; however, the fluctuations were small and the pressure pulse from the change of rate at Well 7-2 was easily observed. Pressures were taken in a similar manner and at similar time intervals to the 1991 test. This test was conducted 48 days after the last field pilot nutrients were injected into the reservoir.

To isolate the points due to the pressure pilse from those taken before the pulse arrived and those affected by boundaries, the change of pressure divided by pulse rate was plotted with respect to time on coordinate paper. As discussed above, pressure data collected before the pressure pulse arrival and those collected after semi-steady state flow conditions induced by boundary effects will form straight lines. Points falling on an early time line (pre-pulse arrival) and a late time line (semi-steady state flow) were not used in the analysis. Plots of change of pressure divided by pulse rate versus the logarithm of time werc used to determine the slope of a line through the remaining points 
for each well. The slopes were used to define interwell permeabilities using Equation 8-16. The average thicknesses of the reservoir between the 7-2 and each of the observation wells were used in the calculations. For the tests at the 5-1, 5-2, and 7-1, thicknesses of $11.5,12.5$, and 14.5 feet $\left(3.5,3.8\right.$ and $\left.4.4 \mathrm{~m}^{3}\right)$ were used. Permeability reduction factors (PRF) were calculated from these values. Estimates of first arrival time of the pressure pulse were also made from the semi-logrithmic figures.

\subsection{Results and Discussion}

\section{Injection Well Tests}

Pressure fall-off tests were performed before, during, and after the nutrient injection process to determine the effects of nutrient injection on the pilot injection well. The results indicate that the injection well experienced a loss of permeability in the region of Well 7-2 after the first nutrient injection, but that no further reduction in injectivity was experienced from later injections of nutrients.

Horner and MDH plots for the February 22, 1991 pressure fall-off test are given in Figures 8.1 and 8.2 and represent the condition of Well 7-2 before the field pilot study. Figures 8.3 and 8.4 are the Horner and MDH plots of the October 7, 1991 test. This test was conducted 30 days after the injection of the ammonium nitrate pre-flush and three days after the injection of the first 12.5 tons (11.3 tonnes) of molasses. Finally, Figures 8.5 and 8.6 are Horner and MDH plots from the January 28, 1992 test conducted 39 days after the last injection of nutrients. Results of the analysis are given in Table 8.1 .

Averaging the results of the February, 1991, test Well 7-2 indicated a permeability of $63 \mathrm{md}\left(0.06 \mu \mathrm{m}^{2}\right)$ and the effect of the fracture treatment was clearly 


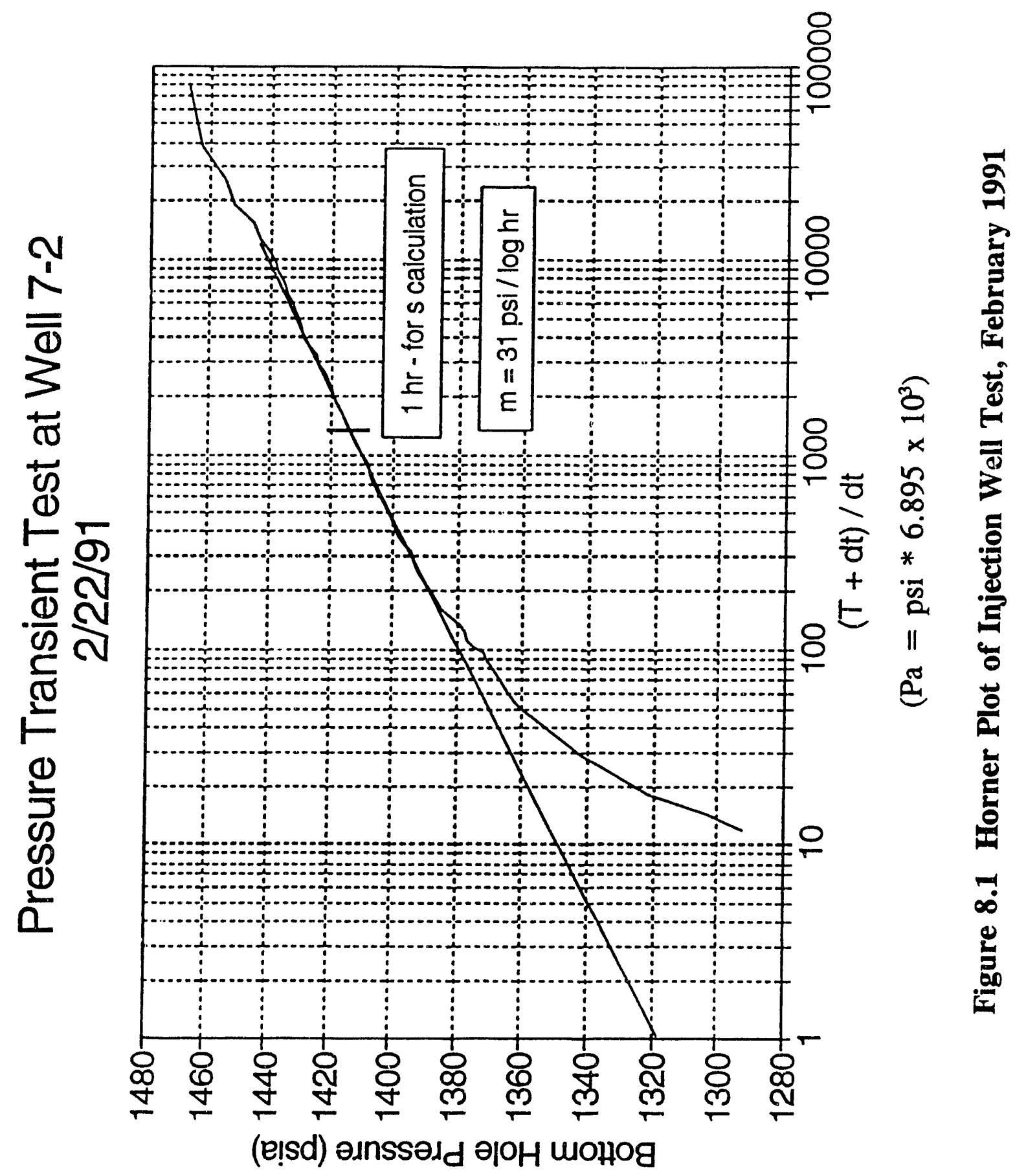




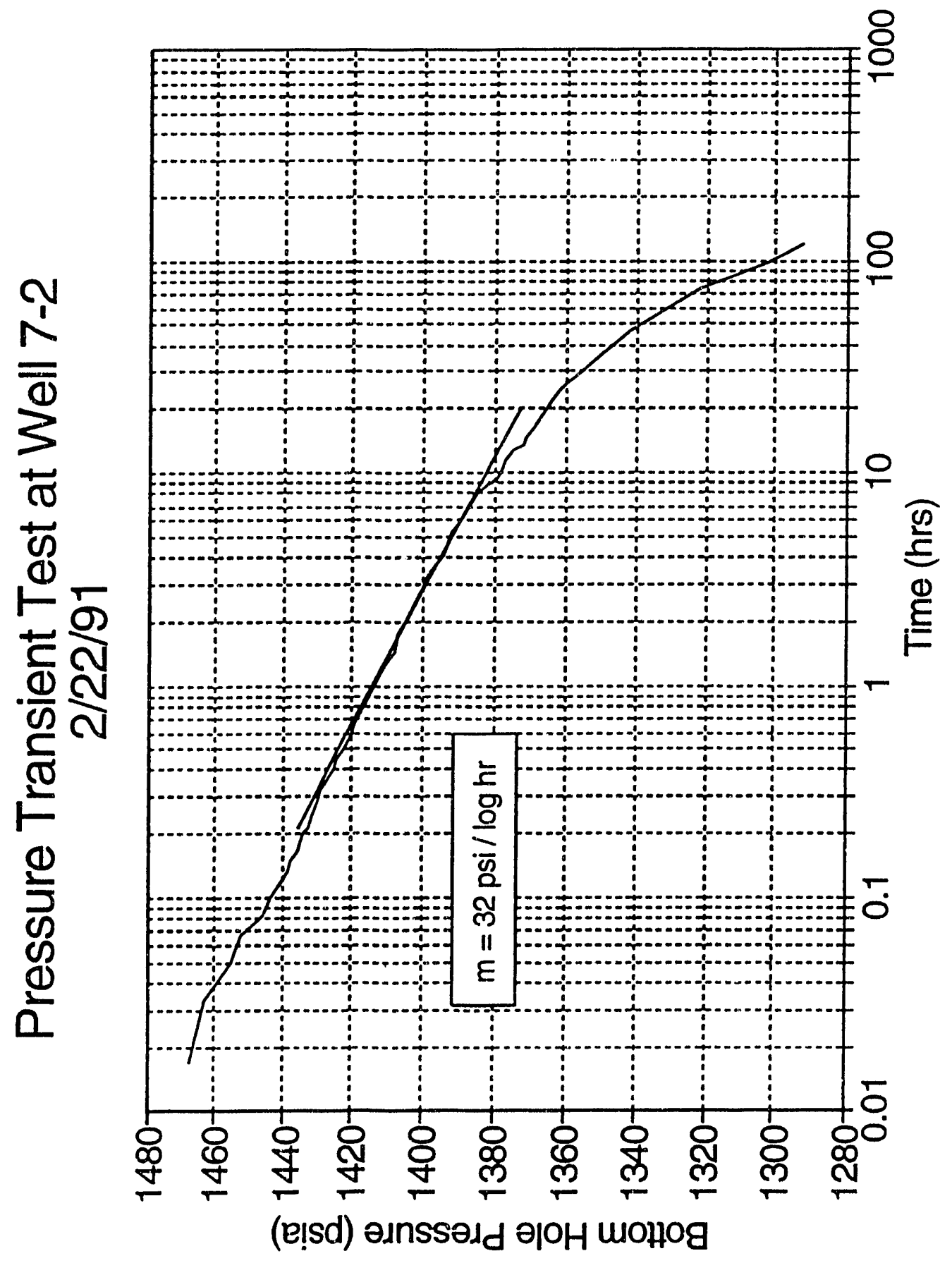

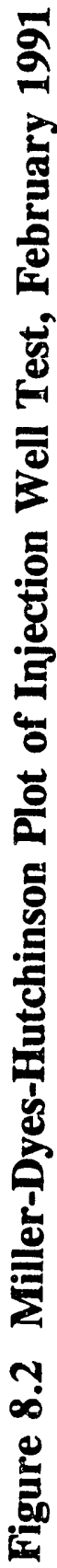




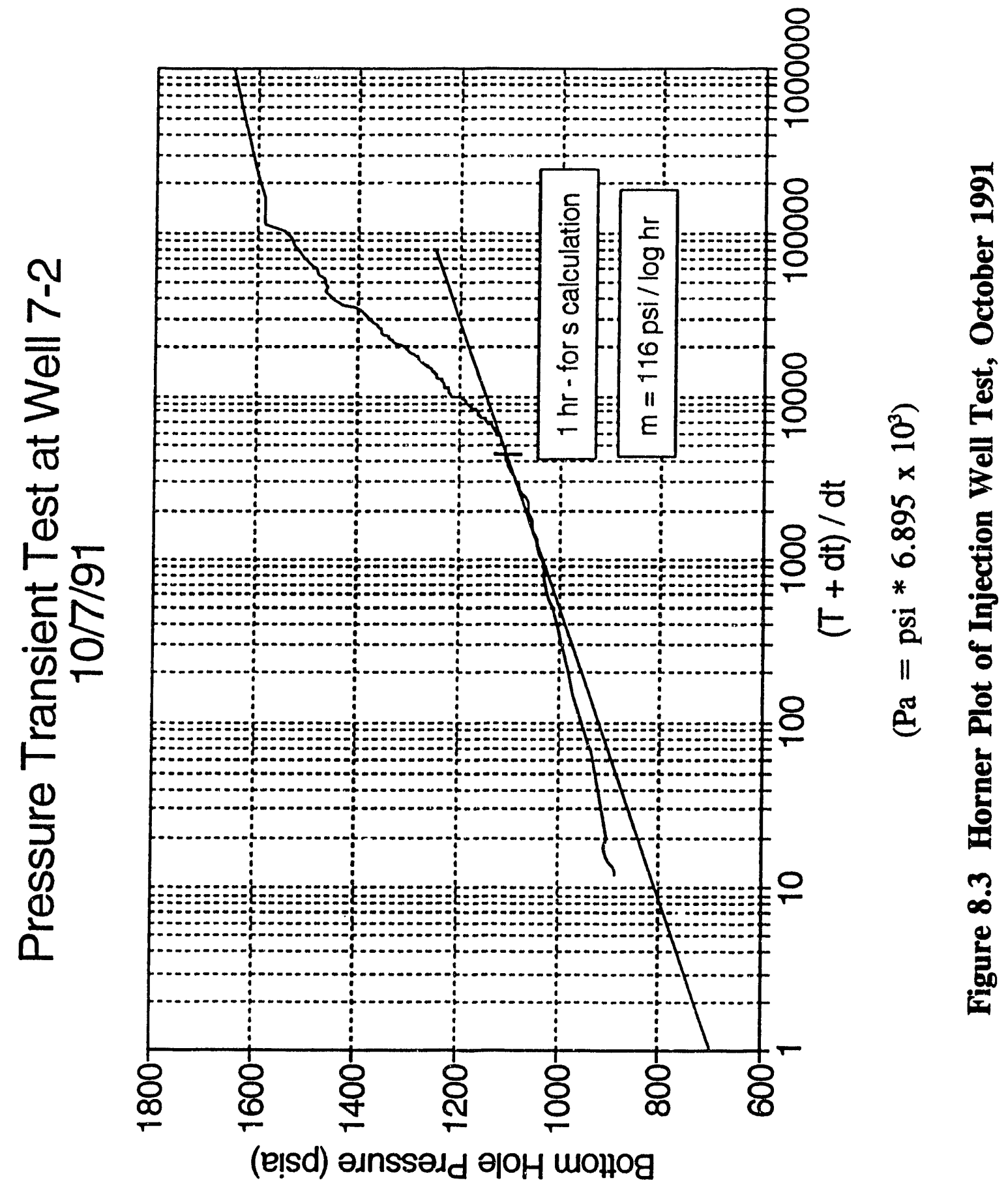




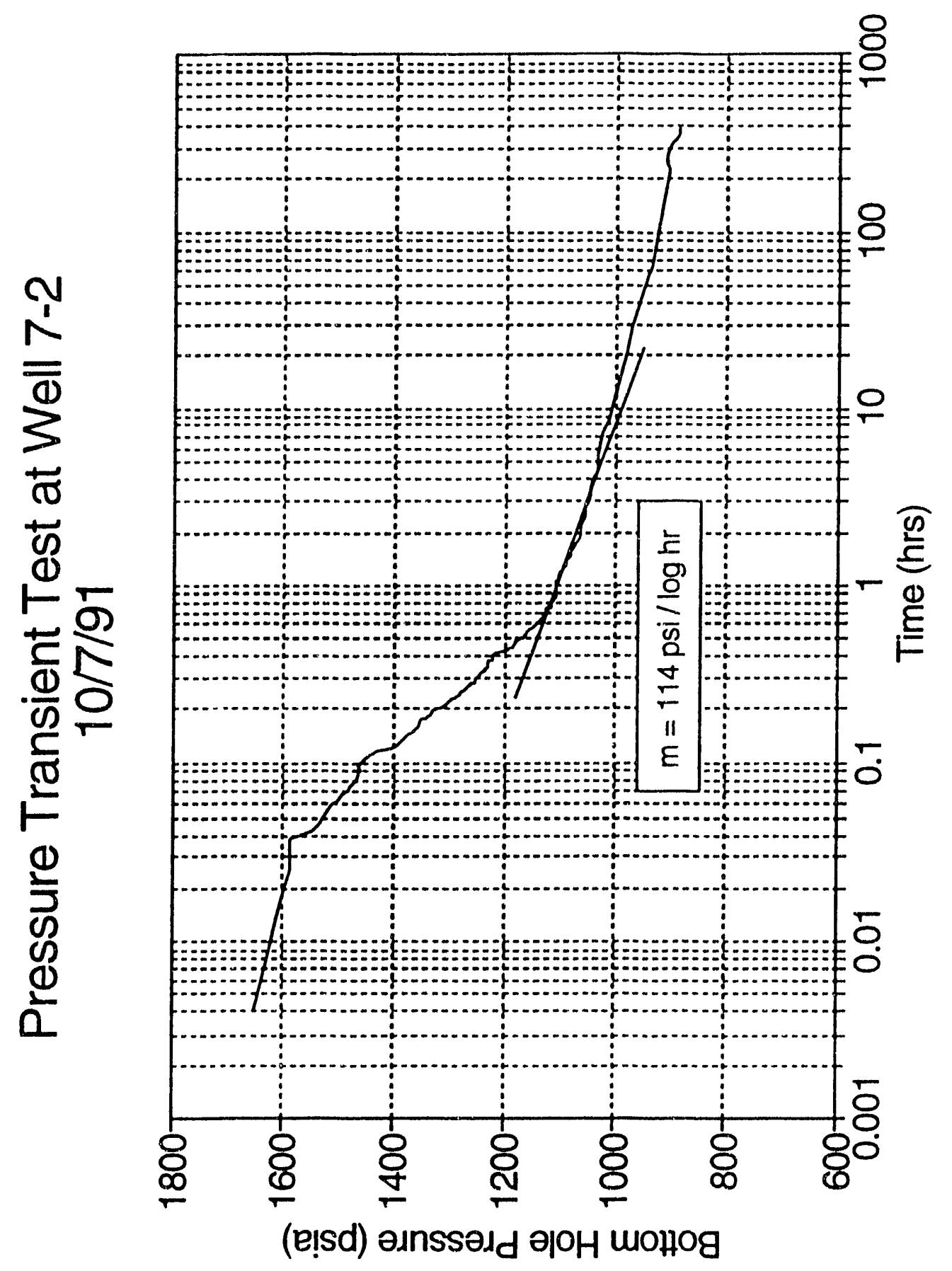

$\frac{2}{8}$

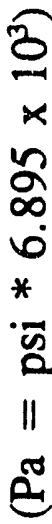

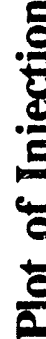

量

$+$

递 


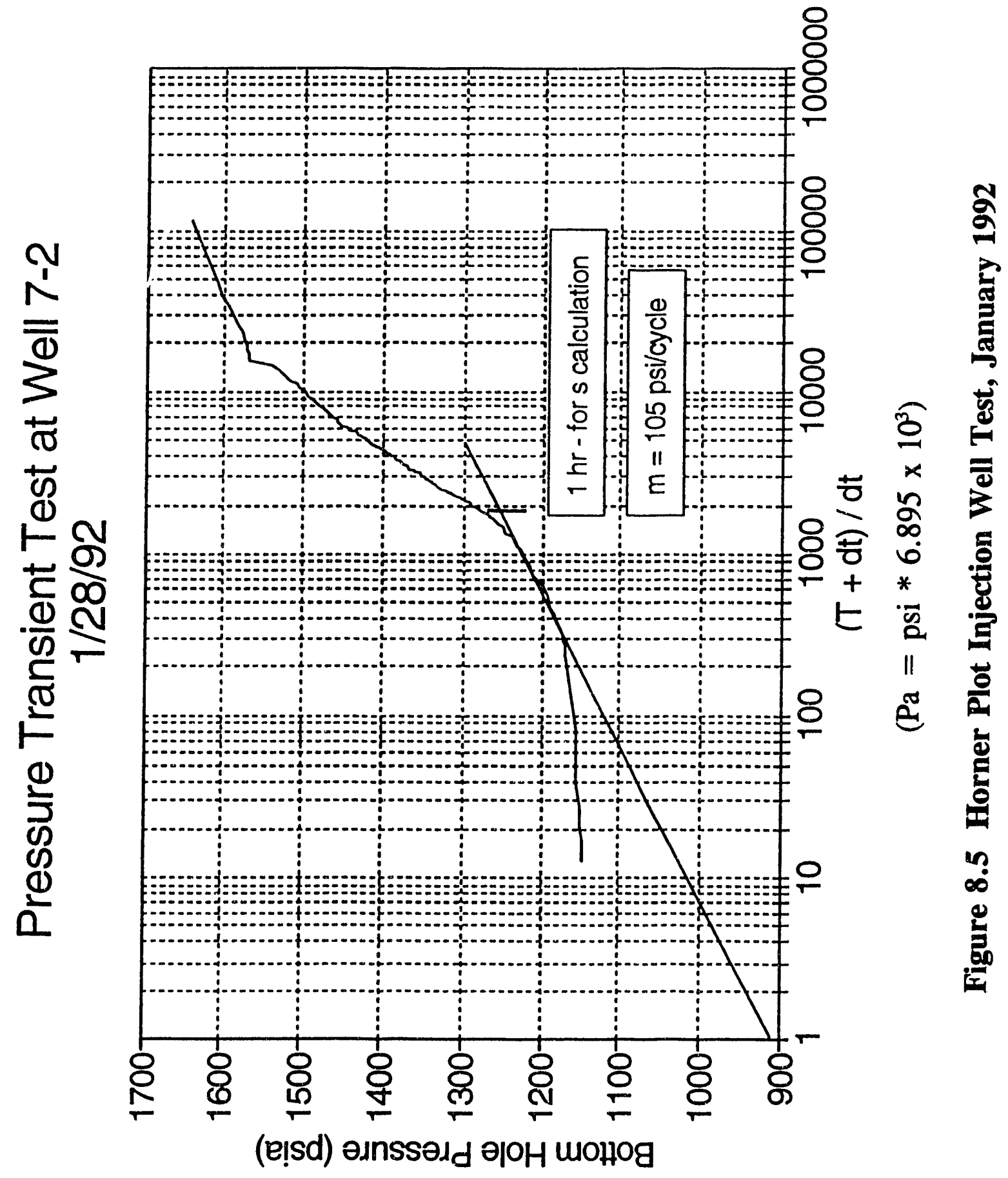



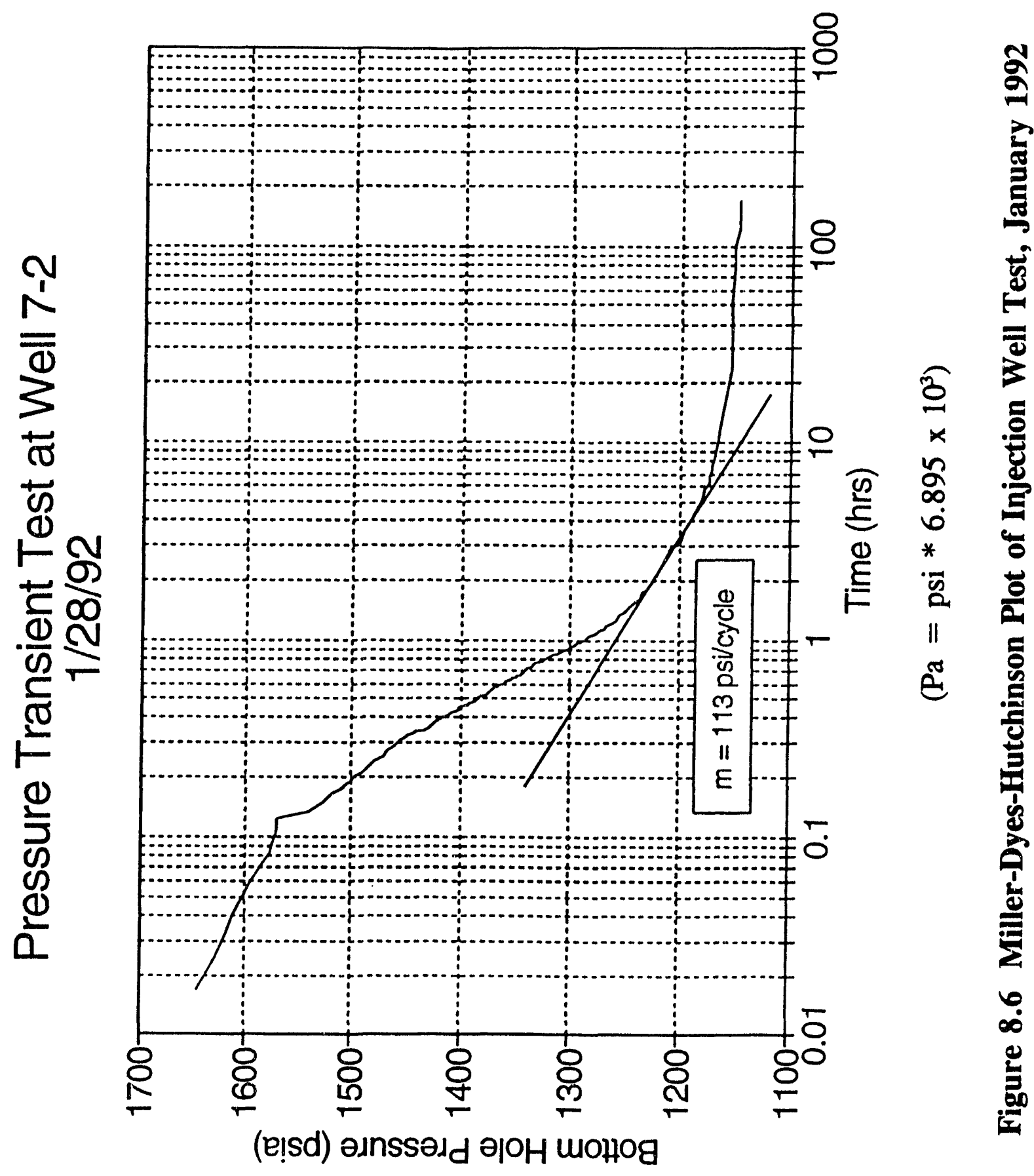
Table 8.1 Pressure Fall-off Test Results

\begin{tabular}{||c|c|c|c|c|c|c||}
\hline \multicolumn{7}{|c||}{ Horner Plot Analysis } \\
\hline Date & I bpd & $\mathrm{m}$ psi/cycle & $\mathrm{k}$ md & $\mathrm{p}_{\mathrm{w}}$ psia & $\mathrm{p}_{\mathrm{hr}} \mathrm{psia}$ & $\mathrm{s}$ \\
\hline $2 / 22 / 91$ & 144 & 31 & 64.0 & 1507 & 1413 & -2.79 \\
\hline $10 / 7 / 91$ & 335 & 116 & 39.7 & 1682 & 1107 & -0.34 \\
\hline $1 / 28 / 92$ & 295 & 105 & 38.7 & 1690 & 1255 & -1.26 \\
\hline & & & & & & \\
\hline Date & $\mathrm{I}$ bpd & $\mathrm{m}$ psi/cycle & $\mathrm{k}$ md & $\mathrm{p}_{\mathrm{w}} \mathrm{psia}$ & $\mathrm{p}$ 1hr psia & $\mathrm{s}$ \\
\hline $2 / 22 / 91$ & 144 & 32 & 61.8 & 1507 & 1413 & -2.88 \\
\hline $10 / 7 / 91$ & 335 & 114 & 40.4 & 1682 & 1107 & -0.25 \\
\hline $1 / 28 / 92$ & 295 & 113 & 35.9 & 1690 & 1255 & -1.56 \\
\hline
\end{tabular}

$$
\begin{aligned}
& \mathrm{m}^{3}=\mathrm{bpd} * 0.1590 \\
& \mathrm{~Pa}=\mathrm{psi}^{*} 6.895 \times 10^{3} \\
& \mathrm{~m}^{3}=\mathrm{md} * 9.869 \times 10^{-10}
\end{aligned}
$$


present in the skin of -2.84 . After the first nutrient treatment the permeability and skin values of $40 \mathrm{md}\left(0.04 \mu \mathrm{m}^{2}\right)$ and -0.3 , respectively, clearly indicate that some injection capacity of Well 7-2 was lost. This may have been caused by the nutrient injections or the six months of field operations before the nutrient injections. With only three days of brine injection since molasses injection a "ring" of higher viscosity fluid existed in the reservoir around Well 7-2 because of a lack of dispersion of the molasses rich fluid. The effects of this may have been observed in this test. Results from the last test indicated a permeability of $37.3 \mathrm{md}\left(0.037 \mu \mathrm{m}^{2}\right)$ and a skin of -1.41 . Injection of the remainder of the nutrient treatments and their metabolism did not further reduce the permeability in the vicinity of the 7-2. The improvement in skin value from the second test may be due to a more complete flushing or the complete metabolism of injected nutrients from the area around Well 7-2.

The loss of permeability and increase of the skin effect between the February and October 1991 tests also may have been due to regular field operations. Six months of regular field injection operations were performed between the first pressure fall-off test and the first nutrient injections. The reduction in permeability may be due to this operation rather than the nutrient injection. The surface injection pressures before and after the first nutrient injections [ 790 psig and 800 psig, respectively $\left(5.4 \times 10^{6}\right.$ and 5.5 x $10^{6} \mathrm{~Pa}$ absolute)] were approximately the same at the same rate of injection [300 bpd $\left.\left(47.7 \mathrm{~m}^{3} / \mathrm{d}\right)\right]$. Fifty tons (45 tonnes) of additional molasses were injected after the second well test without additional loss of permeability. This also supports the theory that the permeability loss was the result of either the six months of operation or the molasses rich fluid "ring". 
The decrease in permeability near Well 7-2 did not interfere with the injection of the nutrient treatments to the pilot area. All nutrient injections were carried out at a rate of $300 \mathrm{bpd}\left(47.7 \mathrm{~m}^{3} / \mathrm{d}\right)$ (or more) and surface pressures at or below $800 \mathrm{psig}\left(5.5 \times 10^{6}\right.$ Pa gauge), the Oklahoma Corporation Commission allowable injection pressure.

\section{Interwell Pressure Interference Tests}

Figures 8.7 through 8.9 present plots of pressure change divided by pulse rate on coordinate paper for each pilot production well. The plots were used to define the early and late time periods. Data from these periods were not used in the transient analysis. Both the 1991 test and 1992 test are plotted on a single figure and annotated. Plots of pressure change divided by pulse rate versus the logarithm of time, Figures 8.10 through 8.12, were used to determine slopes of lines through the points not eliminated in the previous evaluation. Late time points are not shown on these figures. Early time points were retained to allow first arrival time estimates. Results of these analyses are given in Table 8.2.

Using both slopes and arrival times permeability reduction factors for Well 5-1 are in good agreement. This is also true for Well 5-2. Well 7-2 values are not in agreement although both indicate a reduction in permeability. The pressure falloff test of Well 7-2 on February 1991 (Table 8.1$)$ indicated 64 md $\left(0.064 \mu \mathrm{m}^{2}\right)$ permeability and the interference test between Wells 7-2 and 7-1 indicated $60 \mathrm{md}\left(0.060 \mu \mathrm{m}^{2}\right)$. The interference test performed simultaneously between Well 7-2 and Wells 5-1 and 5-2 indicate $154 \mathrm{md}\left(0.154 \mu \mathrm{m}^{2}\right)$ and $181 \mathrm{md}\left(0.181 \mu \mathrm{m}^{2}\right)$, respectively. This suggests that a region of high permeability existed between Well 7-2 and the wells in Tract 5 previous to nutrient injection. The permeability reduction factors in the pilot area indicate that 


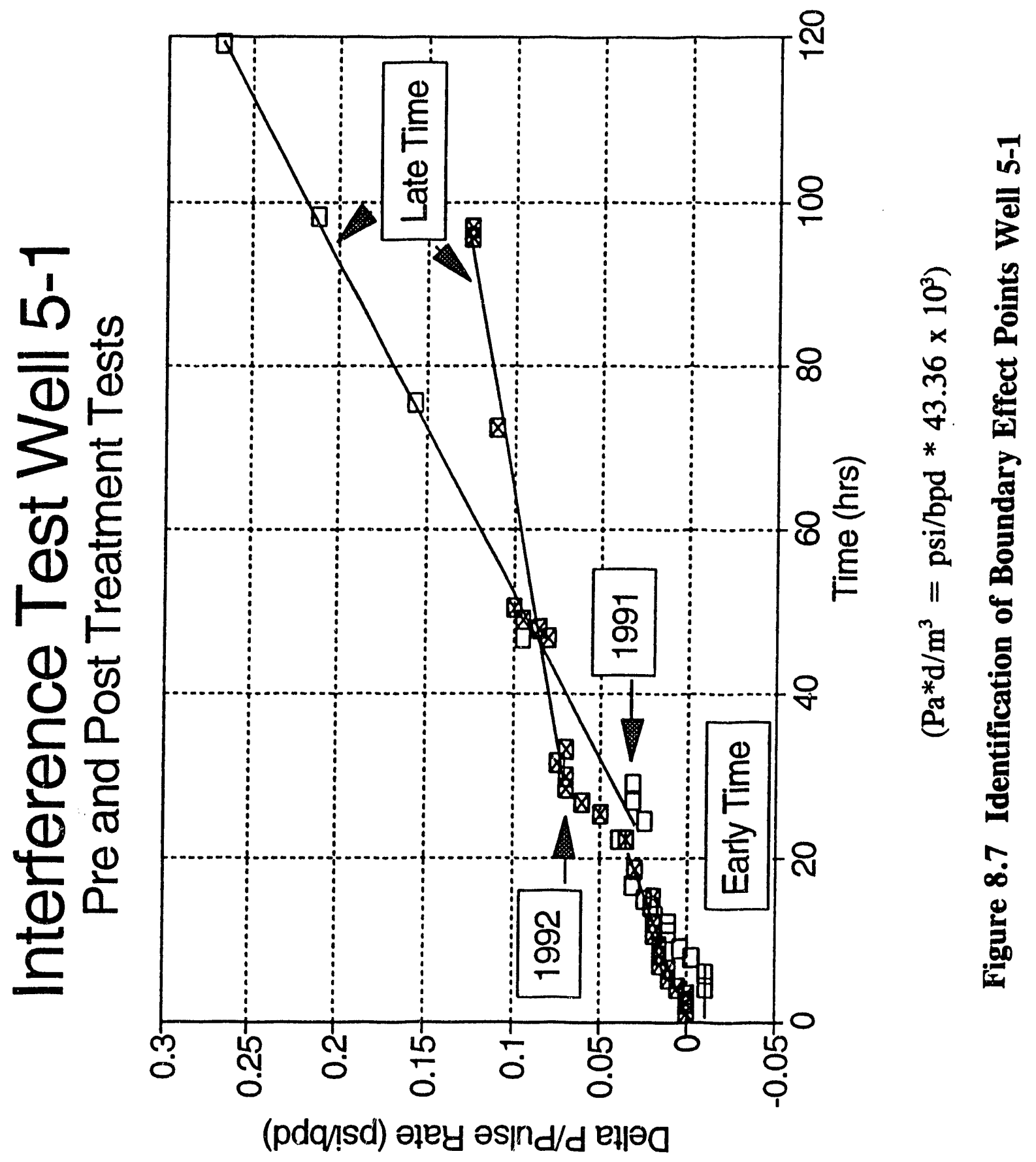




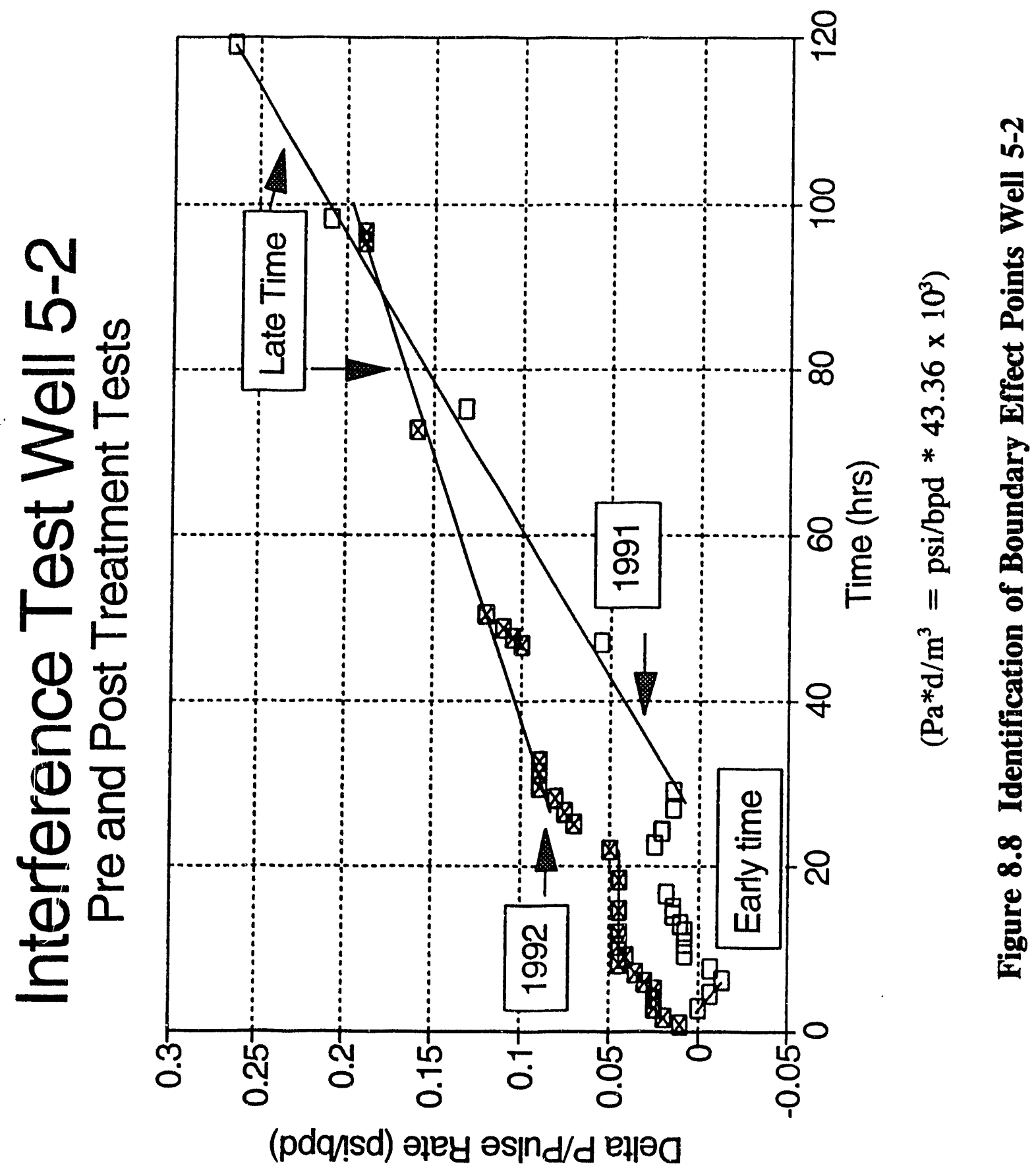




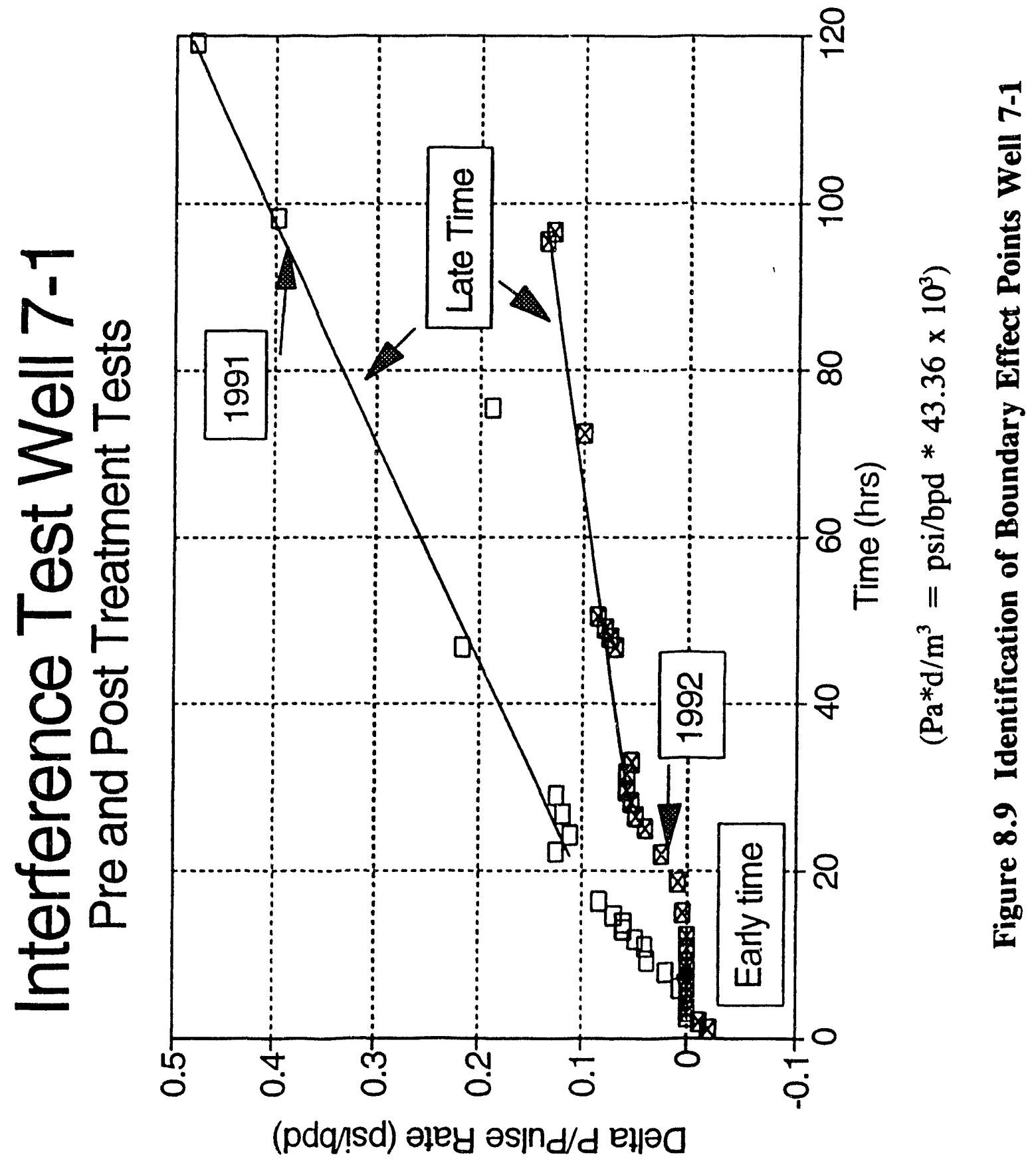




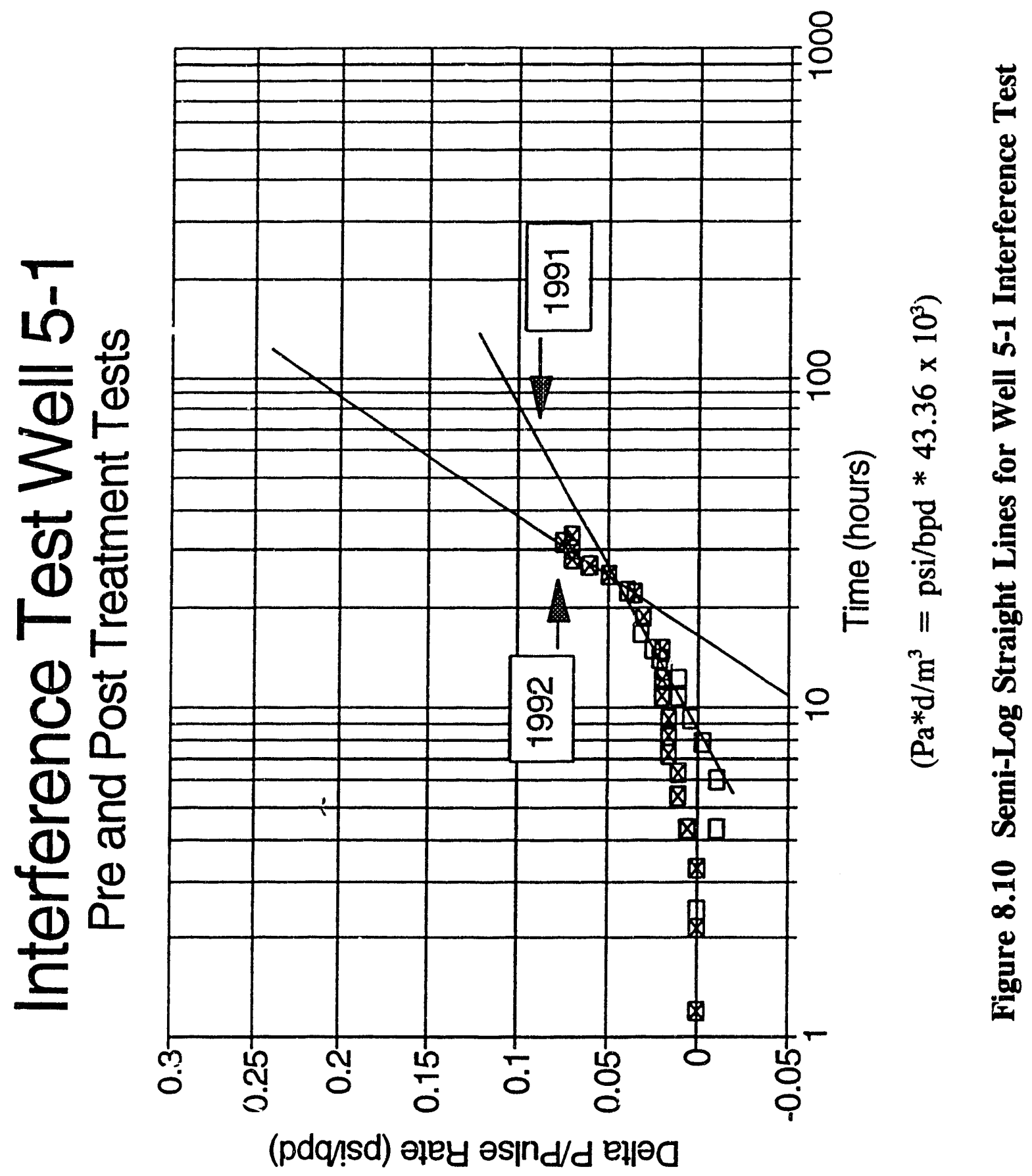




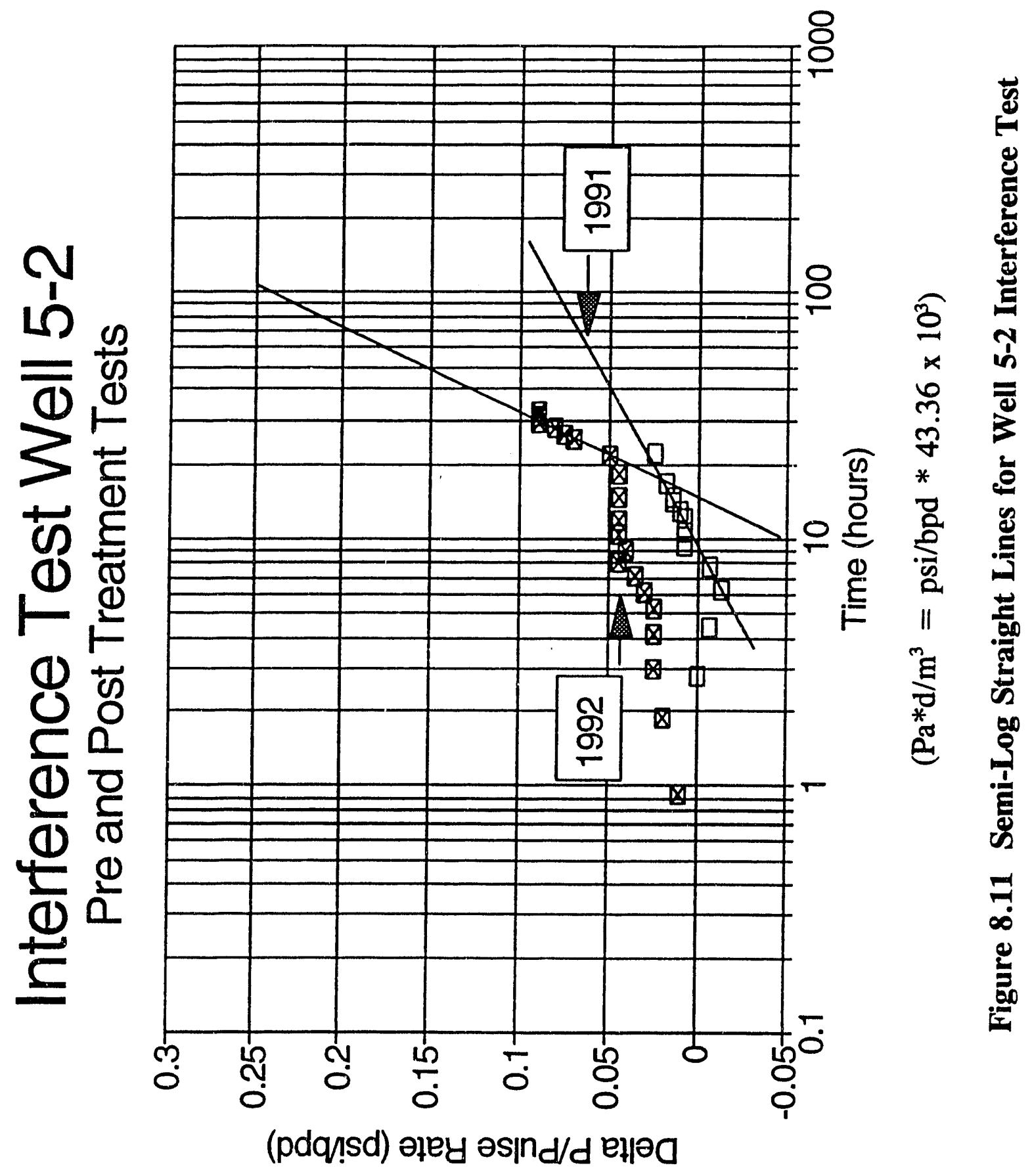




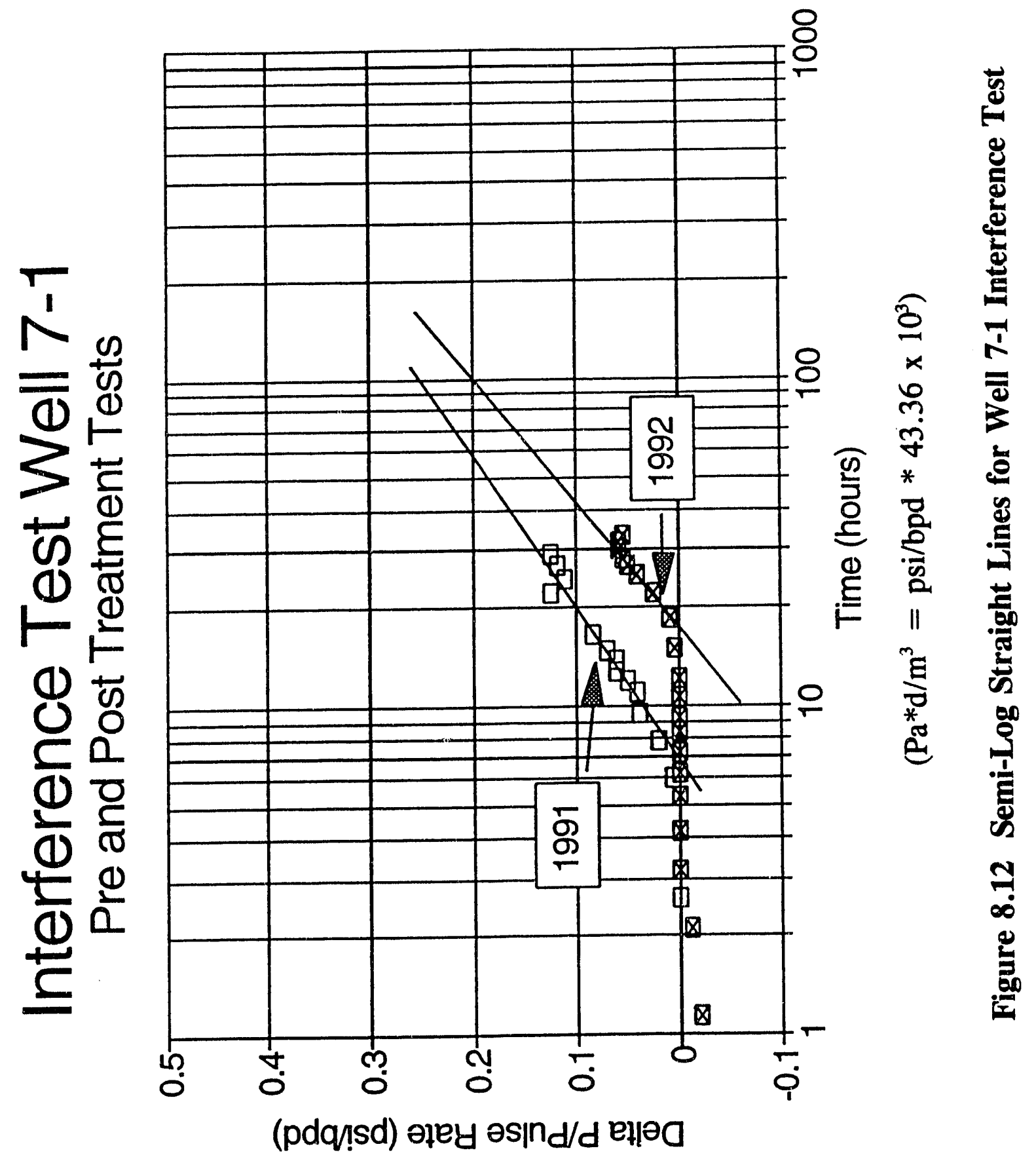


Table 8.2 Interference Pressure Test Results

\begin{tabular}{|c|c|c|c|c|c|c|}
\hline Well - Test & $\begin{array}{c}\text { Pulse } \\
\text { size } \\
\text { bpd } \\
\end{array}$ & $\begin{array}{c}\text { m } \\
\text { psi/bpd } \\
\text { /cycle } \\
\end{array}$ & $\begin{array}{c}\mathbf{k} \\
\mathbf{m d} \\
\end{array}$ & $\begin{array}{c}\text { PRF } \\
\text { from } \\
\mathbf{m} \\
\end{array}$ & $\begin{array}{c}\mathbf{t}_{\text {arrival }} \\
\mathbf{h r} \\
\end{array}$ & $\begin{array}{l}\text { PRF } \\
\text { from } \\
t_{\text {arrival }} \\
\end{array}$ \\
\hline $5-1 \quad 1991$ & 144 & 0.101 & 154.0 & & 7.7 & \\
\hline $5-1 \quad 1992$ & 100 & 0.276 & 56.4 & 0.37 & 21 & 0.37 \\
\hline 5-2 1991 & 144 & 0.0791 & 180.9 & & 6 & \\
\hline $5-2 \quad 1992$ & 100 & 0.289 & 49.5 & 0.27 & 21 & 0.29 \\
\hline $7-1 \quad 1991$ & 144 & 0.205 & 60.2 & & 8 & \\
\hline $7-1 \quad 1992$ & 100 & 0.285 & 43.3 & 0.72 & 16 & 0.50 \\
\hline
\end{tabular}

$$
\begin{aligned}
& \mathrm{m}^{3} / \mathrm{d}=\mathrm{bpd} * 0.1590 \\
& \mathrm{~Pa} \cdot \mathrm{d} / \mathrm{m}^{3}=\mathrm{psi} / \mathrm{bpd} * 43.36 \times 10^{3} \\
& \mu \mathrm{m}^{2}=\mathrm{md} * 9.869 \times 10^{-10}
\end{aligned}
$$


nutrient injection and microbial activity reduced the permeability of pilot area flow paths. Microbial growth caused greater reductions in permeability in the region toward Tract 5. This indicates selective plugging occurred in the high transmissivity region toward Wells 5-1 and 5-2. Less than $15 \mathrm{md}\left(0.015 \mu \mathrm{m}^{2}\right)$ difference exists between the three post-treatment slope determined interwell permeabilities. Post-treatment interwell permeabilities using arrival time permeability reduction factors differ by no more than $27 \mathrm{md}\left(0.027 \mu \mathrm{m}^{2}\right)$. Both methods show that a more uniform permeability distribution was produced in the pilot area. Establishing a more uniform permeability distribution in the affected area is indicative of a successful selective plugging process.

\subsection{Conclusions}

Well 7-2 evidenced reduced permeability after nutrient injection into this well. Although permeability was reduced following injection of the first nutrients, injection of later nutrient treatments and brine did not significantly further reduce the permeability and the injections were performed with normal surface injection pressures. Uniformity of rates and pressures over the duration of the nutrient injection operations implies the reduction in permeability was the result of unconsumed molasses around the well bore or the result of six months of operations between the first pressure test performed and the test after the first nutrient injection.

Evidence of a successful selective plugging process exists in the pilot area. The results of the post-treatment interwell pressure tests indicate the permeabilities of the interwell paths were reduced by the microbial process and the pilot area permeabilities became more uniform. Reducing permeability in high permeability flow paths and

establishing a uniform permeability distribution in the reservoir is indicative of a 
successful selective plugging process.

\subsection{Nomenclature}
A
reservoir area, $\mathrm{cm}^{2}$
B
formation volume factor, reservoir bbl/stb
$c_{t}$
total compressibility, $\mathrm{psi}^{-1}$ or atm ${ }^{-1}$
$\mathrm{C}_{\mathrm{A}} \quad$ Dietz shape factor, dimensionless
h
thickness, $\mathrm{ft}$ or $\mathrm{cm}$
k
permeability, md or Darcies
m
slope, psi/logarithmic cycle
$\mathrm{p}$
pressure, psia or atmospheres
$\mathrm{p}_{\mathrm{lhr}}$
pressure after 1 hour of test time, psia
$\mathrm{p}_{\mathrm{i}} \quad$ initial pressure, psia or atmospheres
$p_{w f}$
flowing well pressure, psia
$\mathrm{p}_{\mathrm{ws}}$
shut-in well pressure, psia
PRF
permeability reduction factor, dimensionless
q
flow rate, bpd or $\mathrm{cc} / \mathrm{sec}$
r
radius, $\mathrm{ft}$ or $\mathrm{cm}$
$r_{w}$
well bore radius, $\mathrm{ft}$ or $\mathrm{cm}$
$r_{\text {inf }}$
radius of influence of a pressure test, $\mathrm{ft}$ or $\mathrm{cm}$
S
skin, dimensionless
$\mathrm{t}$
time, hours or seconds
$\Delta \mathrm{t}$
time from closure of a flowing well, hours or seconds
$\mathrm{T}$
time of prior flow period, hours or seconds 
viscosity, centipoise

$\phi$

porosity, fraction

$\gamma$

Euler's constant, 1.781 


\section{Chapter 9. Tracer Studies}

\subsection{Introduction}

Tracer tests were performed in the Southeast Vassar Vertz Sand Unit (SEVVSU) pilot area to determine the dominant flow paths conveying injection water in the pilot region. Three tests were performed in the field. The first and second tests were performed before nutrient injection and served to identify a major flow path in the reservoir. The third test was performed after the last of the nutrients were injected and any subsequent microbial growth had occurred. Changes in the arrival time of tracer at a production well indicate a change in a flow path in the reservoir caused by nutrient injection.

\subsection{Theory}

Brigham and Abbaszedah-Dehghani (1987) discussed the analysis of tracer responses for determining reservoir description. A stream-line model is used to describe the permeability of a layered reservoir. This is combined with a plot of tracer concentration at a production well versus time to identify the permeability and thickness of an arbitrarily chosen number of layers. Simply stated, the tracer concentration plot is divided among the layers. The arrival time of the tracer during that period and the amount of tracer recovered during that period is related to the layer permeabilitythickness product. Individual values of permeability and thickness may be calculated.

Field applications of several tracers in evaluating an EOR project are presented by Lichtenberger (1991). The recovery of the different tracers was reported. The most successful tracer, with $90 \%$ recovery, was sodium thiocyanate (SCN). A simplified 
version of the model by Brigham and Abbaszedah-Dehghani is presented and used to perform a 20 layer model of the field being studied.

Both authors address the qualitative benefits of tracer studies. The use of tracers can identify dominant flow paths in the reservoir. Lichtenberger discusses the importance of their use in planning an enhanced oil recovery process.

In the SEVVSU, the tracer injected was detected at a well to the northeast of the injection well. The tracer response at this well was very brief and a detailed plot of tracer concentration versus time was not obtained. Without a detailed tracer production curve the quantitative analysis technique can not be performed.

In this study, the length of time from injection to arrival of tracer at a production well was used as a qualitative measure of interwell transmissivity. Two tests were performed in the field. The arrival times of tracer at the tracer producing well were used to qualitatively measure the effectiveness of a selective plugging enhanced oil recovery field trail. The change in arrival times indicates a high transmissivity flow path in the reservoir was substantially reduced in its capacity to transmit fluids.

\subsection{Tracer Selection}

A fluorescent dye was chusen as the tracer to be used in the field. The attributes provided by fluorescent dyes were simple visual detection under ambient light at high concentrations and visual detection under ultraviolet light at low concentrations (Davis, et al., 1985). Absorbance properties of these tracers were known and low concentrations could be detected by spectrophotometric analysis. Lichtenberger (1991) discusses various tracer attributes and problems associated with their use. The ideal tracer is defined as

"a material that moves at the same speed as the injected fluids, is not adsorbed or broken 
down by the chemical or bacteriological environment in the reservoir, and that can be detected and quantitated at the high dilutions that can be expected." Radioactive tracers were not used in this study for safety concerns. Especially during injection very high concentrations of radioactive material must be handled and, if early breakthrough should occur before the tracer has sufficiently decayed, the risk of contaminating the field surface facilities exists. Because of high salinities in the SEVVSU, the arrival of certain inorganic salts would potentially be masked. Alcohols and organic solvents can be used by bacteria in the reservoir. Because a large community of bacteria were expected to be cultivated in the reservoir, these were not chosen. Some chemicals such as SCN are biocides and would not be compatible with the microbial project.

Many fluorescent dyes are available and their properties have been compiled by Smart and Laidlaw (1977). Inquiries indicated two of these as likely candidates for the microbial field pilot. Sodium fluorescein (yellow, green at high concentrations) (Weaver and Wilson, personal communication, 1990) had been used successfully in oil field operations. Rhodamine WT (orange) (Sabatini, personal communication, 1991 and Sabatini and Austin, 1991) was in service in ground water studies performed in environmental applications. Lichtenberger (1991) reports that some fluorescent tracers were readily adsorbed onto rock material. Laboratory tests were conducted which indicated sodium fluorescein displayed low absorbency in the presence of crushed Vertz sandstone. Subsequent tests indicate either absorbance after extended contact with Berea sandstone or absorbance of the fluorescein into bacterial cells which cause significant loss of tracer. These tests are described in the following section. 


\subsection{Tracer Experimental Analysis}

The experiments described in this section were conducted to provide information about tracer retention within a core. All experiments were carried out using oil and brine taken from Well 1A-9 of SEVVSU. The experiments were performed at reservoir temperature.

\section{Core Preparation}

The cores used in this experiment were cut from Berea sandstone. The cores were steam cleaned for two weeks to remove humic acid and organic materials. After steam cleaning, the cores were dried for twenty-four hours at $125^{\circ} \mathrm{C}$ and placed in a vacuum desiccator to cool. J-B Weld, a metal coating mixture, was applied uniformly to the outer surface of the core. The ends of the cores were not coated. The coating was allowed to age overnight. Two aluminum end plates with rubber gaskets and Swagelock taps were mounted at the ends of the cores.

\section{Experimental Procedure}

Figure 9.1 is a diagram of the experimental apparatus used in this experiment. A displacement metering pump was used to inject the liquids into the core and a sealed glass bottle was used to collect the effluent from the downstream end of the core. The sealed glass bottle provided a simple method to collect water, oil and gas phases without contaminating the samples with air. Three pressure gauges were placed at the upstream end, middle and downstream end of the core. After checking for leaks the core assembly was placed in an $35^{\circ} \mathrm{C}$ oven. Before connecting a core for an experimental run, all lines were filled with injection liquids to assure that no air would enter the core during injection. The core was then vacuum saturated with brine. The pore volume and the 


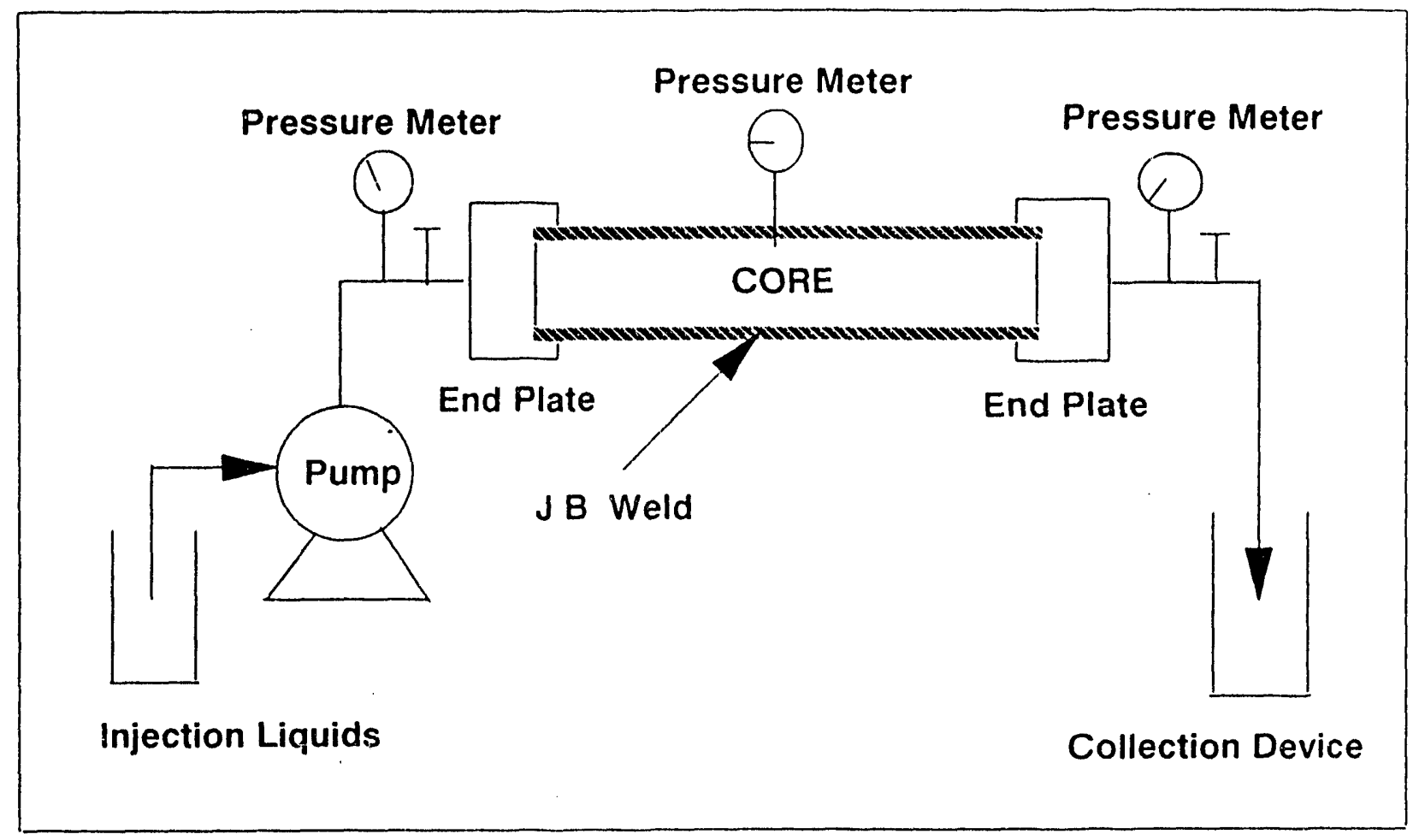

Figure 9.1 Diagram of Tracer Experiment Apparatus 
absolute permeability of the core were determined. Oil was then injected into the core and it was flooded to immobile water saturation. The connate water saturation and the effective permeability to oil were determined. The core was then flooded with brine to residual oil saturation and the effective permeability to brine was determined.

After these steps were completed, one-half pore volume of tracer was injected into Core \#1 followed by $3 \mathrm{PV}$ brine to displace the tracer. The effluent tracer concentration was determined by absorbance and the amount of tracer absorption was calculated by mass balance.

For Core $\# 2$, after pore volume, absolute permeability, effective permeability to brine, effective permeability to oil, connate water saturation and residual oil saturation were determined, one pore volume of nutrient was injected and then the core was shut-in for a two-week incubation period. After the treatment of nutrient injection and incubation, one-half pore volume of tracer slug was injected and retained in the core for 22 days. Produced fluids from the core were analyzed for the presence of sodium fluorescein by photo-absorbance, fluorescence, and high pressure liquid chromatography.

\section{Experimental Results}

A summary of the experiments is listed in Table 9.1. Figure 9.2 illustrates the plot of the effluent concentration data from Core \#1 versus injected pore volumes. The open squares of Figure 9.2 are the experimental effluent concentrations from Core \#1. The solid line of Figure 9.2 represents the simulated solution from the dispersion model (Brigham and Abbaszedah-Dehghani, 1987). Both experimental and simulated effluent concentrations were normalized by using the ratio of effluent concentration to the original concentration. As shown in Figure 9.2, the simulated effluent concentration curve 
Table 9.1 Summary of Experimental Results

\begin{tabular}{|c|c|c|c|}
\hline & & Core \#1 & Core \#2 \\
\hline Dimensions & $\begin{array}{l}\text { Cross Section Area } \\
\text { Length } \\
\text { Bulk Volume } \\
\text { Pore Volume } \\
\text { Porosity }\end{array}$ & $\begin{array}{l}23 \mathrm{~cm}^{2} \\
50 \mathrm{~cm} \\
1150 \mathrm{ml} \\
212 \mathrm{ml} \\
18.5 \% \\
\end{array}$ & $\begin{array}{l}3.3 \mathrm{~cm}^{2} \\
19 \mathrm{~cm} \\
215 \mathrm{ml} \\
38 \mathrm{ml} \\
17.7 \% \\
\end{array}$ \\
\hline Saturation & Absolute Permeability & $210 \mathrm{md}$ & $71 \mathrm{md}$ \\
\hline $\begin{array}{l}\text { Oil Flood } \\
\text { (Vassar Oil) }\end{array}$ & $\begin{array}{l}\text { Effective Perm. to Oil } \\
\text { Original Oil Saturation } \\
\text { Connate Water Saturation }\end{array}$ & $\begin{array}{l}145 \mathrm{md} \\
73 \% \\
27 \% \\
\end{array}$ & $\begin{array}{l}53 \mathrm{md} \\
71 \% \\
29 \% \\
\end{array}$ \\
\hline $\begin{array}{l}\text { Water Flood } \\
\text { (Vassar Brine) }\end{array}$ & $\begin{array}{l}\text { Effective Perm. to Water } \\
\text { Residual Oil Saturation }\end{array}$ & $\begin{array}{l}62 \mathrm{md} \\
21 \% \\
\end{array}$ & $\begin{array}{l}14 \mathrm{md} \\
28 \%\end{array}$ \\
\hline Tracer Slug & $\begin{array}{l}\text { Volume Injected } \\
\text { Incubation Period } \\
\text { Original Concentration } \\
\text { Tracer Recovery } \\
\text { Tracer Loss } \\
\end{array}$ & $\begin{array}{l}106 \mathrm{ml} \\
1 \text { day } \\
5 \mathrm{mg} / 1 \\
99 \% \\
1 \% \\
\end{array}$ & $\begin{array}{l}19 \mathrm{ml} \\
22 \text { days } \\
5 \mathrm{mg} / 1 \\
10 \% \\
90 \% \\
\end{array}$ \\
\hline $\begin{array}{l}\text { Nutrient Inj. } \\
\text { Treatment }\end{array}$ & $\begin{array}{l}\text { Volume Injected } \\
\text { Incubation Period } \\
\text { Total Pressure Increase } \\
\text { Effective Perm, to Water after } \\
\text { Treatment }\end{array}$ & & $\begin{array}{l}38 \mathrm{ml} \\
14 \text { days } \\
5.8 \mathrm{psig} \\
6.4 \mathrm{md}\end{array}$ \\
\hline
\end{tabular}

Table 9.2 Absorbance and Concentration

\begin{tabular}{||l|c|c||}
\hline \multicolumn{1}{|c|}{ FLUIDS } & $\begin{array}{c}\text { ABSORBANCE } \\
\text { (unit) }\end{array}$ & $\begin{array}{c}\text { CONCENTRATION } \\
\text { (mg/L) }\end{array}$ \\
\hline F1 (Original Tracer) & 0.74 & 5.01 \\
\hline F2 (Residual Tracer) & 0.70 & 4.74 \\
\hline F3 (Residual Tracer) & 0.68 & 4.60 \\
\hline
\end{tabular}




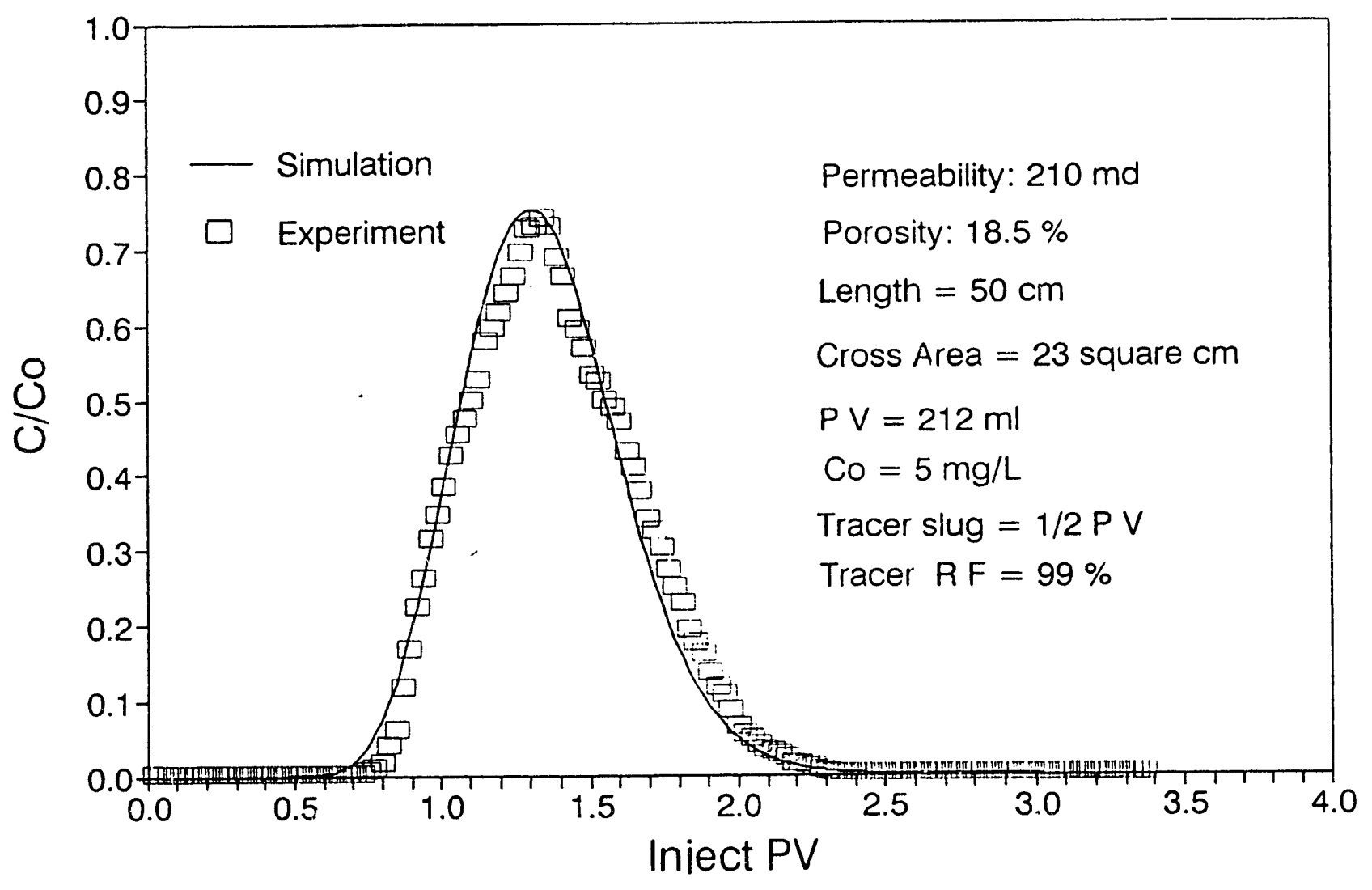

Figure 9.2 Plot of $\mathrm{C} / \mathrm{Co}$ versus Injected Pore Volumes (Core \#1, Tracer Analysis) 
matches the experimental effluent concentration data. From Figure 9.2, the tracer recovery factor is calculated to be $99 \%$, which implies that there was almost no absorption of sodium fluorescein within the core. Core \#2 was inoculated with one pore volume of nutrient and shut-in for a 14-day incubation period. The pressure increases were monitored during the incubation period. Figure 9.3 shows the pressure increases during the incubation period for Core $\# 2$. The lower curve with filled squares shows the regular plot of pressure increases versus incubating time. The upper curve with filled triangles represent the semilog plot of pressure increases versus incubating time. The pressure increased a total $6 \mathrm{psi}\left(41.4 \times 10^{3} \mathrm{~Pa}\right)$ during the 14-day incubation period for Core $\# 2$. Core $\# 2$ was flooded with 5 pore volumes of brine to displace the half pore volume of tracer slug retained within the core for 22 days. Only $10 \%$ of the tracer was recovered, which meant that $90 \%$ of sodium fluorescein was lost during 22-day incubation period.

\section{Tracer Adsorption on the Crushed Rock}

This experiment was conducted to investigate adsorption of fluorescein on crushed

rock. The rock, cut from Vassar Vertz Sand Unit cores, was crushed and screened using a 20 -mesh sieve. The tracer was prepared by diluting fluorescein with distilled water to a solution of $5 \mathrm{mg} / \mathrm{L}$.

As shown in Figure 9.4, the original tracer solution (F1) was first mixed with the crushed rock; second, the residual tracer solution (F2) was filtered and re-mixed with rock; finally, the solution (F3) was collected and filtered.

All original and residual tracer solutions were measured for their absorbance (Table 9.2), and the tracer concentrations were calculated using a calibration chart 


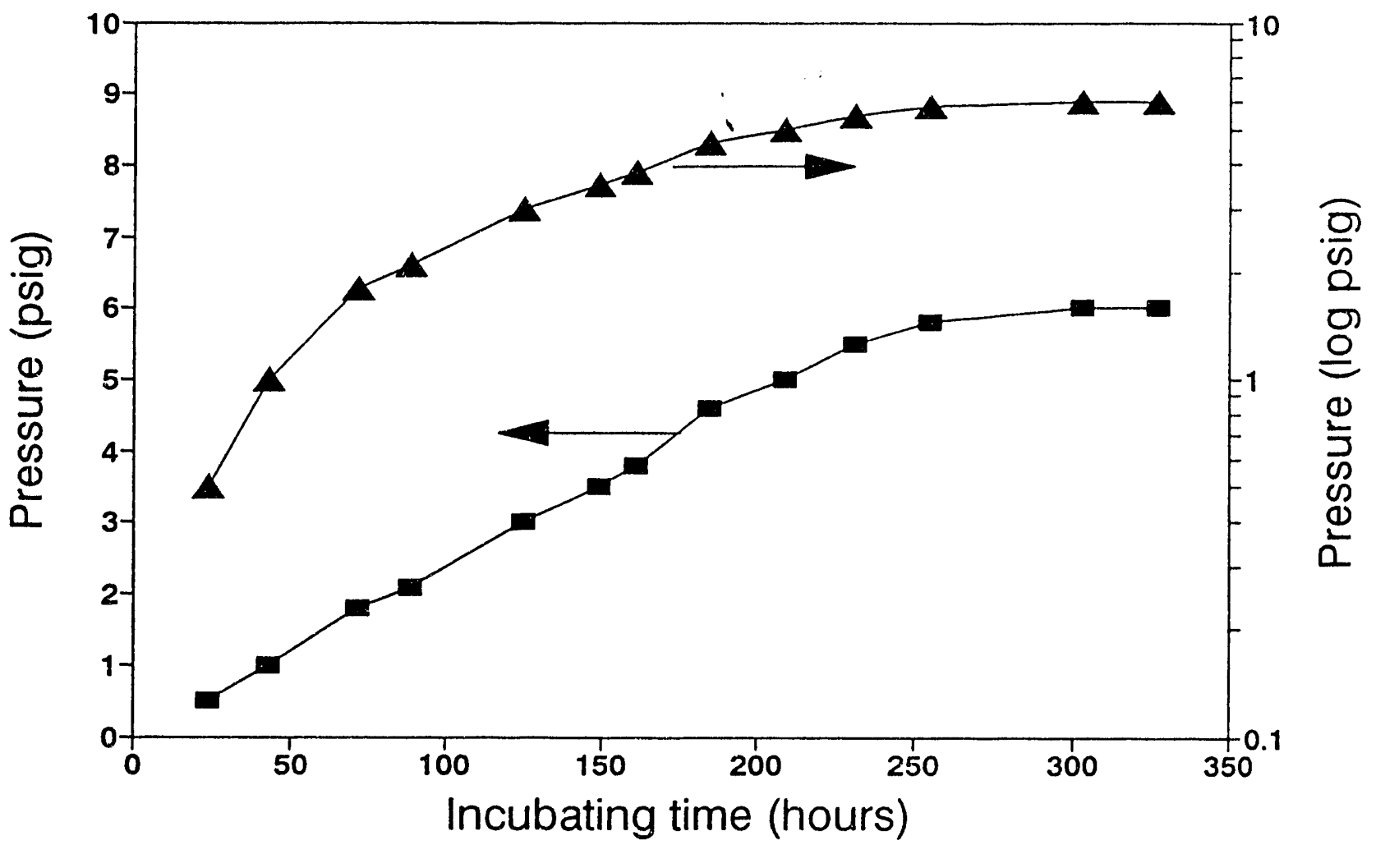

$$
\left(\mathrm{Pa}=\mathrm{psi} * 6.895 \times 10^{3}\right)
$$

Figure 9.3 Pressure Changes during Incubation

(Core \#2, Nutrient Injection Treatment) 


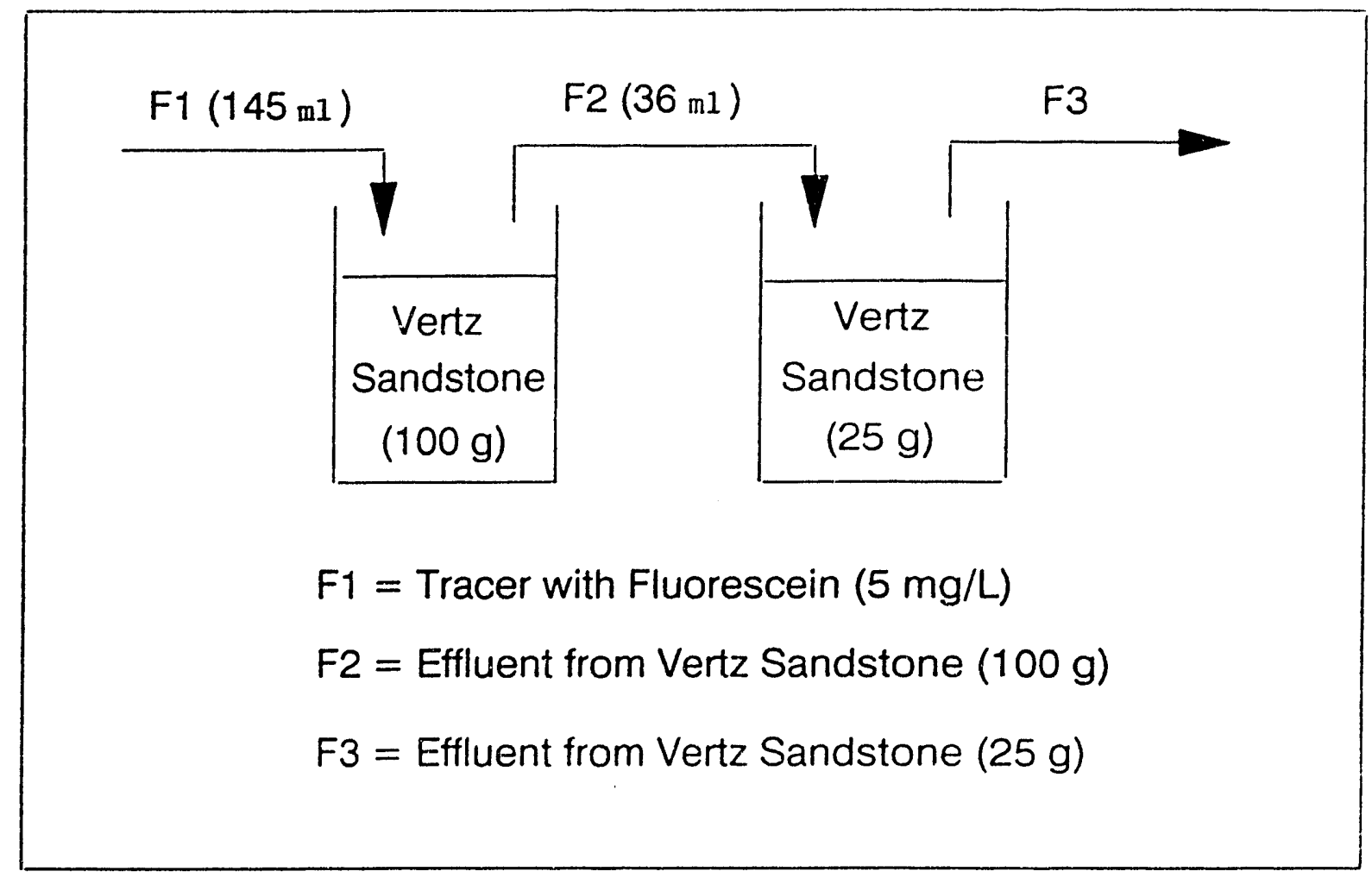

Figure 9.4 Tracer Test for Crushed Vassar Rock 


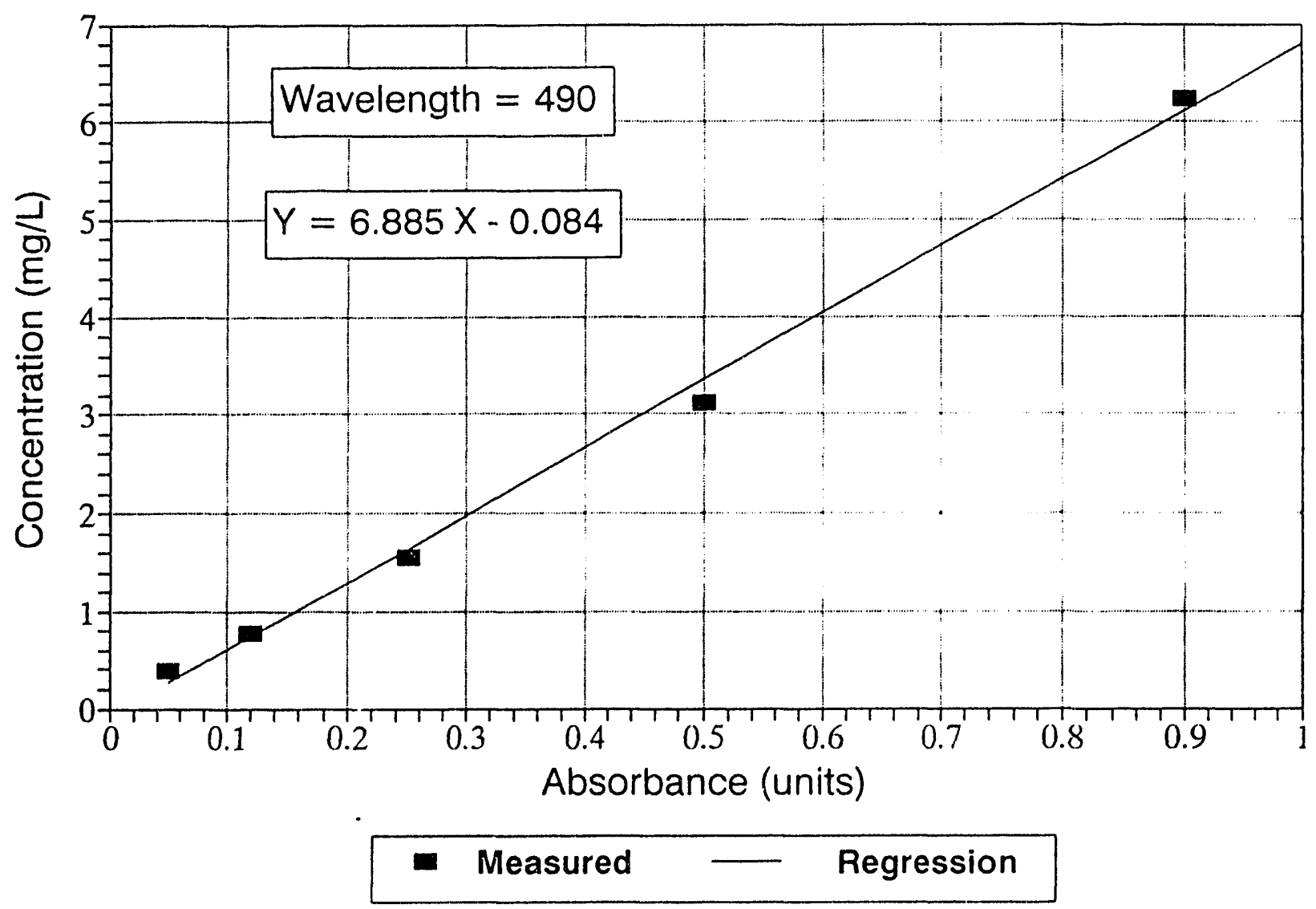

Figure 9.5 Spectrometer Calibration of Fluorescein 
(Figure 9.5). The results indicated that adsorption of fluorescein on the crushedVertz sandstone is very small.

\section{Experimental Conclusions}

(1) There was little adsorption of sodium fluorescein within the Berea sandstone core and the crushed Vertz sandstone.

(2) Metabolic gas production and cell growth occurred within the core after it was inoculated with nutrients and incubated for two weeks.

(3) Some affinity exists between sodium fluorescein and microorganisms, which results in the loss of fluorescein. Sodium fluorescein was probably not a good tracer to choose for the MEOR project.

\subsection{Field Procedures}

Tracer injection was performed using the skid-mounted triplex pump loaned to the project by the Halliburton Services Research Center. Sodium fluorescein powder was mixed with 40 gallons $\left(0.15 \mathrm{~m}^{3}\right)$ of brine water from the SEVVSU in a 55 gallon $(0.21$ $\mathrm{m}^{3}$ ) drum. The tracer fluid was filtered through two thirty inch $(76 \mathrm{~cm}) 125$ micron filters and injected into the injection stream from the field injection pump. The tracer was expected to mix thoroughly with the main injection stream. Concentration of the tracer was calculated from the total volume of fluid injected in the well during the addition of the forty gallons of tracer in the drum. Injection of the tracer took from 30 to 45 minutes. Once the initial forty gallons $\left(0.15 \mathrm{~m}^{3}\right)$ were injected into the injection flow line, the drum was washed with brine until the drum, pump, filters, and connecting hoses were cleared of tracer. This process took as long as two hours, however, this period was not used in calculating tracer treatment concentration. 
Ten milliliter samples of produced fluid were collected from the observation wells before the tracer was injected and daily afterward. Samples were examined immediately for color under ambient light. After settling in a low light condition to allow separation of particulate matter and hydrocarbons, samples were measured for fluorescence in a spectrophotometer at 490 nanometers (the absorbance maximum for sodium fluorescein). These samples were also visually inspected under ultraviolet light for fluorescence. Finally, samples that were still in question as to the presence or absence of tracer were tested in a high performance liquid chromatograph. The final tracer study sample frequency was reduced to weekly after three months. After three months, it was assumed dispersion would allow detection of tracer within any week long period.

\subsection{Results and Changes in Field Operating Policy from Results}

The first tracer study was initiated April 11, 1991. Sodium fluorescein (500 gm) was injected into Well 7-2 at a concentration of $300 \mathrm{ppm}(300 \mathrm{mg} / \mathrm{l})$. Samples were collected daily from Wells 5-1, 5-2, and 7-1. Fourteen days after injection of the tracer, fluorescein was fortuitously detected at Well 1A-9 during normal operations. Referring to Plate $\mathrm{I}$, the $1 \mathrm{~A}-9$ is $1870 \mathrm{ft}(570 \mathrm{~m})$ northenst of Well 7-2. An active injection well, Well 7-3, is directly between Wells $7-2$ and $1 \mathrm{~A}-9$. The true first arrival time of the tracer is not known since Well $1 \mathrm{~A}-9$ was not being regularly sampled. Immediately after discovery of tracer in the 1A-9, Wells $1 \mathrm{~A}-1$ and $1 \mathrm{~A}-5$ were sampled and also discovered to have tracer present.

It had been expected that pilot injection water would travel west because of the high pressure ridge established by the line of injectors to the east and the low pressure region established by the production wells to the west. The results of the tracer test 
clearly indicated that a dominant injection water bearing flow path existed between Well 7-2 and the three southwest wells in the 1A tract. The rapid arrival normally indicates a fracture system.

Past history of the field did not contain any information that would support the hypothesis of a fracture system. During the waterflooding operations, first water production from the 1A-9 occurred almost 11 months after Wells 7-2 and 7-5 were converted to injectors. When Wells 7-3 and 3-3 were converted to injectiors, Well 1A-9 was already producing water, but no increase in water production rate was observed for over a year thereafter. The floodfront had apparently advanced uniformly with large amounts of secondary oil recovery and nearly complete volumetric sweep. In the pilot region, it was estimated that $60 \%$ of the original oil in place had been recovered through primary and secondary recovery. Core samples were routinely taken as each well was drilled. No cores indicated the existence of a fracture system. Although there were higher permeability layers in the formation, the Dykstra-Parson's V factor (Dykstra and Parsons, 1950) was approximately 0.35 indicating a uniform formation. If a fracture system did exist in the field, the expected response would be early break-through of injection water and low oil recovery because of poor sweep efficiency.

Investigation of surrounding events in the field disclosed that injection volumes had fallen significantly in Well 7-3 and 7-5 during the period in which Well 7-2 was receiving injection prior to February, 1991. Injection pressure at these wells had not changed. The volume of water that will be accepted by an injection well depends in part on the difference between the injection pressure and the pressure of the surrounding formation. Apparently, the increase in subsurface pressure caused by $7-2$ injection had 
reduced this difference in pressure for the injecturs to the east. Well 7-2 had become a principle injector for the line drive waterflood.

Alan Erwin of Sullivan and Company, the operator of the SEVVSU, suggested increasing production from the pilot production wells and increasing injection into Wells 3-3, 7-3, and 7-5. This was expected to draw the brine injected into Well 7-2 west ioward the pilot production wells because of increased resistance to flow toward the northeast. Pumping units on Wells 5-1, 5-2, and 7-1 were modified to lift 150, 180, and 300 bbl per day $\left(23.8,28.6\right.$, and $\left.47.7 \mathrm{~m}^{3} / \mathrm{d}\right)$, respectively. The injection rate at Well $7-2$ remained at $300 \mathrm{bbl}$ per day $\left(47.7 \mathrm{~m}^{3} / \mathrm{d}\right)$. The operator treated injection Wells $3-3,7-3$, and 7-5 with a near well bore cleaning treatment. Significant increases in injectivity were achieved at these three wells.

With the new injection and production rates in place for 30 days the flow paths in the region were expected to have reached a steady-state condition and a second tracer study was performed in early August 1991. Sodium fluorescein was injected using the same protocol as the first test. A low concentration of tracer arrived simultaneously at Wells 1A-9, 1A-1, and 1A-5 in 18 days. Twenty-four days after tracer injection a large concentration of tracer was detected at Well 1A-7. The results confirmed the existence of a high volume injection water bearing flow path from Well 7-2 to the western part of the 1A tract. Some of the increased injection into Well 7-3 and 7-5 apparently joins this flow producing a dilute concentration of tracer in this region. The tracer arrival at Well 1A-7 may have been from the first or second tracer injection. Tracer was not observed at Well 1A-7 after the first tracer injection.

This tracer study showed that the change of operating policy in the field was not 
able to completely direct flow from Well 7-2 to the east. It was decided to proceed with the injection of nutrients into Well 7-2. Nutrient injection was initiated with the additional goal that the fluid flow from Well 7-2 to Well $1 \mathrm{~A}-9$ would be diverted by the microbial process. For the remainder of the field pilot the 1A wells, specifically Wells 1A-1, 1A-5, and 1A-9, were included in all sampling and field monitoring.

On February 18, 1992, 60 days after the last nutrient injection, the final tracer test was performed. Injection and production conditions in the pilot area were identical to those of the August, 1991, test. Two kilograms of sodium fluorescein tracer were injected in Well 7-2 at a concentration of $1300 \mathrm{ppm}(1300 \mathrm{mg} / \mathrm{l})$. As of July 13, 1992, tracer had not been detected in any field production wells.

\subsection{Conclusions}

The two tracer studies conducted prior to the nutrient treatments established that a dominant injection water conveying flow path existed between the injection well, 7-2, and the 1A tract. After the nutrient treatments were completed, tracer was again injected into Well 7-2 to determine if in situ microbial growth and activity had altered the flow paths between Well 7-2 and the wells in the 1A tract. No tracer had been detected in the 1A wells by July 13,1992, 140 days after this last tracer injection. Thus, in situ microbial growth and activity apparently obstructed this water channel, and altered the flow paths in this region of the restivoir.

The primary goal of the Microbial Field Pilot Study, to selectively plug high permeability flow paths in the reservoir, was successfully achieved. The injected water travelling the flow path from Well $7-2$ to the $1 \mathrm{~A}$ region of the field was diverted. The change in arrival time of the tracer at Well 1A-9 implies that this flow path ceased to 
function at least temporarily as a major flow channel. 


\section{Chapter 10. Biochemical Responses in the SEVVSU}

\subsection{Introduction}

Chemical and microbiological monitoring of coproduced brines both prior to and during the field pilot study indicated the overall effects of the nutrient injection on the Southeast Vassar Vertz Sand Unit (SEVVSU) reservoir. The biological and biochemical effects of nutrient injection on the reservoir were monitored by determining the concentrations of nutrients, metabolic byproducts and microbial numbers in brines produced from the reservoir before and after nutrient injections.

\subsection{Materials and Methods}

\section{Biochemical Analysis}

Brine samples were routinely collected from wells 5-1, 5-2, 7-1, 1A-1, 1A-5 and 1A-9. Nitrate and nitrite analyses were performed using chemical test kits (Spectroquant). Hydrogen sulfide was determined colorimetrically (Tanner, 1989). Sulfate concentration was determined by high performance liquid chromatography using an ion exchange column and a conductivity detector. Volatile fatty acids were determined by gas chromatography. Alkalinity was determined as outlined by Clesceri et al. (1989) and total carbohydrates were determined by the phenol-sulphuric acid method (Gerhardt et al., 1981).

\section{Bacteriological Analyses}

Enumeration studies were done by the three-tube most probable number (MPN) technique. Aerobic heterotrophic bacteria, anaerobic heterotrophic bacteria, anaerobic molasses-nitrate using bacteria, and sulfate-reducing bacteria were enumerated using 
media containing $15 \% \mathrm{NaCl}$ as previously outlined (Knapp et al., 1990).

\subsection{Results and Discussion}

\section{Pre-treatment Data}

Prior to nutrient treatment of the pilot area biochemical and microbiological analyses were carried out routinely. Concentrations of salinity, alkalinity, sulfide, sulfate, nitrite, nitrate, carbohydrate and volatile fatty acids were determined as were most probable numbers of sulfate and nitrate reducing bacteria, aerobic and anaerobic fermentative bacteria. These studies showed that the flood waters from the reservoir were highly saline containing 11 to $19 \% \mathrm{NaCl}$, and 1 to $2 \%$ calcium and magnesium ions. Diverse populations of anaerobic bacteria capable of growing with simple nutrient

additions at these salinities were present throughout the reservoir. An active sulfaicreducing population was present in the waterflooded areas of the reservoir and in the water tanks at the field tank battery. Both sulfate reducing and nitrate reducing bacteria were isolated and characterized. Of these, five nitrate reducing bacteria were chosen for more extensive study. These were shown to be new obligate halophiles with a definite requirement for salt of concentrations greater than $6 \%$. Of the various carbohydrate and inorganic nutrient mixtures tested, a molasses-ammonium nitrate mixture best stimulated their growth (Bhupathiraju et al., 1991). During the period February, 1990 and August, 1991 the sulfide concentration in the reservoir increased from an average of $11 \mathrm{mg} / 1$ to over $52 \mathrm{mg} / \mathrm{l}$. This increase in souring was probably due to biological sulfate reduction as a result of increased injection of make-up water used in the flood water of the reservoir. The make-up water has a sulfate concentration of $2,500 \mathrm{mg} / 1$. Other possible mechanisms responsible for hydrogen sulfide production include thermal decomposition 
of organic sulphur compounds, thermochemical sulfate reduction and nonoxidative dissolution of pyrite, although these are not likely due to the relatively low temperature of the SEVVSU $\left(37^{\circ} \mathrm{C}\right)$.

\section{Microbial Activation by Nutrient Treatment}

Fifty days following the initial August 29th injection of 2.6 tons (2.4 tonnes) of ammonium nitrate, the produced brine nitrate concentration in the pilot production wells increased from undetectable levels to about 5 to $10 \mathrm{mg} / \mathrm{l}$. Coproduced brine sulfide concentrations in the pilot area decreased from an average of $52 \mathrm{mg} / \mathrm{l}$ to $28 \mathrm{mg} / \mathrm{l}$ during the same time period (Fig. 10.1, Table 10.1). However, because of the high sulfide concentrations in the original brine and the high sulfate concentration in the make-up water, the amount of ammonium nitrate added was not sufficient to inhibit transient increases in sulfide concentration of the coproduced brines due to molasses metabolism after injection of the molasses and ammonium nitrate. About 56 days after the second nutrient injection the sulfide concentrations increased and peaked at $203 \mathrm{mg} / \mathrm{l}$ for wells $5-1$ and 5-2 respectively and $334 \mathrm{mg} / 1$ for $7-1$ before returning to $65 \mathrm{mg} / 1$ (Fig. 10.1). A similar peak in sulfide concentration occurred in 5-1, 5-2 and 7-1 brines 57 days after the final nutrien: injection. This time, however, the sulfide concentration of 7-1 brine attained a maximum of $195 \mathrm{mg} / \mathrm{l}$ while values for $5-1$ and $5-2$ were $251 \mathrm{mg} / 1$ and 184 $\mathrm{mg} / \mathrm{l}$ respectively (Fig. 10.1, Table 10.1). Sulfide levels also increased in the brine from wells in the 1A tract although the levels were substantially lower than the pilot production wells (Fig. 10.2, Table 10.1). It should be emphasized that although large increases in sulfide production were noted these increases were transient and did not affect the long term sulfide concentrations in the produced brines. By March, 1992 the 


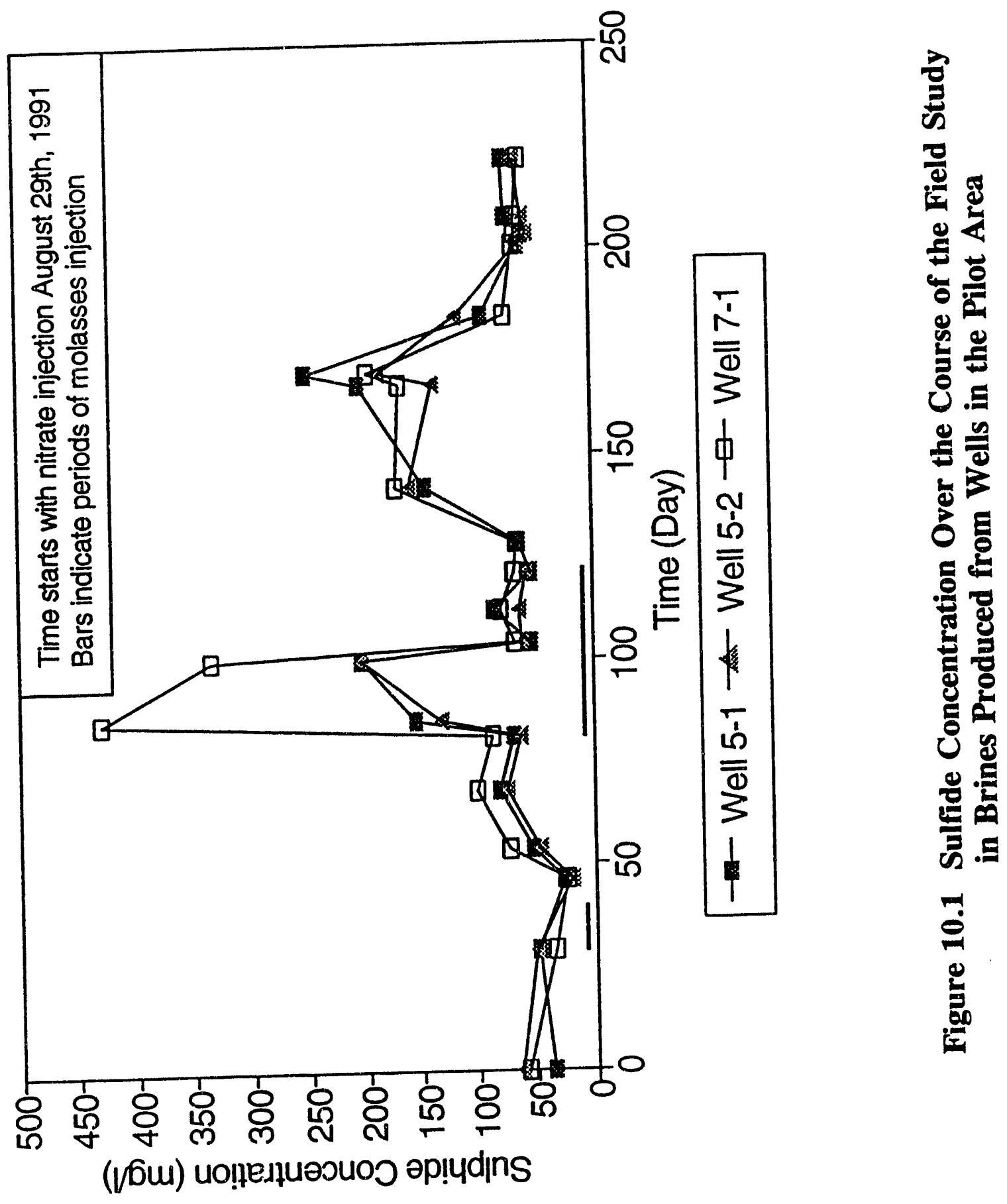


Table 10.1 Sulfide Results of Coproduced Brines (mg/l)

\begin{tabular}{||r|r|r|r|r|r|r||}
\hline \multicolumn{1}{|c|}{ Date } & \multicolumn{1}{|c|}{ Day } & \multicolumn{1}{c|}{$5-1$} & \multicolumn{1}{c|}{$5-2$} & \multicolumn{1}{c|}{$7-1$} & \multicolumn{1}{c|}{ A-1 } \\
\hline \hline Feb. 15, 1990 & & & & & 6.60 & 14.23 \\
\hline Aug. 29, 1991 & 0 & 35.59 & 64.82 & 59.79 & 16.96 & 30.56 \\
\hline Sept. 27, 1991 & 29 & 48.93 & 50.37 & 33.93 & 22.49 & 23.25 \\
\hline Oct. 14, 1991 & 46 & 26.19 & 21.10 & 23.20 & ND & 37.96 \\
\hline Oct. 22, 1991 & 54 & 52.82 & 46.10 & 73.16 & 50.04 & 5.94 \\
\hline Nov. 18, 1991 & 81 & 68.17 & 63.12 & 86.02 & 58.43 & 33.42 \\
\hline Nov. 22, 1991 & 85 & 153.95 & 131.88 & 429.44 & 124.45 & 92.17 \\
\hline Dec. 6, 1991 & 100 & 203.03 & 203.03 & 334.49 & 99.84 & 22.53 \\
\hline Dec. 10, 1991 & 104 & 52.23 & 60.75 & 65.88 & 47.28 & 28.94 \\
\hline Jan. 3, 1992 & 128 & 62.35 & ND & 64.12 & 29.65 & 27.39 \\
\hline Jan. 17, 1992 & 142 & 144.69 & 157.30 & 170.95 & 132.73 & 93.08 \\
\hline Feb. 14, 1992 & 251.16 & 184.34 & 195.13 & 87.62 & 112.97 \\
\hline Mar. 20, 1992 & 60.19 & 60.19 & 64.48 & 25.09 & 37.70 \\
\hline May 20, 1992 & 67.51 & ND & 49.90 & 22.89 & 35.80 \\
\hline
\end{tabular}




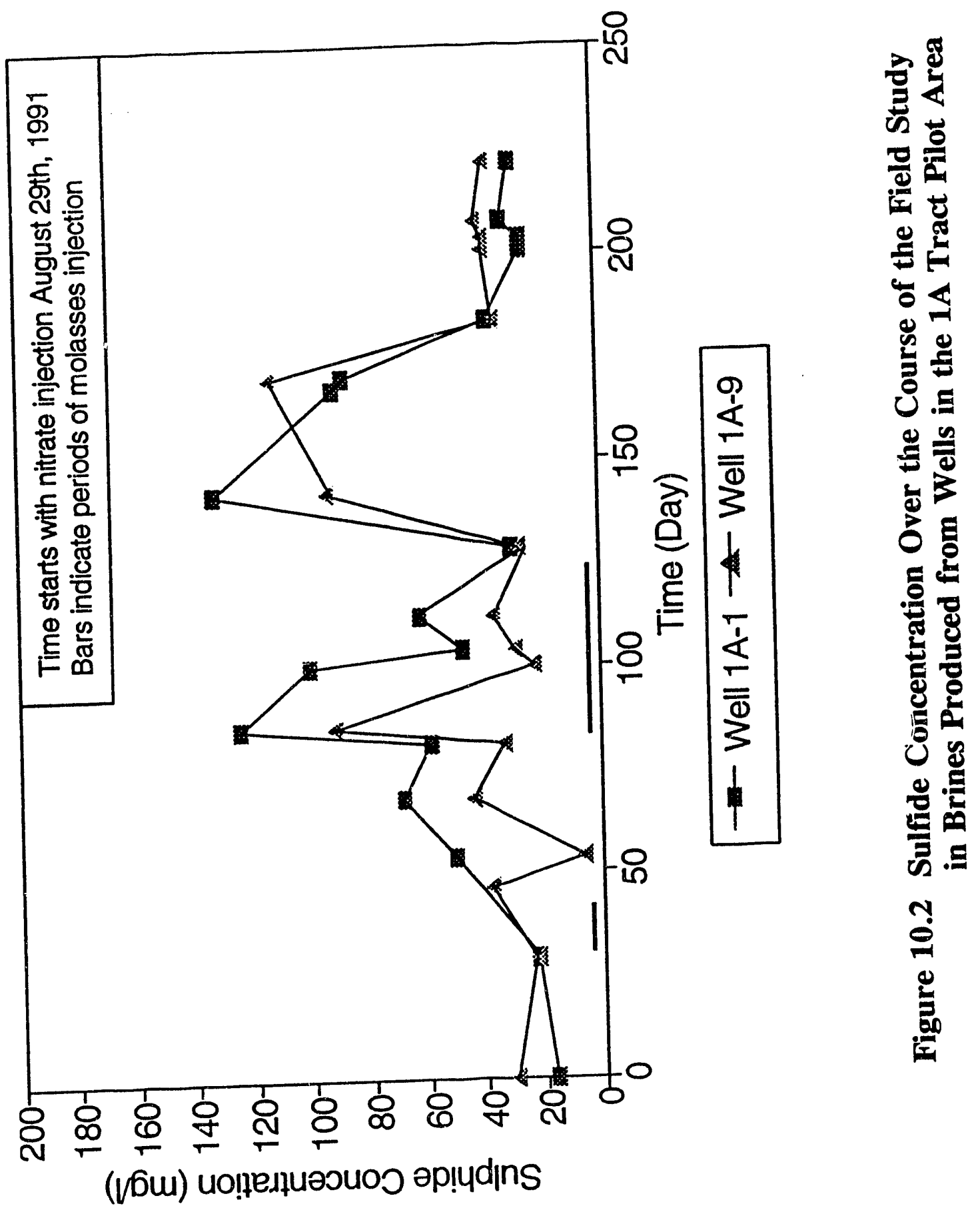


concentrations had returned to a baseline value of $44 \mathrm{mg} / \mathrm{l}$ (Table 10.1). Sulfate reducing bacteria rusubers in the coproduced brines from 5-1 and 5-2 were similarly observed to increase with nutrient injection and sulfide concentration although changes in bacterial counts were relatively small (Table 10.2). Numbers of sulfate reducing bacteria in the 7-1 brine samples were also observed to peak although the increase occurred 25 days after that of both 5-1 and 5-2. Sulfate reducing bacteria numbers in the coproduced brine from the $1 \mathrm{~A}$ tract remained relatively stable throughout the entire trial period (Table 10.2). Molasses-nitrate utilizing bacteria numbers in 5-1 and 5-2 brine decreased 10 fold over the first 70 days of the trial period and then remained constant at 23 cells per $\mathrm{ml}$. Molasses-nitrate utilizing bacteria in the $1 \mathrm{~A}-9$ brine decreased by 10,000 fold during the same time period while those in the $1 \mathrm{~A}-1$ brine remained relatively constant throughout the trial (Table 10.3). The low counts of the molasses-nitrate utilizing bacteria determined after injection of molasses and ammonium nitrate during this trial are possibly as a result of sulfide toxicity due to the high sulfide concentrations attained. During the latter part of 1991 , analysis of coproduced brine alkalinity was initiated. Increases of almost $50 \mathrm{mg} / \mathrm{CaCO}_{3}$ for well $5-1$ and $100 \mathrm{mg} / 1$ for wells $5-2$ and 7-1 respectively were observed from baseline concentrations determined in April, 1991. Regular analysis thereafter showed an increasing trend until concentrations peaked on January 17th (day 142) for wells 5-2 and 7-1 and on February 14th for well 5-1 at 375, 275 and $275 \mathrm{mg} / \mathrm{C} \mathrm{CaCO}_{3}$ respectively (Fig. 10.3). Similar profiles were noted for the $1 \mathrm{~A}$ tract coproduced brines. Increases of about $100 \mathrm{mg} / 1 \mathrm{CaCO}_{3}$ were observed in the 1A-1 and 1A-9 brines in January, 1992 over a baseline value of about 150 to $175 \mathrm{mg} / 1$ $\mathrm{CaCO}_{3}$ determined between July, 1989 and February, 1990. By February, 1992 these 
Table 10.2 Sulfate Reducing Bacteria Numbers in the Coproduced Brines (cells/ml)

\begin{tabular}{||c|c|c|c|c|c||}
\hline Date & $5-1$ & $5-2$ & $7-1$ & $1 \mathrm{~A}-1$ & $1 \mathrm{~A}-9$ \\
\hline \hline Aug. 29, 1991 & $2.40 \times 10^{2}$ & $9.33 \times 10^{1}$ & $4.27 \times 10^{1}$ & $9.30 \times 10^{1}$ & $4.27 \times 10^{1}$ \\
\hline Nov. 5, 1991 & $9.33 \times 10^{2}$ & $4.27 \times 10^{2}$ & $4.77 \times 10^{1}$ & $4.27 \times 10^{2}$ & $9.33 \times 10^{1}$ \\
\hline Dec. 6, 1991 & $4.27 \times 10^{2}$ & $2.40 \times 10^{2}$ & $2.30 \times 10^{1}$ & $2.40 \times 10^{2}$ & $9.33 \times 10^{1}$ \\
\hline Jan. 17, 1992 & $2.40 \times 10^{2}$ & $9.30 \times 10^{1}$ & $4.62 \times 10^{2}$ & $2.40 \times 10^{2}$ & $9.33 \times 10^{1}$ \\
\hline Feb. 11, 1992 & $9.30 \times 10^{2}$ & $4.27 \times 10^{2}$ & $4.27 \times 10^{1}$ & $2.05 \times 10^{2}$ & $9.33 \times 10^{1}$ \\
\hline Mar. 3, 1992 & $2.31 \times 10^{1}$ & $2.31 \times 10^{1}$ & $9.20 \times 10^{0}$ & $4.27 \times 10^{1}$ & $9.20 \times 10^{0}$ \\
\hline Apr. 22, 1992 & $9.33 \times 10^{1}$ & $\mathrm{ND}$ & $9.33 \times 10^{1}$ & $2.40 \times 10^{2}$ & $9.33 \times 10^{1}$ \\
\hline
\end{tabular}

$\mathrm{ND}=$ Not Determined 
Table 10.3 Molasses-nitrate Utilizing Bacteria in the Coproduced Brines (cells/ml)

\begin{tabular}{||c|c|c|c|c|c||}
\hline \hline Date & $5-1$ & $5-2$ & $7-1$ & $1 \mathrm{~A}-1$ & $1 \mathrm{~A}-9$ \\
\hline \hline Aug. 29, 1991 & $1.10 \times 10^{3}$ & $4.62 \times 10^{2}$ & $4.27 \times 10^{1}$ & $2.40 \times 10^{2}$ & $2.34 \times 10^{5}$ \\
\hline Nov. 5, 1991 & $2.31 \times 10^{1}$ & $2.31 \times 10^{1}$ & $2.31 \times 10^{1}$ & $2.40 \times 10^{2}$ & ND \\
\hline Dec. 6, 1991 & $2.31 \times 10^{1}$ & $2.31 \times 10^{1}$ & $2.31 \times 10^{1}$ & $2.31 \times 10^{1}$ & $2.31 \times 10^{1}$ \\
\hline Jan. 17, 1992 & $2.31 \times 10^{1}$ & $2.31 \times 10^{1}$ & $2.31 \times 10^{1}$ & ND & ND \\
\hline Feb. 11, 1992 & $2.31 \times 10^{1}$ & $2.31 \times 10^{1}$ & $2.31 \times 10^{1}$ & ND & ND \\
\hline Apr. 22, 1992 & $9.33 \times 10^{2}$ & ND & $9.33 \times 10^{2}$ & $2.40 \times 10^{3}$ & $4.27 \times 10^{2}$ \\
\hline
\end{tabular}

ND $=$ Not Determined 


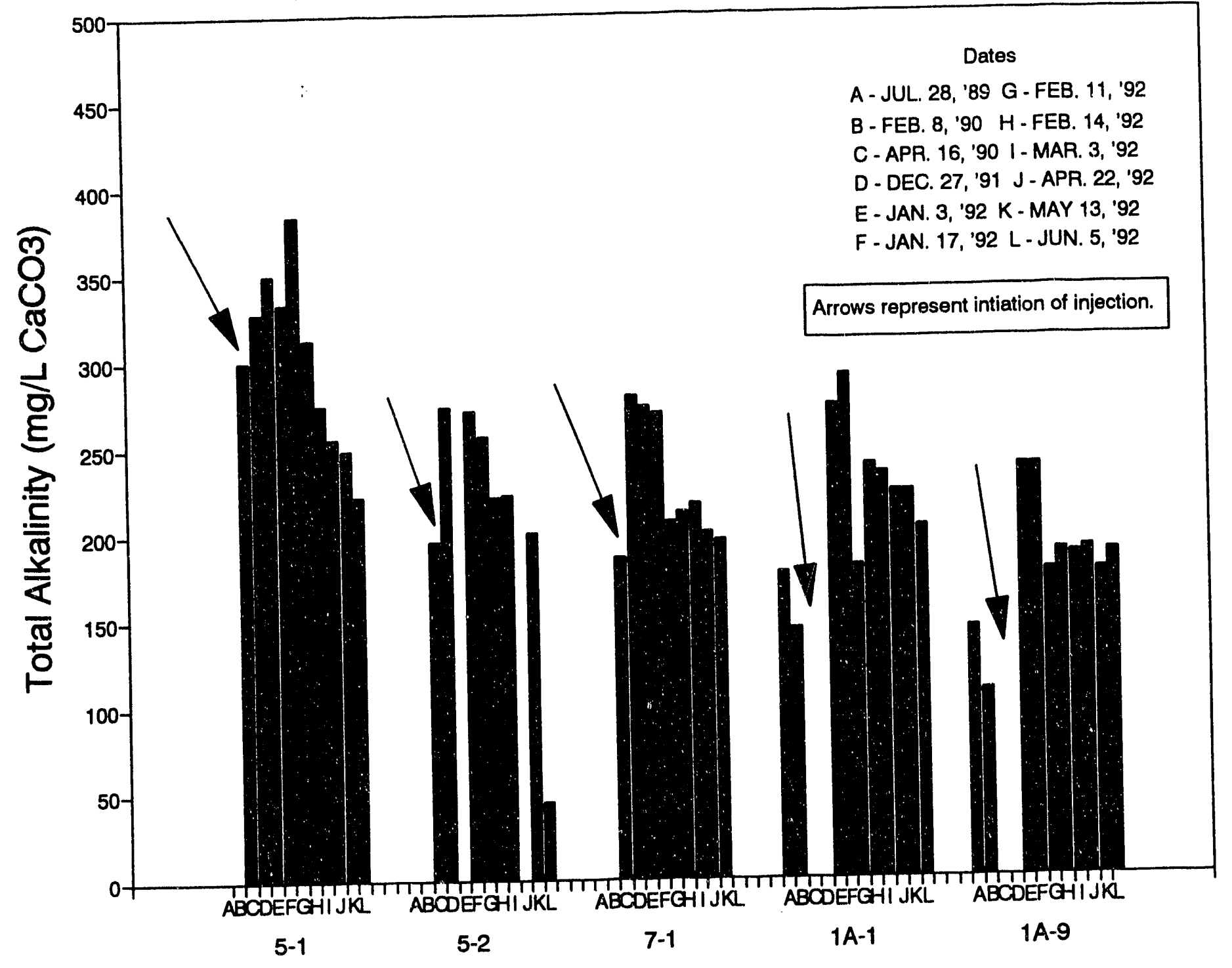

Figure 10.3 Brine Alkalinities during the Field Pilot Study 
values were decreasing back toward baseline values (Fig 10.3). The increases in alkalinity are believed to result from microbial production of $\mathrm{CO}_{2}$ due to molasses metabolism in the reservoir although expected metabolic products such as nitrite or volatile fatty acids were not detected in the brine waters of the production wells during the entire pilot trial. The lack of expected microbial products indicates that the rate limiting step in the complete mineralization of the molasses is the initial metabolism of the carbohydrate.

\subsection{Conclusions}

Both chemical and microbiological changes were observed over the course of this field study. Increased sulfide concentrations in the coproduced brines prior to nutrient injection are probably due to a stimulation of the sulfate reducing bacteria present in the reservoir although physiochemical interactions may be partly responsible. In many reservoirs with moderate temperatures $\left(<80^{\circ} \mathrm{C}\right)$ microbial sulfate reduction is believed to be the primary source of sulfide (McInerney et al., 1992). The initial injection of ammonium nitrate resulted in a significant decrease (about 50\%) in sulfide levels in the coproduced brines from the $1 \mathrm{~A}$ tract and the pilot production wells as suggested by the results of Jack et al. (1985) and Jenneman et al. (1986). However, insufficient nitrate was injected with the molasses to inhibit transient increases in sulfide production due to carbohydrate metabolism. The alkalinity results, indicative of $\mathrm{CO}_{2}$ production in the reservoir, imply that the observed permeability modifications are probably the result of microbial metabolism of the molasses and ammonium nitrate by indigenous bacteria.

Finally, it should be emphasized that the overall biological effects of the stimulation of in situ microbial populations in an oil reservoir are transitory and that four 
months after the last injection of nutrients both sulfide and alkalinity values had returned to pre-test levels with no permanent chemical alteration in the coproduced brines being noted. 


\section{Chapter 11. Conclusions}

1) The primary goal of the project, to selectively plug high permeability flow paths in the reservoir, was successfully achieved. The changes in interwell permeabilities between Well 7-2 and the three pilot production wells show that selective plugging of flow paths occurred. The permeability distribution in the pilot area was more uniform after microbial treatment than before. Of note, the flow path from Well 7-2 to the $1 \mathrm{~A}$ region of the field was blocked. The change in arrival time of the tracer at Well 1A-9 implies that this flow path ceased to function as a major flow channel at least temporarily.

2) Although a very small enhanced oil recovery target was present because of efficient production and waterflooding of the formation before the pilot study, tertiary oil was recovered.

3) An increase in alkalinity and the absence of other metabolic products indicated that the injected carbohydrate was completely mineralized to carbon dioxide by in situ metabolism.

4) The ammonium nitrate injection prior to injection of carbohydrates decreased sulfide levels in the pilot area. Not enough nitrate was injected to prevent sulfide production in the presence of the large quantity of injected carbohydrate.

5) Injectivity at the pilot injection well was not significantly impaired by the injection of nutrients. Desired injection rates were achieved at surface pressures at or below the field limits.

6) The chemical effects of microbial waterflooding are transient. Alkalinity and sulfide 
levels returned to pre-test levels after the nutrients were consumed. A permanent change in composition of produced brines was not indicated.

7) Total fluid production from Well $1 \mathrm{~A}-9$ began to fluctuate between less than $100 \mathrm{bpd}$ $\left(16 \mathrm{~m}^{3} / \mathrm{d}\right)$ to near $250 \mathrm{bpd}\left(40 \mathrm{~m}^{3} / \mathrm{d}\right)$ after nutrient treatment of the field. Examination of the other operational activities in the field did not find an explanation for this fluctuation. By elimination, it was concluded that the injection of nutrients and the resultant increases in microbial activity caused this change. The mechanism causing this erratic production behavior is not known. On the average Well 1A-9's oil production rate was unchanged by the microbial treatments. 


\section{References}

Agarwal, R.G., Al-Hussainy, R., Ramey, H.J. Jr.; "An Investigation of Wellbore Storage and Skin Effect in Unsteady Liquid Flow: I. Analytical Treatment", Society of Petroleum Engineers Journal, September, 1970, pp. 279-290.

American Public Health Association, American Water Works and Water Pollution Control Federation: Standard Methods for the Examination of Water and Waste Water. Sixteenth Edition, Americarı Public Health Association, Washington, DC (1985) 92-100, 856-859.

American Šociety of Testing and Materials, 1987. "D445, Kinematic Viscosity of Transparent and Opaque Liquids (and calculation of Dynamic Viscosity), and D446, Glass Capillary Kinematic Viscometers," 1987 Annual Book of ASTM Standards, Volume 05.D1, pp. 235-261.

Balch, W. E., and Wolfe, R. S., 1976. "New Approach to the Cultivation of Methanogenic Bacteria: 2-Mercaptoethanelsulfonic acid (HS-CoM)-dependant Growth Of Methanobacterium ruminatium in a pressurized Atmosphere." Appl. Environ. Microbiol. 32:781-791.

Banwart, G.J., 1981. Basic Food Microbiology. AVI Publishing Co., Westport.

Beckmann, J.W., "The action of bacteria on mineral oil", Ind. Eng. Chem. News, 4:3, November 10, 1927.

Brigham, W.E. and Abbaszedah-Dehghani, M., "Tracer Testing for Reservoir Description", Journal of Petroleum Technology, May 1987, pp. 519-527.

Bryant, M. P., 1972. Commentary on the Hungate Technique for Culture of Anaerobic Bacteria. Amer. J. Chem. Nutr. 25: 1324-1328.

Bryant, R.S., Burchfield, T.E., Dennis, D.M., Hitzman, D.O., and Porter, R.E., "Microbial Enhanced Waterflooding, A Pilot Study", in Microbial Enhanced Oil Recovery - Recent Advances, E.C. Donaldson, ed., Elsevier Science Publishers B.V., Amsterdam, 1991, pp. 399-419.

Bryant, R.S., Burchfield, T.E., Dennis, D.M., Hitzman, D.O., Microbial Enhanced Waterflooding Pilot Project, Mink Unit, Delaware-Childers (OK) Field, Topical Report, NIPER-508 (DE91002252), U.S. Department of Energy, 1991.

Bryant, R.S. and Douglas, J., "Evaluation of Microbial Systems in Porous Media for Enhanced Oil Recovery", SPE Reservoir Engineering, Volume 3, Number 2, pp. 489-495, May 1988. 
Buckley, S.E., and Leverett, M.C., "Mechanism of Fluid Displacement in Sands", Transactions of AIME, 146: 107-116, 1942.

Burchfield, T.E. and Bryant, R.S., editors, Proceedings of the Symposium on Applications of Microorganisms to Peiroleum Technology, CONF-870858, U.S.D.O.E., 1988.

Chatfield, C., The Analysis of Time Series: An Introduction, Third Edition, Chapman and Hall, London, 1985.

Civan, F., Knapp, R.M., and Ohen, H.A., "Automatic Estimation of Model Parameters for Swelling and Migration of Fine Particles in Porous Media", Paper presented at the AICHE Meeting in New Orleans, LA, March 6-10, 1988.

Clark, J.B., Munnecke, D.M., and Jenneman, G. E., "In Situ Microbial Enhancement of Oil Production", Dev. Ind. Microbial. 22:695-701, 1981.

Clesceri, L.S., Greenberg, A.E., Trussell, R.R., Standard Method for the Examination of Water and Wastewater, APHA-AWWA-WPCF, 17th Edition, 1989.

Cochran, W. G., 1950. Estimation of Bacterial Densities by means of the "Most Probable Number". Biometrics 6, 105-116.

Collins, R.E., Flow of fluids Through Porous Media, Research \& Engineering Consultants, Inc., Englewood, CO (1961).

Crawford, P.B., "Possible Bacterial Correction of Stratification Problems", Producers Monthly, 25:10-11, 1961.

Crawford, P.B., "Water Technology: Continual Changes Observed in Bacterial Stratification Rectification", Producers Monthly, 26:12, 1962.

Dake. L.P., Fundamentals of Reservoir Engineering, Elseveir, Amsterdam, The Netherlands, 1978.

Davidson, W.S. and Russell, H.H., "An MEOR Pilot Test in the Loco Field", in Proceedings of the Symposium on Applications of Microorganisms to Petroleum Technology, Burchfield, T.E., Bryant, R.S., ed., NIPER-351 CONF-870858 (DE88001232), U.S. Department of Energy, pp. VII1-VII12, 1988.

Davis, S.N., Campbell, D.J., Bentley, H.W., Flynn, T.J., Ground Water Tracers, National Water Well Association, Robert S. Kerr Environmental Research Laboratory, USEPA, Ada, Oklahoma, 1985. 
Dietz, D.N., "Determination of Average Reservoir Pressure from Build-Up Surveys", Journal of Petroleum Technology, August, 1965, pp. 955-959.

Donaldson, E.C., and Clark, J.B., editors, Proceedings of 1982 International Conference on Microbial Enhancement of Oil Recovery, CONF-8205140, U.S.D.O.E., 1983.

Donaldson, E.C., Chilingarian, G.V., Yen, T.F., editors, Microbial Enhanced Oil Recovery, Elsevier, Amsterdam, 1989.

Donaldson, E.C., editor, Microbial Enhancement of Oil Recovery - Recent Advances, Elsevier, Amsterdam, 1991.

Dykstra, H. and Parsons, R.L., Secondary Recovery of Oil in the United States, Second Edition, American Petroleum Institute, New York, 1950.

Earlougher, R.C., Jr., Advances in Well Test Analysis, Society of Petroleum Engineers of AIME, Dallas, TX (1977).

Gerhardt, P., Murray, R.G.E., Costilow, R.N., Nester, E.W., Wood, W.A., Krieg, N.R., Phillips, G.B., Manual of Methods for General Microbiology, American Society for Microbiology, 1981.

Hach Chemical Co. 1985. Hach Water and Wastewater Analysis Procedure Manual, 3rd Edition. Hach Chemical Co., Ames, IA.

Hitzman, D.O., "Microbial Enhanced Oil Recovery - The Time Is Now", in Microbial Enhanced Oil Recovery - Recent Advances, E.C. Donaldson, ed., Elsevier Science Publishers B.V., Amsterdam, 1991, pp. 11-20.

Hogg, R.V. and Craig, A.T., Introduction to Mathematical Statistics, Third Edition, The Macmillan Company, London, 1970.

Holmgren, C.R. and Morse, R.A., "Effect of Free Gas Saturation on Oil Recovery by Waterflooding", Transactions of AIME, 192:285-296, 1951.

Horner, D.R., "Pressure Build-up in Wells", Proceedings, Third World Petroleum Congress, E.J. Brill, Leiden (1951) II, 503.

Intera-ECL Petroleum Technologies, Eclipse 100 Black Oil Simulator Reference Manual, Vol. 1 and 2, Version 91A, Intera-Bergeson, Petroleum Product Division, Denver, Colorado, 1991. 
Ivanov, M.V. and Belyaev, S.S., "Biotechnology of Enhancement of Oil Recovery Based on the Geochemical Activity of Microorganisms (Field Experiments)," in Microbial Enhanced Oil Recovery - Recent Advances, E.C. Donaldson, ed., Elsevier Science Publishers B.V., Amsterdam, 1991, pp. 421-432.

Jack, T.R. and DiBlasio, E., "Selective Plugging for Heavy Oil Recovery", In J.E. Zajic and E.C. Donaldson (ed.), Microbes and Oil Recovery, Vol. 1., Bioresources Publications, El Paso, TX, p. 205-212, 1985.

Jack, T.R., Thompson, B.G., and DiBlasio, E., "The Potential for Use of Microbes in the Production of Heavy Oil", Proceedings of the 1982 International Conference on the Microbial Enhancement of Oil Recovery, Nat. Tech. Inf. Serv., Springfield, VA, CONF-8205140, 1983, 88-93.

Javaheri, M., Jenneman, G.E., McInerney, M.J., Knapp, R.M., "Anaerobic Production of a Biosurfactant by Bacillus licheniformus JF-2", Applied and Environmental Microbiology, p. 698-700, September, 1985.

Jenneman, G.E., McInerney, M.J., and Knapp, R.M., "Effect of Nitrate on Biogenic Sulfide Production", Appl. Environ. Microbiol. 51:1205-1211, 1986.

Jenneman, G.E., "The Potential for In-Situ Microbial Applications", in Microbial Enhanced Oil Recovery, Donaldson, E.C., Chillingarian, G.V., Yen, T.F., (editors), Elsevier, Amsterdam, The Netherlands, 1989.

Jenneman, G.E., Knapp, R.M., Menzie, D.E., Revus, D.E., Clark, J.B., and Munnecke, D.M., "Transport Phenomena and Plugging in Berea Sandstone Cores Using Microorganisms", In, E.C. Donaldson and J.B. Clark, (eds.) Proceedings of the 1982 International Symposium on Microbial Enhancement of Oil Recovery, Nat. Tech. Inf. Serv., Springfield, VA, CONF-8205140, 1983, 71-75.

Jenneman, G.E., Knapp, R.M., McInerney, M.J., Menzie, D.E., and Revus, D.E.,"Experimental Studies of In-Situ Microbial Enhanced Oil Recovery", Society of Petroleum Engineers Journal, February 1984, 33-37.

Jenneman, G.E., McInerney, M.J., Knapp, R.M., "Microbial Penetration through Nutrient-Saturated Berea Sandstone", Applied and Environmental Microbiology, August 1985, pp. 383-391.

Jenneman, G.E. and Clarke, J.B., "The Effect of In-Situ Pore Pressure on MEOR Processes", SPE/DOE 24203, presented at the SPE/DOE Eighth Symposium on Enhanced Oil REcovery, Tulsa, OK, April 22-24, 1992.

Kalish, P.J., Stewart, J.E., Rogers, W.F., and Benneth, E.O., "The Effect of Bacteria on Sandstone Permeability", Journal of Petroleum T'echnology, 16:805-814, 1964. 
Raiders, R.A., Maher, T.F., Knapp, R.M., and McInerney, M.J., "Selective Plugging and Oil Displacement in Crossflow Core Systems by Microorganisms",paper SPE 15600 presented at the 61 st Annual Meeting of the Society of Petroleum Enginers of AIME, New Orleans, LA, Oct. 1986b.

Sabatini, D.A. and Austin, T.A., "Characteristics of Rhodamine WT and Fluorescein as Adsorbing Ground-Water Tracers", Ground Water, 29(3):341-349, May-June 1991.

Sabatini, D.A., Assistant Professor, Department of Civil Engineering and Environmental Science, University of Oklahoma, Norman, Oklahoma, personal communication, 1991.

Scarbrough, J., Eckert, W., Pino, H., "Southeast Vassar Field Vertz Sand Unit Simulation Study", Project Report, PE4223, University of Oklahoma, (unpublished), 1987.

Sheehy, A.J., "Microbial Physiology and Enhanced Oil Recovery", in Microbial Enhanced Oil Recovery - Recent Advances, E.C. Donaldson, ed., Elsevier Science Publishers B.V., Amsterdam, 1991, pp. 37-44.

Silfanus, N.J., "Microbial Mechanisms for Enhanced Oil Recovery from High Salinity Core Environments", Masters Thesis, University of Oklahoma, Norman,Oklahoma, 1990.

Smart, P.L. and Laidlaw, I.M.S., "An Evaluation of Some Fluorescent Dyes for Water Tracing", Water Resources Research. 13(1):15-33, February 1977.

Stalkup, F.I., Jr., Miscible Displacement, Monograph series, SPE, Richardson, TX, 1984.

Stegemeier, G.L., "Mechanism of Entrapment and Mobilization of Oil in Porous Media", in Improved Oil Recovery by Surfactant and Polymer Flooding, Shah, D.O., Schechter, R.S., ed., Academic Press, Inc., New York, New York, 1977.

Tanner, R.S., Haack, T.K., Semet, R.F., and Greenley, D.E., 1985. A Mild Steel Tubular Flow System for Biofilm Monitoring. Proceedings of the United Kingdom National Academy of Corrosion Engineers Corrosion '85, Harrowgate, UK, 259-269.

Tanner, R. S., 1989. Monitoring Sulfate-Reducing Bacteria: Comparison of Enumeration Media. J. Micro. Methods. 10: 83-90. 
Merkt, E.E., "The Effect of Bacteria on the Permeability of Oil Reservoir Rocks", Thesis, University of Texas, Austin, Texas, 1943, 14-29.

Miller, C.C., Dyes, A.B., Hutchinson, C.A., Jr., "The Estimation of Perme bility and Reservoir Pressure from Bottom-Hole Pressure Build-up Characteristics", Transactions of AlME, 189:91-104, 1950. Also, Reprint Series, No. 9- Pressure Analysis Methods, Society of Petroleum Engineers of AIME, Dallas, TX (1967), 11-24.

Moore, T.F. and Slobod, R.L., "The Effect of Viscosity and Capillarity on The Displacement of Oil by Water", Producers Monthly, August 1956, 20-30.

Muskat, M., Flow of Homogeneous Fluids Through Porous Media, McGraw-Hill Book Company, New York, NY (1937), J.W. Edwards, Inc., Ann Arbor (1946).

Myers, G.E., and Samiroden, W.D., "Bacterial Penetration in Petroliferous Rocks", Producers Monthly, April 1967, 22-25.

Oil and Gas Journal, PennW'ell Publications, Vol. 90, Number 29, pg 3, July 20, 1992.

Oklahoma Geological Survey, 1972, Geology and Earth Resources of Oklahoma, University of Oklahoma, Norman, OK.

Oppenheimer, H.D. and Hiebert, K.F., "Microbial Enhanced Oil Production Field Tests in Texas", in Proceedings of the Symposium on Applications of Microorganisms to Petroleum Technology, Burchfield, T.E., Bryant, R.S., ed., NIPER-351 CONF-870858 (DE88001232), U.S. Department of Energy, pp. XII1-XII15, 1988.

Perkins, R.K. and Johnston, O.C., "A Preview of Diffusion and Dispersion in Porous Media", Transactions of AIME, 228:70, 1963.

Qin, T.L. and Yang, G.H., "A Brief Introduction to the Progress of MEOR in China", in Microbial Enharced Oil Recovery - Recent Advances, E.C. Donaldson, ed., Elsevier Science Publishers B.V., Amsterdam, 1991, pp. 29-34.

Raiders, R.A., Freeman, D.C., Jenneman, G.E., Knapp, R.M., McInerney, M.J., and Menzie, D.E., "The Use of Microorganisms to Increase the Recovery of Oil Form Cores", Paper SPE 14336 presented at the 60th Annual Meeting of the Society of Petroleum Engineers of AIME, Las Vegas, NV, Sept. 1985.

Raiders, R.A., McInerney, M.J., Revus, D.E., Torbati, H.M., Knapp, R.M., and Jenneman, G.E., "Selectivity and Depth of Microbial Plugging in Berea Sandstone Cores", Journal of Industrial Microbiology, 1986a, 195-203. 
Knapp, R.M., Silfanus, N.J., McInerney, M.J., Menzie, D.E., Chisholm, J.L., "Microbial Mechanisms for Enhanced Oil Recovery from High Salinity Core Environments", presented at American Institute of Chemical Engineers 1990 Spring Annual Meeting, March 18-22, Orlando, Fl, 1990.

Knapp, R.M., McInerney, M.J., Menzie, D.E., Raiders, R.A., Microbial Field Pilot Study, Final Report, DOE/BC/14084-6, U.S. Department of Energy, 1989.

Knapp, R.M., McInerney, M.J., Menzie, D.E., Chisholm, J.L., Microbial Field Pilot Study, Annual Report, $11 / 22 / 88$ to $12 / 31 / 89$, DOE/BC/14246-5, National Technical Information Services, Springfield, VA, November 1990.

Knapp, R.M., McInerney, M.J., Menzie, D.E., Chisholm, J.L., Microbial Field Pilot Study, Annual Report, $1 / 02 / 90$ to $12 / 31 / 90$, DOE/BC/14246-8, National Technical Information Services, Springfield, VA, March 1992.

Kyte, J.R., Stanclift, R.J., Jr., Stephen, S.C., Jr., and Rapoport, L.A., "Mechanism of Water Flooding in The Presence of Free Gas", Transactions of AIMF: 207:215-221, 1956.

Lazar, I., "MEOR Field Trials Carried Out Over the World During the Last 35 Years", in Microbial Enhanced Oil Recovery - Recent Advances, E.C. Donaldson, ed., Elsevier Science Publishers B.V., Amsterdam, 1991, pp. 485-530.

Lazar, I., Dobrota, S., Stefanescu, M., Sandulescu, L., Constantinescu, P., Morosandu, C., Botea, N., Iliescu, O., "Preliminary Results of Some Recent MEOR Field Trials in Romania", in Microbial Enhanced Oil Recovery - Recent Advances, E.C. Donaldson, ed., Elsevier Science Publishers B.V., Amsterdam, 1991, pp. 365-385.

Lichtenberger, G.J., "Field Applications of Interwell Tracers for Reservoir Characterization of Enhanced Oil Recovery Pilot Areas", SPE 21652, Production Operations Symposium, Oklahoma City, Oklahoma, April 7-9, 1991.

Matthew, C.S., and Russell, D.G., Pressure Buildup and Flow Tests in Wells, Society of Petroleum Engineers of AIME, Dallas, TX (1967).

McInerney, M.J., and Westlake, D.W.S., "Microbially Enhanced Oil Recovery" in Microbial Mineral Recovery, H. L. Ehrlich and C. L. Brierley (eds.). McGraw-Hill Publishing Company, New York, pp 409-44.5, 1990.

Melrose, J.C. and Brandner, C.F., "Role of Capillary Forces in Determining Microscopic Displacement Efficiency for Oil Recovery by Waterflooding", Journal of Canadian Petroleum Technology, October-December, 1974, 54-62. 
Torbati, H.M., Raiders, R.A., Donaldson, E.C., McInerney, M.J., Jenneman, G.E., and Knapp, R.M., "Effect of Microbial Growth and Pore Entrance Size Distribution in Sandstone Cores", Journal of Industrial Microbiology, 1986, 227-234.

Updegraff, D.M., "The Effect of Microorganisms on the Permeability and Porosity of Petroelum Reservoir Rock", in Microbial Enhanced Oil Recovery, Zajic, J.E., Cooper, D.C., Jack, T.R., Kosaric, N., editors, PennWell Books, Tulsa, OK, 1983, pp. 37-44.

Vasquez, M. and H. D. Beggs. "Correlations for Fluid Physical Property Prediction." Journal of Petroleum Technology, June, 1980, Vol. 269, pp. 968-970.

Vela, S. and McKinley, R.M., "How Areal Heterogeneities Affect Pulse-Test Results", Society of Petroleum Engineers Journai (September, 1970) 181-191, : Transactions, AIME, 237.

Wagner, M., "Microbial Enhancement of Oil Recovery from Carbonate Reservoirs with Complex Formation Characteristics", in Microbial Enhanced Oil Recovery Recent Advances, E.C. Donaldson, ed., Elsevier Science Publishers B.V., Amsterdam, 1991, pp. 387-398.

Weaver, J.D., and Wilson, J.M., Completions Research and Engineering Department, Halliburton Services Research Center, Duncan, Oklahoma, personal communication, 1990.

Willhite, G. P., 1986, Waterflooding, SPE Textbook Series, Vol. 3, Society of Petroleum Engineers, Richardson, TX, p. 244.

Yen, T.F., Microbial Enhanced Oil Recovery: Principle and Practice, CRC Press, Boca Raton, Florida, 1990.

Zajic, J.E., and Donaldson, E.C., editors, Microbes and Oil Recovery 1, Bioresourcès Publications, El Paso, Texas, 1985.

Zhang, X. and Yang, J., personal communication, 1992.

ZoBell, C.E., Bacteriological Process for Treatment of Fluid-Bearing Earth Formation, U.S. Patent 2,413,278, 1946.

ZoBell, C.E., "Bacterial Release of Oil from Oil-Bearing Minerals", Parts I and II, World Oil, 126(13):36-47 (I), 127(1):35-41, 1947.

ZoBell, C.E., Recovery of Hydrocarbons, U.S. Patent 2,641,566, 1953. 

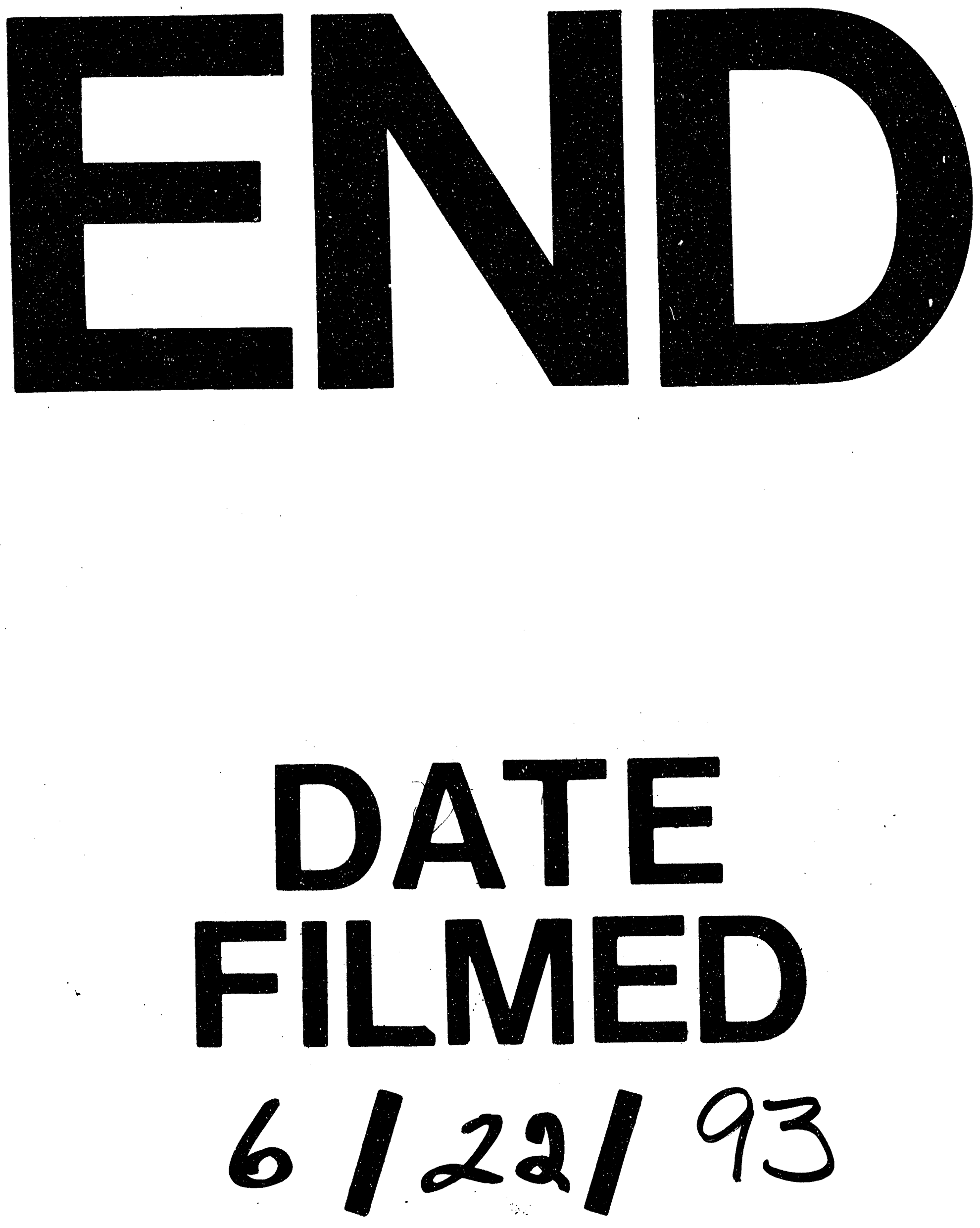

I 


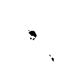

